\title{
Collaborative curriculum design to increase science teaching self-efficacy
}

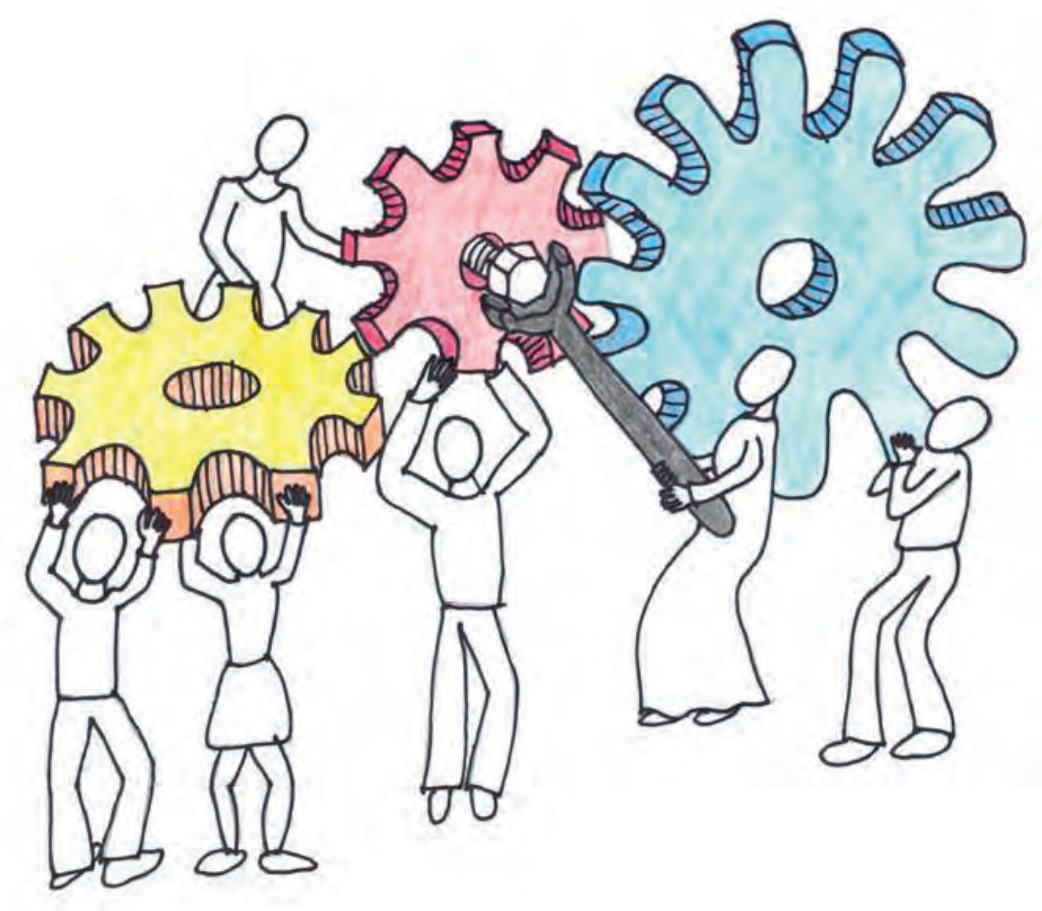

Chantal Velthuis 



\title{
COLLABORATIVE CURRICULUM DESIGN TO INCREASE SCIENCE TEACHING SELF-EFFICACY
}

\author{
Chantal Velthuis
}


DOCTORAL COMMITTEE

Chairman Prof. dr. ir. A. J. Mouthaan - University of Twente

Promotor Prof. dr. J. M. Pieters • University of Twente

Assistant promotor Dr. P. H. G. Fisser -SLO

Members Prof. dr. J. J. H. van den Akker - University of Twente

Prof. dr. J. H. Walma van der Molen - University of Twente

Prof. dr. M. J. de Vries - University of Delft

Prof. dr. J. M. Voogt - University of Amsterdam

Dr. J. van Keulen - Hogeschool Windesheim Flevoland

Dr. M. Gellevij - Saxion University of Applied Sciences

Velthuis, C. H.

Collaborative curriculum design to increase science teaching self-efficacy

Thesis University of Twente, Enschede.

ISBN 978-90-365-3668-4

DOI $\quad 10.3990 / 1.9789036536684$

Omslagontwerp: Monique van den Eijnden Overbeek

Layout: Chantal Velthuis

Printer: Ipskamp Drukkers B.V. Enschede

(C) Copyright, 2014, C. H. Velthuis 


\title{
COLLABORATIVE CURRICULUM DESIGN TO INCREASE SCIENCE TEACHING SELF-EFFICACY
}

\author{
DISSERTATION \\ to obtain \\ the degree of doctor at the University of Twente, \\ on the authority of the rector magnificus, \\ prof. dr. H. Brinksma, \\ on account of the decision of the graduation committee \\ to be publicly defended \\ on Thursday the $5^{\text {th }}$ of June 2014 at 16:45 \\ by \\ Chantal Velthuis \\ born on the $17^{\text {th }}$ of May, 1979 \\ in Dalfsen, the Netherlands
}


Promotor

Assistant promotor
Prof. dr. J. M. Pieters

Dr. P. H. G. Fisser

This dissertation has been approved by the promotor and assistant promotor 
'Educational change depends on what teachers do and thinkit is as simple and complex as that.' (Fullan, 1991, pp 117) 



\section{TABLE OF CONTENTS}

LIST OF FIGURES AND TABLES

vii

1. INTRODUCTION

1.1 Origin of the investigation 1

1.2 Theoretical underpinnings 3

1.2.1 Science in the primary school 3

1.2.2 Science teaching self-efficacy 5

1.2.3 Professional development programs and science teaching $\begin{array}{ll}\text { self-efficacy } & 7\end{array}$

1.2.4 Teacher design teams 8

$\begin{array}{ll}1.3 \text { Research questions } & 9\end{array}$

1.4 Research approach 9

$\begin{array}{ll}\text { 1.4.1 The initial solution strategy } & 10\end{array}$

$\begin{array}{ll}\text { 1.4.2 A cyclic approach of designing } & 10\end{array}$

$\begin{array}{ll}\text { 1.4.3 The role of the researcher } & 11\end{array}$

$\begin{array}{ll}1.5 \text { Overview of the investigation } & 12\end{array}$

2. MEASURING SCIENCE TEACHING SELF-EFFICACY BELIEF, THE DEVELOPMENT OF THE STEBI-NL

$\begin{array}{ll}2.1 \text { Introduction } & 18\end{array}$

2.2 Problem statement and research questions 20

$\begin{array}{ll}2.3 \text { Theoretical framework } & 20\end{array}$

$\begin{array}{ll}2.4 .1 & \text { Self-efficacy } \\ 2.4 .2 & 20\end{array}$

2.4.2 Measuring self-efficacy 22

2.4 Methodology 24

2.4.1 Instrument development 24

2.4.2 Participants 25

$\begin{array}{lll}2.4 .3 & \text { Data analysis } & 26\end{array}$ 
2.5 Findings from instrument development 26

2.5.1 Preliminary reliability measurements 27

2.5.2 Factor and reliability analysis of PSTE and STOE 27

2.5.3 Re-examining the STOE construct 28

2.6 Further analysis 28

2.6.1 PSTE and years of study $\quad 29$

2.6.2 PSTE and perceived SMK 30

2.6.3 PSTE and attitude toward science 30

2.6.4 PSTE and science teaching-related experience 30

$\begin{array}{ll}\text { 2.6.5 PSTE and gender } & 31\end{array}$

2.7 The STEBI-NL 31

2.8 Conclusion and discussion 33

3. TEACHER TRAINING AND PRE-SERVICE TEACHERS' SELF-EFFICACY FOR SCIENCE TEACHING $\quad 37$

3.1 Introduction 37

3.2 Theoretical Framework 38

$\begin{array}{lll}3.2 .1 & \text { Self-efficacy } & 38\end{array}$

3.2.2 Sources of increases in self-efficacy 39

3.2.3 Pre-service teachers' science teaching self-efficacy 39

3.3 Problem statement and research questions 42

3.4 Methodology 42

3.4.1 Participants 42

3.4.2 The science method courses 43

$\begin{array}{lll}3.4 .3 & \text { Instruments } & 46\end{array}$

3.4 Results 47

3.5 Conclusions and Discussion 52

4. COLLABORATIVE CURRICULUM DESIGN AND THE SCIENCE TEACHING SELF-EFFICACY OF PRE-SERVICE TEACHERS

4.1 Introduction 59

4.2 Theoretical framework $\quad 61$

4.2.1 Self-efficacy 61

4.2.2 Science teaching self-efficacy and curriculum reform 62

4.2.3 Teacher design teams and self-efficacy 63 
4.3 Context of the study $\quad 64$

$\begin{array}{ll}4.4 \text { Methodology } & 65\end{array}$

$\begin{array}{lll}\text { 4.4.1 Participants } & 65\end{array}$

$\begin{array}{lll}4.4 .2 & \text { Intervention } & 65\end{array}$

$\begin{array}{lll}4.4 .3 & \text { Instruments } & 68\end{array}$

$\begin{array}{lll}\text { 4.4.4 Data analysis } & 70\end{array}$

$\begin{array}{ll}4.5 \text { Results } & 70\end{array}$

$\begin{array}{ll}\text { 4.6 Discussion } & 78\end{array}$

$\begin{array}{ll}4.7 \text { Conclusions } & 81\end{array}$

5. COLLABORATIVE CURRICULUM DESIGN TO INCREASE SCIENCE TEACHING SELF-EFFICACY: A CASE STUDY 83

5.1 Introduction 83

5.2 Theoretical framework $\quad 84$

$\begin{array}{lll}\text { 5.2.1 Self-efficacy } & 84\end{array}$

5.2.2 Sources of increases in self-efficacy 85

5.2.3 Self-efficacy and professional development programs 86

$\begin{array}{lll}\text { 5.2.4 TDT and self-efficacy } & 87\end{array}$

5.3 Problem statement and research question 87

$\begin{array}{ll}5.4 \text { Methodology } & 88\end{array}$

$\begin{array}{lll}5.4 .1 & \text { Participants } & 88\end{array}$

$\begin{array}{ll}\text { 5.4.2 The TDT program } & 90\end{array}$

$\begin{array}{lll}5.4 .3 & \text { Instruments } & 90\end{array}$

5.5 Results 92

5.6 Conclusion and Discussion 96

6. THE PROCESS OF COLLABORATIVE CURRICULUM DESIGN AND THE $\begin{array}{ll}\text { SCIENCE TEACHING SELF-EFFICACY } & 101\end{array}$

$\begin{array}{ll}6.1 \text { Introduction } & 102\end{array}$

$\begin{array}{ll}6.2 \text { Theoretical framework } & 103\end{array}$

$\begin{array}{ll}6.3 \text { Methodology } & 105\end{array}$

$\begin{array}{lll}\text { 6.3.1 Participants } & 105\end{array}$

$\begin{array}{lll}\text { 6.3.2 TDT team program } & 106\end{array}$

$\begin{array}{lll}\text { 6.3.3 Instruments and data collection } & 108\end{array}$ 
6.4 Results

6.4.1 The influence of the principal on the curriculum design process

6.4.2 Teaching experiences

6.4.3 Valuable design activities

6.5 Discussion and conclusions

7. EXTERNAL SUPPORT IN COLLABORATIVE CURRICULUM DESIGN TO INCREASE THE SCIENCE TEACHING SELF-EFFICACY OF PRIMARY TEACHERS

7.1 Introduction

7.2 Theoretical framework

7.2.1 Science teaching self-efficacy

7.2.2 Science teaching self-efficacy in relation to TDT

123

7.2.3 Improving TDTs for increasing science teaching selfefficacy

7.2.4 External support in TDTs

126

$\begin{array}{ll}7.3 \text { Problem statement and research questions } & 128\end{array}$

$\begin{array}{ll}7.4 \text { Methodology } & 128\end{array}$

$\begin{array}{lll}7.4 .1 & \text { Participants } & 128\end{array}$

$\begin{array}{lll}7.4 .2 & \text { The TDT program } & 129\end{array}$

$\begin{array}{lll}7.4 .3 & \text { Instruments } & 130\end{array}$

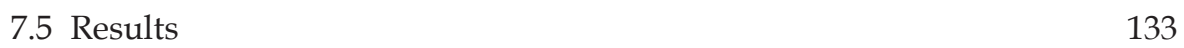

$\begin{array}{lll}\text { 7.5.1 Science teaching self-efficacy } & 133\end{array}$

$\begin{array}{lll}\text { 7.5.2 } & \text { External support and interactions } & 134\end{array}$

7.5.3 External support and frequency of science teaching 136

7.5.4 External support and new ideas in science teaching 136

$\begin{array}{ll}\text { 7.5.5 Valuable types of external support } & 139\end{array}$

$\begin{array}{ll}7.6 \text { Discussion and conclusions } & 141\end{array}$

$\begin{array}{lll}\text { 7.6.1 The teachers } & 141\end{array}$

$\begin{array}{lll}\text { 7.6.2 The design task } & 142\end{array}$

$\begin{array}{ll}\text { 7.6.3 Additional external support } & 144\end{array}$

$\begin{array}{lll}\text { 7.6.4 Limitations } & 145\end{array}$ 
8.1 Recapitulation

8.1.1 Aims and research questions

8.1.2 Research approach

8.2.1 Measuring science teaching self-efficacy belief, the development of the STEBI-NL

8.2.2 Teacher training and pre-service teachers' self-efficacy for science teaching

8.2.3 Collaborative curriculum design and the science teaching self-efficacy of pre-service primary teachers

8.2.4 Collaborative curriculum design to increase science teaching self-efficacy

8.2.5 The process of collaborative curriculum design and the science teaching self-efficacy

8.2.6 External support in collaborative curriculum design to increase the science teaching self-efficacy of primary teachers

8.3 Overall conclusion

8.3.1 The new approach: TDTs extended with external support for increasing self-efficacy

8.4 Reflection on the research outcomes

8.4.1 The STEBI-NL

8.4.2 The observation instrument

8.4.3 Factors in teacher training programs

8.4.4 The value of TDTs for increasing in-service teachers' science teaching self-efficacy

8.4.5 Insights into the processes of a TDT in relation to science teaching self-efficacy

8.5 Reflection on the research approach

8.6 Recommendations for teacher trainers 
REFERENCES

ENGLISH SUMMARY

187

NEDERLANDSE SAMENVATTING

193

DANKWOORD

CURriculum Vitae

203

LIST OF PUBLICATIONS

205 


\section{LIST OF FIGURES AND TABLES}

\section{FIGURES}

1.1 Research overview, the relation between teacher training programs (TT), research questions and the studies

6.1 'Level of collaboration' and 'Instructional relevance' are combined to determine the interactions' Likelihood of Increasing Science teaching Self-efficacy, or LISS level

7.1 The processes in a TDT in relation to the science teaching selfefficacy of teachers in the team

7.2 The processes in a TDT, including external support, in relation to the science teaching self-efficacy of teachers in the team

7.3 'Level of collaboration' and 'Instructional relevance' are combined to determine the interactions' Likelihood of Increasing Science teaching Self-efficacy, or LISS level (Velthuis et al., 2013)

8.1 Research overview and the relation between teacher training programs (TT), research questions and the studies

8.2 'Level of collaboration' and 'Instructional relevance' are combined to determine the interaction's Likelihood to Increase Science teaching Self-efficacy (LISS level)

8.3 The processes in a TDT including external support, in relation to the science teaching self-efficacy of teachers in the team

8.4 Curriculum spider web (Van den Akker, 2003)

8.5 The proposed new approach to a science teacher training program for increasing science teaching self-efficacy as represented in Van den Akker's curriculum spider web (2003). 


\section{TABLES}

2.1 Distribution of teacher student respondents over college years 25

2.2 Items to be included in further analysis 29

2.3 STEBI-NL, the PSTE scale 31

2.4 STEBI-NL, the STOE scale $\quad 32$

3.1 The distribution of participating pre-service primary teachers across years and universities 43

3.2 Characteristics of the science courses in the major program of University A and B $\quad 45$

3.3 Mean PSTE scores by years of teacher training 47

3.4 PSTE scores of pre-service teachers by self-rated SMK for teaching science 48

3.5 PSTE scores of pre-service teachers by their self-rated frequency of science teaching 49

3.6 Tukey post hoc test for PSTE and the frequency of science teaching 49

3.7 Independent samples t-tests (two-tailed) comparing mean PSTE scores for years 1 and 2 at Universities A and B 50

3.8 Independent samples t-tests (two-tailed) comparing mean selfrated SMK for three science domains for years 1 and 2 at Universities A and B

4.1 Course content and activities during the two parts of the preservice teacher training program 66

4.2 List of instruments and related questions 68

4.3 Means for PSTE and STOE scores before and after the minor $\begin{array}{ll}\text { program with TDTs } & 71\end{array}$

4.4 Means for self-rated knowledge scores in the technology domain before and after the minor including participation in a TDT $\quad 72$

4.5 Mean scores for student teachers' beliefs about the extent of improvement in their ability to teach science by inquiry after the minor including participation in TDTs

4.6 Overview of the science week programs; teams 1, 2 and 3 were without an expert and teams 4 and 5 were guided by an expert

4.7 Curriculum materials scores along with the accompanying notes, teams 1, 2 and 3 were without an expert and teams 4 and 5 were $\begin{array}{ll}\text { guided by an expert } & 75\end{array}$

$\begin{array}{ll}5.1 \text { Participants in TDT } & 89\end{array}$ 
5.2 STEBI-NL results of team members, before, during and after the design process in the TDT.

6.1 Characteristics of teachers in the TDTs

6.2 A summary of the suggested activities and goals per meeting in the process guide

6.3 List of instruments and related questions

6.4 Observation guide: the different levels of collaboration

6.5 Observation guide: the different levels of instructional relevance

6.6 Time spent at different LISS levels by TDT 1 and 2 during the various design activities

7.1 Characteristics of the teachers participating in the TDT

7.2 List of instruments and related questions

7.3 PSTE and STOE results for team members before and after participating in the TDT program

7.4 Time spent on different LISS levels during design activities by the TDT

7.5 TDT teachers' ratings of the value of classroom observation, school visit and additional activities to support inquiry-based teaching

8.1 A summary of the TDT program 


\section{CHAPTER 1 Introduction}

The first chapter presents an overview of the dissertation. The chapter begins with a short description of the origin of this investigation. This is followed by a section describing the situation regarding science education in primary schools in the Netherlands. Then the theoretical framework guiding this investigation is presented, followed by a description of the research questions and the research design. Finally, a general overview of the investigation is given, including the structure of the dissertation.

\subsection{ORIGIN OF THE INVESTIGATION}

'The Netherlands is a world-class player. When it comes to competitiveness, innovation, scientific research and education, we still rank among the front runners in international comparisons despite the economic downturn.' (Techniekpact, 2013, p. 2). This is a great achievement, but whether the Netherlands will still be a world-class competitive player in innovation and science in the future is uncertain. The Netherlands must cope with a growing shortage of well-educated and highly skilled workers in the field of science. More than 70.000 construction workers, installers, electricians, metal workers, engineers and system analysts will be retiring each year between now and 2020. And each year, the education system produces only about 10,000 skilled workers to take their places (Techniekpact, 2013, p. 2). To remain a leading competitor in innovation and science, the Netherlands needs to invest in education in order to prepare more well-educated and highly skilled workers in the field of science (Platform Beta Techniek, 2009; Techniekpact, 2013).

Most children make important choices regarding their course of study and future career when they are between ten and fourteen years old (Van Keulen, 2009; Walma van der Molen, 2008). At that age, attitude towards science is already fixed for the majority of children (Turner \& Ireson, 2010). The recent international 
comparative study on trends in mathematics and science education (TIMSS 2011; Martin, Mullis, Foy, \& Stanco, 2012), in which about 52 countries participated, indicated that only $45 \%$ of Dutch children in grade four like learning science, which is below the overall average of $53 \%$ for all participating countries. In the Netherlands, children's attitudes towards science are often based on a negative image of science: dirty, dangerous, just for boys (Platform Beta Techniek, 2008). A more realistic view of science can be expected to have a positive influence on children's attitude towards science and therefore on their likely choice of science as a career path. The good news is that children who have more science education in primary school also have a more realistic view of science compared to the children who have less science education (Walma van der Molen, 2008). This emphasizes the importance of science in the primary curriculum for increasing the number of well-educated and highly skilled workers in sciencerelated fields in the future. However, the same international comparative study on trends in mathematics and science education (TIMSS, 2011) also showed that Dutch primary teachers spend an average of only 42 hours per year on science instruction in grade 4 (children aged 9-12), which is about half the average time devoted to fourth grade science instruction in other countries (Martin et al., 2012). To motivate more Dutch children to study science or choose a career in science, it may be important to allocate more time to science instruction in primary schools.

Besides the allocation of more time, science education should emphasize children's inquiry skills as well as their science knowledge. A few generations ago, teachers could expect that the content they taught would hold true for the lifetime of their students. Today, children need to be capable of constantly learning and growing, of positioning and repositioning themselves in a swiftly-changing world. Science is the foundation of a knowledge-based society; to be able to participate in a swiftlychanging world built upon science, it is important for all citizens to understand the nature of science, to form opinions about science-based issues such as global warming or genetically engineered food, and to have the skills to find answers for themselves. The capacity to use science knowledge, to identify questions and to draw evidence-based conclusions in order to understand and to make decisions about the natural world and the changes made to it through human activity is called scientific literacy by the Organisation for Economic Co-Operation and Development (OECD, 2007). Inquiry-based learning provides a good path for the achievement of scientific literacy (Brickman, Gormally, Armstrong, \& Hallar, 2009; Ergul, Simsekli, Calis, Ozdilek, Gocmencelebi, \& Sanli, 2011). Inquiry-based learning is described as approaches to learning that are based on the investigation of questions, scenarios or 
problems (Van Graft \& Kemmers, 2007). Young children are curious about the world around them and eager to explore it. For instance, this curiosity is reflected by the way children are interested in a mirror, in using a flashlight or in playing with sand and water. Children are constantly figuring out how the world works and this natural curiosity is a perfect starting point for teaching them science (Fisser, 2009; Van Graft \& Kemmers, 2007). By doing science, children can develop the skills needed to ask questions, collect information, organize and test their ideas, and hence develop scientific literacy in a natural way. However, the TIMSS study showed that only $5 \%$ of the primary teachers in the Netherlands teach science by inquiry in at least half of their science lessons, while the comparable international average is $40 \%$ of primary teachers (Martin et al., 2012). In the Netherlands, textbooks and worksheets are the most frequent basis of science instruction in the fourth grade, used by an average of $74 \%$ and $72 \%$ of the primary teachers, respectively (the comparable international averages are $70 \%$ and $41 \%$ ). In addition, only $4 \%$ of Dutch primary teachers use science equipment and materials in their lessons, which is far below the average for all participating TIMSS countries (36\%). This might also be the reason why only 35\% of fourth grade Dutch children reported being engaged during science lessons, below the $45 \%$ average for the TIMSS countries.

In conclusion, in order to ensure that everyone has the capability to participate well in our society and that more children choose science-related study and careers, change must occur in the primarily school curriculum. Science should be taught more often to give children a more realistic view of science (Walma van der Molen, 2008) and primary teachers should teach science more by inquiry to allow the children to become more scientifically literate (Van Graft \& Kemmers, 2007). The aim of this investigation is find a way to professionalize primary teachers so that they perceive themselves as better able and are willing to teach science more frequently to their children and so that they teach science by inquiry instead of using only textbooks and structured materials.

\subsection{THEORETICAL UNDERPINNINGS}

\subsubsection{Science in the primary school}

Because of the wide use of the term science education in the Netherlands as well as internationally, it is first necessary to consider what is meant by science education in this dissertation. Science is both a body of knowledge that represents 
the current understanding of natural systems and the process whereby that body of knowledge has been established and is being continually extended, refined, and revised (Duschl, Schweingruber, \& Shouse, 2007, p. 26). Science in Dutch primary schools is called 'Natuuronderwijs en techniek' and includes biology, environmental science, chemistry, physics and technology (Van Graft \& Kemmers, 2007). In the Netherlands, science education belongs to a broader learning area of 'social and environmental studies' (Greven \& Letschert, 2006). In this learning area, children learn about themselves, how people interact, how to solve problems and how to give meaning to their existence. Children learn about the natural environment and phenomena that occur within it. Furthermore, children orient themselves in the world, nearby, far away, in the future and in the present, and make use of cultural heritage. The core objectives for science education in primary schools are described by Greven and Letschert (2006) and translate for the purposes of this investigation as follows:

(1) Children learn to distinguish and identify most common plants and animals in their own environment and learn how they function in their habitat;

(2) Children learn about parts of plants, animals, and humans and about the structure and function of their parts;

(3) Children learn to investigate materials and physical phenomena, including light, sound, electricity, force, magnetism, and temperature;

(4) Children learn to describe the weather and climate in terms of temperature, precipitation and wind;

(5) Children learn to find connections between the functioning, design, and use of materials for products in their own environment;

(6) Children learn to design, realise, and evaluate solutions for technical problems;

(7) Children learn that the position of the earth in relation to the sun causes our seasons and the day and night cycle.

In the Netherlands, these core objectives fall under three domains: living nature (biology and environmental sciences), non-living nature (chemistry and physics) and technology. Living nature is addressed in core objectives 1, 2, 4 and 7, non-living nature can be found in core objective 4 and technology in core objectives 5 and 6 .

The core objectives are meant to give direction to science education in primary schools in the Netherlands (Greven \& Letschert, 2006). Primary schools are free to decide how they are going to achieve these main objectives. In practice, this 
means that primary schools might differ in the amount of time spent on science education and the way science is included in the school curriculum. The consequence is that in some primary schools, science is a subject in the program even for the youngest children, while in other schools science is only taught to the older children. Furthermore, science can be integrated with history and geography in some primary schools, while in other schools technology can be a separate subject in the program, distinct from science.

To influence primary teachers in the Netherlands to spend more time on science education and to teach science more by inquiry, in 2008 the government launched an innovation initiative called VTB-pro (Broadening Science in Primary Schools, a program to professionalize teachers), to encourage teachers to participate in a professional development program. The VTB-pro programs concentrated mainly on primary teachers' science-related subject matter knowledge (SMK), pedagogical content knowledge (PCK), and attitudes towards science. Improvements were observed in all three learning areas; however, at $90 \%$ of the schools that participated in the VTB-pro program, teachers still judged science as not important enough to warrant finding additional time for it in the already overloaded curriculum (Rommes, Van Gorp, Delwel, \& Emons, 2010). This result indicates that it is not enough to professionalize teachers with regard to (teaching) science, but that it is even more important to motivate teachers to search for alternative solutions for teaching science in their overloaded curriculum so that they do not give up on finding additional time so easily. This is related to what is called teaching (self) efficacy.

\subsubsection{Science teaching self-efficacy}

Research findings on efficacy in teacher education suggest that behaviors, levels of persistence at a task, degree of risk-taking, and openness to innovation are related to levels of self-efficacy (Ashton \& Webb, 1986; Tschannen-Moran \& Hoy, 2007). Self-efficacy was initially defined by Bandura (1977) as one's belief in one's ability to perform an action that will lead towards a specific goal. The components of self-efficacy are personal self-efficacy and outcome expectancy beliefs (Bandura, 1977). Personal self-efficacy reflects a self-assessment of one's ability to perform a specific task and outcome expectancy belief is one's expectation that performing the task will result in the desired outcome. A person with a high sense of self-efficacy will set higher goals for themselves, are less afraid of failure, and will find new strategies when old ones fail. If the sense of self-efficacy is low, one 
will avoid the task or give up easily. Self-efficacy is commonly understood as domain and context specific; one can have different levels of self-efficacy in different domains or for particular situations of functioning (Bandura, 1977). This implies that teachers' self-efficacy may vary from subject to subject, so that a teacher with high self-efficacy for teaching mathematics might not have the same high self-efficacy for science teaching. Science teaching self-efficacy is defined by Ramey-Gassert and Shroyer (1992, p. 27) as 'the belief or confidence that a teacher has in his or her ability to teach science effectively'.

Czerniak and Shriver (1994) found that teachers with high science teaching selfefficacy had less anxiety about teaching science and were more likely to teach by inquiry. Teachers who do not feel confident in their ability to teach science, i.e. with low science teaching self-efficacy, on the other hand, were found to: (1) rely more on textbooks and structured materials and exercises, because they are afraid of children asking questions (Appleton \& Kindt, 1999; Harlen \& Holroyd, 1997; Jarvis \& Pell, 2004); (2) allocate as little time to the subject as possible (Appleton \& Kindt, 1999; Harlen \& Holroyd, 1997; Jarvis \& Pell, 2004); and (3) compensate for spending less time on material for which they have low confidence by spending more time on material for which they have higher confidence, for example, doing more biology and less physics or chemistry (Harlen \& Holroyd, 1997). All of these studies investigating the effect of science teaching self-efficacy on the way teachers teach science indicate that improving science teaching self-efficacy might be the key to motivating teachers to teach science more often and with more of an inquiry approach, and to persevere in finding additional time for science.

According to Bandura (1997), people's self-efficacy can be developed through four main sources of influence or information: mastery experiences, vicarious experiences, social persuasion, and physiological responses. In his words, mastery experiences are the most effective way of creating a high feeling of self-efficacy, and the more successful the experience, the more likely it is that one will repeat or extend the behaviour. Vicarious experiences, which are examples of the experiences of others, similar to oneself, can also increase the sense of efficacy: "If they can do it, I can, too". The third source of influence on people's beliefs that they have what it takes to succeed is what Bandura calls social persuasion, being persuaded verbally by others that one possesses the capability to master given activities. Unrealistic boosts in efficacy are proven to be immediately challenged by the disappointing results of one's efforts. The last source of self-efficacy 
information is reduction of one's stress reactions, which has to do with physical and psychological aspects associated with being in a given functional situation and how these aspects are perceived and interpreted. Someone's mood affects his or her judgments of personal efficacy.

\subsubsection{Professional development programs and science teaching self-efficacy}

Science education research reveals that various factors associated with both science methods courses and science content courses contribute to science teaching self-efficacy, (Bleicher \& Lindgren, 2005; Cantrell, Young, \& Moore, 2003; Palmer, 2006; Schoon \& Boone, 1998; Settlage, 2000). The difference between science methods courses and science content courses is the aim of the course: science methods courses aim to instruct pre-service teachers in the skills needed to teach science, such as relevant teaching strategies, assessment of pre-service teachers' science knowledge and application of classroom management techniques, while science content courses aim to instruct them about science itself. Science methods courses have a positive impact on self-efficacy for teaching, especially when the program takes into account the four main influences on selfefficacy (Cantrell et al., 2003; Settlage, 2000).

Other studies have demonstrated the importance of SMK, or a good understanding of science, for science teaching self-efficacy (Rohaan, Taconis, \& Yochems, 2012; Schoon \& Boone, 1998; Yilmaz-Tuzun, 2008), which implies the value of science content courses for increasing science teaching self-efficacy. However, simply increasing the amount of science content in their courses has been shown to have minimal effect on teachers' science teaching self-efficacy (Moore \& Watson, 1999; Schoon \& Boone, 1998).

On the negative side, a decrease in self-efficacy has been observed when teachers begin to implement a change initiative learned in a science methods course in their own classroom, or when they apply new theory to the classroom (Moseley, Reinke, \& Bookout, 2002; Ross, McKeiver, \& Hogaboam-Gray, 1997; TschannenMoran \& McMaster, 2009). The implementation of an educational change in their own classrooms seems to be a critical moment in teachers' self-efficacy. Tschannen-Moran and McMaster (2009) showed that when teachers who received training comprising a workshop, a demonstration in which the presenter taught a new teaching strategy and a protected mastery experience were supported with implementation by a follow-up conversation and assistance received during 
coaching, they ended up with strengthened self-efficacy, as opposed to a drop in their science teaching self-efficacy without the coaching. Supporting teachers with implementation can therefore be expected to prevent a decrease in science teaching self-efficacy as a consequence of the implementation. Collaborative curriculum design, a form of professional development in which teachers collaborate to design curriculum materials, takes place within the context of their own school and effectively challenges problems with the implementation of a new science program directly during the professional development program. In addition to effective implementation, several studies have shown the value of collaborative curriculum design for teacher learning (Rock \& Wilson, 2005; Sibbald, 2009; Voogt, 2010) and collaborative curriculum design also seems to be valuable for increasing in-service teachers' self-efficacy (Mintzes, Marcum, Messerschmidt-Yates \& Mark, 2012; Sibbald, 2009).

\subsubsection{Teacher design teams}

One specific type of collaborative curriculum design is working in Teacher Design Teams (TDTs). According to Handelzalts $(2009$, p. 7) a TDT is defined as 'a group of at least two teachers, from the same or related subjects, working together on a regular basis, with the goal to (re)design and enact (a part of) their common curriculum'. Professional development in collaborative teacher teams is a way in which teachers can make the connection between the intention to teach and their actual teaching practice in their classroom (Harris, 2003). The collaborative team activities cover (part of) a design cycle: problem analysis or definition, design of curriculum products, implementation of the products in practice, and evaluation/reflection on the products and redesign. Furthermore, the interaction of the teachers in the team contributes to the teachers' professional development (Handelzalts, 2009). Loucks-Horsley (2003) found that participating in collaborative design improved teachers' awareness of diverse pedagogical approaches and their science content knowledge. Expected effects of a TDT include both support for the implementation of change, by designing curriculum materials directly in the teachers' classroom practice and professional development (Handelzalts, 2009; Voogt, Westbroek, Handelzalts, Walraven, McKenney, Pieters, \& de Vries, 2011). Professional development is also known to increase teachers' self-efficacy (Cantrell et al., 2003; Settlage, 2000). In addition to this, it has been noted that coaching and assistance during implementation of an educational change are very important for teachers' self-efficacy, as demonstrated by Tschannen-Moran and McMaster (2009). Therefore, collaboratively designing a 
science curriculum and subsequent collaborative support in implementing the curriculum, through the use of a TDT, might be a good way to improve the science teaching self-efficacy of primary school teachers and thereby get them to teach (all areas of ) science more often and use an inquiry approach more often.

\subsection{RESEARCH QUESTIONS}

In order to fulfill the need for scientific literate citizens and well-educated and highly skilled workers in science-related fields, current educational practice needs to be changed; insights from the literature have thus led to the following research question:

What are the characteristics of an effective science teacher training program for increasing primary teachers' science teaching self-efficacy?

In addressing this question, four sub-questions are posed. The four sub-questions are:

(1) What factors in teacher training programs promote (or hinder) growth in teachers' science teaching self-efficacy?

(2) What is the effect of collaborative curriculum design on teachers' science teaching self-efficacy?

(3) Which design stages and which corresponding activities in a professional development program with a teacher design team promote (or hinder) growth in the teachers' science teaching self-efficacy?

(4) What kind of support do primary teachers need to improve their science teaching self-efficacy when they must collaboratively design and implement their own science curriculum?

\subsection{RESEARCH APPROACH}

The research approach in this investigation was inspired by both design-based research and action research, because effective characteristics of both could be optimally applied in an integrated manner to achieve the intended outcomes. Design-based research and action research both aim to develop solutions to 
complex problems in teaching practice (Van den Akker, Gravemeijer, McKenney, \& Nieveen, 2006; Reason \& Bradbury, 2001). The advantage of developing a solution for an educational problem in actual teaching practice is that the research outcomes will have immediate practical relevance. Both research approaches have a similar goal of developing effective learning environments and a similar intention of producing scientific knowledge regarding factors that affect the implementation of the intervention and its design process (Van den Akker et al., 2006; McNiff \& Whitehead, 2010). However, design-based research and action research differ in their emphasis on producing scientific design knowledge and on the immediate improvement of teacher's own educational practice. In this investigation, a combination of the strengths of both approaches is applied in order to tackle the research and design problem effectively and to answer the research questions adequately, as will be explained in the next sections.

\subsubsection{The initial solution strategy}

The emphasis in design-based research is on developing design knowledge that can be effectively applied in other problem contexts as well. Its difference in respect with action research can be illustrated by how the initial development of a solution to a problem experienced in teaching practice occurs. In design-based research, an initial design is developed based on both outcomes from an analysis of the actual problem context and evidence from a theoretical framework. Action research immediately begins with a plan of action to improve what is already going on in the teacher's own practice. Improvement of this practice will be pursued by formulating actions, implementing those actions, and reflecting upon these implemented actions. Based on these reflections, actions can be revised or new actions can be implemented. Instead, in this dissertation, a plan for immediately improving what is already happening in the researchers' own teaching practice (as in action research) was based on the outcomes from an analysis of the educational problem in the context of two different teacher training universities and from the theoretical framework developed (as in design-based research).

\subsubsection{A cyclic approach of designing}

In both design-based research and action research, the actual design or plan for action is the main object of study. In design-based research a cycle of analysis, design, evaluation and refinement leads to a more optimal design and this, 
together with evidence from previous research, usually results in input for design principles. Design principles are therefore empirically and theory-based assumptions which underpin the design (McKenney \& Reeves, 2012) but which are also subsequently refuted, validated or refined during the research, a process that is intended to contribute to knowledge building. The aim in validating these design principles is to further help others select and apply the most appropriate substantive and procedural knowledge for specific design and development tasks in their own settings (McKenney, Nieveen, \& Van den Akker, 2006).

Action research is based on a cycle of action and reflection that yields several improved versions of the design to solve the actual educational problem. Action research starts with the development of a plan of action to improve what is already happening in the teacher's practice. Next, in the context in which the intervention occurs, evidence of the effects of action is collected and analyzed and reflection on the effects is a basis for further planning, subsequent action and reflection, through a succession of cycles. The process of finding a solution is integrated with normal teacher practice and is used as a way to understand the effect of the intervention, as well as the factors that affect the intervention (McNiff \& Whitehead, 2010).

This investigation uses a cyclic approach that is a combination of design-based research and action research. Just as in both of these research designs, the main object of study is the different stages of improvement of the intervention. The process of finding a solution is integral to the normal teacher practice of the researcher. The consequence is that this research contributes from the start to improving teaching practice with an effective teacher training program. On the other hand, in each cycle the analysis of the previous design will be used in combination with a theoretical framework to formulate refined design principles regarding ways to improve the intervention and to create knowledge about characteristics of an effective teacher training program to increase primary teachers' science teaching self-efficacy.

\subsubsection{The role of the researcher}

The researcher in this investigation is a science teacher educator in a teacher training college for both pre-service teachers and in-service teachers. The overlapping roles of the researcher, being teacher, designer, and evaluator all in one, may interfere with carrying out methodologically sound research. In action 
research, this may happen by introducing personal biases in data gathering and analysis, the uncertainty as to whether the solution arrived at is also the optimal solution and the consequence that action research typically involves only one organisation (McNiff \& Whitehead, 2010; Van der Zee, 2010). In design-based research, the researcher collaborates very close with practitioners to arrive at the merits of a particular design for users in real contexts (Van den Akker et al., 2006). Due to the nature of design-based research, which involves prototyping in the specific educational context, the design researcher could often find herself playing the conflicting roles of advocate and critic (Alayyar, 2011; McKenney et al., 2006; Vervoort, 2013).

However, based upon the characteristics of both design-based research and action research, in this dissertation the teacher and researcher roles are combined. By acting in these different roles, a deepened understanding of the context and the research problem was expected, which could provide additional insights that helped support adequate analysis of the research problem. Moreover, a researcher's overlapping roles of developer and teacher could provide an opportunity to gain deeper and often sharper insights into the strengths and the weaknesses of a design in ways that cannot be accomplished as easily by an external researcher (Alayyar, 2011; McKenney et al. 2006). In addition, being both a researcher and a teacher could help to influence the implementation process and enable the seamless integration of the data collection activities into the on-going courses (Alayyar, 2011; Vervoort, 2013). The process of overlapping roles, activities and responsibilities can make the developed intervention ecologically valid and relevant and usable to those who need it (Alayyar, 2011; Vervoort, 2013), without requiring collaboration with other practitioners. Finally, methodological concerns as a result of the dual role of the researcher are taken into account by having a theoretical framework for each design and by using both quantitative and qualitative instruments to measure the effect of the teacher training program on science teaching self-efficacy.

\subsection{OVERVIEW OF THE INVESTIGATION}

The main aim of this investigation is to identify design characteristics of an effective teacher training program for increasing science teaching self-efficacy. To be able to determine the effects of design characteristics of a teacher training 
program, qualitative research methods are used, as are typically reported in many other studies, as well as quantitative ones. A quantitative instrument is considered an added value in this research approach because this can reduce the possibility of a personal bias in data gathering and analysis by the researcher. Therefore, in addition to the qualitative methods, for this investigation a quantitative instrument to assess the science teaching self-efficacy of (pre-service) primary teachers is developed (Chapter 2) *.

Subsequently, six different studies are carried out to answer the research questions. In the first two studies is the educational problem validated and analysed. The other four studies are analyses of three stages of the evolving teacher training program. Studies one to three were conducted with pre-service teachers and studies four to six with in-service teachers. An overview of the studies and the relation between teacher training programs and research questions is depicted in Figure 1.1 and explained in the next section.

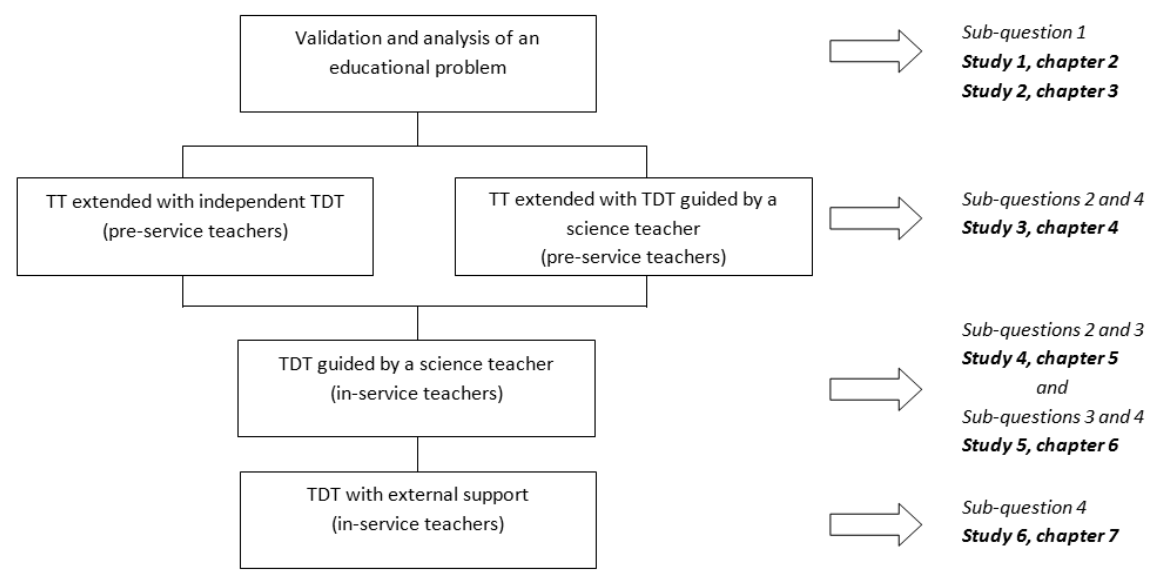

Figure 1.1. Research overview, the relation between teacher training programs (TT), research questions and the studies

In the first study (described in Chapter 2), both the level of self-efficacy of the preservice primary teachers in the science domain and factors related to this selfefficacy are determined in order to analyse the problem more in depth. In the second study (described in Chapter 3), the focus is on two different teacher training programs for gaining insight into effective combinations of different

* The STEBI-NL is available on request 
science courses within teacher training programs and into elements in the science courses that can be valuable for improving the science teaching self-efficacy of the pre-service primary teachers. The pre-service science teaching self-efficacy scores of a cross-sectional sample across four different years of study in two different universities are analyzed to determine factors in teacher training programs that can promote or hinder growth in science teaching self-efficacy (sub-question 1).

Based on these insights into the development of science teaching self-efficacy by the pre-service teachers during their 4 year teacher training program and the factors in their teacher training that promote or hinder this growth (study 1 and 2 ), research literature is collected and analysed regarding the use of TDT as a possible solution for increasing pre-service teachers' self-efficacy in the third study (described in Chapter 4). Following this analysis, part of the teacher training program is extended with a TDT program to determine whether collaborative curriculum design can positively contribute to their science teaching self-efficacy. Two different cohorts of pre-service teachers in the minor program (years 3 and 4 of teacher training) with two different versions of TDTs (independent TDTs and TDTs guided by a science teacher) are compared. In the first cohort's TDTs, the task is to design a science week at a primary school guided only by a process guide, which means that the goals and activities are planned per meeting. The TDTs in the second cohort must carry out the same assignment, but these TDTs have the added element of a science teacher educator guiding the design process, asking critical questions, bringing ideas and being able to answer questions regarding content and process. The third study aims to answer research question 2: What is the effect of collaborative curriculum design on teachers' science teaching self-efficacy? and to gain insight in the fourth research question: What kind of support do primary teachers need to improve their science teaching self-efficacy when they must collaboratively design and implement their own science curriculum?

During the fourth study (described in Chapter 5), TDTs made up of in-service teachers use the same process guide as the pre-service teachers used in the third study. The TDT's task is adjusted to better fit with in-service teacher practice. The TDTs in this study have to redesign their own curriculum. The science teacher educator plays the role of an external facilitator, guiding the team, leading discussions and providing study materials and other resources. The fourth study aims to answer research question 2 as well: What is the effect of collaborative curriculum design on teachers' science teaching self-efficacy? along with research 
question 3: Which design stages and which corresponding activities in a professional development program with a teacher design team promote (or hinder) growth in the teachers' science teaching self-efficacy? The purpose of this case study is to gain indepth information about the value of TDTs for increasing the science teaching self-efficacy of different types of primary school teachers: experienced and less experienced and interested and not interested in science.

The fifth study (described in Chapter 6) focuses on answering research question 3: Which design stages and which corresponding activities in a professional development program with a teacher design team promote (or hinder) the teachers' science teaching selfefficacy? and research question 4: What kind of support do primary teachers need to improve their science teaching self-efficacy when they must collaboratively design and implement their own science curriculum? In this study, an observation instrument is developed and applied to be able to determine the value of team interactions within the team for increasing science teaching self-efficacy**. By observing the LISS-level of the team's interactions (the Likelihood that the discussion will Increase Science teaching Self-efficacy), the design stages and activities that tend to promote or hinder growth in self-efficacy are determined. In addition, the influence of the principal on the design process is observed in order to consider the principal's role in the TDT, and the influence of the design process on the teachers' science teaching experiences is observed to consider whether teachers do need additional support regarding science teaching to ensure mastery experiences.

Based on the evaluations from studies 3, 4 and 5, in the sixth study (described in Chapter 7) the assumption is tested that some teachers need additional support to develop and/or implement curriculum materials for science in their classrooms. Additional literature regarding external support in TDTs is studied and consequently the TDT program is extended with external support, such as visiting an exemplary school, additional activities to support teachers with science teaching, classroom observations and feedback on lesson outlines. The sixth study aims to answer sub-question 4: What kind of support do primary teachers need to improve their science teaching self-efficacy when they must collaboratively design and implement their own science curriculum?

** The observation instrument is available on request 


\section{CHAPTER $2 \dagger$}

\section{Measuring science teaching self-efficacy belief, the development of the STEBI-NL}

This study focuses on assessing the self-efficacy of pre-service primary teachers for teaching science. The sense of self-efficacy is a powerful predictor of behavior in the classroom. Teachers who feel confident to teach science allocate more time to this subject and they teach the subject in a different way than less confident teachers. A Dutch instrument was developed to measure teacher self-efficacy in the area of science teaching, based on the STEBI-A created by Riggs and Enochs (1990). This instrument measures Personal Science Teaching Efficacy (PSTE) and Science Teaching Outcome Expectancy (STOE). The validation results show that the basic integrity of the PSTE scale was maintained, but the STOE scale needs more research. From the results of our study we conclude that the most important factors that influence pre-service teachers' self-efficacy are their general attitude toward teaching science, their self-reported confidence in their level of subject matter knowledge (SMK) and how many years they have been enrolled in the teacher training program. No significant gender differences in PSTE scores were found for pre-service teachers. The research-based information presented here enables us to improve current practices so that that pre-service primary teachers can develop increased self-efficacy beliefs. More time should be allocated in the pre-service training curriculum to gaining experience in science teaching, which would allow for development of a positive attitude toward science teaching. Furthermore, pre-service primary teachers need to develop higher confidence in their levels of science SMK.

$+\quad$ This chapter was submitted as: Velthuis, C., Fisser, P., Ormel, B., \& Pieters, J. (submitted). Measuring Science Teaching Efficacy Belief, the development of the STEBI-NL 


\subsection{INTRODUCTION}

The Netherlands is coping with a growing shortage of well-educated people in science and technology. Only $16 \%$ of Dutch secondary students earn a degree in science education compared to $26 \%$ in other parts of Europe (Platform Beta Techniek, 2008). This relatively low interest in science and technology manifests itself during secondary school, but most students have already eliminated the choice of science previously, during their years in primary school (Osborne \& Dillon, 2008; Young \& Kellogg, 1993). Interest in science education should therefore be enhanced during primary school, but results from the international comparative study on trends in mathematics and science education (Martin, Mullis, Foy, \& Stanco, 2012) indicate that this has not yet been realized in the Netherlands. A total of 3461 fourth grade children from 128 different Dutch primary schools participated in TIMSS 2011. The results show that Dutch primary school children are not among the top 10 best achieving student samples in the domain of science, and this has been the case since 2007 (Meelissen \& Drent, 2008). The same study also shows that only 45 percent of Dutch children in fourth grade like learning science, which is also below the average of all participating countries (53\%). One reason for this might be found in the amount of time allotted for science teaching in the primary school curriculum. Dutch teachers spend an average of only 30-45 minutes per week on science education in grade 4 , which is about half of the average time devoted to science instruction in the other TIMMS countries. Furthermore, only $5 \%$ of primary teachers in the Netherlands teach science by inquiry in at least half their science lessons, while the comparable international average is $40 \%$ (Martin et al., 2012). This might also be the reason why only $35 \%$ of Dutch children in fourth grade reported being engaged during science lessons, which is $10 \%$ lower than the overall average of the TIMSS countries.

To improve science education in the Netherlands and to motivate more Dutch children for studying science or a career in science, the government began a national initiative in 2008 to encourage science teachers to participate in a professional development program for teaching science in primary schools. This professional development program concentrates on teachers' subject matter knowledge (SMK), pedagogical content knowledge (PCK), and attitude towards science. However, at $90 \%$ of the schools that participated in the professional development program, teachers still judged science as not important enough to warrant finding additional time for it in the already overloaded curriculum 
(Platform Beta Techniek, 2010). Of the time they do spend on science, $85 \%$ is dedicated to biology, while only $15 \%$ concerns subjects from physics and chemistry. Not surprisingly, Dutch children have low achievement and attitude in those areas (Meelissen \& Drent, 2008). This might imply a connection between the time allotted to science by the teacher and student achievement.

A major question becomes why teachers spend so little time on these science subjects. Several answers are possible, and they may not be mutually exclusive. For example, the three " $\mathrm{R}$ 's" - reading, writing and arithmetic - are now largely emphasized in the Dutch educational system, at the expense of other domains such as science. Second, about $80 \%$ of all Dutch primary teachers are female, and the research shows that females tend to have less interest in science-related topics compared to males (e.g., Taasoobshirazi \& Carr, 2008). Another reason for not spending much time on science is that physics and chemistry are subjects in which Dutch teachers do not feel very confident; teachers also have low selfefficacy in relation to science teaching in general (Meelissen \& Drent, 2008). This could be because most students who enter pre-service primary school training in the Netherlands graduate from secondary school without science-related courses, which means that many lack any foundational science knowledge. This probably contributes to their low self-efficacy for teaching science.

Dutch teacher training colleges do include science-related courses in their curriculum, to develop a better understanding of science and of how to teach science in primary schools. Courses can differ between teacher training colleges, but in general, the major program of teacher training includes science content courses and methods courses (which are also often aimed at reinforcing science content knowledge). In the minor program, which is the specialization phase, preservice teachers must specialize in the specific age of the children they want to teach (with topics that can include science education for younger children), and they must specialize in a specific subject (with subjects that include those taught in elementary school, among them biology or technology, for example), regardless of the age of the children they want to teach. Despite this, many pre-service teachers do not develop their science teaching capabilities to the fullest, because not all of these courses are mandatory. Therefore, they are not able to grow in their self-efficacy for teaching science, and will probably not spend much time on science in their future classrooms., It is important for teacher training colleges to know which factors influence the development of self-efficacy in science teaching. 
If they are more aware of what aspects have an influence, they can adapt their curriculum (and their in-service training) to accommodate these factors.

\subsection{PROBLEM STATEMENT AND RESEARCH QUESTION}

This study focuses on the development of an instrument that assesses the selfefficacy of Dutch pre-service primary teachers for teaching science. Such an instrument could be used a) to determine pre-service primary teachers' level of self-efficacy for science teaching and the factors that influence this self-efficacy in order to make curriculum revisions, and b) to measure the development of preservice primary teachers' science teaching self-efficacy over a longer period of time. This study is therefore trying to answer the following research questions:

(1) What instruments that measure the self-efficacy of pre-service primary teachers for science teaching are available and which of these instrument can be used in the Dutch context?

(2) Does an adapted instrument for measuring the self-efficacy of Dutch preservice primary teachers for science teaching have adequate reliability and validity for its intended use?

(3) What factors may influence the science teaching self-efficacy of pre-service primary teachers?

\subsection{THEORETICAL FRAMEWORK}

In this study we focus on measuring pre-service teachers' self-efficacy for science teaching, which we frame from the perspective of Bandura's notion of self-efficacy.

\subsubsection{Self-efficacy}

Bandura (1977) presented self-efficacy as one's perceived ability to perform an action that will lead successfully toward a specific goal. Teachers' sense of selfefficacy is a powerful predictor of their behavior in the classroom, because selfefficacy affects the effort a teacher invest in teaching. Teachers with a high sense of self-efficacy will set higher goals for themselves, are less afraid of failure, will find new strategies when old ones fail, and they will allocate more time to this subject in their teaching (Jarvis \& Pell, 2004). If the sense of self-efficacy is low, teachers will 
avoid the task or give up easily (Tschannen-Moran \& Hoy, 2001) and teachers are less likely to teach science at all (Ramey-Gassert, Shroyer, \& Straver, 1996).

Along with the likelihood of teaching science, a second important reason to consider the self-efficacy of teachers is that research shows that if teachers feel more confident to teach science, they teach the subject in a different way than less confident teachers. Teachers who do not feel confident rely more on textbooks and structured materials or exercises and are more afraid of children asking questions (Harlen \& Holroyd, 1997; Jarvis \& Pell, 2004), compared to teachers who do feel confident and who more often use approaches such as inquiry-based learning, which incorporates essential skills such as finding solutions to real-life problems by asking questions, designing and conducting investigation, gathering information, drawing conclusions and reporting findings (Colgoni \& Eyles, 2010; Donovan \& Bransford, 2005; Van Graft \& Kemmers, 2007). But approaches like inquiry-based learning present additional challenges to teachers and their selfefficacy. They must focus on the curiosity, questions and inquiry skills of students instead of on the information given in a textbook. This specific form of selfefficacy seems to be associated with knowledge about specific science subjects and the skills to teach these subjects, also known as the pedagogical content knowledge, or PCK, of a teacher (Shulman, 1986). The development of PCK partially takes place at the teacher training college, but is mainly influenced by real teaching experiences, because during these experiences one builds up knowledge, skills, confidence and a certain attitude toward education and teaching (Shulman, 1987). But to start developing science PCK, a teacher also needs to have enough confidence (Appleton, 2008). This makes the process of developing science PCK a complex one. An equilibrium must be found between subject matter knowledge (SMK), knowledge about the learners and pedagogical approaches and the confidence to combine these two in a teaching situation.

Hence, it is very important for novice teachers and pre-service primary teachers to develop confidence in their ability to teach science successfully in a real classroom situation, which means that they need to develop high(er) self-efficacy (Bleicher, 2004; Scharmann \& Orth Hampton, 1995). According to Bandura (1994), people's beliefs about their efficacy can be developed by four main sources of influence: mastery experiences, examples of experiences provided by social models, social persuasion, and reducing people's stress reactions. Mastery experiences are the most effective way of creating a high feeling of self-efficacy and the more succesful 
the experience, the more likely the individual will repeat or extend the behavior. Examples or experiences from others, similar to oneself, also increase the sense of efficacy: "if they can do it, I can too". People's beliefs that they have what it takes to succeed are influenced by what Bandura calls "social persuasion", to be persuaded verbally by others that one possesses the capabilities to master given activities. But social persuasion has to be done with care: unrealistic boosts in efficacy are immediately challenged by the disappointing results of one's efforts. Reducing people's stress reactions has to do with someone's physical and psychological state and how this state is perceived and interpreted. For instance, someone's mood affects his or her judgments of personal efficacy. Altering a negative emotional tendency and the interpretations of physical states is important. For training and learning situations this means that in addition to raising people's beliefs in their own capabilities, the training/trainers should structure situations in ways that bring success and avoid placing people prematurely in situations where they are likely to fail often (Bandura, 1994, 1997; Pajares, 1997).

Beside factors that can be influenced at teacher training colleges, there are also factors that cannot (completely) be influenced by training, such as previous training and knowledge, and gender. Gender specificity in science education is a crossnational problem (Buccheria, Abt Grbera, \& Brhwilera, 2011) and may be attributed to stereotypic preferences for specific topics (Baram-Tsabaria \& Yardena, 2008), because scientific subjects are often considered to be genuinely masculine (Kerger, Martin, \& Brunner, 2011). This implies that besides increasing self-efficacy for science teaching in general, it might be important to focus specifically on increasing the self-efficacy of female primary (pre-service) teachers.

From what has been stated here, we argue that there are several possible influential factors in the development of self-efficacy related to science teaching. For our study, the factors of gender, stereotypical ideas about or attitude toward science, stage of development related to PCK and SMK, and the way in which developing a higher sense of self-efficacy is incorporated into the pre-service training curriculum are important ones to consider.

\subsubsection{Measuring self-efficacy}

Enochs and Riggs (1990) urged that the early detection of low self-efficacy for primary science teaching is critical to any teacher preparation program. They developed the Science Teaching Efficacy Belief Instrument (STEBI), an instrument 
based on Bandura's self-efficacy theory that specifically aims at the beliefs of (preservice) teachers about science in teaching and learning. The instrument intends to measure the self-efficacy of pre- and in-service primary teachers with two scales: Personal Science Teaching Efficacy (PSTE, self-assessment of someone's teaching competence) and Science Teaching Outcome Expectancy (STOE, teachers' expectations that teaching can influence student learning). Enochs and Riggs made two versions, version A for primary teachers (Riggs \& Enochs, 1990) and version B for primary pre-service teachers (Enochs \& Riggs, 1990). The STEBIB dropped two of the original 25 items from the STEBI-A, modified the verb tenses in the items to reflect the future orientation to teaching of pre-service teachers, and maintained the naming of the two scales as PSTE and STOE (Bleicher, 2004). The STEBI contains items such as, "I am typically able to answer students' science questions" in the teaching efficacy scale and "Increased effort in science teaching produces little change in students' science achievement" in the outcome expectancy scale. Respondents answer on a 5-point Likert scale, ranging from strongly agree (5) to strongly disagree (1).

A number of studies have been carried out based on the instrument developed by Enochs and Riggs. For instance, the reliability and internal validity of STEBI-B were re-examined in 2004, resulting in the STEBI-B revised (Bleicher, 2004). The STEBI A, STEBI B and the STEBI B-revised have been used in many studies to measure science teaching self-efficacy and outcome expectancy in (pre-service) primary teachers (see, for instance, Bleicher, 2007; Christol \& Adams; RameyGassert, et al., 1996; Tosun, 2000). The STEBI-A and STEBI-B have also been used as the basis for new versions of the instrument that are related to various content domains, such as the STEBI-CHEM (Rubeck \& Enochs, 1991) to measure teaching self-efficacy for teaching chemistry, the SEBEST (Ritter, Boone, \& Rubba, 2002) to measure teacher beliefs toward science teaching and learning in regard to considerations of ethnicity, language minorities, gender, and socioeconomic factors, and the MTEBI to measure both self-efficacy and outcome expectancy of pre-service teachers in the area of teaching mathematics (Enochs, Smith, \& Humker, 2000). The STEBI has also been translated to other languages, such as Turkish (Savran Gencer \& Cakiroglu, 2007), Greek (Mavrikaki \& Athanassiou, 2011), and Danish (Andersen, Dragsted, Evans, \& Sørensen, 2003). All studies report a high reliability in relation to measuring personal science teaching selfefficacy (Cronbach's $a>.8$ ) and a moderate reliability in relation to measuring outcome expectancy (Cronbach's a between .7 and .8). 


\subsection{Methodology}

The reported importance of self-efficacy and the ease of use and the high reliability and validity of the STEBI makes it a logical starting point for a Dutch instrument to measure teacher self-efficacy in the area of science teaching. By using an existing instrument instead of developing a new one, time and effort can be saved and it will be possible to compare the findings with those from other (international) studies. When translating an existing instrument into another language, careful attention must be paid to validity and reliability: it can be argued that translating indeed yields a whole new instrument. Cultural differences in language and/or target group and a too literal translation of items by which the item becomes outlandish or peculiar can have an influence on the interpretation of the item and therefore on its validity and reliability (Behling \& Law, 2000). Therefore, in order to create a valid and reliable instrument that measures personal science teaching selfefficacy, a Dutch version of the Science Teaching Efficacy Belief Instrument (the STEBI-NL) was developed and administered for the first time.

\subsubsection{Instrument development}

At Dutch teacher education colleges, students are required to practice teaching in real classes from the first year onward; therefore it seems reasonable to expect them to develop their own stance towards science education. The self-efficacy items on the STEBI-NL are therefore based on the STEBI-A, which enables us to determine the current self-efficacy of all pre-service teachers in years 1 to 4 of their course of study, rather than the self-efficacy beliefs they expect to hold in the future.

The original STEBI-A (Riggs \& Enochs, 1990) was translated in such a way that the Dutch version should perform in practically the same way as the original version. Forward- and back-translations were used to achieve this. In the first stage, four psychology students from the University of Twente as well as a science teacher educator individually translated the instrument from English to Dutch. Translations were compared and where differences were found a discussion took place, after which the final items from this group of translators were formulated. Next, 13 primary teachers were asked to give feedback on the clarity of the phrasing, and based on their feedback minor textual changes were made to the items. After this, two of the researchers from this study examined the items, backtranslated the items, and agreed with the translations done by the group. The resulting instrument consisted of 25 items for measuring the two constructs of 
Personal Science Teaching Efficacy (PSTE; 13 items) and Science Teaching Outcome Expectancy (STOE; 12 items). Each item is a statement to which respondents indicate the extent they agree with it by choosing an answer from a 5-point Likert scale ranging from strongly agree (5) to strongly disagree (1), similar to the original instrument. Along with these 25 self-efficacy items, additional questions were included asking about attitude: the pre-service teachers' enjoyment in relation to science teaching, difficulties the pre-service teachers think they might encounter, and their personal interest in the domain of science. The final questionnaire also contained a number of questions about the respondent's background (gender, experience, previous program of study, etc.) to account for other factors that might influence their self-efficacy. The instrument was distributed on paper to the pre-service primary teachers while they were present at their teacher education college.

\subsubsection{Participants}

The STEBI-NL was administered for pilot-testing to pre-service primary teachers at five teacher education colleges that enroll the same type of students: graduates from secondary education and students from vocational education who graduated as teacher assistants. At all teacher education colleges, preparation to teach in primary schools involves four successive years of coursework in combination with internships. The questionnaire was distributed on paper in all year 1 and a part of the year 2 classes (not all year 2 teachers administered the questionnaires to their classes). The number of first and second year respondents in this study is therefore a reasonable reflection of the total population of pre-service teachers at the teacher education colleges. The respondents from years 3 and 4 do not represent the population; because of their different choices in specialization, their internships, and because these pre-service teachers were digitally approached to complete the questionnaire, not all pre-service teachers responded in these years. Table 2.1 shows the distribution of the students over the years of study.

Table 2.1 Distribution of teacher student respondents over college years

\begin{tabular}{|lll} 
Year & $\mathbf{n}$ & Percentage \\
\hline 1 & 170 & 45 \\
\hline 2 & 106 & 28 \\
\hline 3 & 58 & 15 \\
\hline 4 & 44 & 12 \\
\hline total & 378 & 100 \\
\hline
\end{tabular}




\subsubsection{Data analysis}

Two methods were used to draw conclusions about the validity of the STEBI-NL self-efficacy scales: expert appraisal for content validity during the process of translating the instrument and factor analysis after administering the instrument for construct validity by providing evidence as to which items relate to the PSTE construct and which to the STOE construct (Bowling 1997; Jack \& Clarke, 1998). To determine the reliability of the STEBI-NL as a measure of the internal consistency of the PSTE and the STOE items, the Cronbach's a statistic was used. De Vellis (2003) provided tentative benchmarks for the interpretation of Cronbach's a which we will use in this study: <.60 unacceptable; between .60 and 65 undesirable; between .65 and .70 minimally acceptable; $>.70$ respectable; $>.80$ very good. For further analysis of the instrument, means and standard deviations were calculated and Pearson correlations $(r)$ and $t$-tests were used to assess the relationship between responses on the STEBI-items and responses to the questions about the respondents' background. Correlation coefficients of .10, .30 and .50, irrespective of the sign, are interpreted as small, medium and large correlations, respectively (Green \& Salkind, 2008).

After administering the STEBI-NL the answers to these items were scored, where strongly disagree is scored as 1 point, disagree as 2 points, and further up to 5 points for strongly agree. The items that were phrased negatively in the questionnaire were reverse coded. All respondents together were treated as one group when checking the validity and the reliability of the instrument. The data were factor analyzed using the principal components method with Varimax rotation and the factors that emerged were checked for reliability. Based on the results of the factor analysis and reliability analysis, some initial analyses were carried out in relation to the pre-service primary teachers' self-efficacy scores and the STEBI-NL questionnaire was refined.

\subsection{FINDINGS FROM INSTRUMENT DEVELOPMENT}

The STEBI-NL was analyzed using the data from the 378 pre-service primary teachers who completed the instrument. 


\subsubsection{Preliminary reliability measurements}

The reliability of all STEBI self-efficacy items together was respectable, with a Cronbach's a of .73. Looking at the two different constructs of PSTE and STOE, the reliability for the PSTE scale was very good with a Cronbach's a of .86. The reliability of the STOE scale was not good enough with a Cronbach's a of .56. According to the item analysis statistics, some items could be removed from the STOE scale to raise the Cronbach's a, but this would not move it above .6. Studies with the original English STEBI also show that the reliability of the PSTE scale is better than the STOE scale, but Cronbach's a for the STOE scale was not this low. This led us to do a factor analysis to see which items relate to the PSTE construct and which to the STOE construct, to verify our conceptualization of the two constructs.

\subsubsection{Factor and reliability analysis of PSTE and STOE}

An exploratory factor analysis revealed seven factors with eigenvalues larger than one and together explaining $54 \%$ of the variance. All items in two of the factors belonged to the PSTE construct, with all items loading at least .5, except for item 21 ("Given a choice, I would not invite the principal to evaluate my science teaching "). The items belonging to the STOE construct were distributed over the remaining five factors with only item 16 ("If parents comment that their child is showing more interest in science, it is probably due to the child's teacher") having a factor loading below .5. When further exploring this and forcing the software to extract only two factors, $30 \%$ of the variance is explained. The first factor contains all the PSTE items. Items 2 (I am continually finding better ways to teach science) and 21 (Given a choice, I would not invite the principal to evaluate my science teaching) had insufficient factor loadings (.38 and .47 respectively) and there was some cross loading with item 13 (Increased effort in science teaching produces little change in some students' science achievement), which belongs to the STOE construct. Removing items 2 and 21 did not yield a higher Cronbach's a for the PSTE scale, but these items were checked again on content. The reasons for this re-checking is that in general the items used in the PSTE factor are relatively straightforward: "I know ...", "I can ...", "I understand ...". Item 21 is slightly different ("Given a choice, I would..."), but item 2 in particular ("I am continually finding better ways to teach science") shows a different perspective than the other items. This statement refers to improving one's teaching practice rather than one's self-efficacy with the existing practice. Therefore it was decided to leave this item out in the further analysis of the results. Only 5 items out of the 12 that are supposed to measure STOE had a factor loading of .5 or more in the further exploration of the two 
factors that were extracted, and the reliability of these 5 items together was still insufficient to make up a scale ( $\alpha=.56$, not different than when including all items).

\subsubsection{Re-examining the STOE construct}

It was noticed that the pre-service primary teachers in their first year of college were particularly likely to use the middle (neutral) answering option from the 5point Likert scale very often. It could be argued that the STEBI-NL might not be appropriate for measuring the self-efficacy and outcome expectancy of this group of respondents, because they have had limited teaching experience. However, when we excluded the first year students from our analysis and calculated the reliability of each scale again, Cronbach's a for PSTE remained high $(\alpha=.88)$ and the reliability of STOE remained unacceptable low $(\alpha=.58)$. Another reason besides their limited teaching experience might be the STOE construct itself. By its nature, the construct is more complicated than PSTE because it measures the outcome expectancy of education. Typically statements relate student effects (outcomes and interests) to teacher's efforts and effectiveness. However, effects of education arise from a complex of interrelated influences, making it harder to pinpoint the precise effect of the teacher's practice. So it may be expected that STOE is harder to measure than PSTE. Moreover, the STOE statements read less straightforwardly than the PSTE statements, so more problems can be expected with the STOE items: the more complicated the phrasing, the less beneficial translation is for its clarity. Furthermore it was noticed that the items to be removed based on the factor analysis were all of the negatively phrased sentences. Content analysis of the problematic items did not reveal any clearer pattern, but a focus group interview with 12 pre-service teachers confirmed our thoughts related to both the complex nature of the STOE construct and the fact that the items were negatively phrased.

\subsection{FURTHER ANALYSIS}

Reliability and factor analysis showed no major problems with the PSTE construct. It was therefore decided to carry out additional analyses based on this construct to get an indication of the relation between the PSTE construct, attitude toward science, and the respondent's background. An elaborated description of the analysis of the results from the STEBI-NL can be found in Velthuis, Fisser, and 
Pieters (2013a), but here we focus on the factors that are related to the self-efficacy of pre-service teachers, in order to further develop the STEBI-NL. The PSTE items that are included in this analysis can be found in Table 2.2.

Table 2.2 Items to be included in further analysis

\section{PSTE items}

Even when I try very hard, I will not teach science as well as I will most subjects.

I know the steps necessary to teach science concepts effectively.

I am not very effective in monitoring science experiments.

I generally teach science ineffectively.

I understand science concepts well enough to be effective in teaching primary science.

I find it difficult to explain to students why science experiments work.

I am typically able to answer students' science questions.

I wonder if I have the necessary skills to teach science.

Given a choice, I will not invite the principal to evaluate my science teaching.

When a student has difficulty understanding a science concept, I am usually at a loss as to how to help the student understand it better.

When teaching science, I usually welcome student questions.

I do not know what to do to turn students on to science

Descriptive statistics show that the mean score for PSTE is $3.3(S D=.54)$, indicating that the respondents think neutrally to slightly positively about their personal science teaching efficacy. PSTE was further analyzed in relation to how long the pre-service teachers have been enrolled in the teacher training college, their gender, their ideas and attitudes related to science, their perceived SMK, and their in-school teaching experience. These analyses are in the service of further developing an instrument that measures factors that may have an influence on the science teaching self-efficacy of pre-service teachers.

\subsubsection{PSTE and years of study}

Because self-efficacy is probably associated with the teacher's Pedagogical Content Knowledge and the development of PCK takes place in part at the teacher training college, it is interesting to see whether PSTE and the number of years that a preservice teacher has been enrolled in the teacher training college are related. The results of this study show that there is a significant small to medium correlation between PSTE and the number of years enrolled $(r=.21, p<.01)$. ANOVA analysis showed that the main increase in PSTE takes place in the second year of teacher training college. No increase was seen in the subsequent years. For the further 
development of the STEBI-NL this indicates that number of years of study should be included in as background information in the final version of the instrument.

\subsubsection{PSTE and perceived SMK}

In the theoretical framework it was argued that the confidence to teach science is associated with knowledge about specific science subjects and it was argued that this would also have an influence on self-efficacy. One of the background questions was therefore related to the pre-service primary teachers' perceived subject matter knowledge on several sub-domains of science. To see if this should be included in the final version of STEBI-NL, a correlational analysis was carried out, which showed that there is a significant medium correlation between the confidence that the respondents have in relation to their science knowledge (all domains combined) and their PSTE $(r=.42, p<.01)$. A higher level of confidence in subject matter knowledge is related to a higher level of PSTE.

\subsubsection{PSTE and attitude toward science}

In the theoretical framework it was suggested that one's self-efficacy for science teaching may depend on his or her ideas and attitudes toward science. A set of background questions was related to the pre-service teachers' attitude with regard to teaching science. These questions are about their enjoyment in relation to science teaching, about difficulties they think they might encounter, and about their personal interest in the domain of science. It was seen that there are large correlations between PSTE and enjoyment $(r=.49, p<.01)$, between PSTE and perceived difficulties $(r=.53, p<.01)$, and between PSTE and personal interest $(r=$ $.44, p<.01)$. This strongly indicates that background questions regarding attitude toward science should be included in the final version of the STEBI-NL.

\subsubsection{PSTE and science teaching-related experience}

Because the skills to teach science could also influence one's self-efficacy, correlations were calculated between PSTE and choice of an elective assignment as well as in-school teaching experience. The choice of an science related elective assignment correlates significantly with PSTE $(r=.26, p<.01$, small-medium). Experience with teaching biology $(r=.37, p<.01)$ and teaching physics/chemistry $(r=.31, p<.01)$ during in-school training both have medium-sized significant correlation with PSTE. Background questions on teaching-related experience should therefore be considered for inclusion in the final version of the STEBI-NL. 


\subsubsection{PSTE and gender}

In the theoretical framework it was mentioned that female pre-service teachers might have less interest or confidence in science and science teaching and this might also show up in their self-efficacy. However, when looking at the data from our study, no significant gender difference in mean scores on PSTE was found.

\subsection{THE STEBI-NL}

Based on the analysis of the results on the STEBI-NL it was decided that:

(1) All negatively worded items will be re-phrased to make positive statements;

(2) The items that were discussed as complicated during the focus group interview with the pre-service teachers will be made either less complex or more specific for the Dutch context;

(3) PSTE Item 2 ("I am continually finding better ways to teach science") will be removed.

Tables 2.3 and 2.4 give an overview of the original and the re-phrased items. For research and curriculum innovation purposes, it is advised to also include background questions about the number of years of study, perceived SMK, attitude toward science, and teaching-related experience.

Table 2.3 STEBI-NL, the PSTE scale

\section{PSTE, original items PSTE, rephrased items}

1. Even when I try very hard, I will not teach 1 . I will teach science as well as I will most science as well as I will most subjects. subjects.

2. I know the steps necessary to teach science 2. I know the steps necessary to teach science concepts effectively. concepts.

3. I am not very effective in monitoring 3. I am able to guide students during science science experiments. experiments in such a way that they can find answers to their own questions.

4. I generally teach science ineffectively. $\quad 4$. In general I am satisfied with the way I teach science.

5. I understand science concepts well enough 5. I understand science concepts well enough to be effective in teaching primary science. to be effective in teaching primary science.

6. I find it difficult to explain to students why 6 . I am able to explain to students why science science experiments work. experiments work.

7. I am typically able to answer students' 7 . I am typically able to answer students' science questions. science questions.

8. I wonder if I have the necessary skills to 8 . I have the necessary skills to teach science. teach science. 
Table 2.3 STEBI-NL, the PSTE scale (Continued)

\section{PSTE, original items}

9. Given a choice, I will not invite the principal to evaluate my science teaching.

10. When a student has difficulty understanding a science concept, I am usually at a loss as to how to help the student understand it better.

11. When teaching science, I usually welcome student questions.

12.I do not know what to do to turn students on to science.

\section{PSTE, rephrased items}

9. I do not mind if the principal is in my classroom during my science teaching.

10. When a student has difficulty understanding a science concept, I usually know how to help the student understand it better.

11. When teaching science, I usually welcome student questions.

12.I know what to do to motivate students for science.

Table 2.4 STEBI-NL, the STOE scale

\section{STOE, original items}

1. When a student does better than usual in science, it is often because the teacher exerted a little extra effort.

2. When the science grades of students improve, it is often due to their teacher having found a more effective teaching approach

3. If students are underachieving in science, it is most likely due to ineffective science teaching.

4. The inadequacy of a student's science background can be overcome by good teaching.

5. The low science achievement of students cannot generally be blamed on their teachers

6. When a low-achieving child progresses in science, it is usually due to extra attention given by the teacher.

7. Increased effort in science teaching produces little change in students science achievement.

8. The teacher is generally responsible for the achievement of students in science.

9. Students' achievement in science is directly related to their teacher's effectiveness in science teaching.

\section{STOE, rephrased items}

1. When a student does better than usual in science, it is because the teacher exerted extra effort for this student.

2. When the science grades of students improve, it is due to a changed teaching approach by the teacher

3. If students are doing well in science, it is most likely due to an effective science teaching approach at school.

4. The inadequacy of a student's science background can be overcome by teaching science with a changed teaching approach

5. Good science achievement by students is generally due to the quality of the teachers

6. When a low-achieving child progresses in science, it is usually due to extra attention given by the teacher.

7. Increased effort in science teaching produces a positive change in students science achievement.

8. The teacher is generally responsible for the achievement of students in science.

9. Students' achievement in science is directly related to their teacher's effectiveness in science teaching. 


\section{STOE, original items}

10. If parents comment that their child is showing more interest in science, it is probably due to the child's teacher.

\section{STOE, rephrased items}

10. If parents comment that their child is showing more interest in science, it is probably due to the quality of the teacher's science teaching.

11. Good science teaching has little effect on the achievement of students with low motivation.

11. Good science teaching has little effect on the performance of students with low motivation

12. Even teachers who teach science well 12. Teachers who teach science well can help cannot help some students to learn science

The new version of the PSTE and STOE scales has been used in a follow-up study with 46 pre-service students (Velthuis, Fisser, \& Pieters, submitted b), and proved to be more robust, with a Cronbach's a of .84 for PSTE and a Cronbach's a of .74 for STOE.

\subsection{CONCLUSION AND DISCUSSION}

This study focused on identifying factors that may influence the self-efficacy of Dutch pre-service primary teachers in the science domain, and on developing an instrument to assess their self-efficacy.

From the literature it was found that the factors of gender, prejudiced or stereotypical ideas about science, stage of development related to PCK and SMK, and the way in which developing a higher sense of self-efficacy is incorporated in the curriculum of the pre-service training are important to consider when studying pre-service primary teachers' self-efficacy for science teaching. A Dutch version of the Science Teaching Efficacy Belief Instrument was developed, the STEBI-NL, which contains several background questions to account for potential influential factors as found in the literature, and items that measure PSTE and STOE. The basic integrity of the PSTE scale was shown by the findings of this study to be maintained in this Dutch version. Only one item was discarded from this scale. This item differs slightly from the other PSTE-items because it refers to improving one's teaching practice rather than one's confidence with existing practice. However, the STOE scale had problematic results in the factor and reliability analyses. These items have been considered to be relative good probes 
for measuring pre-service teachers' outcome expectancy beliefs (Bleicher, 2004; Enochs \& Riggs, 1990; Riggs \& Enochs, 1990), but other studies have also reported issues with the formulation of the items. For instance, Bleicher (2004) indicates that some items on the STOE-scale need to be reformulated, such as by using only the word "students" without the preceding qualifier "some". It appears that these types of modification can clarify the intent of the items and might increase the reliability of the instrument.

The items in the new version of STOE, as presented in Table 4, prove to be more reliable, but more research is needed because of the complex nature of this scale. It is questionable whether pre-service students, even those with some teaching experience in internships, are capable of giving a meaningful answer to the STOE items. Based on the results of administering the STEBI-NL, it can be concluded that for Dutch pre-service primary teachers, several factors have a connection with PSTE: number of years of study, perceived SMK, attitude toward science, and teaching-related experience.

The new version of the STEBI-NL is currently being used at teacher training colleges to determine the self-efficacy of pre-service teachers in order to adapt the curriculum to their needs, as well as to assess the self-efficacy of in-service teachers in order to develop a professional development trajectory to increase their self-efficacy for teaching science. In relation to the use of the STEBI-NL at teacher training colleges to determine the self-efficacy of pre-service teachers, several remarks can be made. First of all, it is not possible for a teacher training college to change certain aspects of its students, such as gender or prior knowledge. However, several issues raised here are things that can be accounted for in the curriculum of a teacher training college. More time can be dedicated to getting experience in science education, to learning more subject matter knowledge and to gaining a positive attitude toward science and science teaching. Corresponding to Bandura's ideas about how to develop efficacy (Bandura, 1994), we suggest that the colleges incorporate the ideas of Bandura $(1994,1997)$ and Pajares (1997) by ensuring that the curriculum and the courses of the college give pre-service students the opportunity to have successful experiences with teaching science, starting with small-scale science-related activities that can be practiced in a safe environment (mastery experiences). From the results of this study, which are more elaborately described in Velthuis, Fisser, and Pieters (2013a), it can be seen that this has a positive effect: pre-service teachers who took the opportunity to choose a science-related elective assignment had a higher PSTE than those who did not do an elective science-related assignment. These mastery 
experiences should be accompanied with good examples or 'best practices' to get a better idea of the possibilities of teaching science (vicarious experiences provided by social models). This implies that the teacher educators and teachers at the schools where the pre-service teachers do their in-school training should act as role models. This in itself is something for future research, because it can be questioned whether teachers who currently work at primary schools themselves have sufficient selfefficacy in science teaching. They have had similar training at the teacher training colleges. But by giving the pre-service teachers the opportunity to start by practicing small-scale teaching experiences with peers, extending this to small-scale experiences in a class room and eventually combining several (successful) smallscale experiences into a complete lesson will help the pre-service teachers to get the confidence that they can teach science in practice (people's beliefs that they have what it takes to succeed and reducing people's stress reactions). We can confirm Bandura's (1994) and Pajares' (1997) ideas with our results, as we have seen that experience with teaching biology and teaching physics/chemistry during in-school training correlates significantly with PSTE.

In conclusion, we can say that it is possible to measure the science teaching selfefficacy of Dutch pre-service primary teachers with the STEBI-NL. Measuring their Personal Science Teaching Efficacy (PSTE) presented no problems. The Science Teaching Outcome Expectancy (STOE) construct is more complex because it measures outcome expectancies, which relate student outcomes and interests to the teacher's efforts and effectiveness. The new version of the STEBI-NL as described in this article tried to take care of these issues, but the complex nature of the STOE construct compels us to do more research into this particular part of the STEBI-NL. It would also be interesting to compare these results with other international (translated) STEBI-instruments.

With the results of this study and the availability of the STEBI-NL, we hope to better inform teacher educators and to improve current pre-service training. The research-based information that has been presented here enables us to improve current practices so that pre-service primary teachers can develop increased selfefficacy beliefs, and ultimately to increase not only the amount of time spent on science in the classroom, but also the depth at which science is discussed with the children. In order to do this, we recommend follow-up longitudinal studies of pre-service students during their studies and in their early teaching careers. 


\section{ChApter $3 \ddagger$ \\ Teacher training and pre-service primary teachers' self-efficacy for science teaching}

This study focuses on the improvement of pre-service teachers' self-efficacy for teaching science by including science courses within the teacher training program. Knowing how efficacy beliefs change over time and what factors influence the development by pre-service primary teachers of positive science teaching efficacy beliefs may be useful for teacher training universities, so that they can adapt their curriculum to accommodate these factors. Participants included 292 pre-service primary teachers, a cross-sectional sample from two different universities in the Netherlands across the four different years of study in the training program. Based upon our results, we conclude that the science teaching self-efficacy of pre-service teachers, in particular, improved during years 1 and 2, and not during years 3 and 4. Higher levels of self-rated subject-matter knowledge and science teaching experience in primary schools both contributed to higher levels of personal self-efficacy for science teaching. Differences at the university level in courses taken during the first year between science content courses and science methods courses also influenced the pre-service teachers' development of science teaching self-efficacy. After their first year, the pre-service teachers from the university with science content courses had significantly higher self-efficacy than pre-service teachers from the university that offered science methods courses. After the second year of teacher training, however, this difference in self-efficacy was no longer present.

\subsection{INTRODUCTION}

The Dutch universities that train primary teachers prepare pre-service teachers to teach children from 4 to 12 years old in all subjects, including science. The teacher

\# This chapter was published as: Velthuis, C, Fisser, P., \& Pieters, J. (2013). Teacher training and pre-service primary teachers' self-efficacy for science teaching. Journal of Science Teacher Education, DOI: 10.1007/s10972-013-9363-y 
training program takes four years, and the pre-service teachers are expected to acquire subject-matter knowledge and pedagogical knowledge for mathematics, language, the arts, history, science and all other subjects taught in the primary schools. A central challenge for primary teacher training universities is to develop a training program that prepares the pre-service teachers to become teachers with high teaching efficacy in all subjects. Unfortunately, we know from the TIMMS study (Trends in International Mathematics and Science Study) that only 27\% of Dutch teachers feel confident about teaching science in the primary school, and that primary teachers even consider science to be less important than language or mathematics (Martin, Mullis \& Foy, 2008). Dutch teachers spend only an average of 30-45 minutes per week on science education in grade 4 , which is less than many other countries, including Hungary, Singapore, England, Japan and Italy (Martin, Mullis \& Foy, 2008). In addition, the amount of learning by inquiry during science lessons is less in the Netherlands than in the aforementioned countries (Meelissen \& Drent, 2008). This study aims to improve the preparation provided by the science coursework within teacher training programs by focusing on increasing the science teaching self-efficacy of pre-service teachers. Science teaching self-efficacy is important because a high sense of science teaching selfefficacy has been associated with teachers' lasting interest in science, a positive desire to help students and the willingness to improve science teaching (Bandura, 1997; Ramey-Gassert, Shroyer \& Straver, 1996; Tschannen-Moran \& Woolfolk Hoy, 2007). Knowing the factors that influence the development by pre-service teachers of positive science teaching efficacy beliefs and how efficacy beliefs change over time may be useful for teacher training universities, in order to adapt their curriculum to take these factors into account.

\subsection{THEORETICAL FRAMEWORK}

\subsubsection{Self-efficacy}

Teachers' sense of self-efficacy for teaching is a powerful predictor of their behavior in the classroom. Self-efficacy is defined by Bandura (1977) as one's perceived ability to perform an action that will lead successfully towards a specific goal. Teachers with a high sense of self-efficacy for teaching will set higher goals, be less afraid of failure, and find new strategies when old ones fail (Bandura, 1977; Tschannen-Moran \& Woolfolk Hoy, 2007). Bandura (1977) described two components of self-efficacy: personal science teaching efficacy and outcome expectancy. 
Personal science teaching self-efficacy is the belief in one's ability to perform the behavior and outcome expectancy is the belief that the behavior will lead to desirable outcomes. Self-efficacy is commonly understood as domain- and contextspecific; one can have different levels of self-efficacy beliefs in different domains or for particular situations of functioning. Teachers' self-efficacy beliefs may vary from subject to subject, so that a teacher with high self-efficacy for teaching mathematics might not have the same high self-efficacy for science teaching (Bandura, 1977).

\subsubsection{Sources of increases in self-efficacy}

According to Bandura (1997), people's beliefs about their self-efficacy can increase based upon four main sources of information. Mastery experiences are the most effective way of creating a high feeling of self-efficacy, and the more successful the experience, the more likely it is that one will repeat or extend that behavior. Vicarious experiences, which are observed examples or experiences undergone by others who are similar to oneself, can also increase the sense of efficacy: 'if they can do it, I can, too'. The third source of information that influences people's beliefs that they have what it takes to succeed is what Bandura calls 'social persuasion', or being persuaded verbally by others that one possesses the capabilities to master given activities. The final source of information that can increase self-efficacy is a reduction in people's stress reactions, which has to do with physical and psychological aspects and how these aspects are perceived and interpreted. One's mood affects one's judgements of self-efficacy.

Apart from the sources of increases in self-efficacy as described by Bandura, the amount of 'science' content knowledge or subject matter knowledge (SMK) is an important predictor for science teaching self-efficacy, particularly for personal science teaching self-efficacy. High science knowledge scores correspond with high personal self-efficacy scores for teaching science (Rohaan, Taconis, \& Jochems, 2012; Schoon \& Boone, 1998).

\subsubsection{Pre-service teachers' science teaching self-efficacy}

For those who train teacher, the crucial question is how to prepare pre-service teachers for science teaching; in other words, what is the best way to enhance the science teaching self-efficacy of pre-service teachers in teacher training programs. Science education research reveals that various factors associated with science courses contribute to science teaching self-efficacy, both science methods courses 
and science content courses (Bleicher \& Lindgren, 2005; Cantrell, Young, \& Moore, 2003; Palmer, 2006; Schoon \& Boone, 1998; Settlage, 2000). The difference between science methods courses and science content courses is the aim of the course; science methods courses aim to instruct pre-service teachers on the skills needed to teach science, such as relevant teaching strategies, assessment of students' science knowledge and application of classroom management techniques, while science content courses aim to instruct them about science itself.

Science methods courses can have a positive impact on self-efficacy for teaching, especially when the program takes into account the four main influences on selfefficacy (Cantrell et al., 2003; Settlage, 2000). Settlage (2000) measured self-efficacy for teaching before and after participation in a methods course. The main purpose of the methods course was to teach teachers a new instructional approach. Both personal science teaching efficacy and outcome expectancy increased significantly. Preparing and teaching science lessons also seems to be an important element in the science methods courses, as demonstrated by Cantrell et al. (2003). The time spent on science teaching in a primary school or mastery experiences was associated with increases in pre-service teachers' personal science teaching self-efficacy during this course.

Other studies demonstrated the importance of subject matter knowledge, or a good conception of science for increasing the science teaching self-efficacy (Schoon \& Boone,1998; Rohaan et al., 2010; Yilmaz-Tuzun, 2008. However, simply increasing the amount of science content in their courses can have just little a effect on preservice teachers science teaching self-efficacy belief (Moore \& Watson, 1999; Schoon \& Boone, 1998). A reason is that the holding of alternative conceptions of science interfere with learning (Nussbaum \& Novick, 1982). For these pre-service teachers, science may seem confusing or incomprehensible because their variant conceptions provide a faulty foundation for the formation of new insights.

For a full understanding of the concepts presented in the science content courses, pre-service teachers consider demonstration, hands-on activities, discussions and further explanations to be important factors (Bleicher \& Lindgren, 2005; Schoon \& Boone, 1998).

Palmer (2006) studied a science course having both purposes: teaching about instructional methods and content. This course did provide demonstrations, 
hands-on activities and examples of lessons, but not enactive mastery experiences, which is considered to be the most powerful source of increases in self-efficacy (Bandura, 1997). Without mastery experiences, significant increases in self-efficacy over the duration of the course were still observed by Palmer (2006). The preservice teachers said that they gained confidence directly from success in understanding content and pedagogy, which implies additional sources that influence pre-service teachers' self-efficacy, namely cognitive content mastery and cognitive pedagogical mastery.

All of these studies were at the level of science courses and not at the level of a teacher training program to prepare teachers. Only Cantrell et al. (2003) studied whether or not science teaching self-efficacy beliefs changed over the course of three semesters. During the first semester, students attended a science content course in combination with an introductory methods course, during the second semester students attended an advanced methods course and a three week practicum experience and the third semester was their teaching experience. No significant differences were observed in outcome expectancy beliefs. However, scores on personal science teaching self-efficacy increased significantly; the effect size for semester 2 compared to semester 1 was 1.12 and semester 3 compared to semester 2 was 82 .

The teacher training program in the study of Cantrell et al. consist of both science content courses and science method courses to increase the science teaching selfefficacy of pre-service teachers. However, it could be that a teacher training program only consisting of science method courses, in which pre-service teachers have to develop lessons in authentic situations might be more valuable for increasing the self-efficacy, because it is known that developing lessons brings about deeper understanding of a topic and assists pre-service teaching in developing confidence that the lessons can be undertaken and accomplished (Woolfolk, 1993). In this study, two different teacher training programs will be compared, one with only science method courses and one with a combination of science content and method courses, to determine the most effective combination of courses in teacher training programs for increasing the science teaching selfefficacy of the pre-service teachers. 


\subsection{PROBLEM STATEMENT AND RESEARCH QUESTION}

Science education in primary schools in the Netherlands needs to be improved (Meelissen \& Drent, 2008). More time should be spent on science education and teachers should use inquiry approaches for teaching science more often, which will yield better results for the children in the field of science (Martin, Mullis \& Foy, 2008; Meelissen \& Drent, 2008). Increased self-efficacy beliefs can result in more time spent on science in the classroom and the depth at which science is discussed with the children (Jarvis \& Pell, 2004). In this study we focus on two different Dutch teacher training programs for gaining insight in effective combinations in science courses within teacher training programs and into elements in the science courses that can be valuable for improving the science teaching self-efficacy of pre-service primary teachers. The study seeks to answer the following research questions:

(1) What is the effect of teacher training on pre-service primary teachers' science teaching self-efficacy in the Netherlands?

(2) How are self-rated SMK and frequency of science teaching related to the science teaching self-efficacy of pre-service primary teachers?

(3) Are there any significant differences in science teaching self-efficacy scores between pre-service primary teachers from two different teacher education universities, and how do university-level differences in curriculum content and assessment of the pre-service teachers relate to other factors influencing science teaching self-efficacy (level of self-rated SMK and frequency of science teaching)?

\subsection{Methodology}

\subsubsection{Participants}

This study was conducted at two different universities in the Netherlands. Both universities are located in the eastern part of the Netherlands and enroll the same type of students: graduates from secondary education and students from vocational education who graduated as teacher assistants. About $15 \%$ of the sample population was male and ages ranged from 17 to 39. Preparation to teach in primary schools in both universities involves four successive years of coursework in combination with an internship. There is coursework related to all of the subjects taught in primary schools; just as for the other subjects, the coursework in science is 
intended. The major differences between the two universities are the content of the courses in the first year and how pre-service teachers are assessed after these courses. University A starts out with science methods courses that are assessed by practical assignments and a theoretical test, while University B mainly concentrates on science content that is assessed by theoretical tests in the first year. A total of 292 respondents were included in our cross-sectional analysis, divided over the two universities and the years of coursework. The questionnaire was distributed on paper in all year one and a part of the year two classes (1/3 of University A and 3/4 of University B, because not all year 2 teachers administered the questionnaires to their classes). The first and second year respondents in this study is therefore a reasonable reflection of the total population in both Teacher Universities. The respondents of year 3 and 4 do not represent the population completely, because of their different choices in specialization, their internships, and because these preservice teachers were digitally approached to complete the questionnaire. The data were collected from the participants after they had completed the course year. Table 3.1 presents an overview.

Table 3.1 The distribution of participating pre-service primary teachers across years and universities

\begin{tabular}{|llllll|} 
& Year $\mathbf{1}$ & Year $\mathbf{2}$ & Year 3 & Year 4 & Total \\
\hline University A & 67 & 22 & 16 & 29 & 134 \\
\hline University B & 75 & 55 & 27 & 1 & 158 \\
\hline Total & 142 & 77 & 43 & 30 & 292 \\
\hline
\end{tabular}

\subsubsection{The science methods courses}

The training programs at both universities are organized in a major / minor structure. The major is the basic program during the first two years, which prepares students in general for their future profession as a primary school teacher. The third and fourth years offer opportunities for specialization. Besides the training program at both universities, pre-service teachers also do an internship. During the minor program, the pre-service teachers must observe and teach lessons by themselves; during the third and fourth years, pre-service teachers have more responsibilities and must teach the children the educational program for a complete school day every week of the school year.

The program content at the two universities differs with respect to the science courses, especially in the first year. The science courses at University A are mainly methods courses, but they also aim to reinforce science content knowledge. There are 
two methods courses during the first year, one specifically about science education and one about environmental education. The lectures from the first course involve numerous examples of lessons that are relevant to primary classrooms, and cover topics from living nature (biology) and non-living nature (chemistry and physics). At the end of the course, the pre-service teachers must teach a science lesson themselves in the primary school. In addition, their pedagogical content knowledge (PCK) is assessed in a theoretical test. During the second course, students learn how they can use the school environment to teach children about science, history and geography. The students experience in the method courses how they have to teach science in the primary school by doing 'hands-on', inquiry based activities by themselves and subsequently by reflecting on the 'hands-on' activities they learn how they can teach those activities in the primary school practice.

The science courses at University B are science content courses during the first year. University B offers two science content courses, one focusing on knowledge of living nature and the other focusing on knowledge of non-living nature, technology, and research and design skills. The students do hands-on, inquiry based activities to improve their own knowledge base and design skills. The preservice teachers at University B take two theoretical tests, which assess mainly subject matter knowledge.

During the second year, both universities offer pre-service primary teachers two science methods courses. At University A, pre-service teachers attend two advanced methods courses that are specific for science. For both courses, preservice teachers must complete a practical assignment that assesses their teaching performance and a theoretical test. University B also offers pre-service teachers two methods courses. The first one is specifically about how to teach science. During this course pre-service teachers learn about various examples of good practices, which they can try carrying out in the classroom with primary students. This course is comparable with the first year methods course at University A. However, the assessment at University B is only a theoretical test and does not include a performance assessment. The second course at University B is a combination of science and visual arts. Pre-service teachers learn how to teach science in combination with arts by reflecting on an hands-on activity: the construction of a musical instrument out of several different materials. The characteristics and the content of the program for the major in primary education at both universities are summarized in Table 3.2. 
Table 3.2 Characteristics of the science courses in the major program of University $A$ and $B$

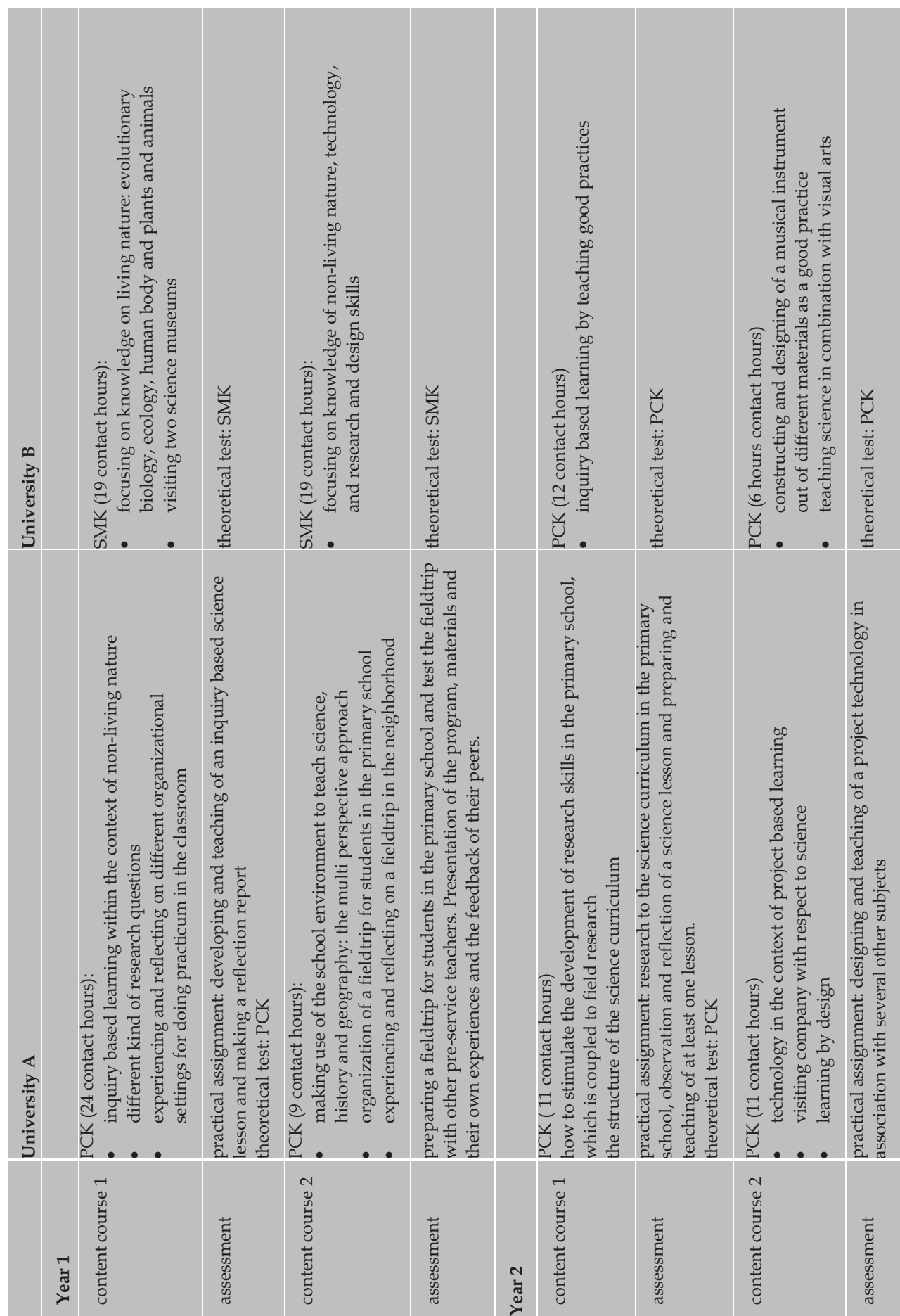


There are also differences between the minor programs at both universities. At University A, pre-service teachers must specialize in the specific age of the children they want to teach. This choice also determines the subject matter in which they will specialize. One of the possible specializations is science for younger children. At University B, pre-service teachers can specialize in a subject matter, for example, biology or technology, regardless of the age of the children they want to teach.

\subsubsection{Instruments}

The STEBI-NL (Fisser, Ormel, \& Velthuis, 2010) was used to measure science teaching self-efficacy of the pre-service teachers from years 1, 2, 3 and 4 of the training programs. The STEBI-NL was translated from an existing, commonly used English instrument: the STEBI-A (Science Teaching Efficacy Belief Instrument), an instrument based on Bandura's self-efficacy theory that specifically aims at the beliefs of (pre-service) teachers about science in teaching and learning (Bleicher, 2004; Bursal, 2010; Riggs \& Enochs, 1990). The instrument intends to measure the self-efficacy of pre- and in-service elementary teachers with two scales: Personal Science Teaching Efficacy (PSTE, self-assessment of one's teaching competence) and Science Teaching Outcome Expectancy (STOE, teachers' expectations that teaching can influence student learning). Enochs and Riggs made two versions, version A for elementary teachers (Riggs \& Enochs, 1990) and version B for elementary pre-service teachers (Enochs \& Riggs, 1990). The difference between these two is the tense of the items, present tense being used for the teachers and future tense for the students. In this study, we used the translated version of the STEBI-A, because pre-service teachers in this study do teach primary school students from year 1 and our interest was in the current selfefficacy of these pre-service elementary teachers. The STEBI-NL is a 23-item instrument, containing items such as, "I am able to answer students' science questions" (PSTE - 12 items total) and "Increased effort in science teaching produces little change in some students' science learning" (STOE - 11 items total). The pre-service teachers used a 5-point Likert scale, ranging from strongly agree (5) to strongly disagree (1), to indicate their opinions on the statements. Negative items are reverse-coded and item-scores are summed to get the score for each scale. A higher score indicates a higher self-efficacy. Pre-service teachers, who did not score all the items were excluded from the results. Fisser et al. (2010) showed that the reliability for the PSTE scale was very good, with a Cronbach's a of .86. The reliability of the STOE scale was unacceptable, with a Cronbach's a of .56. In 
this study, only the PSTE will be used for analysis, and because of the low reliability $(<.6)$, the results for the STOE scale will not be further analyzed.

Secondly, additional questions were asked of the pre-service teachers to determine the relation between self-rated knowledge and self-efficacy, and the relation between frequency of science teaching experiences and science teaching self-efficacy. The questions are: (1) To what extent (insufficient - 1/ sufficient - 2/ good - 3) do you feel that you have the subject knowledge to teach science within living nature (biology), non-living nature (physics and chemistry) and technology; and (2) To what extent (often/a few time/not) have you already taught science in the primary school? The same questions are also used to see how differences in content and assessment in primary teacher education programs relate to the level of self-rated SMK and frequency of science teaching, the possible factors influencing science teaching self-efficacy.

\subsection{RESUlts}

\section{General outcomes on self-efficacy beliefs}

Due to the low reliability of the STOE scale and high reliability of the PSTE scale of the STEBI-NL, we report only on the results for the latter scale. Table 3.3 shows the mean PSTE scores by years of teacher training, where the possible minimum score is 12 and maximum score is 60 . The mean PSTE score after one year of teacher training is 37.96 (5.06) and reaches its maximum after two years: 42.86 (5.82). During the third and fourth year the mean PSTE score of pre-service teachers slightly decreases, but this decrease is not significant. These descriptive results can be interpreted as showing that pre-service primary teachers are slightly positive about their self-efficacy in relation to science teaching.

Table 3.3 Mean PSTE scores by years of teacher training

\begin{tabular}{|llll|} 
Years of teacher training & $\mathbf{n}$ & PSTE Mean & SD \\
\hline 1 & 139 & 37.96 & 5.06 \\
\hline 2 & 76 & 42.86 & 5.82 \\
\hline 3 & 41 & 41.24 & 7.33 \\
\hline 4 & 30 & 41.07 & 5.56 \\
\hline
\end{tabular}

A one-way between-group analysis of variance (ANOVA) was conducted to explore the pattern of teacher training on PSTE. There was a significant difference 
in PSTE scores of pre-service teachers in the different years of teacher training $(F(3,282)=13.312 ; p=.000)$. Post hoc tests using Tukey's HSD showed that PSTE scores are significantly lower in year 1 than in any of the other years, but no other comparisons were significant.

\section{Self-rated SMK knowledge}

All pre-service teachers were asked to rate their own subject matter knowledge for teaching about living and non-living nature and technology as insufficient, sufficient or good. Cross-sectional descriptive statistics were calculated to analyze PSTE scores of pre-service teachers with a self-rated good, sufficient and insufficient level of science teaching SMK. The results are presented in Table 3.4.

Table 3.4 PSTE scores of pre-service teachers by self-rated SMK for teaching science

\begin{tabular}{|c|c|c|c|}
\hline & n & PSTE Mean & SD \\
\hline \multicolumn{4}{|c|}{ Self-rated SMK for teaching living nature } \\
\hline insufficient & 50 & 34.82 & 5.36 \\
\hline sufficient & 179 & 40.56 & 5.32 \\
\hline good & 56 & 43.09 & 6.09 \\
\hline \multicolumn{4}{|c|}{ Self-rated SMK for teaching non-living nature } \\
\hline insufficient & 149 & 37.51 & 5.78 \\
\hline sufficient & 112 & 42.42 & 4.93 \\
\hline good & 24 & 44.75 & 5.33 \\
\hline \multicolumn{4}{|c|}{ Self-rated SMK for teaching technology } \\
\hline insufficient & 174 & 37.90 & 5.60 \\
\hline sufficient & 97 & 43.06 & 4.92 \\
\hline good & 14 & 46.00 & 6.13 \\
\hline
\end{tabular}

There was a statistically significant difference in PSTE scores of the pre-service teachers with different self-rated levels of SMK for each of the three domains, living nature $(F(2,282)=32.121 ; p=.000)$, non-living nature $(F(2,282)=36.147 ; p=$ $.000)$ and technology $(F(2,282)=37.383 ; p=.000)$.

The results of the Tukey post hoc test indicate that there is a significant difference $(p=.000)$ in PSTE scores across all three domains between pre-service primary teachers with self-rated insufficient SMK and pre-service primary teachers with self-rated sufficient and good levels of SMK. The difference in PSTE between teachers with self-rated sufficient knowledge and teachers with good knowledge is only significant in the living nature domain $(p=.008)$. 


\section{Teaching science}

All pre-service teachers were asked how often they have taught science in the primary school. The reason that pre-service teachers may have never taught science is because pre-service teachers do their internship mainly on a specific day during the week. If science is not on the program on that day, the pre-service teachers have to ask for a change in the schedule to be able to teach science or to perform their practical assignments. Cross-sectional descriptive statistics were conducted to analyze PSTE scores of pre-service teachers in terms of the frequency with which they have taught science (never, a few times or often). The results are presented in Table 3.5.

Table 3.5 PSTE scores of pre-service teachers by their self-rated frequency of science teaching

\begin{tabular}{|llll|}
\multicolumn{1}{l}{} & $\mathrm{n}$ & PSTE Mean & SD \\
\hline Frequency of teaching science & & & \\
\hline never & 113 & 36.81 & 5.12 \\
\hline a few times & 132 & 41.52 & 5.40 \\
\hline often & 41 & 44.34 & 5.99 \\
\hline
\end{tabular}

There was a statistically significant difference in PSTE scores of the pre-service teachers with different levels of self-rated teaching frequency $(F(2.283)=38.495 ; p$ $=.000$ ). The results of the Tukey post hoc test (Table 3.6) showed that pre-service teachers who had never taught science to children had significantly lower PSTE scores than those who had taught children a few times, while pre-service teachers who had taught science often had significantly higher PSTE scores than those who had taught only a few times or never. There is a larger effect size for the difference between never teaching science and teaching it a few times (1.35) than for the difference between teaching science a few times and teaching it often (.49).

Table 3.6 Tukey post hoc test for PSTE and the frequency of science teaching

\begin{tabular}{|lllllll|}
$\begin{array}{l}\text { Dependent } \\
\text { Variable }\end{array}$ & $\begin{array}{l}\text { (I) frequency } \\
\text { of science } \\
\text { teaching }\end{array}$ & $\begin{array}{l}\text { (J) frequency } \\
\text { of science } \\
\text { teaching }\end{array}$ & $\begin{array}{l}\text { mean } \\
\text { difference } \\
\text { (I-J) }\end{array}$ & Sig. & $\begin{array}{l}\text { Effect } \\
\text { size }\end{array}$ & $\begin{array}{l}\text { Cohen's } \\
\text { categories }\end{array}$ \\
\hline PSTE & Never & Often & $-7.536^{*}$ & .000 & 1.35 & Large \\
\hline & Never & A few times & $-4.710^{*}$ & .000 & .90 & Large \\
\hline & A few times & Often & $-2.826^{*}$ & .010 & .49 & Moderate \\
\hline
\end{tabular}


Different programs and pre-service teachers' science teaching self-efficacy

An independent samples $t$-test was used to determine if there were significant differences between the two universities for teacher education with regard to the science teaching self-efficacy of their pre-service teachers during their major program (the first two years). As seen in Table 3.7, there is a significant difference in PSTE between students at the two universities after the first year of teacher training $(p<.05)$. Even though it is a small difference, it is a significant difference, which could imply that after one year, the pre-service teachers who participated in a science content course believe that they are more able to teach science compared to the pre-service teachers who participated in a science method course. After two years of teacher training there was no longer any difference between the PSTE scores of the pre-service primary teachers from the two different universities.

Table 3.7 Independent samples t-tests (two-tailed) comparing mean PSTE scores for years 1 and 2 at Universities $A$ and $B$

\begin{tabular}{|c|c|c|c|c|c|c|}
\hline & & n & Mean & SD & df & $p$ \\
\hline \multirow[t]{6}{*}{ PSTE } & Year 1 & & & & & \\
\hline & University A & 65 & 36.86 & 5.16 & 137 & $.016^{*}$ \\
\hline & University B & 74 & 38.93 & 4.81 & & \\
\hline & Year 2 & & & & & \\
\hline & University A & 22 & 43.50 & 5.48 & 74 & .638 \\
\hline & University B & 54 & 42.59 & 5.98 & & \\
\hline
\end{tabular}

Note: *. The difference is significant at the 0.05 level ( 2 tailed).

The major difference between the training programs at University $B$ and University A is the content of the first year science courses. University B mainly concentrates on SMK, while University A starts directly with pedagogical content knowledge. An independent samples t-test was conducted to compare the selfrated subject matter knowledge of the pre-service teachers from both universities after one and two years of teacher training. No significant differences were found between the self-rated SMK of pre-service teachers from University A and those from University B (years 1 and 2).

The self-rated SMK of the pre-service teachers at both universities increased significantly during the second year in two of the three domains, as shown in Table 3.8. At University A, the self-rated SMK of pre-service teachers after the second year was significantly higher in the domains of living and non-living nature, compared to that of the pre-service teachers after their first year. At University B, 
this was the case for the domains of living nature and technology. However, after completing the major program at both universities, second year pre-service teachers do not believe that their knowledge to teach about non-living nature and about technology science is sufficient (mean self-rated knowledge $<2.00$ ).

Table 3.8 Independent samples t-tests (two-tailed) comparing mean self-rated SMK for three science domains for years 1 and 2 at Universities $A$ and $B$

\begin{tabular}{|lllllll|}
\hline & & Mean & SD & df & $p$ \\
\hline Living nature & University A & & & & & \\
\hline & Year 1 & 67 & 1.81 & .657 & 44.3 & $.045^{*}$ \\
\hline & Year 2 & 22 & 2.09 & .526 & & \\
\hline & University B & & & & & \\
\hline & Year 1 & 74 & 1.89 & .563 & 127 & $.000^{*}$ \\
\hline & Year 2 & 55 & 2.27 & .560 & & \\
\hline Non- living nature & University A & & & & & \\
\hline & Year 1 & 67 & 1.42 & .581 & 87 & $.037^{*}$ \\
\hline & Year 2 & 22 & 1.73 & .631 & & \\
\hline & University B & & & & & .757 \\
\hline & Year 1 & 74 & 1.53 & .667 & 127 & \\
\hline & Year 2 & 55 & 1.56 & .660 & & \\
\hline & University A & & & & & .111 \\
\hline Technology & Year 1 & 67 & 1.33 & .533 & 87 & \\
\hline & Year 2 & 22 & 1.55 & .596 & & $.047^{*}$ \\
\hline
\end{tabular}

Note: *. The minimum score is 1 (insufficient) and the maximum score is 3 (good). The difference is significant at the 0.05 level ( 2 tailed).

Science teaching is known to be an important factor for increasing science teaching self-efficacy and therefore cross-sectional descriptive statistics and independent samples t-tests were done for the frequency of science teaching by pre-service teachers at the two universities in their first two years. Contrary to our expectations, no significant differences were found in the self-rated science teaching frequency of pre-service teachers at University A compared to that of those at University B, after both one year and two years of teacher training.

If practical assignments did not result in pre-service teachers' perceiving that they were teaching science more frequently, we then questioned whether the practical 
assignments completed by student at University A might yield science teaching (mastery) experiences, which are more valuable for increasing science teaching self-efficacy than the more 'voluntary' science experiences of the pre-service teachers of University B. An independent samples $t$-test was used to determine whether there was a significant difference in the science teaching self-efficacy of the pre-service teachers from University A who taught science just a few times compared to the same group from University B across the first two years. No significant differences in PSTE were found between pre-service teachers who had taught science a few times, from the two universities. There were also no significant differences in PSTE found when comparing the pre-service teachers at the two universities who reported teaching science at the other two levels of frequency, never and often.

\subsection{CONCLUSIONS AND DISCUSSION}

This study focused on gaining insight into the elements in science courses within teacher training programs that are associated with improvements in the science teaching self-efficacy of pre-service primary teachers in the Netherlands. In this section, the conclusions will be described and the results will be discussed, in order of the main research questions. Then some general remarks will be made about the research design.

To answer the first research question regarding the effect of teacher training on pre-service primary teachers' science teaching self-efficacy in the Netherlands, the STEBI-NL was administered. From the results obtained, it can be concluded that the teacher training of pre-service primary teachers results in a significant increase in personal science teaching self-efficacy (PSTE) over the level at the end of the first year, but no significant differences in PSTE were found between any of the later program years. These results suggest that personal science teaching selfefficacy is improved primarily during the two-year major program of the teacher training till slightly positive. Because the pre-service teachers do have just a little teaching experience after two years, good beliefs about their personal science teaching self-efficacy cannot be expected. However, becoming more experienced with teaching during the minor stage does not result in an increase in science teaching self-efficacy belief of the pre-service teachers. The courses in the minor program seem not to have an impact on the science teaching self-efficacy, or it 
could also be that the minor courses prevent an 'implementation dip'. Several researchers have found an 'implementation dip' in self-efficacy as in-service teachers begin to implement their training in relation to a change initiative (Mosely, Reinke, \& Bookout, 2002; Ross, McKeiver, S., Hogaboam-Gray, 1997). For example, Mosely at al. (2002) showed a significant drop in teachers' self-efficacy approximately 7 weeks after finishing training for professional development, when the teachers were back at their own schools to implement what they had learned. In the Netherlands, pre-service teachers teach lessons in primary school from the beginning of their teacher training; however, starting in the third year, pre-service teachers must teach the children the educational program every week for a complete school day. So, it might be that the pre-service teachers experience difficulty in translating what they have learned about science teaching at the university to the very busy educational program of the primary school where there are children with different needs. Tschannen-Moran and McMaster (2009) also demonstrated the difficulty of implementation for teachers by showing the importance for teachers' self-efficacy of coaching and assistance during implementation. For pre-service teachers, implementation is even more difficult because they are less experienced. Based on this result, one recommendation could be to assist and coach the pre-service teachers better when they begin taking on more responsibility for the educational program. This in itself is something for future research, because it raises the question of what the best way is to organize the coaching of the pre-service primary teachers. The science teacher from the university can coach pre-service teachers in the primary school, but another possibility would be to professionalise the teachers in the primary school so that they can assist and coach the pre-service teachers with the implementation on location. Professional development might be needed for inservice teachers, because those teachers had similar training at the teacher training colleges and might also have low science teaching self-efficacy.

The second question to be answered in this study was: 'How are self-rated SMK and frequency of science teaching related to the science teaching self-efficacy of pre-service primary teachers?' Based on the results of the additional questionnaire and the STEBI-NL, we can conclude that higher levels of self-rated subject matter knowledge are related to a higher level of personal science teaching efficacy. There is a larger difference in PSTE between pre-service teachers with self-rated insufficient knowledge and those with sufficient knowledge than there is between teachers with self-rated sufficient knowledge and those with good knowledge. 
This result suggests that improving SMK in a science content course could be especially valuable when pre-service teachers believe that they have insufficient knowledge to teach science. When teachers believe that they already have sufficient knowledge to teach science, a content course might be less effective for raising levels of self-efficacy. This variation in PSTE differences related to the selfrated SMK levels of pre-service teachers might also explain the varying findings in literature. For example, both Schoon and Boone (1998) and Watters and Ginns (2000) showed that increasing the amount of science content resulted in very little effect on pre-service teachers' self-efficacy. On the other hand, both Rohaan et al. (2012) and Yilmaz-Tuzun (2008) showed the importance of subject matter knowledge for increasing the science teaching self-efficacy of pre-service teachers.

The second factor influencing science teaching self-efficacy observed in this study was the frequency of science teaching in the primary school. In line with Bandura's (1997) conclusion that mastery experience is the most important source of self-efficacy increases, we also found a positive relation between the frequency of science teaching and the PSTE of the pre-service teachers. The difference in PSTE is larger between pre-service teachers who never taught science and who taught science a few times than it is between pre-service teachers who taught science a few times and who taught science more often. This result suggests that the science teaching self-efficacy of pre-service teachers is increased mostly by their first teaching experiences in the classroom. Science teaching self-efficacy might continue to increase by teaching more science lessons; however, the effect seems to be less impressive. It could be that the experiences in the classroom become more 'normal' and become less effective for increasing science teaching self-efficacy. After a few science lessons, it might be that teachers are more aware of their own skills and knowledge levels and are also able to estimate better the reactions of the children in the classroom.

Another explanation could be that the pre-service teachers, who taught often science, had taught those lessons, with the help of textbooks and less by inquiry. When pre-service teachers reported to teach science frequently, science was not only taught in the context of the practical assignment, but it was on the program in the primary school. It could be that the pre-service teachers in this case had taught science in the way the primary school teacher normally does, so in a less innovative way with the help of textbooks. It seems therefore be important to challenge the pre-service teachers to try new teaching strategies or to teach 
subjects they feel less comfortable with. Telling pre-service teachers that they can meet these challenges along with telling them to try them, is in line with Bandura's (1997) third source of self-efficacy, social persuasion. Those challenges could result in new, unexpected successes, which might result in increases in selfefficacy when pre-service teachers teach science often. Those challenges can be provided by the university; however it might be better to professionalize the inservice teachers, so that they are capable to challenge the pre-service teachers. First, additional research to the quality of teaching is necessary to confirm that the pre-service teachers who received practical assignments from university teach in ways more consistent with professional expectations of high quality science.

The third aim of this study was to determine differences in science teaching selfefficacy scores between pre-service primary teachers from two different programs for teacher education. In addition, the relation between curriculum content and the level of self-rated SMK, and between the mode of assessment of pre-service teachers during the program and their perceived frequency of science teaching in the classroom was determined.

The main differences between the two universities are the content of the first year courses and how pre-services teachers are assessed after these courses. The main purpose of the science courses at University A was to teach the pre-service teachers how to teach science to primary children; therefore, they took two methods courses. At University B, the main purpose of the first year was to reinforce the pre-service teachers' content knowledge; therefore, those pre-service teachers took two science content courses. After one year of teacher training, the differences in curricula result in significant higher PSTE levels for students at University B. During the second year, the pre-service teachers at University A took two advanced methods courses and the pre-service teachers at University B also took two methods courses, although these were introductory. Even though there was a significant difference in the PSTE scores of the pre-service teachers when comparing the first and the second year of teacher training, there was no significant difference between the PSTE scores of the pre-service teachers from the two different universities. There were also no significant differences found between the self-rated knowledge of students from University A compared to students from University B after either year 1 or year 2 of teacher training. However, the self-rated knowledge of the preservice teachers from both universities increased during the second year in every domain. This result indicates that pre-service teachers might perceive themselves to 
be learning SMK not only in science content courses, but also in the methods courses, which also aim to reinforce SMK by doing hands-on activities within the different science domains.

But overall the two different major programs of both universities do not lead to differences in science teaching self-efficacy nor to the self-rated knowledge levels. So, it seems that the content of the program during the first two years is not the reason for the low self-efficacy beliefs of the third and fourth year pre-service teachers. The reason for the low self-efficacy belief might be found in the third and fourth year of teacher education, because at that time the pre-service teachers have to translate what they have learned in university to the primary school practice. In many primary schools in the Netherlands, the teachers still rely on textbooks and structured materials (Meelissen \& Drent, 2008) instead of inquiry based learning; approaches to learning that are based on the investigation of questions, scenarios or problems. Thus pre-service teachers have to practice with inquiry based learning primarily in primary schools, where in-service teachers still judged science as not important enough to warrant finding additional time for it in the already overloaded curriculum (Platform Beta Techniek, 2010). To make it easier for the pre-service teachers to practice with inquiry based learning in the primary school, it might be important that in-service teachers become also aware of the importance of inquiry based science teaching and to increase also their science teaching self-efficacy. This implies that a combination of in-service teacher training and pre-service teacher training might result in a better environment for pre-service teachers to practice their science teaching, because the in-service teacher can coach the pre-service teacher with the translation of the theory about inquiry based teaching to the primary school classroom setting. This might result in more successes in the classroom, which is known to improve the science teaching self-efficacy (Bandura, 1997).

Furthermore, the relation between of the mode of assessing the pre-service teachers and the self-perceived frequency of science teaching was determined. At University A pre-service teachers are assessed by practical assignments and a theoretical test about PCK, while the pre-service teachers at University B are assessed only by theoretical tests, which are primarily about SMK in the first year and about PCK in the second year. In contrast to our expectations, no significant differences can be found between pre-service teachers at University A compared to pre-service teachers at University B in self-perceived science teaching frequency, after both one 
year and two years of teacher training. In addition, practical assignments for students at University A also did not result in more valuable science teaching experiences for increasing science teaching self-efficacy compared to the more 'voluntary 'science experiences of the pre-service teachers at University B. We can conclude from this result that practical assignments as a form of performance assessment do not contribute to the students' perception of having experienced more science teaching in the classroom. Science courses, methods or science content, in combination with an internship, as carried out at University B, seem to challenge pre-service teachers to teach science. Pre-service teachers might not need the additional pressure of a performance assessment. Despite there is no effect of the mode of assessment on the frequency of teaching, it would be very interesting for further research to investigate if there is a differences in the quality of teaching of the pre-service teachers as a result of the different mode of assessment.

A few critical remarks can be made regarding the methodology used in the presented study. First of all, this was a cross-sectional study, with science teaching self-efficacy measured at one time, with different participants in every group. A longitudinal, follow-up study at two universities is planned, to have more power in detecting long-term effects of differences in curricula on science teaching self-efficacy in the first year of science teaching. A longitudinal study, with hypotheses based on the current study, can strengthen our results and minimize the effects of extraneous variables, such as differences in science knowledge as result of prior education or gender.

To be able to measure both components of self-efficacy in the follow-up study, the STEBI-NL needs to be improved by clarifying the STOE items, but meanwhile taking care of the validity of the instrument by taken into account that the interpretation of the items remained the same as of the original items, only in an other cultural context.

With this study, we aimed to better inform teacher educators and to improve current pre-service primary teacher training for science teaching to be able to improve science teaching self-efficacy. Overall, to improve the teacher training program to increase the self-efficacy of the graduates of the teacher training University, the content of science courses in the major program, science content or science method, seems not to make a difference. More important is to improve the program from the third year, when students take the responsibility for the 
educational program and begin to translate of what they have learned about inquiry based science teaching in the primary school program. Creating a situation in the primary internship schools, which reflects better the theory educated in the teacher training programs, could make it easier for students to practice with science teaching and might result in an additional increase in science teaching self-efficacy also from the third year. Such a primary school situation might be created for example, by combining the pre-service teacher training with an in-service teachers training about the newest insights in science teaching. The in-service teacher is in this way, better able to coach the pre-service teacher with the translation of theory into the primary school practice, which might result in a better feeling of the pre-service teachers about their science teaching. Another possibility to decrease the gap between theory and practice could be that the science teacher from the university is going to coach the pre-service teachers directly in the primary school. A third opportunity could be to give the preservice teachers the assignment to redesign the textbook based curriculum to an inquiry based curriculum in collaboration with peers in the same internship school. By designing activities directly in the classroom situation, they might face and solve the problems with the translation of theory to practice in collaboration. Collaboration seems to be important especially for teachers with a low belief of teaching self-efficacy, because these teachers need ongoing encouragement and positive reinforcement (Ramey-Gassert, 1996).

The best way to improve the teacher training program from the minor stage is probably a combination of the above-mentioned solutions. 


\section{CHAPTER $4 \$$}

\section{Collaborative curriculum design and the science teaching self-efficacy of pre-service primary teachers}

The purpose of this study was to establish the value of Teacher Design Teams (TDT) as part of the science specialization training program within primary-level teacher training at a Teacher Training University in the Netherlands for increasing the science teaching self-efficacy of pre-service primary school teachers. In addition, the added value of expert guidance for increasing self-efficacy was determined. A TDT is a group of teachers working together to (re)design and enact (part of) their common curriculum. In this study the assignment for the TDTs was to design a science week for children in a primary school, during which the preservice teachers were to teach science by inquiry. Data were collected from in total 20 pre-service teachers from five different teams, two teams guided by an expert and three without an expert. The results indicate that TDTs guided by an expert are especially valuable for increasing science teaching self-efficacy.

\subsection{INTRODUCTION}

Primary-level teacher training programs at Dutch universities prepare pre-service teachers to teach children from 4 to 12 years old in all subjects. The teacher training program takes 4 years, which means 4 years to learn subject matter knowledge, pedagogical content knowledge and pedagogical knowledge for mathematics, language, arts, history, science and all other subjects in the primary school. Previous studies showed that that graduated students do have only slightly positive science teaching self-efficacy beliefs (Velthuis, Fisser, \& Pieters, 2013a). In addition, only 53\% of future primary teachers in the final year of their teacher training program intend to teach science when they are in-service teachers

$\S$ This chapter has been submitted as: Velthuis, C., Fisser, P., \& Pieters, J. (submitted). Collaborative curriculum design and the science teaching self-efficacy of pre-service primary teachers 
(Van Uum \& Gravenmeijer, 2012). To improve current pre-service primary teacher training for science teaching, two teacher training programs with different science courses, content and method were compared regarding the development of science teaching self-efficacy by pre-service teachers in the Netherlands were studied in our previous study (Velthuis et al., 2013a). A remarkable finding was that, despite their participation in science specialization programs in both their third and fourth years of study, the science teaching self-efficacy of the pre-service teachers stabilized in the third year.

Besides coursework, preparation to teach in primary schools in the Netherlands involves internships as well. From the third year on, pre-service teachers must teach the children for one complete school day every week. This means that beginning in their third year of teacher training, pre-service teachers are responsible for the organization and the content of the educational program in the primary school. The pre-service teachers are expected to translate what they have learned in their university courses about teaching children science by inquiry into the existing program in the primary schools. In many cases, this means that preservice teachers must revamp science education. However, the in-service teachers are often not able to support the pre-service teachers with the problems they are experiencing in applying inquiry-based teaching in the classroom, because current in-service teachers frequently rely on textbooks and structured materials (Meelissen \& Drent, 2008). Therefore, it seems important to provide better support during the minor stage for pre-service teachers trying to implement inquiry-based learning in their primary school practice.

One way in which teachers can make the connection between the intention to teach and their actual teaching practice in their classroom is by designing or redesigning a common curriculum or a part of a curriculum in collaboration within a TDT (Harris, 2003). Several studies show the value of TDTs for teachers' learning (Voogt, Westbroek, Handelzalts, Walraven, McKenney, Pieters, \& de Vries, 2011) and TDTs also seem to be valuable for increasing in-service teachers self-efficacy (Mintzes, Marcum, Messerschmidt-Yates, \& Mark, 2012; Sibbald, 2009). However, only a few studies have investigated the value of TDTs for preservice teachers. And the few available studies regarding TDTs and pre-service teachers are not consistent in the educational program supporting the TDT and the support of experts within the TDT (Agyei \& Voogt, 2012; Alayyar, Fisser, \& Voogt, 2011). 
The study aims to answer the following research questions:

(1) What is the value of a TDT for increasing the science teaching self-efficacy of pre-service primary teachers during the science specialization component of their teacher training?

(2) What is the added value of including a science teacher expert in the TDTs in relation to pre-service teachers' science teaching self-efficacy? And more specifically: What is the added value of the science teacher for improvements in the pre-service teachers' self-rated subject-matter knowledge, the belief about their ability to teach science by inquiry and the quality of the developed educational materials?

\subsection{THEORETICAL FRAMEWORK}

\subsubsection{Self-efficacy}

Teachers' sense of self-efficacy is a powerful predictor of their behaviour in the classroom. Self-efficacy is defined by Bandura (1977) as one's perceived ability to perform an action that will lead successfully towards a specific goal. Teachers with a high sense of self-efficacy will set higher goals, be less afraid of failure, and find new strategies when old ones fail (Tschannen-Moran \& Woolfolk Hoy, 2007). Bandura (1977) described two components of self-efficacy: personal self-efficacy and outcome expectancy. Personal self-efficacy is the belief in one's ability to perform a behaviour and outcome expectancy is the belief that the behaviour will lead to desirable outcomes. Self-efficacy is commonly understood as domain- and context-specific; one can have higher or lower self-efficacy beliefs in different domains or for particular functional situations. Teachers' self-efficacy beliefs may vary from subject to subject, so that a teacher with a high self-efficacy for teaching mathematics might not have the same level of self-efficacy beliefs for science teaching. (Bandura, 1977).

According to Bandura (1997), people's belief about their self-efficacy can be developed through four main sources of influence or information: mastery experiences, vicarious experiences, social persuasion, and physiological responses. Mastery experiences are the most effective way of creating a high feeling of self-efficacy, and the more successful the experience, the more likely it is that one will repeat or extend the behaviour. Vicarious experiences, which are examples or experiences of others, similar to oneself, can also increase the sense of 
efficacy: "If they can do it, I can, too". The third source of influence on people's beliefs that they have what it takes to succeed is what Bandura calls social persuasion, being persuaded verbally by others that one possesses the capabilities to master given activities. Unrealistic boosts in efficacy are proven to be immediately challenged by the disappointing results of one's efforts. The last source of self-efficacy information is reduction of one's stress reactions, which has to do with physical and psychological aspects associated with being in a given functional situation and how these aspects are perceived and interpreted. Someone's mood affects his or her judgments of personal efficacy.

\subsubsection{Science teaching self-efficacy and curriculum reform}

From the results of a cross-sectional study conducted in two universities (Velthuis et al., 2013a), it was concluded that pre-service primary teacher training in the Netherlands improved personal science teaching self-efficacy, in particular during the initial, more basic part of the teacher training. However, the later subject area specialization part of the training did not impact the science teaching self-efficacy of pre-service teachers in those universities (Velthuis et al., 2013a). The lack of increase in science teaching self-efficacy in the third and fourth years might be explained by the difficulties experienced with the implementation of what they learned in their university coursework. When teachers begin to implement a change initiative, or translate theory to practice, a decrease in self-efficacy has been observed by other researchers (Mosely, Reinke, \& Bookout, 2002; Ross, McKeiver \& Hogaboam-Gray, 1997). For example, Ross et al. (1997) found that implementation of an educational reform lowered teacher efficacy. Teachers who participated in their study were encouraged to revise their teaching methods without knowing the effects on student learning, which resulted in uncertainty about the consequences of their actions and thus a decrease in self-efficacy beliefs. Furthermore, Mosely et al. (2002) showed a significant drop in teachers' self-efficacy approximately 7 weeks after finishing a science methodology course, when the teachers were back at their own schools to implement what they had learned. And more recently, TschannenMoran and McMaster (2009) demonstrated the difficulty of implementing a new teaching strategy for teachers of beginning readers, by showing the importance for teachers' self-efficacy of receiving coaching and assistance during implementation.

As demonstrated in these studies by Ross et al. (1997), Mosely et al. (2002), and Tschannen-Moran and McMaster (2009), the implementation of a change initiative is difficult for teachers. However, implementation seems likely to be even more 
difficult for pre-service teachers compared to in-service teachers, because the preservice teachers are often more concerned with classroom management (Davis, Petish, \& Smithey, 2006). Some studies have shown a relation between having concerns about discipline and classroom management, and engaging in practices that are less reform-oriented (Appleton \& Kindt, 2002; Tabachnick \& Zeichner, 1999). Appleton and Kindt (2002) described the importance of supportive colleagues for encouraging beginning teachers to enact challenging or risky activities: in a study with nine early-career teachers they found that the teachers were encouraged to try out new ideas by talking them through with other teachers. Networking seems to be valuable for beginning teachers for discussing issues with respect to science teaching self-efficacy and to challenge them to teach science, because both verbal persuasion and mastery experiences are sources of information influencing self-efficacy beliefs (Bandura, 1997).

\subsubsection{Teacher Design Teams and self-efficacy}

An example of a network of teachers where discussions with colleagues about science teaching take place and where teachers are challenged to enact science teaching activities is a Teacher Design Team (TDT). According to Handelzalts (2009, p. 7) a TDT is defined as 'a group of at least two teachers, from the same or related subjects, working together on a regular basis, with the goal to (re)design and enact (a part of) their common curriculum'. A TDT is a way in which teachers can make the connection between the intention to teach and their actual teaching practice in their classroom (Harris, 2003). Agyei and Voogt (2012) and Alayyar et al. (2011) showed the value of TDT for pre-service teachers. Agyei and Voogt (2012) showed that working in TDTs increased pre-service teachers' confidence in designing mathematics lessons and it improved their teaching performance through sharing experiences and expertise with their immediate colleagues. Alayyar et al. (2011) concluded that pre-service teachers developed practical skills and a positive attitude while developing a solution for a problem related to science teaching. The findings of these studies suggest that TDTs can also be valuable for pre-service teacher training.

The design of science curriculum through participation in a TDT might be valuable for improving the science teaching self-efficacy of pre-service teachers. The first expected effect of a TDT is that the use of collaboratively designed curriculum materials will be discussed in the team, which will encourage the pre-service teachers to try out the new materials (Appleton \& Kindt, 2002; Handelzalts, 2009), 
which is likely to lead to changes and successes in the classroom. Those mastery experiences and social persuasion are major sources of self-efficacy, according to Bandura (1997). Secondly, participating in a TDT contributes to professional development (Handelzalts, 2009). Loucks-Horsley (2003) found that participating in a TDT improved teachers' awareness of diverse pedagogical approaches and their science content knowledge. High science knowledge scores correspond with high personal self-efficacy scores for teaching science (Rohaan, Taconis, \& Jochems, 2012; Schoon \& Boone, 1998). Thus, if pre-service teachers do learn about science by participating in the TDT, this could also be related to higher self-efficacy beliefs. Additionally, professional development in a TDT takes place collaboratively, through interactions and exchange of ideas among the participants (Voogt et al., 2011), which is also known to be important for increasing self-efficacy (Mintzes et al., 2012; Ross et al., 1997; Watters \& Ginns, 2000).

In conclusion, TDTs seem to be potentially valuable for increasing science teaching self-efficacy. However, more information is needed to identify effective support and conditions needed to foster the development of self-efficacy of preservice teachers in a TDT. For example, Agyei and Voogt (2012) began the training program in his study with a two week introductory workshop aimed to prepare pre-service teachers by giving them the theoretical foundations/concepts as well as practical skills they needed to work successfully in TDTs. Subsequently, the TDTs modeled their own lessons in the design stage ( 3 weeks). The TDTs in the study by Alayyar et al. (2011), on the other hand, were coached by several experts (pedagogical, technological and content) throughout the course (12 weeks, 2 hours per week). Only two meetings were used to introduce the pre-service teachers to the assignment being addressed by the TDT.

\subsection{CONTEXT OF THE STUDY}

The intervention in this study was designed as a 'regular' part of the science specialization training program in the Bachelor's degree program of Edith Stein University for Teacher Education in Hengelo, the Netherlands. The study began in 2010 with an intervention including TDTs but without experts. In the next cohort, starting in 2011, the TDTs were expanded to include an expert, because it was hypothesized that having such an expert in the team might be even more supportive for the pre-service teachers and should result in increased science teaching self-efficacy beliefs. 


\subsection{Methodology}

\subsubsection{Participants}

Two cohorts of pre-service primary teachers participated in this study. Both groups were in the subject-matter specialization (minor) program of their teacher training at the Edith Stein University for Teacher Education in the Netherlands (years 3 and 4 , in total a half year of study). The first cohort started the minor program in 2010 with 18 student primary teachers divided over 3 teams. The second cohort started in 2011 with 4 student primary teachers divided over 2 teams, both guided by an expert (a science teacher). The pre-service teachers who participated in this study all chose to specialize in science teaching.

\subsubsection{Intervention}

The TDT program was designed within and added to the existing subject-matter specialization (minor) program. The entire minor takes half a year of study (30 EC), divided over the third year (20 EC) and the fourth year (10 EC). The educational program of the minor program, the TDT program and the relation between those programs is explained in the next paragraphs.

\section{The minor program in the third year}

The main assignment during the third year minor program is a TDT design task. The pre-service teachers in the TDT must design a science week for primary school children around the subject of sustainability and environmental education, in which the pre-service teachers must teach science by inquiry (Van Graft \& Kemmers, 2007). This is an approach to teaching and learning in which children are investigating scientific phenomena and designing solutions to real-life problems. During the first 8 weeks the students are supported by an educational program offered by different experts: science, mathematics, language, technology and pedagogy (3 hours a week). The main content of the educational program is presented in Table 4.1. The experts make use of different teaching approaches during the supporting educational program, such as: discussions in response to videos, hands-on activities followed by reflection, inquiry-based learning. 
Table 4.1 Course content and activities during the two parts of the pre-service teacher training program

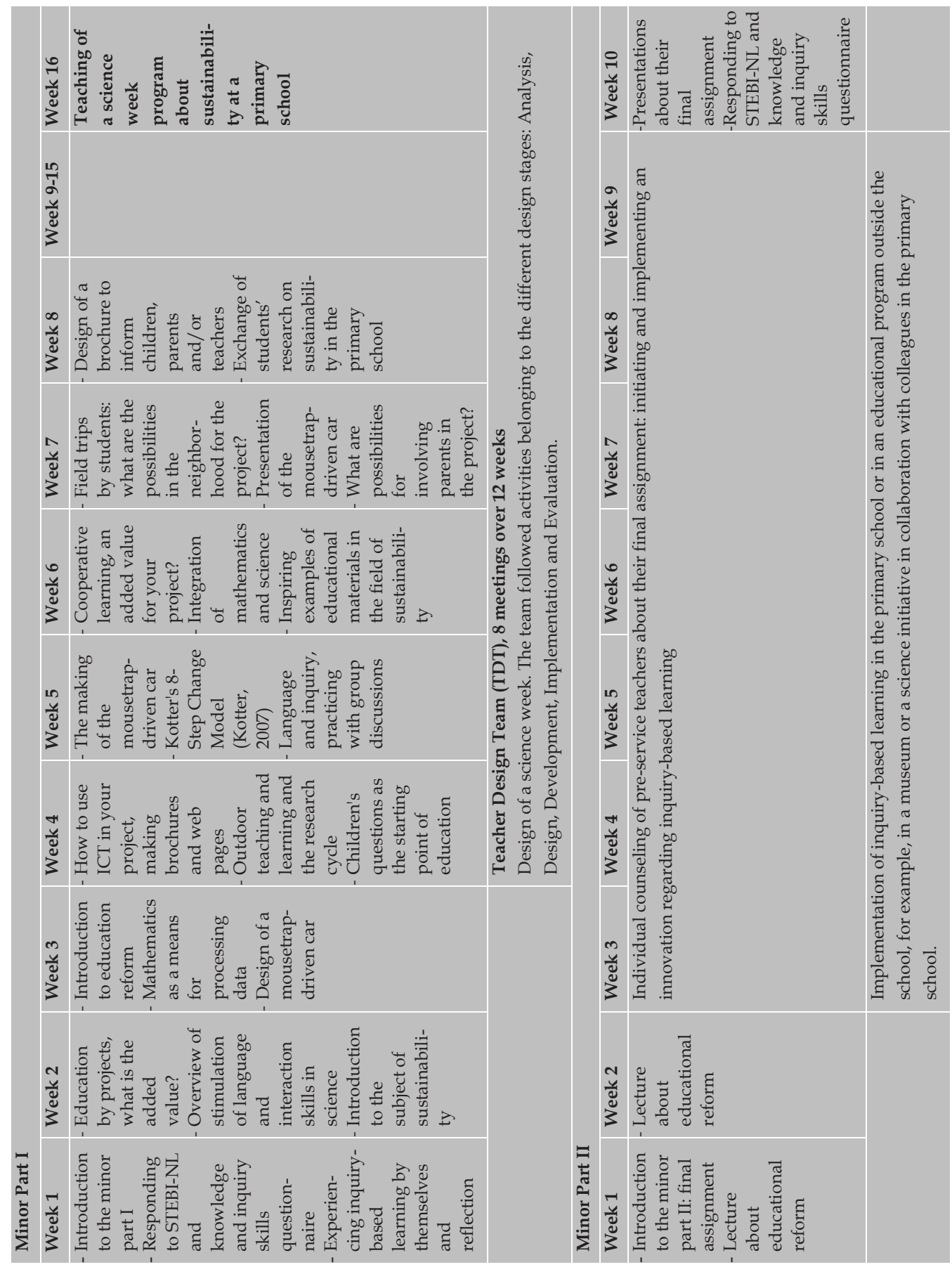




\section{Teacher design teams}

Eight meetings of two hours each were planned for working in the TDT from week 4 till week 15, parallel to some degree to the supporting educational program. The TDTs' assignment was to design a science week and to enact their project in week 16 in a primary school. The team size of the TDT was related to the design task, or the number of primary school classes for which the team has to develop the week, with a minimum of 2 classes. The meetings were guided by a process guide, which means that goals and activities are planned per meeting on paper. The activities during the design process were associated with the ADDIE model: Analysis, Design, Development, Implementation, and Evaluation, (Dick \& Carey, 1996). Each TDT first had to analyze the opportunities for the science week in their primary school and the needs of the teachers in the school. Alternative approaches to the science week were explored and a design for the week was created. During the development of the science week, the team could repeat the design or even analysis activities to improve the final product; the process guide allowed for non-linear processes. Throughout the whole design process, specific activities were planned to keep in mind the upcoming implementation in the primary school. Besides the support by the process guide, the TDTs of cohort 2 were also supported by a science teacher who functioned as an expert. The science teacher knew the supporting educational program and was an active member during the meetings, which meant that she asked critical questions, brought up ideas and answered the questions of the student teachers in the team regarding content and the design process.

\section{The minor program in the fourth year}

The second part of the minor program (10 EC) consists of a final assignment in which students need to prove individually that they can initiate and implement an innovation regarding inquiry-based learning in an existing educational program. This could be the primary school program of the school where the student teacher is already doing his/her internship or a program in a museum or a science company. The main objective is that future teachers will convince inservice teachers or employees of the importance of and the opportunities for inquiry-based learning. Successful performance for the second part of the minor is assessed individually by a presentation in which they demonstrate what they achieved in collaboration with in-service teachers or employees and also how they executed the reform process. 


\subsubsection{Instruments}

Three instruments were used for the purpose of this study. Table 4.2 shows how the different instruments are related to the research sub-questions.

Table 4.2 List of instruments and related questions

\begin{tabular}{|c|c|c|c|c|}
\hline & $\begin{array}{l}\text { Changes in } \\
\text { self-efficacy }\end{array}$ & $\begin{array}{l}\text { Changes in } \\
\text { self-rated SMK }\end{array}$ & $\begin{array}{l}\text { Belief about } \\
\text { improvement in } \\
\text { their ability to } \\
\text { teach by inquiry }\end{array}$ & $\begin{array}{l}\text { Quality of the } \\
\text { educational } \\
\text { materials } \\
\text { developed }\end{array}$ \\
\hline STEBI-NL & $\mathrm{x}$ & & & \\
\hline $\begin{array}{l}\text { Knowledge and } \\
\text { inquiry skills } \\
\text { questionnaire }\end{array}$ & & $x$ & $\mathrm{x}$ & \\
\hline $\begin{array}{l}\text { NSRC selection } \\
\text { criteria }\end{array}$ & & & & $x$ \\
\hline
\end{tabular}

\section{STEBI-NL}

The STEBI-NL (Velthuis, Fisser, Ormel, \& Pieters, submitted a) was translated from an existing, commonly used English instrument: the STEBI-A (Science Teaching Efficacy Belief Instrument), an instrument based on Bandura's selfefficacy theory that specifically aims at the beliefs of (student) teachers about science in teaching and learning (Bleicher, 2004; Riggs \& Enochs, 1990). The STEBI-NL is a 24-item instrument comprising two scales, Personal Science Teaching Efficacy (PSTE, self-assessment of one's teaching competence) and Science Teaching Outcome Expectancy (STOE, teachers' expectations that teaching can influence student learning). The reliability for the personal science teaching self-efficacy-scale (PSTE) was very good, with a Cronbach's a of .84, and the reliability of the science teaching outcome expectancy-scale (STOE) was respectable, with a Cronbach's a of .74. The STEBI-NL was used to measure the science teaching self-efficacy of the pre-service primary teachers. The STEBI-NL is administered to both cohorts at the start and the end of the minor program. Due to absences during the meetings in which the questionnaire was administered, only 10 out of the 20 pre-service teachers had data for both administrations.

\section{Knowledge and inquiry skills questionnaire}

At the end of the STEBI-NL, the pre-service teachers were asked one additional question (1) at the start of the minor and two additional questions ( 1 and 2 ) at the end of the minor, to determine the added value of having an expert in the TDTs for 
improvement in their self-rated subject matter knowledge and for improvement in their belief that they can teach science by inquiry. The questions are:

(1) To what extent do you feel that you have the subject knowledge to teach science within living nature (biology), non-living nature (physics and chemistry) and technology? (3-point scale, inadequate / adequate / good);

(2) To what extent do you believe that you are better able to teach science by inquiry after the minor program? (5-point scale, in which very limited $=1$ and very high $=5$ )

\section{NSRC selection criteria}

The curriculum materials that were developed to support the science week program as designed in the TDTs were analyzed to determine whether having an expert in the team is an added value for the quality of the science week materials prepared for primary schools. 'Criteria for Selecting Inquiry-Centered Science Curriculum Materials' (NSRC, 1997, pp. 63-75), developed by the National Science Resources Center (NSRC) were used for analyzing the curriculum materials. The criteria were originally used as a checklist by science materials adoption committees in school districts throughout the United States to review and select primary science curriculum materials in order to achieve their main goal of teaching science in the primary school through inquiry-centered or inquiry-based learning. The criteria are subdivided into three sets: (1) pedagogical appropriateness, (2) science content and (3) presentation of information and format. The first set, pedagogical appropriateness, consists of criteria about strategies for building conceptual understanding (6 items), teaching science as inquiry (2 items) and applying an effective instructional approach (4 items). Criteria in the second set concern science content (9 items), and the third set deals with the presentation and format of written materials. Because the aim in analyzing the developed science week preparation was to determine differences in quality of the content, if present, between the materials produced by TDTs with and without an expert, we only used the first two sets of criteria. Only 7 items from the set about science content were used, because the items about supporting materials for teachers and related to the content reflecting different viewpoints did not match the assignment in our program.

The NSRC selection criteria were used as a checklist in this study, just as science materials adoption committees use them. Three science teachers checked 
individually whether the materials meet the criteria. The materials were scored for each criterion as follows: the material meets the criterion totally (2), the material meets the criterion partially (1) or the material does not meet the criterion at all (0).

\subsection{DATA ANALYSIS}

\section{Questionnaires}

The teachers used a 5-point Likert scale, ranging from strongly disagree to strongly agree, to indicate their opinions on the statements in the STEBI-NL. Both the PSTE and the STOE scale consist of 12 statements, so the minimum score of a pre-service teacher on each scale is 12 and the maximum score is 60. A higher score indicates higher self-efficacy. Mean scores before and after participation in a TDT were calculated for all the pre-service teachers who participated in TDTs, both with and without an expert.

A Wilcoxon signed ranks test for two related samples was used to determine the difference in PSTE, STOE and self-rated knowledge between before and after participation in the TDT, since only 10 pre-service teachers completed questionnaires both before and after participation in the minor program.

\section{NSRC selection criteria}

Mean scores were calculated per category: strategies for building conceptual understanding (6 items), teaching science as inquiry (2 items), applying an effective instructional approach (4 items) and science content (7 items) and categorized as excellent $(100 \%$ of the maximum possible score), very good $(87,5 \%)$, good $(75 \%)$, amply sufficient (62,5\%), sufficient (50\%) and insufficient (below 50\%). Accompanying notes were added by the researcher to explain the scores.

\subsection{Results}

TDTs and self-efficacy

The Wilcoxon signed ranks test for the STEBI-NL results revealed a significant difference between pre and post intervention scores at $\mathrm{p}<0.05$ for both personal science teaching self-efficacy $(p=.017)$ and outcome expectancy $(p=.037)$ as can be seen in Table 4.3 . 
Table 4.3 Means for PSTE and STOE scores before and after the minor program with TDTs

\begin{tabular}{|c|c|c|c|c|c|c|c|}
\hline & $\begin{array}{l}\text { Pre } \\
\text { M (SD) }\end{array}$ & $\begin{array}{l}\text { Post } \\
\text { M (SD) }\end{array}$ & $\begin{array}{l}\text { Negative } \\
\text { Ranks } \\
\text { (n) }\end{array}$ & $\begin{array}{l}\text { Positive } \\
\text { Ranks } \\
\text { (n) }\end{array}$ & $\begin{array}{l}\text { Ties } \\
\text { (n) }\end{array}$ & $\mathbf{Z}$ & $p$ \\
\hline \multicolumn{8}{|c|}{ Personal science teaching self-efficacy (PSTE) } \\
\hline TDT $(n=10)$ & $44.8(2.74)$ & $50.1(3.81)$ & 1 & 8 & 1 & -2.39 & $.017^{*}$ \\
\hline $\begin{array}{l}\text { Independent TDT } \\
(\mathrm{n}=6)\end{array}$ & $46.0(2.61)$ & $48.2(1.33)$ & 1 & 4 & 1 & -1.41 & .157 \\
\hline Guided TDT $(n=4)$ & $43.0(2.00)$ & $53.0(4.69)$ & 0 & 4 & 0 & -1.83 & .068 \\
\hline \multicolumn{8}{|c|}{ Outcome expectancy (STOE) } \\
\hline $\operatorname{TDT}(\mathrm{n}=10)$ & $43.7(2.00)$ & $46.7(4.57)$ & 1 & 8 & 1 & -2.08 & $.037^{*}$ \\
\hline $\begin{array}{l}\text { Independent TDT } \\
(\mathrm{n}=6)\end{array}$ & $44.0(2.09)$ & $46.5(3.94)$ & 1 & 5 & 0 & -1.37 & .172 \\
\hline Guided TDT $(n=4)$ & $43.3(2.06)$ & $47.0(6.06)$ & 0 & 3 & 1 & -1.60 & .109 \\
\hline
\end{tabular}

Note: *. The difference is significant at the 0.05 level (2-tailed).

Before the minor program, the pre-service teachers' average response for PSTE fell between neutral (36) and agree (48) with a mean PSTE of 44.8 (SD = 2.74). The preservice teachers responded more affirmatively to the same propositions after participating in the minor program (between agree and strongly agree) with a mean PSTE of 50.1 (SD = 3.81). The Wilcoxon signed-ranks test showed that the PSTE of 8 out of 10 student teachers improved, that the PSTE of 1 student decreased and that the PSTE of one student teacher did not change.

The results for STOE scores showed a significant change of 3 points from an average of $43.7(\mathrm{SD}=2.00)$ before the minor program to $46.7(\mathrm{SD}=4.57)$ at its conclusion. The average response of the student teachers to the outcome expectancy items was between neutral and agree at both timepoints, but moved closer to agree after participating in the minor. The Wilcoxon signed-ranks test showed that the STOE of 8 out of 10 student teachers improved, that the STOE of 1 student decreased and that the STOE of 1 teacher did not change.

When the student teachers were divided into those in the independent TDTs ( $\mathrm{n}=$ 6) and those in the TDTs guided by a science teacher $(n=4)$, no significant differences were observed between pre- and post minor program scores for PSTE or STOE in either group.

However, the pre-service teachers in the TDTs guided by the science teachers had greater growth in their mean scores for PSTE (10.00) and STOE (3.75) than those in 
the independent TDTs (2.17 for PSTE and 2.50 for STOE). In addition, there was improvement in the PSTE of $100 \%$ of the pre-service teachers in the TDTs guided by the science teacher and $67 \%$ of the pre-service teachers in the independent TDTs. The STOE scores of $75 \%$ of the pre-service teachers in the guided TDTs and $83 \%$ of those in the independent TDTs improved. It should be noted that the STOE score of one student in an independent TDT actually decreased after the minor program, while the STOE score of only one student in the TDT guided by the science teacher did not show improvement.

TDTs and self-rated knowledge

The Wilcoxon signed ranks test for the knowledge and inquiry skills questionnaire results (Table 4.4) revealed a significant difference between pre and post minor program scores at $\mathrm{p}<0.05$ for self-rated knowledge about technology $\mathrm{r}(p=.046)$, but not in living $(p=1.000)$ and non-living nature $(p=.180)$.

Table 4.4 Means for self-rated knowledge scores in the technology domain before and after the minor including participation in a TDT

\begin{tabular}{|llllllll|}
\hline Technology & $\begin{array}{l}\text { Pre } \\
\text { M (SD) }\end{array}$ & $\begin{array}{l}\text { Post } \\
\mathbf{M}(\mathrm{SD})\end{array}$ & $\begin{array}{l}\text { Negative } \\
\text { Ranks } \\
(\mathbf{n})\end{array}$ & $\begin{array}{l}\text { Positive } \\
\text { Ranks } \\
(\mathbf{n})\end{array}$ & $\begin{array}{l}\text { Ties } \\
(\mathbf{n})\end{array}$ & $\mathbf{Z}$ & $p$ \\
\hline TDT $(\mathrm{n}=10)$ & $1.7(.48)$ & $2.1(.57)$ & 0 & 4 & 6 & -2.00 & $.046^{*}$ \\
\hline $\begin{array}{l}\text { Independent TDT } \\
(\mathrm{n}=6)\end{array}$ & $1.7(.52)$ & $2.0(.00)$ & 0 & 2 & 4 & -1.41 & .157 \\
\hline Guided TDT $(\mathrm{n}=4)$ & $1.8(.50)$ & $2.3(.50)$ & 0 & 2 & 2 & -1.41 & .157
\end{tabular}

Note: *. The difference is significant at the 0.05 level ( 2 tailed).

These results showed that for six student teachers, their self-ratings regarding knowledge about domain technology remained the same after participation (ties), and that four student teachers rated their knowledge about technology higher after participation in the TDT (4 positive ranks). The mean self-rated knowledge score about technology is just above the level of adequate (2.1) after participating in the minor, which is not the case for the other domains: living nature 1.9 (.32) and non-living nature 1.8 (.63). No significant difference between pre- and posttest regarding self-rated knowledge was found when the total sample was split into the pre-service teachers in the independent TDT and the pre-service teachers in the guided TDT. 
TDT and beliefs about improvement in the ability to teach science by inquiry

On average, student teachers' rating of the improvement in their ability to teach science by inquiry after the minor program approaches high, with a mean rating of 3.9 (.92), just below the level of high (average $=3$ and high $=4$, Table 4.5 ).

Table 4.5 Mean scores for student teachers' beliefs about the extent of improvement in their ability to teach science by inquiry after the minor including participation in TDTs

$\begin{array}{llll} & \begin{array}{l}\text { TDT }(\mathbf{n}=\mathbf{1 5}) \\ \text { M (SD) }\end{array} & \begin{array}{l}\text { Independent TDT }(\mathbf{n}=\mathbf{1 1}) \\ \mathbf{M}(\mathrm{SD})\end{array} & \begin{array}{l}\text { Guided TDT (n = 4) } \\ \text { M (SD) }\end{array} \\ \begin{array}{l}\text { Belief about } \\ \text { improvement in ability }\end{array} & 3.9(.92) & 3.7(.91) & 4.3(.96) \\ \text { to teach science by } & & & \\ \text { inquiry } & & & \end{array}$

Note: The minimum score is 1 (very limited) and the maximum score is 5 (very high).

Pre-service teachers in TDTs without an expert believed that their ability to teach science by inquiry improved after the minor program, with a mean score of 3.7 (.91). Pre-service teachers in TDTs guided by a science teacher believed that their ability to teach science by inquiry improved more, with a mean score of $4.25(.96)$.

\section{Evaluating the curriculum materials}

The curriculum materials were evaluated by using the NSRC selection criteria. Table 4.6 gives an overview of the different team products by presenting the subject of the science week, the age of the students who were taught, the main content and the student activities. Teams 1, 2 and 3 designed the science week without an expert and teams 4 and 5 were guided by an expert.

Table 4.6 Overview of the science week programs; teams 1, 2 and 3 were without an expert and teams 4 and 5 were guided by an expert

\begin{tabular}{lllll} 
TDT & Age & Subject & Content & Student activities \\
\hline 1 & $4-12$ & Energy & Hydro energy (4-6) & Watching a film with discussion \\
& & Wind energy (7-8) & afterwards, playing in a water table, \\
& & Kinetic energy (9-10) & visiting a water mill, experiments with \\
& & Solar energy (11-12) & (mall planning and designing activities \\
& & windmill/chain reactions), structured \\
& & experiments (making a solar bbq/oven), \\
& & answering research questions regarding \\
& & energy using books, computers, etc., \\
& & demonstration or presentation for parents
\end{tabular}


Table 4.6 Overview of the science week programs; teams 1, 2 and 3 were without an expert and teams 4 and 5 were guided by an expert (Continued)

\begin{tabular}{|c|c|c|c|c|}
\hline TDT & Age & Subject & Content & Student activities \\
\hline 2 & $4-12$ & Water & $\begin{array}{l}\text { Aquatic animals, taste of } \\
\text { water, floating/ sinking, } \\
\text { liquid layers (4-8) } \\
\text { brightness of water, } \\
\text { aquatic animals and } \\
\text { plants, oxygen in water, } \\
\text { surface tension, water } \\
\text { purification (9-12) }\end{array}$ & $\begin{array}{l}\text { Discussing and philosophizing about } \\
\text { function of water, experiments (making } \\
\text { layers with oil, water and syrup and } \\
\text { tasting water), field trip (looking for } \\
\text { aquatic animals/plants), watching a } \\
\text { demonstration experiment about surface } \\
\text { tension, purification of water, } \\
\text { presentation }\end{array}$ \\
\hline 3 & $4-12$ & Sustainability & $\begin{array}{l}\text { Different kinds of } \\
\text { garbage, cradle to cradle, } \\
\text { garbage collector and } \\
\text { truck, energy (4-6) } \\
\text { the above and recycling, } \\
\text { cradle to cradle (7-9) } \\
\text { the above and } \\
\text { endangered animals and } \\
\text { the role of humans (10- } \\
\text { 12) }\end{array}$ & $\begin{array}{l}\text { Collection of garbage in the school } \\
\text { environment, discussions, visit from a } \\
\text { garbage collector with truck or visiting a } \\
\text { charity shop, games, making something } \\
\text { new from garbage, looking for } \\
\text { information about endangered animals in } \\
\text { books, computers etc., presentation for } \\
\text { parents }\end{array}$ \\
\hline 4 & $6-7$ & Water & $\begin{array}{l}\text { Power of water, how } \\
\text { water pistols work, } \\
\text { distance and height of } \\
\text { bridges, triangular and } \\
\text { bow structure of bridges, } \\
\text { solidity, balance, weight, } \\
\text { sinking and floating, } \\
\text { wind-energy }\end{array}$ & $\begin{array}{l}\text { Experiencing the power of water, } \\
\text { building a bridge (including } \\
\text { investigations with different } \\
\text { constructions and real bridges and } \\
\text { testing the bridge with weights), building } \\
\text { a ship (including an investigation with } \\
\text { different materials and discussion about } \\
\text { wind energy), field trip (looking for } \\
\text { aquatic animals), making a wall frieze of } \\
\text { the week }\end{array}$ \\
\hline 5 & $4-12$ & Survival & $\begin{array}{l}\text { Properties of materials, } \\
\text { construction of a } \\
\text { shelter(4-6), } \\
\text { the above and stability, } \\
\text { connections, tools, } \\
\text { measure (7-9), } \\
\text { the above and energy for } \\
\text { moving (10-12) }\end{array}$ & $\begin{array}{l}\text { Discussion, investigation of possible } \\
\text { materials for a shelter and making of a } \\
\text { shelter or a form of transport with } \\
\text { materials from nature (including making } \\
\text { of a draft proposal on paper, an } \\
\text { evaluation on content and process with } \\
\text { the teacher when planning and working, } \\
\text { and testing), presentation of process and } \\
\text { product }\end{array}$ \\
\hline
\end{tabular}

Table 4.7 shows the results on the curriculum materials evaluation checklist along with the accompanying notes that were made by the assessors. 
Table 4.7 Curriculum materials scores along with the accompanying notes, teams 1, 2 and 3 were without an expert and teams 4 and 5 were guided by an expert

\begin{tabular}{|c|c|c|c|c|c|c|}
\hline & \multicolumn{2}{|c|}{ TDT 1: Energy } & \multicolumn{2}{|c|}{ TDT 2: Water } & \multicolumn{2}{|c|}{ TDT3: Sustainability } \\
\hline $\begin{array}{l}\text { Strategies } \\
\text { for } \\
\text { building } \\
\text { conceptua } \\
1 \text { under- } \\
\text { standing }\end{array}$ & $\begin{array}{l}3 \\
8 \\
8\end{array}$ & $\begin{array}{l}\text { Materials focus on } \\
\text { several experiences } \\
\text { within the concept of } \\
\text { energy. Whether the } \\
\text { activities contribute to } \\
\text { the development of } \\
\text { scientific reasoning } \\
\text { and problem solving } \\
\text { skills depends on the } \\
\text { teacher and not the } \\
\text { materials. }\end{array}$ & 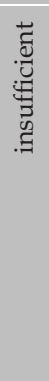 & $\begin{array}{l}\text { The focus is on water, } \\
\text { but related concepts are } \\
\text { studied very } \\
\text { superficially, with no } \\
\text { logical sequence. The } \\
\text { curriculum materials do } \\
\text { not contribute to the } \\
\text { development of } \\
\text { scientific reasoning and } \\
\text { problem solving. }\end{array}$ & $\begin{array}{l}7 \\
8 \\
8 \\
0\end{array}$ & $\begin{array}{l}\text { Materials focus on } \\
\text { several experiences } \\
\text { within the concept of } \\
\text { sustainability. } \\
\text { Whether the activities } \\
\text { contribute to the } \\
\text { development of } \\
\text { scientific reasoning } \\
\text { and problem solving } \\
\text { skills depend on the } \\
\text { teacher. }\end{array}$ \\
\hline $\begin{array}{l}\text { Teaching } \\
\text { science as } \\
\text { inquiry }\end{array}$ & 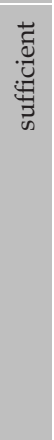 & $\begin{array}{l}\text { The students are not } \\
\text { coached on doing } \\
\text { investigation/design. } \\
\text { If they cannot plan or } \\
\text { design their own } \\
\text { investigation, the } \\
\text { students have to do a } \\
\text { structured } \\
\text { experiment, (which } \\
\text { are available). They } \\
\text { also do not learn how } \\
\text { to express their } \\
\text { results. }\end{array}$ & 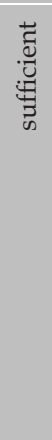 & $\begin{array}{l}\text { The students are not } \\
\text { coached on doing } \\
\text { investigation in the } \\
\text { materials, but older } \\
\text { students can do their } \\
\text { own investigation. They } \\
\text { also do not learn how to } \\
\text { express their results. }\end{array}$ & 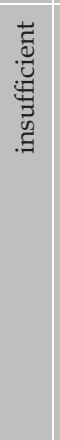 & $\begin{array}{l}\text { Students do not make } \\
\text { use of the research } \\
\text { cycle. They mainly do } \\
\text { structured activities. }\end{array}$ \\
\hline $\begin{array}{l}\text { Using an } \\
\text { effective } \\
\text { instruc- } \\
\text { tional } \\
\text { approach }\end{array}$ & 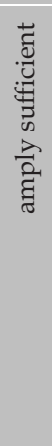 & $\begin{array}{l}\text { There are more } \\
\text { student-directed } \\
\text { activities than teacher- } \\
\text { facilitated activities. } \\
\text { There is no strategy to } \\
\text { assess students } \\
\text { learning. There is } \\
\text { integration with } \\
\text { language (word web } \\
\text { and discussion) and } \\
\text { good guidance } \\
\text { regarding } \\
\text { collaborative learning. }\end{array}$ & 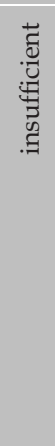 & $\begin{array}{l}\text { There are both student- } \\
\text { directed and teacher- } \\
\text { facilitated activities but } \\
\text { they do not } \\
\text { complement each other. } \\
\text { There is no strategy for } \\
\text { the teacher to assess the } \\
\text { presentations. } \\
\text { Presentation is a goal in } \\
\text { language, but what do } \\
\text { the students learn in } \\
\text { this week? }\end{array}$ & $\begin{array}{l}\text { T } \\
8 \\
0 \\
0\end{array}$ & $\begin{array}{l}\text { There is a good } \\
\text { balance between } \\
\text { student-directed and } \\
\text { teacher-facilitated } \\
\text { activities Students can } \\
\text { work collaboratively } \\
\text { and alone, but there is } \\
\text { no real teamwork. } \\
\text { There is no strategy } \\
\text { for the teacher to } \\
\text { assess. There is } \\
\text { integration with other } \\
\text { subjects. }\end{array}$ \\
\hline $\begin{array}{l}\text { Science } \\
\text { content }\end{array}$ & $\begin{array}{l}7 \\
8 \\
8 \\
\infty\end{array}$ & $\begin{array}{l}\text { The content is } \\
\text { accurately represented } \\
\text { and appropriate for } \\
\text { the grade levels. The } \\
\text { content could } \\
\text { emphasize scientific } \\
\text { inquiry more. }\end{array}$ & 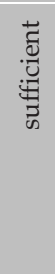 & $\begin{array}{l}\text { The content is taught } \\
\text { very superficially and } \\
\text { could emphasize } \\
\text { scientific inquiry more. }\end{array}$ & $\begin{array}{l}7 \\
8 \\
0 \\
0\end{array}$ & $\begin{array}{l}\text { The content is } \\
\text { accurately } \\
\text { represented, not } \\
\text { always appropriate } \\
\text { for the grade levels. } \\
\text { The content } \\
\text { emphasizes scientific } \\
\text { inquiry just a little. }\end{array}$ \\
\hline
\end{tabular}


Table 4.7 Curriculum materials scores along with the accompanying notes, teams 1, 2 and 3 were without an expert and teams 4 and 5 were guided by an expert (Continued)

\begin{tabular}{|c|c|c|c|c|}
\hline & \multicolumn{2}{|r|}{ TDT4: Water } & \multicolumn{2}{|r|}{ TDT5: Survival } \\
\hline $\begin{array}{l}\text { Strategies } \\
\text { for } \\
\text { building } \\
\text { conceptual } \\
\text { understan- } \\
\text { ding }\end{array}$ & $\begin{array}{l}\overline{0} \\
8 \\
8\end{array}$ & $\begin{array}{l}\text { The focus is on water, and related } \\
\text { concepts are studied hands-on, but } \\
\text { with no logical sequence and } \\
\text { depth. The activities contribute to } \\
\text { the development of scientific } \\
\text { reasoning and problem solving } \\
\text { skills. }\end{array}$ & $\begin{array}{l}\overline{0} \\
8 \\
8 \\
0\end{array}$ & $\begin{array}{l}\text { The instruction and coaching of the } \\
\text { teacher focus more on process then } \\
\text { on content. The activities } \\
\text { contribute to the development of } \\
\text { scientific reasoning and problem } \\
\text { solving skills. }\end{array}$ \\
\hline $\begin{array}{l}\text { Teaching } \\
\text { science as } \\
\text { inquiry }\end{array}$ & $\begin{array}{l}7 \\
8 \\
0 \\
2 \\
2 \\
>0\end{array}$ & $\begin{array}{l}\text { The students are coached in an } \\
\text { appropriate way about the process } \\
\text { of designing by the activities. The } \\
\text { students can choose and plan their } \\
\text { own design(process) and have to } \\
\text { defend the process and the } \\
\text { product. }\end{array}$ & $\begin{array}{l}\text { Do } \\
8 \\
8\end{array}$ & $\begin{array}{l}\text { There are a lot of suggestions for } \\
\text { coaching students with the design } \\
\text { process. But it depends on the } \\
\text { teacher what to do with it. The } \\
\text { students can make and plan their } \\
\text { own design (process) and have to } \\
\text { defend the process and the } \\
\text { product. }\end{array}$ \\
\hline $\begin{array}{l}\text { Using an } \\
\text { effective } \\
\text { instruct- } \\
\text { tional } \\
\text { approach }\end{array}$ & $\begin{array}{l}\text { "0. } \\
8 \\
8\end{array}$ & $\begin{array}{l}\text { There is a good balance between } \\
\text { student-directed and teacher- } \\
\text { facilitated activities. There is } \\
\text { integration with math and good } \\
\text { guidance regarding collaborative } \\
\text { learning. There is a strategy to } \\
\text { assess the students on both process } \\
\text { and content. }\end{array}$ & $\begin{array}{l}\bar{Z} \\
8 \\
8 \\
0.0\end{array}$ & $\begin{array}{l}\text { There are more student-directed } \\
\text { activities compared to teacher- } \\
\text { facilitated activities. There is } \\
\text { integration with math and } \\
\text { guidance regarding collaborative } \\
\text { learning. There is a strategy to } \\
\text { assess the students on both process } \\
\text { and content. }\end{array}$ \\
\hline $\begin{array}{l}\text { Science } \\
\text { content }\end{array}$ & $\begin{array}{l}0 \\
8 \\
80\end{array}$ & $\begin{array}{l}\text { The material offers a lot of content } \\
\text { in a short timeframe, raising the } \\
\text { question whether the children will } \\
\text { understand all content at the end of } \\
\text { the week. The content emphasizes } \\
\text { scientific inquiry. }\end{array}$ & $\begin{array}{l}\bar{Z} \\
8 \\
8 \\
60\end{array}$ & $\begin{array}{l}\text { The material offers ideas for an } \\
\text { appropriate level of content, } \\
\text { however the quality depends on } \\
\text { students and the quality of the } \\
\text { teacher and is not included in the } \\
\text { materials. The content emphasizes } \\
\text { scientific inquiry. }\end{array}$ \\
\hline
\end{tabular}

The materials developed by TDTs 1, 4 and 5 were at least sufficient for all categories: building conceptual understanding, teaching science as inquiry, applying an effective instructional approach and science content. The materials developed by TDT 3 were only insufficient regarding 'teaching as inquiry' (other 
categories good), but the materials from TDT 2 were insufficient for building of conceptual understanding and applying an effective instructional approach and sufficient for teaching science as inquiry and the science content. The results indicate that the curriculum materials from the TDTs with expert guidance focus more on inquiry as the basis of student learning experiences, compared to the other teams (very good and good, compared to insufficient and sufficient).

The difference in materials on the degree of inquiry-based learning found with the checklist corresponds also with the accompanying notes. The materials developed by TDT 3 are very structured and do not contribute at all to the development of scientific reasoning and problem solving skills. The science week materials from TDTs 1 and 2 give children the opportunity to investigate, but if the children cannot do it by themselves, they are not coached. The materials from TDTs 4 and 5, the teams with expert guidance, contribute best to the development of scientific reasoning by coaching the children with the design process, e.g. they investigate several possibilities for the design together and discuss design proposals. In addition, TDTs 4 and 5 have strategies to assess what the children learn during the science week on both process and content, and the other teams do not. Thus the teams with the guidance of an expert seem to focus on learning by inquiry, while the other teams seem to focus on showing the 'results' of the week.

Another main difference between the teams that can be seen in the notes is the achieved level of depth regarding science content in the materials. The science weeks of TDTs 2 (no expert) and 4 (with an expert) cover more related concepts, which results in superficial knowledge of those science concepts, while the science week of TDT 3 (no expert) covers only one major concept, with related concepts that are studied in depth. The science week of TDT 5 (with an expert) is more student-directed and the material offers opportunities for coaching on both process and content, which means that the level of depth in the science week depends on the interaction between the children and the pre-service teachers. So, the material offers opportunities for an appropriate level of depth regarding content, but the level of depth depends on the quality of the children and the teacher. The difference in depth regarding science content in the materials therefore seems not to depend on the guidance of the expert in the team. 


\subsection{Discussion}

The value of a minor program with TDTs for increasing self-efficacy

The results obtained with the STEBI-NL showed that participating a minor program that includes a TDT results in a significant increase in personal science teaching self-efficacy (PSTE) and science teaching outcome expectancy (STOE) of pre-service primary teachers. A previous study at the same university showed that science teaching self-efficacy remained the same during the minor program when the minor program did not include TDTs (Velthuis et al., 2013a). The results of this study indicate the value of collaborative curriculum design by TDTs during the minor stage of teacher training. Collaborative curriculum design supports pre-service teachers with the implementation of inquiry-based science teaching in the traditional educational program in primary schools, and participating in TDTs is associated with an increase in science teaching selfefficacy during the minor stage, which corresponds with the results of Agyei and Voogt (2012) and Alayyar et al. (2011).

\section{The value of an expert in a TDT}

Being supported by a science teacher in a TDT did seem to result indeed in greater growth in self-efficacy of the participating students compared to the teachers in the independent TDTs, mainly with regard to PSTE. The mean PSTE growth of the students in the guided TDTs was 7.8 points higher compared to the students in the independent TDTs. The science teacher did not seem to make a difference regarding the STOE of the participating students. Our finding that a science teacher seems to provide added value in a TDT regarding self-efficacy is strengthened by the results from the question on the knowledge and inquiry skills questionnaire about the extent to which students believe that the minor program, including participating in a TDT, improved their ability to teach science by inquiry. The students who participated in the TDT guided by the science teacher believed more strongly than the students in the independent TDT that they were better able to teach science by inquiry (by .5 points on a 5 -point-scale), The science teacher was an active participant in the TDT by bringing up ideas, asking critical questions and answering the student teachers' questions. It could be that in this way the science teacher was assisting the TDT so that no uncertainties arose about the content or design process. The students were less hindered by external factors and thereby supported to go on. Ramey-Gassert, Shroyer and Straver (1996) also demonstrated the importance of assistance and support, especially for teachers 
with low self-efficacy beliefs, because these teachers are more inclined to give up or to blame external factors. Besides supporting the process in the team, it might also be that the science teachers' support with the implementation of the science project contributed to the students' self-efficacy. Mosely et al. (2002) and Tschannen-Moran and McMaster (2009) demonstrated in their studies the importance for their teaching self-efficacy of assisting student teachers during implementation. And last, it could be that the ideas of the science teacher, which she brought up during the team meetings, challenged the students in the guided TDTs to try these ideas in practice. It is known that a greater challenge can result in more successful teaching experiences and thus can be more effective for increasing self-efficacy (Bandura, 1997). Additional research with larger numbers of teams guided by an expert and independent teams is needed to be sure that participating in a TDT is a good way to improve science teaching self-efficacy for primary student teachers and that the expert provides added value in a TDT for improving science teaching self-efficacy.

The added value of the expert for increasing self-rated subject matter knowledge

The results show that participating in a minor program with TDTs resulted in a significant increase in self-rated subject matter knowledge in the domain of technology, to an adequate level. When the teachers from the independent TDTs and the guided TDTs were analyzed separately, a significant difference was no longer obtained. The self-rated knowledge of the students was determined by a 3 point-scale. The consequence is that there is a relatively large difference between adequate and good. It might be that there are smaller significant differences between the self-rated knowledge of students within the domains of living and non-living nature, but that we were not able to measure this in this study. LoucksHorsley (2003) has already demonstrated that participating in a TDT can increase the science content knowledge of teachers.

It is clear that participating in the TDT resulted in an increase in self-rated knowledge level to adequate only in the domain of technology. Living nature and non-living nature were still domains for which students believed that they did not have adequate knowledge to teach the corresponding subjects well. Because amount of science content knowledge is known to be important for teachers' selfefficacy (Rohaan et al., 2012; Schoon \& Boone, 1998), it could be that participating in a TDT might be even more valuable for increasing science teaching self-efficacy when the TDTs focus on the science content knowledge of the students as well as 
on applying inquiry-based learning in the primary school practice. Challenging students to think about science content could be an additional task for the science teacher in the TDT that could make a TDT more effective for increasing the students' science teaching self-efficacy.

The added value of the expert for the quality of curriculum materials

The results of evaluating the materials with the NSRC-criteria indicate that the materials developed by the TDTs do not all line up well with inquiry-based learning. The materials that do not match well with all categories of the NSCR criteria were both designed by TDTs without an expert. One main difference between the teams' curriculum materials was that the curriculum materials developed by the TDTs guided by an expert focused more on inquiry as the basis for the learning process compared to the materials from the other teams. It seems that the expert in the team, by taking part in the team design process, assisted the pre-service teachers with the translation of theory about inquiry-based learning to primary school practice, and in this way persuaded the pre-service teachers to teach science by inquiry instead of using textbooks and structured materials. Social persuasion or being persuaded verbally by others that one possesses the capabilities to master given activities, is the third source of self-efficacy (Bandura, 1997) and might explain the additional increase of self-efficacy beliefs of the preservice teachers in the TDTs with an expert. Other aspects such as the achieved level of depth regarding science content in the materials do not depend on the guidance of the expert in the team.

\section{Limitations}

A limitation of our study is that the results are based on only five TDTs total, with only four pre-service teachers in the two TDTs guided by an expert and that only ten participants had complete datasets for both pre and post. From the results of this study, we can conclude that there are differences in growth in science teaching self-efficacy between the teachers in the teams with and without an expert in combination with a TDT in the minor program in one specific University in the Netherlands. Additional research with more teams in combination with different programs is needed to be sure that participating in a TDT is a good way to improve science teaching self-efficacy and that the expert provides added value in a TDT for improving science teaching self-efficacy. 
The second limitation is that the results could be influenced by the fact that the teams without an expert consisted of an average of five pre-service teachers and the teams with an expert of only two pre-service teachers. As scholars have pointed out, the right team size depends on the work to be performed, the size and the complexity of the task (Hackman, 1987). In this study the work to be performed was adapted to the team size by adjusting the amount of children who had to be taught in the project. However we do not know whether the difference in team size did indeed influence our results.

\subsection{CONCLUSION}

TDTs are a valuable addition in the teacher training program to support preservice primary teachers with the application of the theory of innovative education as taught at the Teacher Training University to their primary school practice. Extending the minor stage with TDTs seemed to result in ongoing growth of the science teaching self-efficacy of student primary teachers during the minor stage. The assistance and support of the TDT by a science teacher seemed to have added value for increasing science teaching self-efficacy. 


\section{CHAPTER 5 \\ Collaborative curriculum design to increase science teaching self-efficacy: a case study}

The purpose of this study was to establish whether participation in a Teacher Design Team (TDT) is an effective way to increase the science teaching selfefficacy of primary school teachers who vary in their levels of experience and interest in science. A TDT is a group of at least two teachers from the same or related subjects working together to (re)design and enact (a part of) their common curriculum (Handelzalts, 2009). This study considers the context of a primary school in the Netherlands. Three forms of data were collected to obtain more indepth data about the value of working in a TDT: the Dutch version of the STEBI (Science Teaching Efficacy Belief Instrument, Fisser, Ormel, \& Velthuis, 2010); an additional TDT questionnaire; and a focus group interview. The results indicate that professional development through a TDT can improve science teaching self-efficacy for teachers with varying levels of experience and interest.

\subsection{INTRODUCTION}

The Netherlands has to cope with a growing shortage of people who are welleducated in science. Only 16 percent of Dutch students earn a degree in science education, compared to 26 percent in other parts of Europe (Platform Beta Techniek1, 2008). A partial explanation can be found in the results of the 2011 TIMSS (Martin, Mullis, Foy, \& Stanco, 2012), the international comparative study on trends in mathematics and science education in which more than 52 countries participate. In the Netherlands, 3461 grade 4 children from 128 different elementary schools participated in TIMSS 2011. The results show that Dutch elementary school

\# This chapter has been accepted as: Velthuis, C. Fisser, P., \& Pieters, J. (Accepted, November 2013). Collaborative curriculum design to increase science teaching self-efficacy: a case study. The Journal of Educational Research.

1 Platform Beta Techniek is a Dutch government organization that was assigned to increase the number of graduates in science in 2010 by $15 \%$ compared to 2000 . 
children do not belong to the top 10 best achieving students in the domain of science, which was the case since 2007 (Meelissen \& Drent, 2008). One reason for this might be the time allotted for science teaching in the primary school curriculum. Dutch teachers spend an average of only 30-45 minutes per week on science education in grade 4, which is less than many other countries, including Hungary, Korea, Singapore, Finland, Japan and the Czech Republic (Martin et al., 2012). In addition, the amount of learning by inquiry during science lessons is less in the Netherlands than in those countries (Meelissen \& Drent, 2008). To improve science education in the Netherlands, in 2008 the government started an innovation initiative called VTB-pro ${ }^{2}$, to encourage science teachers to participate in a professional development program. The VTB-pro programs for teaching science in primary schools concentrate mainly on teachers' subject matter knowledge, pedagogical content knowledge (PCK), and attitudes towards science. However, at $90 \%$ of the schools that participated in the VTB-pro program, teachers still judged science as not important enough to warrant finding additional time for it in the already overloaded curriculum (Platform Beta Techniek, 2010).

In consequence, the goal of this study is to design a professional training program for teachers that can result in reform in science education in the Netherlands. The focus is on increasing teachers' science teaching self-efficacy, because we know that teachers with high science teaching self-efficacy belief develop a lasting interest in science, a positive desire to help students, and a willingness to improve their science teaching (Bandura, 1977; Tschannen-Moran \& Woolfolk Hoy, 2007), which are very important for improving science education in primary schools. In this study, collaborative curriculum design by a TDT was introduced to increase the selfefficacy of teachers who varied in their levels of experience and interest in science.

\subsection{THEORETICAL FRAMEWORK}

\subsubsection{Self-efficacy}

The level of implementation of a new teaching strategy depends on the teacher's self-efficacy (Poole \& Okeafor, 1989; Tschannen-Moran \& McMaster, 2009). Selfefficacy is defined by Bandura (1977) as one's perceived ability to perform an

2 VTB-pro (Verbreding Techniek Basisonderwijs-Professionalisering) is a Platform Beta Techniek program that enables teachers to improve their knowledge and skills with respect to science education in the primary school. 
action that will lead successfully towards a specific goal. Teachers with a high sense of self-efficacy for teaching will set higher goals, be less afraid of failure, and find new strategies when old ones fail (Bandura, 1977; Tschannen-Moran \& Woolfolk Hoy, 2007). Bandura (1977) described two components of self-efficacy: personal self-efficacy and outcome expectancy. Personal self-efficacy is the belief in one's ability to perform the behavior and outcome expectancy is the belief that the behavior will lead to desirable outcomes. Self-efficacy is commonly understood as domain- and context-specific; one can have different levels of selfefficacy beliefs in different domains or for particular situations of functioning. Teachers' self-efficacy beliefs may vary from subject to subject, so that a teacher with high self-efficacy for teaching mathematics might not have the same high self-efficacy for science teaching (Bandura, 1977).

\subsubsection{Sources of increases in self-efficacy}

According to Bandura (1997), people's beliefs about their self-efficacy can increase based upon four main sources of information. Mastery experiences are the most effective way of creating a high feeling of self-efficacy, and the more successful the experience, the more likely it is that one will repeat or extend that behavior. Vicarious experiences, which are observed examples or experiences undergone by others who are similar to oneself, can also increase the sense of efficacy: 'if they can do it, I can, too'. The third source of information that influences people's beliefs that they have what it takes to succeed is what Bandura calls 'social persuasion', or being persuaded verbally by others that one possesses the capabilities to master given activities. The final source of information that can increase self-efficacy is a reduction in people's stress reactions, which has to do with physical and psychological aspects and how these aspects are perceived and interpreted. One's mood affects one's judgements of self-efficacy.

Apart from the sources of increases in self-efficacy as described by Bandura, the amount of 'science' content knowledge or subject matter knowledge (SMK) is an important predictor for science teaching self-efficacy, particularly for personal science teaching self-efficacy. High science knowledge scores correspond with high personal self-efficacy scores for teaching science (Rohaan, Taconis, \& Jochems, 2012; Schoon \& Boone, 1998). 


\subsubsection{Self-efficacy and professional development programs}

Science methods courses can have a positive impact on self-efficacy, especially when the program takes into account the four main sources of influence (Cantrell, Young, \& Moore, 2003; Ross \& Bruce, 2007). However, Mosely at al. (2002) found that although teachers experienced an increase in self-efficacy after finishing a professional development for outdoor education, there was a significant drop in self-efficacy approximately 7 weeks later, when the teachers were back at their own schools to implement what they had learned. This result suggests that teachers might experience difficulties with implementation as they translate the innovation to their own teaching practice, which results in a decrease in self-efficacy.

The difficulty of implementation for teachers and the negative effect on self-efficacy correspond with the findings of Tschannen-Moran and McMaster (2009), who demonstrated the importance for teachers' self-efficacy of coaching and assisting the teachers during implementation of what they have learned. In their study, primary teachers participated in one of four different formats for professional development that presented the same teaching strategy with increasing levels of efficacy-relevant input; mastery experiences, vicarious experiences provided by social models, other people's beliefs that they have what it takes to succeed and reducing people's stress reactions (Bandura, 1997; Tschannen-Moran \& Woolfolk Hoy, 2007) . The professional development program that supported mastery experiences through assisting and coaching of the teachers during implementation resulted in an increase in teacher self-efficacy for reading instruction and an increase in implementation of the target teaching strategy. A significant proportion of the teachers who participated in the training program that consisted of information, a demonstration with local students (vicarious experience) and a planning and practice session (a protected mastery experience) were left feeling more inadequate than they had before. Teachers who received only the information about the teaching strategy increased their self-efficacy for reading instruction, although their implementation of the target teaching strategy did not increase.

These results indicate that teachers need feedback and support in their implementation efforts and that telling (verbal persuasion) and watching others (vicarious experiences) were minimally effective in leading to instructional change. Supporting implementation in addition results in authentic task-specific mastery experiences that contribute to self-efficacy improvement (Bandura, 1997; Palmer, 2006; Ramey-Gassert, Stroyer, \& Staver, 1996; Rimm-Kaufman \& Sawyer, 
2004) and thus may also produce teachers with a positive desire to improve their science teaching (Tschannen-Moran \& Woolfolk Hoy, 2007).

\subsubsection{TDT and self-efficacy}

The main goal of a TDT is to have teachers design or redesign and enact (a part of) their common curriculum (Handelzalts, 2009, p. 7). The expected effects of a TDT can be divided among three domains. First, they are expected to lead to changes in the curriculum. Teachers can make the connection between structural changes and reform intentions and their own practice in their classrooms (Harris, 2003). A TDT is expected to develop and use new curriculum materials, which influence teacher practice and thus logically lead to curriculum development in the school. Second, the interaction of the teachers in the team is supposed to contribute to teacher professional development. Loucks-Horsley (2003) found that participating in a TDT improved teachers' awareness of diverse pedagogical approaches and their science content knowledge. Third, the work in the team is supposed to change the way teachers work and interact, contributing to organizational change at both the school-cultural level and the school structural level (Handelzalts, 2009). Both changes in the curriculum and professional development are expected effects of a TDT and, therefore, the reform of the science curriculum through the use of a TDT could also be a way to improve science teaching self-efficacy. Although the value of TDTs in improving self-efficacy is not yet known, what is known is that when providing teacher professional development, support during implementation (Tschannen-Moran and McMaster, 2009) and successes in the classroom can help to increase teachers' self-efficacy (Bandura, 1997; Palmer, 2006; Ramey-Gassert et al., 1996; Rimm-Kaufman \& Sawyer, 2004).

\subsection{PROBLEM STATEMENT AND RESEARCH QUESTION}

Professional development programs for science teaching need to be improved. Current programs result in more knowledge, skills and better attitudes of teachers in the field of science, but these programs do not produce reform of the teaching of science in the primary school (Platform Beta Techniek, 2010). More time for science education and teaching by inquiry motivate more children to learn science, which is necessary to cope with a growing shortage of well-educated people in science in the Netherlands (Platform Beta Techniek, 2008). 
This research is a part of an educational design study (Van den Akker, Gravemeijer, McKenney, \& Nieveen, 2006). During this study a professionalization program through a TDT is developed directly in the context of a primary school. The expectation is that implementation of the program will result in improved educational practice by increasing teachers' science teaching self-efficacy. The effect of implementation of the TDT program on the science teaching self-efficacy of participating team members will be presented in this case study. The purpose of this study is to gain in-depth information about a TDT as way to increase the science teaching self-efficacy of teachers with varying levels of experience and interest in science.

The research questions addressed in this study are:

(1) What is the effect of participating in a TDT on the science teaching selfefficacy of participating team members, measured as both personal science teaching self-efficacy and outcome expectancy?

(2) What elements in the professional development program (TDT) do the teachers see as important for increasing their science teaching self-efficacy?

The results of this study are important for determining whether TDTs are an effective way to increase self-efficacy for science teaching, and for understanding how to improve TDTs as a way to increase self-efficacy so that it is appropriate for the group of participating teachers.

\subsection{Methodology}

\subsubsection{Participants}

As a case study, this study considers the domain of a school, a medium-sized primary school in the Netherlands, with about 190 students. The school can be characterized as having many students with language deficiencies, particularly in relation to reading texts. This school is an academic primary school, with 24 teachers. This means that the team is continually involved with educational innovation by making connections between training and research. Participating in this study therefore fits very well with the principles of this school, especially because science education needs a change. The school purchased a science method 
with financial aid, the 'Science Towers' (in Dutch: www.techniektorens.nl). The 'Science Towers' are cabinets shaped as towers with 80 lesson boxes inside. Each lesson box within the towers is focused on a specific topic within a domain, for example, building a bridge, making soap, etc. Each box has a manual for the children, which guides them through the activity in the box. The problem for the school is that most of the teachers do not use the materials, because the children in this school need too much help from the teachers, which takes too much time in the overloaded school curriculum. This study is therefore a collaborative study between the principal in the school confronted with the need to reform their science program, and the external facilitator who wants to see whether a collaborative redesign of a curriculum is effective for increasing the self-efficacy of the teachers.

The five participants in the TDT were two teachers, a pre-service teacher, the school's principal and the external facilitator who guided the TDT (Table 5.1). Teacher 1 is the most experienced teacher (> 20 years). She teaches the oldest children in the school for just one day a week. Besides her function as teacher, she is also involved with policymaking. As a person, she is very interested in science and wants to spend time to improve science education at her school. Teacher 2 has 3 years of teaching experience. At the start of the program she is just a little interested in science and does want to improve science education, but does not want to be the early adopter. Both teachers participated voluntarily.

The pre-service teacher is in the last year of her studies and is teaching for 2 days a week during this year. The pre-service teacher participated in the TDT in the context of an assignment from her training. The assignment was to make an overview of the science curriculum in the school and provide the school with advice with possible improvements, based on her own classroom experiences with those 'improvements'.

Table 5.1 Participants in TDT

\begin{tabular}{|llll|}
\hline Participant TDT & Student age & $\begin{array}{l}\text { Years of } \\
\text { teaching } \\
\text { experience }\end{array}$ & $\begin{array}{l}\text { Attitude towards science } \\
\text { before TDT }\end{array}$ \\
\hline Teacher 1 & $11-12$ & $>20$ & Very interested \\
\hline Teacher 2 & $8-9$ & 3 & Little interested \\
\hline Pre-service teacher & $6-7$ & 0 & Interested \\
\hline Principal & & & \\
\hline External facilitator & & & \\
\hline
\end{tabular}




\subsubsection{The TDT program}

The whole design process was carried out in eight meetings of approximately two hours each. The assignment of the team was to redesign their science curriculum for students from ages 4 to 12. The team wanted to redesign the science boxes so that (1) children can work more independently with those boxes, and (2) children can learn more by inquiry. A process guide with activities was developed and used for the design process. The team followed activities belonging to the different design stages of the ADDIE model, Analysis, Design, Development, Implementation, and Evaluation, (Dick \& Carey, 1996) . After analyzing the needs and opportunities for a new curriculum, alternative solutions for the curriculum were explored and a prototype for a science box was designed. After completing this activity the team could repeat design or even analysis activities; the process guide allowed non-linear progression. Throughout the whole design process, activities were planned with attention to the upcoming implementation and evaluation. This way of working is more like the practice of an educational designer (Visscher-Voerman \& Gustafson, 2004).

The external facilitator provided the structure for the team's design activities, gave information in response to the team's questions, and stimulated the design process.

\subsubsection{Instruments}

Three forms of data were collected for triangulation. The improved STEBI-NL (Fisser et al., 2010) was used to measure science teaching self-efficacy of the teachers pre-intervention, half-way through the program and post-intervention. STEBI-NL was translated from an existing English instrument: the STEBI-A (Science Teaching Efficacy Belief Instrument), a commonly used questionnaire to measure science teaching self-efficacy (Bleicher, 2004, Bursal, 2010; Riggs \& Enochs, 1990). The STEBI-NL is a 24-item instrument comprising two scales, a Personal Science Teaching Efficacy (PSTE, self-assessment of one's teaching competence) and Science Teaching Outcome Expectancy (STOE, teachers' expectations that teaching can influence student learning). The reliability for the PSTE scale was very good with a Cronbach's $\alpha$ of .84, and for the STOE scale respectable with a Cronbach's $\alpha$ of .74 (Fisser et al., 2010). The STEBI-A contains items such as, "I am able to answer students' science questions" (PSTE - 12 items total) and "Increased effort in science teaching produces little change in some students' science learning" (STOE - 12 items total). The teachers used a 5-point Likert scale, ranging from strongly agree to 
strongly disagree with an extra category outside the Likert scale, not applicable, to indicate their opinion on the statements. The mean scores are calculated for each scale (minimum is 1 and the maximum is 5). A higher score indicates higher selfefficacy. Because there are only three teachers available to complete the STEBI-NL questionnaire in this study, only averages of individuals can be compared and no significance levels can be adjusted. Due to technical problems, no STEBI-NL results were available for teacher 2 before TDT participation.

The teachers in the TDT were asked additional questions about the contribution of the program to their self-rated knowledge and their experiences in the TDT program. The results are used in order to describe more in-depth, the valuable elements in the professional development program (TDT) for the three teachers with varying levels of experience and interest in science. Question 1 was asked before and after participating in the TDT, the other questions only afterwards. Questions are: (1) to what extent (insufficient, sufficient, or good) do you feel that you have the subject knowledge to teach science within living nature (biology), non-living nature (physics and chemistry) and technology; (2) To what extent (very high - 5/high 4/average- 3 /limited - 2/very limited - 1) has the TDT program contributed to your professional development in the following areas: (a) Subject Matter Knowledge $(\mathrm{SMK}),(\mathrm{b})$ knowledge about the nature and purpose of science, (c) knowledge about teaching strategies for science education, (d) knowledge about pupils' learning and learning difficulties in science and (e) knowledge about curriculum design? (Rohaan, Taconis, \& Jochems, 2012); (3) To what extent has the TDT program contributed to a better feeling about your science lessons (same options as question 2) and can you explain?; (4) To what extent (same options as question 2) do you believe that you are better able to teach science by inquiry after the TDT program and can you explain?; (5) What 'activity' during the TDT program was valuable for increasing your self-efficacy and can you explain? and (6) To what extent (same options as question 2) does the TDT structure (ADDIE) provide added value? Can you explain your answer? (7) To what extent (same options as question 2) does the external facilitator provide added value? Can you explain your answer?

A teacher focus group interview was conducted after the TDT program to get more in-depth information about the experiences of the teachers with the TDT as a professional development strategy to improve science teaching self-efficacy. Topics of the interview were: the role of the external facilitator and reflection on their own role in the team. The external facilitator leaded the focus group 
interview. Both in-service teachers participated in the interview, but the preservice teacher was not able to come, because she was ill at that moment. The principal was not invited for the focus group interview, because the presence of the principal could have made the teachers feel less comfortable to say their opinions and reactions.

\subsection{Results}

\section{STEBI-NL}

Participating in a TDT affects both STOE and PSTE levels; however, the STOE and PSTE levels of team members evolved in different ways, as can be seen in Table 5.2.

Table 5.2 STEBI-NL results of team members, before, during and after the design process in the TDT

\begin{tabular}{lllllll} 
& $\begin{array}{l}\text { PSTE } \\
\text { pre }\end{array}$ & $\begin{array}{l}\text { PSTE } \\
\text { during }\end{array}$ & $\begin{array}{l}\text { PSTE } \\
\text { post }\end{array}$ & $\begin{array}{l}\text { STOE } \\
\text { pre }\end{array}$ & $\begin{array}{l}\text { STOE } \\
\text { during }\end{array}$ & $\begin{array}{l}\text { STOE } \\
\text { post }\end{array}$ \\
\hline Teacher $\mathbf{1}$ & 4,00 & 4,09 & 4,64 & 3,92 & 4,33 & 4,08 \\
\hline Teacher 2 & $*$ & 3,50 & 3,83 & $*$ & 3,08 & 3,42 \\
$\begin{array}{l}\text { Pre-service } \\
\text { teacher }\end{array}$ & 3,33 & 3,67 & 3,33 & 3,83 & 3,92 & 3,58
\end{tabular}

Note: *. data are missing.

Even though the number of teachers who participated in the team is not enough to yield results that can be analyzed statistically, there are some results that are interesting to note.

For teacher 1, the most experienced teacher (> 20 years), both her self-efficacy beliefs (PSTE) and her outcome expectancy (STOE) were increased by the TDTprogram. Her PSTE increased most (.53) during the second half of the program, while her STOE increased only during the first half of the program (.41) and decreased again during the second part of the program (.25). Unfortunately nothing can be said about the change in PSTE or STOE for teacher 2 during the first half of the program; however both PSTE and STOE increased during the second half of the program, by .33 and .34 respectively. The pre-service teacher's PSTE increased by .34 during the first half of the program, but fell back to the old level during the second part of the program. Her STOE stayed about the same during the first half of the program (+.09). During the second half of the program her STOE decreased by .34 . 
Now the results of the TDT questionnaire are used to present more in-depth results for the three teacher team-members.

\section{TDT questionnaire; Teacher 1, experienced and interested in science}

The results of the TDT questionnaire indicated that her self-rated knowledge for teaching science within living nature, non-living nature and technology was increased by participating in the TDT from sufficient (before) to good (after). On the other hand, Teacher 1 indicated that she believed that she had learned about SMK to a very limited extent by participating in the TDT, but to a very high extent about curriculum design.

In addition, Teacher 1 believed that after the TDT program she is to an average degree better able to teach science by inquiry, which corresponds with her belief that she learned in a limited to average extent about PCK (limited: nature and the purpose of the subject, reasonable: teaching strategies and pupils learning). She explained furthermore that she did learn to teach science by inquiry from the experiences from her colleagues.

According to Teacher 1, valuable activities in the TDT, which was question five in the TDT questionnaire, were goal setting, working with a plan and the communication with team members. This corresponds with her high rating for the value of the TDT structure (ADDIE) and the external facilitator for structuring the process (TDT questionnaire, question 6).

TDT questionnaire; Teacher 2, three years of teaching experience, a little interest in science The results of the TDT questionnaire indicated that the self-rated knowledge of Teacher 2 only increased for the domain 'technology', from insufficient to sufficient. Her self-rated knowledge within living nature and non-living nature was already sufficient before participation in the TDT and was still sufficient after participation. Teacher 2 believed that the TDT program contributed to her SMK to a high extent. Furthermore, Teacher 2 believed that she learned to a very high extent about curriculum design, to a high extent about teaching strategies and to an average extent about pupils' learning and nature and purpose of science.

In the TDT questionnaire, after participating in the TDT, Teacher 2 noted that she believed that participating in the TDT has contributed to a 'high degree' to a better feeling over her science lessons. Her explanation was that she thinks through her lessons more due to participating in the TDT. Teacher 2 also reported 
that she is to a 'high extent' better able to teach science by inquiry, due to the TDT (TDT questionnaire, question 4).

Valuable activities in the TDT for Teacher 2 were preparing and teaching science lessons. She explained that she became motivated by her successes in the classroom, especially by the enthusiasm of the children.

\section{TDT questionnaire: Pre-service teacher, interested in science}

Before the TDT started, the pre-service teacher rated her knowledge for science teaching as sufficient for technology and good for living and non-living nature. After participating in the TDT her self-rated knowledge was the same for nonliving nature, but decreased for living nature (from good to sufficient and technology (from sufficient to insufficient). The pre-service teacher indeed reported that she believed that the TDT program contributed to a very limited extent to her SMK. Additionally, she believed that she learned to a high extent about curriculum design, and the nature and purpose of science and to an average extent about pupils' learning, but less about teaching strategies (limited) from participating in the TDT. The fact that the pre-service teacher believed that she had learned to just a limited extent about teaching strategies corresponds with her explanation for her answer that participating in the TDT has contributed to 'an average degree' to a better feeling over the science lessons. The pre-service teacher's explanation was that she taught science activities in small groups well, but she really wanted to learn how to teach science with all children at the same time. The pre-service teacher furthermore reported that she feels to a 'reasonable extent' able to teach science by inquiry. She explained that she is still inclined to tell the children what to do instead of guiding the children to the solution.

Valuable activities in the TDT for the pre-service teacher were goal setting and teaching science lessons. Her explanation was that she became motivated by the positive reactions of the children while teaching and she learned from her own teaching experiences by reflection.

According to the pre-service teacher, the external facilitator is very important in the team, because she improved the quality of the TDT program.

\section{Focus group interview: the external facilitator}

The teachers were asked in the focus group interview whether a team of teachers should be able to improve their curriculum by themselves, without the external 
facilitator. Both teachers believed that a team consisting of very experienced teachers would be able to design a curriculum, however teachers need a stimulus to improve their curriculum. According to Teacher 1: 'Experienced teachers don't have the feeling that they need to learn. Somebody from outside the school can trigger those teachers to reflect on their practice from another perspective'.

Besides being the trigger for the team, according to both teachers the external facilitator is also important for the team's focus and for some teaching when necessary. Teacher 2: 'We are in the middle of all school stuff but we missed some terminology, this could make simple things very complex. The external facilitator can translate the input and focus on what is important for their curriculum'. Teacher 1 emphasized that it is very important that the external facilitator is an expert.

Focus group interview: Teacher 1's reflection

Teacher 1 described herself as skeptical, especially during the second part of the TDT program. Outside the team Teacher 1 was also involved with policymaking and experienced a change in priorities on this level. Therefore she got the feeling 'how can this team be successful, when there is not even time for mathematics?', which resulted in reduced confidence in the output of the TDT from the second half of the TDT program. Teacher 1 furthermore said that she really appreciated the enthusiasm from her team members despite the external pressure. She explained that she did learn from the exchange of experiences from her colleagues.

Focus group interview: Teacher 2's reflection

Teacher 2 explained in the focus group interview that she was aware that she hesitated in the beginning and waited to see what others did first. The process up to the goal setting was difficult for her. When it became more clear what the team wanted, she thought: 'what we want must also function in practice, so I am going to do the activities in my class'. She experienced it as a victory that she taught science with her children. After this she became really motivated: 'the children were enthusiastic and because I saw this, I thought, I have to teach science differently, and I will do it! If you see their faces, you have to, right?'.

Both teachers would recommend professional development in the way of a TDT to their colleagues. Their explanation was that teachers are learning by doing. According to Teacher 2: 'I became convinced by trying the activities, designed by ourselves, in the classroom'. Furthermore, both teachers prefer to learn only the 
science knowledge and pedagogy and didactics needed to improve their own practice. They explained that this was more the case in the TDT program compared to the traditional programs that they experienced before.

\subsection{CONCLUSION AND Discussion}

This study aimed to gain in-depth information about a TDT as way to increase the science teaching self-efficacy of participating teachers. In this section, the research questions will be answered and discussed subsequently. Afterwards some methodological difficulties will be discussed.

The first aim of this study was to determine the effect of a TDT on the science teaching self-efficacy of participating team members. Despite the fact that the two in-service teachers and the pre-service teacher were one team, with the same program, their science teaching self-efficacy developed in a totally different way. During the first part of the TDT program, the personal self-efficacy beliefs for teaching science (PSTE) and outcome expectancy (STOE) increased for both the experienced teacher who was very interested in science and the pre-service teacher. No results from this part of the TDT are available for the teacher with 3 years of teaching experience and just a little interest in science. During the second part of the TDT program, PSTE and STOE of the team members changed in completely different ways: for the experienced teacher with very high interest in science, PSTE increased and STOE decreased; for the pre-service teacher with interest in science, both PSTE and STOE decreased; and for the teacher with 3 years of experience and just a little interest in science, both PSTE and STOE increased. This result indicates that other factors besides participation in the TDT influence science teaching self-efficacy especially during the second half of the TDT program, which will be explained in the next sections.

The very experienced teacher believed that her increase in PSTE could be explained by her discussions about the experiences of the other teachers in the team. Those so-called vicarious experiences are already known to be a source of information that influences self-efficacy beliefs (Bandura, 1997). The remarkable decrease in STOE of the very experienced teacher's during the second part of the TDT program was probably due to reduced administrative support from the principal. Outside the team, Teacher 1 was also involved with policymaking and 
she experienced in this function a change in priorities on this level. This resulted in reduced confidence in the outcome of the TDT and a decrease in STOE. This result support the conclusion of Tschannen Moran et al. (1998) that the STOEscale of the STEBI is likely also a measure of external locus of control.

This result suggests that reduced administrative support affects the STOE of experienced teachers.

According to both the less experienced and little interested teacher and the preservice teacher, successes experienced in the classroom were important for increasing their science teaching self-efficacy. Mastery experiences are known to be the main source of information influencing self-efficacy beliefs (Bandura, 1997). From the moment Teacher 2 performed science lessons in her classroom she experienced successes, and the reactions from the children in response to her science lessons were the biggest motivation for her to go on. These mastery experiences might explain Teacher 2's increase in both PSTE and STOE.

The pre-service teacher also experienced successes when doing science in small groups of children. This could explain her PSTE and STOE increase during the first half of the TDT program. However, during the second part of the program, the pre-service teacher experienced the complexity of science teaching with all of the children at the same time in a more inquiry-based way. The experienced difficulties were discussed in the TDT meetings; however, this was probably not enough for the pre-service teacher to increase her science teaching self-efficacy. Implementation of what is learned is difficult for teachers and coaching and assistance during implementation are known to be important for teachers' selfefficacy (Tschannen-Moran \& McMaster, 2009). Implementation is probably even more difficult for pre-service teachers because they are less experienced, which can explain the pre-service teacher's decrease in both STOE and PSTE during the second half of the program.

The second aim of this study was to identity the elements in the professional development program (TDT), which the different teachers saw as important for increasing their science teaching self-efficacy.

The experienced and in science interested teacher volunteered for the TDT to improve science education in her school. To be able to do this, she was looking for cooperation during the development process resulting in the desired instructional 
change at the school level. This might also explain why the experienced teacher believed that knowledge about curriculum design did contribute to her science teaching self-efficacy, and she valued activities such as goal setting with respect to their science curriculum, working with a plan and the communication with team members within the school, outside the TDT the most. For the experienced teacher, working in the TDT is a chance to improve science education in the school, which can explain the importance of administrative support for the outcome expectancy of teachers who already believe that science education is important and who are already able to teach science.

By participating in the team, Teacher 2 wanted to improve their science curriculum, but she was hesitant at the beginning and she really needed her colleagues so that she become convinced that she had to try science teaching by herself. Ramey-Gassert et al. (1996) also demonstrated the importance of collaboration for teachers with low self-efficacy beliefs. That study showed that teachers with low self-efficacy only felt a need or desire to seek out experiences that enhanced their science teaching after they had experienced collaboration with a supportive colleague. Afterwards, Teacher 2 identified preparing and teaching science lessons as the most important activities for increasing her self-efficacy. She reported furthermore that she learned about both curriculum design and science teaching, which are both aspects she needs to learn to reach her main goal, improving the science curriculum.

The pre-service teacher was part of the team because of an assignment from the teacher training college. The assignment was to advise the primary school about how to improve science teaching, based on her own classroom experiences. This assignment was broadly consistent with the assignment of the team to improve the science program; however, the pre-service teacher did not know the science curriculum in the school as well as the in-service teachers and did not know what she wanted to change beforehand. This could explain why the pre-service teacher valued goal setting as most important during the first half of the program and the science lessons during the second half of the TDT program. She first needed goals to improve science education, before she could further professionalize herself in science education and thus be able to fulfill her assignment. The pre-service teacher believed that working in the TDT contributed in a very limited way to her SMK. It might be that extra SMK did not contribute to an increase in her selfefficacy because she believed that she had already a sufficient to good level of 
SMK before the start of the TDT. Furthermore, the pre-service teacher believed that she learned most about curriculum design and the nature and purpose of science and to a limited extent about teaching strategies. The pre-service teacher experienced difficulties with inquiry-based teaching with a group of children, and therefore she probably felt the need to learn more about this domain. TDT might therefore be a way to improve the science teaching self-efficacy of pre-service teachers; however it might be important to support pre-service teachers with implementation in practice.

In conclusion, collaboration in a TDT seems to be a way to improve STOE and PSTE levels of teachers with varying degrees of experience and interest in science, but it seems important to take note of some preconditions associated with the specific target group. Administrative support seems to be especially important to improve the STOE of teachers with high self-efficacy beliefs. For pre-service teachers, it seems to be important to coach them during the implementation of what is learned in the real classroom situation.

In addition, participants in the team considered other elements of the TDT program as important for increasing their science teaching self-efficacy. It seems to be based on what they need to learn to improve their science curriculum, according to themselves. Teachers in the TDT were able to set their own learning path. The main question for teachers in the TDT seems to be: 'What do I need to learn to be able to design a science curriculum that I can teach well' and the answer is found in collaboration with other team members and the external facilitator. All team members were challenged by this question. For less interested and/or less experienced teachers, the TDT program resulted in successes in the classroom that are valuable for improving self-efficacy. For the more experienced teacher in science education, the challenge in the program seems to be to improve science education in the school.

An implementation dip such as observed by Mosely et al. (2007) 7 weeks after the professional development program was not expected, because the team redesigned science boxes to make them suit their own classroom situation. They also planned for development and implementation of additional redesigned science boxes. If those plans are aligned with the policy goals of the new school leader and the teachers get administrative support to fulfill their plans, further development of the curriculum and an increase in the self-efficacy of the team 
members could be expected over the next few years. However, as the experienced teacher mentioned, the policy goals will probably be changed during the next year by the new school leader. This change in policy goals might be damaging for the development of the science curriculum in the school. This study as well as the study by Ramey-Gassert et al. (1996) showed the impact of reduced administrative support on teacher self-efficacy. Without collegial and administrative support, teachers become discouraged and blame external factors, such as lack of resources or lack of time. Thus, a supportive policy for science education seems important to prevent a decrease in teachers' science teaching selfefficacy after participation in the TDT program.

Several critical remarks must be made about this study. First of all, the external facilitator was also the researcher in this study. It could be that the researcher unconsciously influenced the answers of the participants. This bias is minimized by using three different instruments. The missing pre-test data of Teacher 2 and the missing focus interview of the pre-service teacher could have impact the results of this study. However, because of the use of the three instruments, triangulation is possible. Even though the results are based on only three teachers in one TDT, we have seen that there are differences between teachers in how they will respond in this situation, and that we must take note of those differences. Additional research with more teachers in more teams in different schools is needed to be sure that TDT is a good way to improve the science teaching selfefficacy of all kind of teachers and to determine the best combination of team members to improve science teaching self-efficacy (interested or less interested in science, experienced or not-experienced). However, the results of this study leads to extended information about a TDT as way to increase the science teaching selfefficacy of teachers with varying levels of experience and interest in science. 


\section{CHAPTER 6 * \\ The process of collaborative curriculum design and the science teaching self-efficacy}

Collaborative curriculum design has been found to be a powerful way to stimulate teachers' learning (Voogt et al., 2011). There are also some indications that collaborative curriculum design is valuable for increasing science teaching self-efficacy (Mintzes et al., 2012; Velthuis, Fisser, \& Pieters, 2013b). The focus in this study is on science teaching self-efficacy, because the sense of self-efficacy is a powerful predictor in the classroom in such a way that self-efficacy affects the effort they invest in teaching (Bandura, 1977). To further extend our knowledge about collaborative curriculum design as a way to improve teachers' science teaching self-efficacy, in this study, the design processes of two Teacher Design Teams (TDT) in two primary schools in the Netherlands were followed. TDT 1 consists of two primary in-service teachers, one pre-service teachers, the principal and an external facilitator. TDT 2 consists of three in-service teachers and an external facilitator. The interactions during the team meetings were observed and a questionnaire was administered to determine the conducive and hindering design stages for increasing science teaching self-efficacy. Observation of a combination of the level of collaboration and the instructional relevance provide important information about the effectiveness of the team discussion during the process of curriculum design to improve the science teaching selfefficacy. In addition, a contact summary was used to determine the influence of the principal on the design process and the outcomes regarding science teaching of the teachers in the TDTs. The results show that design and development activities provide the most valuable interactions for increasing science teaching self-efficacy. Furthermore, it is important for the TDT to have a clear focus and be administratively supported by the principal, that teachers are encouraged to construct the curriculum materials collaboratively and that the teachers are supported to teach and observe the designed lessons in their classroom practice.

\footnotetext{
- This chapter has been submitted as: Velthuis, C. Fisser, P., \& Pieters, J. (Submitted). The process of collaborative curriculum design and the science teaching self-efficacy
} 


\subsection{INTRODUCTION}

Van Driel, Beijaard and Verloop (2001) argued that implementations of new science programs have often been unsuccessful because they failed to take teachers' existing knowledge, beliefs, and attitudes into account. Many traditional forms of teacher in-service training associated with implementing new science programs did not acknowledge teacher expertise as a valuable school resource and did not account for contextual issues. Collaborative (re)design of curriculum materials as a type of professional development begins with the experiences of the teachers, and their knowledge and beliefs will be restructured by interacting about their own curriculum design (Voogt et al., 2011). Several studies have shown the value of collaborative curriculum design for teachers' learning (Coenders, Terlouw, Dijkstra \& Pieters, 2010; Rock \& Wilson, 2005; Sibbald, 2009; Voogt, 2010), but only a few studies have addressed the effects of collaborative (re)design of curriculum materials on the teachers' self-efficacy beliefs (Mintzes, Marcum, Messerschmidt-Yates, \& Mark, 2012; Velthuis, Fisser, \& Peters, 2013b). Both Mintzes et al. (2012) and Velthuis et al. (2013b) reported that the collaboration process and the teaching experiences seemed to be important for increasing self-efficacy; however, more information is needed to further refine collaborative curriculum design as a professional development program for improving science teaching self-efficacy. In addition, a finding in the study of Velthuis et al. (2013b) was that the principal seemed to influence the design process and hereby the teachers' science teaching self-efficacy.This study investigated in depth the curriculum design process of two design teams and the potential value of the different design activities for increasing science teaching self-efficacy. The value of the design activities was determined by observation of the interactions during the formal team meetings.

The research questions addressed in this study are:

(1) What is the influence of the principal on the curriculum design process and the results of the TDT?

(2) Does participation in curriculum design result in teaching experiences that are known to be important for increasing science teaching self-efficacy?

(3) Which curriculum design stages and which design activities result in the type of interactions between teachers that have a high likelihood of increasing their science teaching self-efficacy? 


\subsection{THEORETICAL FRAMEWORK}

Self-efficacy is defined by Bandura (1977) as one's perceived ability to perform an action that will successfully lead towards accomplishing a specific goal. Teachers with a high sense of self-efficacy will set higher goals, be less afraid of failure, and find new strategies when old ones fail. Teachers with lower levels of self-efficacy tend to avoid difficult or stressful tasks, set lower goals and disengage when faced with a challenge (Tschannen-Moran \& Woolfolk Hoy, 2007). Bandura (1977) suggests that an individual's self-efficacy belief reflects both a self-assessment of one's ability to perform a specific task (personal self-efficacy) and his or her expectation that performing the task will result in the desired outcome (outcome expectancy). In the context of science, personal science teaching self-efficacy may be reflected in a teacher's confidence about his or her own ability to teach science. On the other hand, outcome expectancy may be a judgement about how likely it is that the science program, if appropriately implemented, will help students to achieve a desired level of performance.

Two different approaches to collaborative curriculum design have been observed to contribute to increasing self-efficacy for teaching. Mintzes et al. (2012) and Sibbald (2009) showed the value of variations of 'Lesson Study' for increasing the self-efficacy of primary school teachers. The formal practice of 'Lesson Study' involves 4 to 6 teachers, working at the same school and grade level, who engage in weekly group meetings after school with an administrator and outside adviser. A complete Lesson Study cycle consists of several stages: (1) research and construction of a detailed lesson plan; (2) a teacher implements the lesson in a real classroom, while other team members observe; (3) reflection on the lesson and improvement of the lesson and (4) a second teacher implements the modified lesson, followed again by reflection. Velthuis et al. (2013b) suggested that Teacher Design Teams (TDT) might also be a valuable way to increase science teaching self-efficacy, but this finding was based on only one team with two in-service teachers and one pre-service teacher. Teachers in a TDT collaborate with one another in a formal setting to create new curriculum materials or adapt existing materials, often also with an expert, educational researcher and/or domain expert. TDTs usually focus on student activities, lessons, modules and courses. The collaborative team activities cover (parts of) a design cycle: problem analysis or definition, design of curriculum products, implementation of the products in practice, and evaluation/ reflection on the products and redesign. 
In the research involving Lesson Study and TDT, the collaboration process seemed to be important for increasing teachers' self-efficacy. Mintzes et al. (2012) concluded that the power of the cooperative groups seemed to emerge from the emotional support they provided and from the persuasion that came with negotiating differences of opinion. Persuasion by other team members was also reported as important in the TDT in the study by Velthuis et al. (2013b). One teacher explained that she needed the team meetings before she became convinced that she had to teach science and that she was able to do it. Being persuaded by others that one possesses the capabilities to master given activities or emotional reinforcement is according to Bandura (1986) a major source of information that increase selfefficacy and seems to be a major outcome in collaborative curriculum design for increasing teachers' science teaching self-efficacy. In addition to the emotional reinforcement, in both studies many participants commented on the positive outcomes they observed in the students (Mintzes et al., 2012; Velthuis et al., 2013b). Mastery experiences is also a main source of influence to develop people's belief about their efficacy as defined by Bandura (1986). Mastery experiences are the most effective way to create a high feeling of self-efficacy; the more successful the experience, the more likely one will repeat or extend the given behaviour. According to Bandura, vicarious experiences, which are examples or experiences of others similar to oneself, also increase the sense of efficacy: "if they can do it, I can too". And the final source is reducing people's stress reactions, which has to do with physical and psychological aspects an how these aspects are perceived and interpreted. One's mood affects his or her judgements of their personal efficacy.

The findings of the study by Velthuis et al. (2013b) also suggested that administrative support seemed to be vital for improving self-efficacy by engaging in collaborative curriculum design, which was also found in a study by RameyGassert (1996). This study showed that support from principals and colleagues reinforced the importance of science teaching, which result in more persistence by the teachers to achieve their goal. When the principal did not provide administrative support, such as time in the curriculum or materials for science lessons, teachers will give up the design process easily. The principal seems to influence the collaborative curriculum design process and thereby the science teaching self-efficacy.

Collaborative curriculum design is an important way to encourage professional interactions between teachers, because such professional interactions broaden 
teachers' perspectives (Voogt et al., 2011) and are suggested to be important for increasing science teaching self-efficacy (Mintzes et al., 2012; Velthuis et al., 2013 b). The potential value of teachers' interactions for increasing science teaching self-efficacy depends on both the collaboration level (1) and the instructional relevance (2) of the interaction. The collaboration level is important because collaborative groups have higher levels of self-efficacy regarding the achievement task insofar as the teachers in those teams are challenged by the group members to cope with difficulties and to persevere (Slavin, 1990). Little (1990) describes levels of collaboration with an increasing degree of interdependence: storytelling, help and assistance, sharing and joint work. Collegial interactions with a low level of interdependence are likely to be less valuable for increasing self-efficacy compared to collegial interactions with high level of interdependence. Besides the level of collaboration, it is important for the interaction to be addressing science teaching for it even have the possibility of influencing the teachers' science teaching self-efficacy, because it is known that self-efficacy is highly context dependent (Bandura, 1977). A focus on science teaching will be reflected in instructional relevance, which is the extent to which teams are exploring the relations between the key aspects of learning: content, teachers and students (Cohen \& Ball, 1999; Henry, 2010; Little, 1990). Henry (2010) showed that collaborative teacher teams that explore the relations among all these aspects are the most successful teams, that is, those associated with high student learning gains. Successes in the classroom are important for the teachers' self-efficacy (Bandura, 1986) and therefore interactions about all three aspects of learning have a higher probability of increasing self-efficacy than interaction about one or two aspects of instruction. Interaction about subjects not related to teachers, students or content will not contribute at all to science teaching and thus will not influence the science teaching self-efficacy of the teachers. Combining the level of collaboration and instructional relevance provides important information about the effectiveness of the teacher interactions during the process of curriculum development as a way to improve science teaching self-efficacy.

\subsection{Methodology}

\subsubsection{Participants}

This study was carried out in two medium-sized primary schools in the Netherlands (both around 200 students). TDT 1 consisted of two in-service 
teachers, one pre-service teacher, the principal and the external facilitator. TDT 2 consisted of three in-service teachers and the external facilitor. The principal of this school was willing to join the TDT when the need arose. All members were female and participated voluntarily. Characteristics of the TDT participants are given in Table 6.1.

Table 6.1 Characteristics of teachers in the TDTs

\begin{tabular}{|llll|}
\hline & Participant TDT & $\begin{array}{l}\text { Years of teaching } \\
\text { experience }\end{array}$ & Student age in years \\
\hline TDT 1 & In-service teacher 1 (T2) & $>20$ & $11-12$ \\
& In-service teacher 2 (T1) & 3 & $8-9$ \\
\hline & Pre-service teacher (PT) & 0 & $6-7$ \\
\hline TDT 2 & In-service teacher 1 (T1) & 10 & $11-12$ \\
\hline & In-service teacher 2 (T2) & 5 & $8-9$ \\
\hline & In-service teacher 3 (T3) & $>20$ & $6-7$ \\
\hline
\end{tabular}

\subsubsection{TDT team program}

The teams' assignment was to (re)design (a part of) their science curriculum for students. TDT 1 decided to adapt their method of teaching science for ages 4 through 12, the 'Science Towers' (in Dutch: www.techniektorens.nl as well). The 'Science Towers' are cabinets with lesson boxes focusing on a specific topic, such as building a bridge, making soap, and so forth. Each box has a manual for the children, which guides them through the activity in the box. The team wanted to redesign those boxes so that (1) children could work more independently with those boxes, and (2) children could learn more by inquiry. TDT 2 wanted to develop an inquiry-based project around science. They decided that the project would be intended for the oldest students, aged 11-12, and the topic of the project was 'your own body'. The entire design process was planned in eight meetings of approximately two hours each spread over an academic year. All meetings were video-taped for observation.

The TDTs were guided by a process guide giving suggested goals and activities per meeting. The design activities were associated with the ADDIE model, Analysis, Design, Development, Implementation, and Evaluation (Dick \& Carey, 1996); The team carried out activities belonging to the different design stages, as shown in Table 6.2. The external facilitator guided the team, leaded discussions and provided study materials and other resources. 


\subsubsection{Instruments and data collection}

For the purposes of this study, three instruments were used. Table 6.3 shows how the different instruments are related to the research sub-questions.

Table 6.3 List of instruments and related questions

\begin{tabular}{llll} 
& $\begin{array}{l}\text { Influence of } \\
\text { principal }\end{array}$ & $\begin{array}{l}\text { Teaching } \\
\text { experiences }\end{array}$ & $\begin{array}{l}\text { Valuable design } \\
\text { activities }\end{array}$ \\
\hline Contact Summary Sheet & $\mathrm{x}$ & $\mathrm{x}$ & $\mathrm{x}$ \\
\hline Observation instrument & $\mathrm{x}$ & $\mathrm{x}$ \\
\hline Teacher questionnaire & $\mathrm{x}$ & &
\end{tabular}

\section{Contact Summary Sheet}

A Contact Summary Sheet (Miles \& Huberman, 1984) was used to document the process in the TDTs. The focal questions were: (1) What activities were completed during the meeting? (2) How much time was spent on curriculum design activities? (3) How much time was spent on side activities? (4) What was the role of the principal?(5) Did teachers teach the activities that had been developed in the classroom and if yes, what were their experiences with teaching science? The contact summary sheet was filled in by the external facilitator during the meeting and supplemented with the analysis of the videos of the TDT meetings. The contact summary sheet is used to describe the influence of the principal on the design process.

\section{Observation instrument}

An observation instrument was developed to capture the level of collaboration and the instructional relevance of the interactions during the TDT meetings. Two levels of collaboration were distinguished based on Little's (1990) categories: storytelling, help and assistance, sharing and joint work. Because Little's categories were originally based on how interactions take place in everyday school practice, some adjustments were made to be able to use the classification in our more formal setting. In this study only two levels of collaboration were used: exchange and discussion (see Table 6.4). 
Table 6.4 Observation guide: the different levels of collaboration

\begin{tabular}{ll} 
Level of collaboration & How to recognize? \\
\hline Exchange & $\begin{array}{l}\text { Exchange of class experiences, materials, methods, ideas and } \\
\text { opinions with team members to answer questions, to } \\
\text { brainstorm or to solve a problem without having a discussion }\end{array}$ \\
Discussion & $\begin{array}{l}\text { Materials, methods, ideas or opinions (different alternatives) } \\
\text { are compared and analyzed. By reasoning, the team } \\
\text { collaboratively creates ideas or opinions about what is } \\
\text { important in science education or collaboratively solves a } \\
\text { problem in their school practice }\end{array}$
\end{tabular}

Our level of exchange is comparable with Little's levels of storytelling and help and assistance: collegial interaction with a low or intermediate level of interdependence. Our level of discussion is comparable with Little's levels of sharing and joint work: collegial interaction with a high level of interdependence. Four levels of instructional relevance were distinguished, based on Henry's (2010) classification, see Table 6.5.

Table 6.5 Observation guide: the different levels of instructional relevance

\begin{tabular}{|l|l|}
\hline Gradation of relevance & How to recognize? \\
\hline 0 & $\begin{array}{l}\text { Conversation has no direct bearing on teacher, pupils or } \\
\text { content }\end{array}$ \\
\hline 1 & $\begin{array}{l}\text { Conversation focuses on: teachers in isolation, pupils in } \\
\text { isolation or content in isolation } \\
\text { Conversation explores two elements of instruction and is } \\
\text { missing the third. }\end{array}$ \\
\hline 3 & $\begin{array}{l}\text { Conversations explores/draws connections among all } \\
\text { three elements of instruction: teachers, pupils and content }\end{array}$ \\
\hline
\end{tabular}

The level of collaboration or instructional relevance could change during an activity, because the team completed or began a sub-activity or because of a question or remark from a team member; for example, by involving the role of the teacher in the conversation. Those changes and the reason for the changes were also noted on the observation instrument.

The reliability of the observation instrument was tested in an expert meeting. Seven video fragments from different meetings and activities, half an hour in total, were shown to two science teacher educators. They were asked to score the level of collaboration and the instructional relevance for the different design activities, and they also noted observed changes in level of collaboration and instructional relevance. The inter-rater reliability (Cohen's kappa) of the 
observation instrument was .71 for both the level of collaboration and the level of instructional relevance, which is good (Cohen, 1960).

The level of collaboration and the instructional relevance were subsequently combined to determine the 'Likelihood for Increasing Science teaching Selfefficacy' or LISS levels of the activities. Two levels of collaboration and four levels of instructional relevance were combined to yield seven different LISS-levels (exchange and discussion about subjects not related to instruction are both considered to be level 0, Figure 6.1). The higher the LISS level of the activity, the better the activity is likely to be for improving science teaching self efficacy.

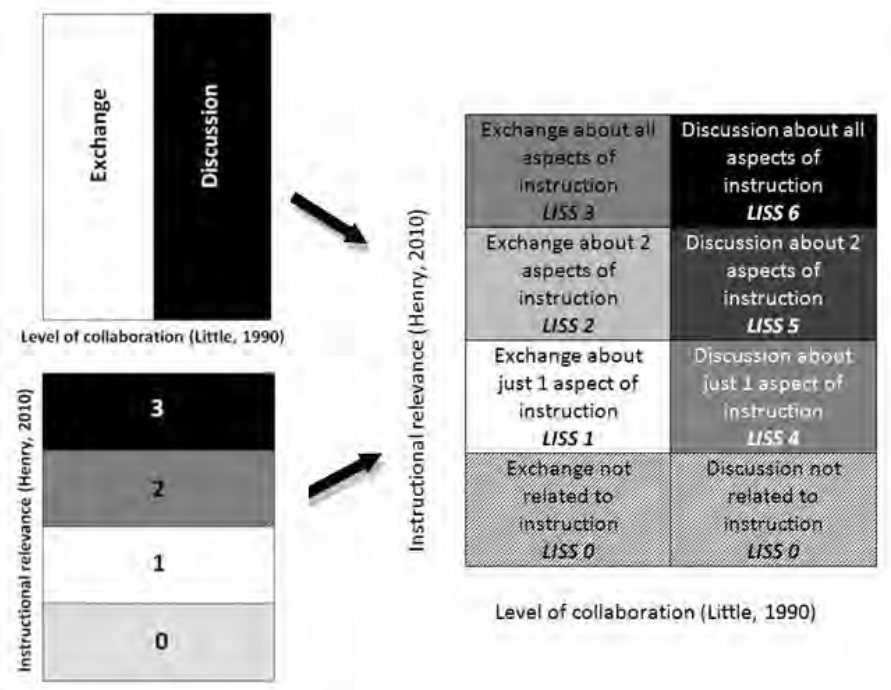

Note. White $=$ low, Gray $=$ intermediate and Black $=$ high likelihood that team interaction will increase self-efficacy.

Figure 6.1 'Level of collaboration' and 'Instructional relevance' are combined to determine the interactions' Likelihood of Increasing Science teaching Self-efficacy, or LISS level

\section{Teacher questionnaire}

After the intervention, the teachers in the TDTs were asked three questions following. The questions were: (1) To what extent (very high - 5/high 4/average- 3/limited - 2/very limited - 1) was the principal an added value for the results in the TDT? (2) Which activity was valuable for you? And can you explain? (3) Which 'activity' was less valuable for you? And can you explain?

Due to prolonged illness was teacher 3 in TDT2 unable to complete the questionnaire. 


\subsection{Results}

\subsubsection{The influence of the principal on the curriculum design process}

Contact summary sheet

The principal at TDT 1's school changed after the fifth meeting of the TDT program. The principal who started the TDT in this school was very involved; he functioned as a team member in the first four meetings by asking questions and bringing ideas, while the team followed the activities in the process guide. In the seventh meeting, teacher 1 said that she experienced a shift in priorities because of the new principal and that from that moment on it seemed to be very difficult to inform and motivate other team members about redesigning the 'science boxes'. The result was that the team spent a lot of time during the seventh meeting on 'creating involvement of the team members outside the team' (71 minutes) and much less time was spent on development (22 minutes), organization (11 minutes) and implementation (3 minutes).

Finally in the eighth meeting, TDT 1 began discussing alternative solutions for the school science program that could realized without a lot of time and energy.

Other than in the first meeting, the principal in TDT 2's school was only part of the team when the team wanted her to be there. As a consequence, the curriculum design process was interrupted by the principal in the fourth meeting, because the planned project did not fulfil her expectations. Subsequently, TDT 2's assignment was modified to address a shortened inquiry-based project and additional 'technical' lessons. The consequence for TDT 2's curriculum design process was that (1) they spent 85 minutes during the fourth meeting on discussing the process of communicating with the principal instead of their curriculum, (2) TDT 2 spent no more time on involving teachers outside the TDT with the project (an activity planned for meetings $4 / 5$ and 6/7/8) and (3) TDT 2 had to modify their overview of the project before they could continue with the design process.

In addition, the principal promised to be part of the team when the team began designing the additional 'technical' lessons during the sixth meeting, but she was absent. The result was that the development of the 'technical' lessons was ultimately postponed to next school year; as a consequence, the eighth and final meeting was cancelled. 


\section{Teacher questionnaire}

The added value of the principal as a team member was viewed as limited by three teachers, and as average and high by one teacher each. The pre-service teachers' explanation for the average value of the principal (TDT 1) was because he could make the link with other developments within the school. Teacher 1 (TDT 1) declared that she believed that the principal had a limited added value for the team, but only under the condition that there was good communication between the principal and the team. Teacher 2 (TDT 2) explained that the principal was especially important in indicating the desired direction for the outcomes of the TDT, but had limited added value as a team member.

\subsubsection{Teaching experiences}

Contact summary sheet

In TDT 1, the pre-service teacher practiced with the science boxes in the classroom (after the second meeting),to gather more information about the 'Science Towers'. Teacher 2 then tested a prototype after the fourth meeting. The pre-service teacher and teacher 2 both taught two activities. Teacher 1 did not work with the science boxes in the classroom.

TDT 2 decided during the second meeting that they wanted to develop the inquiry- based project for only the oldest students, so for those in teacher 1's classroom. The consequence was that she started to teach science lessons after the fifth meeting. During the evaluation of these lessons in the sixth meeting, it became clear that her students focused too soon on their presentations rather than on the investigation itself. After brainstorming about possible solutions, the team decided that one solution was to assist teacher 1 . As a consequence, teacher 2 assisted teacher 1 in the classroom during the second part of the project. Teacher 3 did not teach or observe lessons belonging to the project.

\subsubsection{Valuable design activities}

\section{Observation instrument}

As can be seen in Table 6.6, the interactions with the highest LISS levels took place during the design and development stages. The least valuable interactions for increasing science teaching self-efficacy took place during implementation. In the next paragraphs, we discuss the different design activities separately. 
Table 6.6 Time spent at different LISS levels by TDT 1 and 2 during the various design activities

\begin{tabular}{|c|c|c|c|c|c|c|c|c|c|c|c|c|c|c|}
\hline \multirow[b]{2}{*}{ LISS levels } & \multicolumn{7}{|c|}{$\begin{array}{l}\text { TDT } 1 \\
\text { time spent on a LISS level in minutes }\end{array}$} & \multicolumn{7}{|c|}{$\begin{array}{l}\text { TDT } 2 \\
\text { time spent on a LISS level in minutes }\end{array}$} \\
\hline & 0 & 1 & 2 & 3 & 4 & 5 & 6 & 0 & 1 & 2 & 3 & 4 & 5 & 6 \\
\hline \multicolumn{15}{|l|}{ Analysis } \\
\hline Brainstorming & & 10 & 68 & 10 & & & & & & 23 & 27 & & & \\
\hline \multicolumn{15}{|l|}{ Design } \\
\hline Formulating criteria & & & & & & & 57 & & & & & & & \\
\hline Tyler's questions & & & & 1 & 6 & 35 & 59 & & & & & 5 & 6 & 22 \\
\hline $\begin{array}{l}\text { Creating an } \\
\text { overview }\end{array}$ & & & & 3 & 35 & & & 8 & & & & 5 & 24 & 19 \\
\hline \multicolumn{15}{|l|}{ Development } \\
\hline $\begin{array}{l}\text { Research on } \\
\text { materials }\end{array}$ & & 4 & & 47 & & & 12 & & & 13 & 4 & & & 13 \\
\hline Development & 7 & 4 & & 2 & 6 & 70 & 11 & & & & & & & 42 \\
\hline \multicolumn{15}{|l|}{ Implementation } \\
\hline $\begin{array}{l}\text { Communication } \\
\text { plan }\end{array}$ & 31 & & & & & 3 & & 1 & & & & & & \\
\hline $\begin{array}{l}\text { Organization of } \\
\text { activities }\end{array}$ & 8 & & & & & & & 43 & & & & & & \\
\hline $\begin{array}{l}\text { Creating } \\
\text { involvement }\end{array}$ & 59 & & 2 & 3 & 6 & 1 & & & & & & & & \\
\hline \multicolumn{15}{|l|}{ Evaluation } \\
\hline Evaluation & & & 6 & 19 & & & & & & & 36 & & & \\
\hline
\end{tabular}

During analysis both teams were interacting at LISS levels 1 through 3 (Table 6.6), because they engaged in exchanges of their opinions and experiences, such as their opinions about the value of science for their students and their experiences with science education in their schools. Neither team was ever having discussions during analysis.

During the design stage both TDTs were mainly comparing and analyzing different ideas and opinions or were investigating different alternatives for their project or curriculum, resulting in most of the interactions being at least at LISS level 4 (Table 6.6). Formulating criteria resulted in interactions focusing on classroom practice (high instructional relevance) where the ideas and opinions of the different team members were analyzed and compared (discussion). By formulating criteria, the teachers thought about what they wanted to achieve with science education and what this meant for their classroom practice. TDT 2 spent no time on formulating design criteria. Answering Tyler's questions resulted in a high collaboration level between the teachers in both TDTs, where the teachers explored mainly 2 or 3 aspects of instruction, yielding interactions at LISS-levels 5 and 6. However, the different LISS-levels were not linked to specific questions. Creating an overview of activities in the project or curriculum stimulated more 
valuable interactions for increasing self-efficacy in TDT 2 compared to TDT 1. TDT 2 continued their discussion about Tyler's questions while creating the overview, resulting in LISS levels of 5 or 6 . TDT 1 only selected some subjects from the existing overview in their method of teaching science, the 'Science Towers', which resulted in a discussion mainly about content (LISS 4).

The LISS levels of the interactions during development ranged from 0 to 6 , as can be seen in Table 6.6. Research on existing materials resulted in interactions at different LISS-levels, because the teachers in both teams first had to share their experiences with the materials in the classroom (LISS 3) or the content of the materials (LISS 1) or the content of the materials in relation to their curriculum (LISS 2) before they could discuss the value of the materials for the curriculum they are designing (LISS 6). The interactions during the development of activities were mainly at LISS levels 5 (TDT 1) and 6 (TDT 2). TDT 1 was adjusting the science boxes so that students could work independently with them, and therefore the role of the teacher was only discussed briefly. TDT 2 was jointly developing the content of the workbook and the lessons for their students (LISS 6). Part (TDT1) and even a major part (TDT2) of the development of activities took also place outside the TDT meetings, on an individual basis.

The interactions during implementation were mainly at LISS-level 0 in both teams, due to the content of the conversations (see Table 6.6). Communication of the ideas with other team members outside the TDT resulted in interactions at LISS-level 0 during TDT time, because the principal took the leading role and shared his idea in TDT 1. TDT 2 took just one minute to decide to share their ideas in the corridors. The organization of the science activities resulted in TDT 1 in searching through materials in the 'science towers'(LISS 0), while TDT 2 discussed project organization, for example, organizing supporting materials and guest teachers (LISS 0). Trying to involve the teachers outside the team resulted in TDT 1 in discussions about a change in priorities because of the new principal and the consequences for the team and the teachers, and figuring out when to involve the school team, so with no instructional relevance or LISS- level 0. TDT 2 skipped this activity.

The interactions during the stage of evaluation were mainly at LISS-level 3 in both teams (see Table 6.6). The teachers shared their classroom experiences or worked 
on developing materials, but those experiences or materials were taken for granted and were never analyzed or compared (LISS 1-3).

\section{Teacher questionnaire}

Two out of the five teachers found the design activities formulating of criteria (not executed in TDT 2), development of activities and teaching of designed activities to be valuable. Another valuable activity according to teacher 1 (TDT 1) only was communicating with other teachers. Teacher 1 (TDT 2) mentioned discussions in general as valuable, because the discussions resulted in new insights for her. Teacher 1 (TDT 1) valued development as the least valuable; she believed that development is necessary but it was not valuable for herself. No less valuable activities were indicated by the other teachers.

\subsection{DISCUSSION AND CONCLUSIONS}

This study aimed to further extend what is known about collaborative curriculum design as a professional development program for improving the science teaching self-efficacy of the participating teachers. First, the influence of the principal was considered in relation to the design process. We conclude from the contact summary sheet that the principal had an enormous impact on the process of curriculum design in both teams. A change in principal in the TDT 1's school resulted in a different vision about science education in their school and less administrative support. As a consequence, TDT 1 spent a lot of time on creating involvement with other team members outside the TDT. In TDT 2 there was no clear communication about what the team wanted to achieve and what the principal wanted to achieve, which resulted in a disturbance of the curriculum design process because the designed project did not fulfil the principal's expectations. A lot of time was subsequently spent on discussing among themselves about the process of communicating with the principal.

Neither discussions about creating involvement with other team members (TDT 1) nor discussions about the communication process (TDT 2) focus on science teaching, and therefore the likelihood that these discussions will directly contribute to increasing science teaching self-efficacy (LISS-level) is 0. In addition, there is less time left to spend on curriculum design itself. In this study, design and development activities in particular were observed to result in valuable 
interactions for increasing science teaching self-efficacy. Therefore, it seems important to arrange things so that teachers can spend as much of their time in the TDT as possible on design and development. A clear focus and specific goals for the school, which are shared with the team members, along with administrative support such as time to share results or to ask school team members outside of the TDT to test a prototype, can help with this. The teachers themselves also mentioned a clear focus and good communication between the principal and the team as important for the functioning of a TDT. But, they did not believe that the principal provided added value for the team. Administrative support by the principal has already been demonstrated to be vital to improve self-efficacy (Ramey-Gassert, 1996), and other studies have confirmed that it is essential for a principal to have a clear focus and specific goals for the school that are shared with the team members (Verschuren, 2010; Meirink, Imants, Meijer, \& Verloop, 2010). In conclusion, a clear focus on science education and a corresponding strategy from the principal at the level of organization and people will probably result in more valuable interactions during the TDT for increasing science teaching self-efficacy.

The second aim of this study was to determine whether curriculum design will automatically result in teaching experiences. Neither redesign of the curriculum nor the development of an inquiry-based project automatically mean that teachers will use the constructed materials in their own classroom practice. The observation that not all teachers in the design teams were teaching with prototypes or designed curriculum materials corresponds with what was found by Handelzalts (2009). In his study, there were only a few teams in which a few teachers were piloting the constructed curriculum materials. So, collaboration in a TDT did not seem to result in enough emotional support and persuasion through discussing different opinions in the team to stimulate all teachers to teach the designed lessons in their classroom practice. Successful classroom experiences should be a valuable outcome of collaborative curriculum design, because both mastery and vicarious experiences are known to be main sources of influence to increase science teaching self-efficacy (Bandura, 1986). However, some teachers might need more stimulation than collaborative curriculum design. The teachers in TDT 1 who piloted the science boxes both indicated those teaching experiences to be a valuable design activity. However, it must be noted based on the results of our previous study describing the value of collaborative curriculum design for the different teachers in TDT1 in more depth (Velthuis et al. 2013b) that the self-efficacy 
of the pre-service teacher who experienced science teaching in the classroom did not change following participation in the TDT. A possible explanation could be that her science teaching experience was not successful. Furthermore, teacher 1 of TDT 2 in this study indicated that she experienced the teaching of an inquiry-based project as difficult. This might indicate that besides coaching on curriculum design by a process guide, teachers in a TDT also need coaching on science teaching itself. Coenders et al. (2010) concluded that when teachers 'in a network' develop learning materials, they become equipped for the innovation by resources such as written documents, the coach, the experiences of each teacher, discourse during network meetings and specific literature. The 'network' in their study consisted of three experienced chemistry teachers, all having masters' degrees plus teaching qualifications in chemistry. The teachers in our 'networks' are primary school teachers, and not specialists in science teaching. They do have a coach, each other's experiences, a written document about inquiry-based learning and other specific literature, but it might be that at least some primary teachers need additional support to implement the developed learning materials in their classroom.

The third aim of this study was to determine design stages and activities that result in interactions with a high likelihood of increasing science teaching self-efficacy. The most valuable interactions for increasing science teaching self-efficacy took place during the design and development stages. The most valuable activity for TDT 1 was formulating design criteria for their own design, which was also confirmed by 2 out of the 3 teachers in TDT 1 in their responses on the teacher questionnaire. For TDT 2, the most valuable activity was creating an overview of their science project. The discussions during the development of the activities were valuable in both teams, according to the observation instrument and to two out of the five teachers. However, both teams also decided that they preferred to do at least a part of the development of the curriculum materials individually outside the TDT meetings, which corresponds with the finding by Handelzalts (2009) that teachers prefer to do the construction of the materials individually. We conclude therefore that it seems to be important to encourage the teachers in a TDT to construct the materials in collaboration, especially in a TDT implemented as a professional development program for increasing self-efficacy.

According to the observation instrument, the stage of implementation was of less value for increasing science teaching self-efficacy, due to the content of the conversation. The discussions in both teams during implementation activities 
were about organizational matters most of the time and not about science teaching, which means that these discussion were not likely to influence science teaching self-efficacy directly. However, an implementation plan is very important to ensure successful implementation in the classroom, because success in the classrooms is the most important source of influence on self-efficacy for teaching (Bandura, 1986; Tschannen-Moran \& Woolfolk Hoy, 2007). Therefore, it seems important to make this stage more efficient by achieving the same result, science teaching successes in the classroom, in less time. This result again emphasized the importance of administrative support from the principal.

From the observation instrument it could also be concluded that the evaluation was less valuable for increasing science teaching self-efficacy. During evaluation, the teachers in both TDTs simply shared their experiences with science teaching, but did not ever analyze those experiences more deeply. To make interactions during the evaluation stage more valuable for increasing self-efficacy, it might be better to have teachers observe each other's lessons to see whether the activity fulfills the design criteria. If all teachers see for themselves how the designed curriculum materials function in practice and experience for themselves the effect on the students, they will be better able discuss their different views and opinions and will not have to take the experiences of one teacher as a given. Observing each other's lessons might not only increase the LISS levels of the interations during evaluation-those 'vicarious' experiences' are also in themselves an important means of increasing self-efficacy (Bandura, 1986).

In this study we have demonstrated that determining LISS levels by observing the instructional relevance and the level of collaboration during interactions provides information about the value of such interactions for increasing the science teaching self-efficacy of the participating teachers. The observation instrument is therefore a first step towards a more efficient program for TDTs intended to improve the science teaching self-efficacy of participating teachers, but some caution is necessary with regard to the instrument and the results. More research on the observation instrument in needed, because it is not yet clear whether LISS level 4 (discussion about one aspect of learning) is better than LISS level 3 (sharing of experiences related to all three aspects of learning) for increasing teachers' science teaching self-efficacy. In this study, a switch between LISS levels 3 and 4 would not influence our main results, but it could be that the value of some activities is a little underestimated and of others a little overestimated. 
Despite the limitations of the observation instrument, the findings provide support for some implications regarding the use of TDTs as a means to improve science teaching self-efficacy. First, in order to ensure that the TDT spends as little of their time in the TDT as possible on organizational matters, it is very important that the principal communicate a clear focus in the school team and provide administrative support. Second, it is important to encourage the teachers in the TDTs to teach the lessons that they prepared. Mastery experiences are important for increasing self-efficacy, but it was seen that not all teachers automatically felt the need to teach the lessons that they prepared. Additionally, to ensure that teaching experiences will become mastery experiences, it might be important to support at least some teachers in the TDT regarding their science teaching. Furthermore, teachers need to be encouraged to construct the curriculum materials collaboratively. Teachers prefer to construct the curriculum materials individually; however, the results of this study show that collaborative development can result in valuable interactions for increasing science teaching self-efficacy. And finally, the interactions during the evaluation stage should become more valuable when the teachers observe each other's lessons and critically evaluate those lessons during a meeting on their design criteria. 


\section{CHAPTER $7^{\infty}$ \\ External support in collaborative curriculum design to increase the science teaching self-efficacy of primary teachers}

Discussions about curriculum design and successful teaching experiences in their own classrooms are argued to be key elements for increasing teachers' self-efficacy through collaborative curriculum design. It is further argued that primary school teachers need external support in design teams to make the discussions more valuable and to ensure that the teaching of science is successful. In this study, a whole primary school team, including their principal, designed their own science curriculum. The team was supported with several types of external support, such as visiting an exemplary school, additional activities that support teachers with science teaching, classroom observations and feedback on lesson outlines. The results show that external support provided added value, especially for the teachers who began the program with low science teaching self-efficacy. External support was observed to (1) improve discussions, (2) increase the frequency of science teaching and (3) stimulate the teachers to teach science differently.

\subsection{INTRODUCTION}

Several studies have shown the value of collaborative curriculum design for teachers' learning (Coenders, Terlouw, Dijkstra, \& Pieters, 2010; Rock \& Wilson, 2005; Sibbald, 2009; Voogt, 2010), but only a few studies have addressed the effects of collaborative (re)design on the teachers' self-efficacy beliefs (Mintzes, Marcum, Messerschmidt-Yates, \& Mark, 2012; Velthuis, Fisser, \& Pieters, 2013b). One specific form of collaborative curriculum design is Teacher Design Teams (TDTs). Teachers in a TDT collaborate to create new curriculum or adapt existing curriculum

$\infty$ This chapter has been submitted as: Velthuis, C. Fisser, P., \& Pieters, J. (Submitted). External support in collaborative curriculum design to increase the science teaching self-efficacy of primary teachers 
materials, often with an external facilitator as well (Handelzalts, 2009). In collaborative curriculum design, both the collaboration process and successful teaching experiences with the new curriculum seem to be important for increasing primary teachers' science teaching self-efficacy (Mintzes et al., 2012; Velthuis et al., $2013 b)$. However, the value of discussions has been observed to vary over the entire design process (Velthuis, Fisser, \& Pieters, submitted b) and not all teachers participating in TDTs have engaged in teaching science in their classrooms (Handelzalts, 2009; Velthuis et al., submitted b). At least some primary teachers might therefore need additional support to develop and/or implement curriculum materials in the classroom in the context of collaborative curriculum design if we want them to have improved self-efficacy. Just as in our previous studies (Velthuis et al., 2013, submitted b), the TDT in this study was guided in their curriculum design process. In addition, several types of external support were offered to the TDT in this case-study, such as feedback by the external facilitator on lesson outlines and shared experiences, classroom observations by the external facilitator, additional activities and literature offered by the external facilitator to support science teaching, a visit to an exemplary school. In this study, we aimed to investigate what external support the teachers in the TDT need to (1) improve the discussions in the team and (2) to improve the frequency and quality of their science teaching, because these will improve self-efficacy and they are areas that have been shown not always go well on their own. The results of this study provide evidence about what external support we need to offer primary teachers in a TDT, with the main goal being to increase these teachers' science teaching self-efficacy.

\subsection{THEORETICAL FRAMEWORK}

\subsubsection{Science teaching self-efficacy}

The focus in this study is on increasing primary teachers' science teaching selfefficacy, because teachers with high science teaching self-efficacy belief develop a lasting interest in science, a positive desire to help children, and a willingness to improve their science teaching (Bandura, 1977; Tschannen-Moran \& Woolfolk Hoy, 2007). These factors are very important for improving science education in primary schools. Self-efficacy is defined by Bandura (1977) as one's perceived ability to perform an action that will lead towards a specific goal and reflects both a self-assessment of one's ability to perform a specific task (in this study, personal 
science teaching self-efficacy) and the expectation that performing the task will result in the desired outcome (outcome expectancy).

\subsubsection{Science teaching self-efficacy in relation to TDT}

Given that TDTs provide opportunities for increasing teachers' science teaching self-efficacy beliefs, it is important to consider the relevant processes in a TDT and their effectiveness. First of all, the process of curriculum design results in discussions in a TDT, the importance of which for increasing self-efficacy has been reported by Mintzes et al. (2012), Sibbald (2009) and Velthuis et al. (2013, submitted b). Sibbald (2009) concluded that gains in self-efficacy were most significant during discussions that were sufficiently focused and novel to create appropriate opportunities for depth in the discussion. Velthuis et al. (submitted b) argued that the most valuable interactions for increasing science teaching selfefficacy, that is, interactions with a high LISS level (Likelihood of Increasing Science teaching Self-efficacy), are discussions with both a high level of collaboration or interdependency (Little, 1990) and a focus on science teaching (Henry, 2010). Thus, focusing the discussion in TDTs on science teaching and stimulating negotiation about materials, methods, ideas or opinions may be important keys for increasing science teaching self-efficacy.

In addition, the power of a cooperative group seemed to emerge from the emotional support they provide and from social persuasion (Mintzes et al., 2012, Velthuis et al., 2013b). For example, one teacher in the study by Velthuis et al. (2013b) explained that the team meetings were necessary to convince her that she had to try in her classroom the activities that had been designed by the TDT. Both emotional support and social persuasion are sources of information that can influence one's self-efficacy beliefs, according to Bandura (1986).

Besides social persuasion and emotional support, several teachers mentioned the positive outcomes they observed in the children as valuable for their self-efficacy (Mintzes et al. 2012; Velthuis et al., 2013b). This can best be illustrated by the comment of a teacher in the study by Mintzes et al. (2012): 'I loved the enthusiasm that they felt and there was a lot of self-discovery even though it was directed, it was selfdiscovery on their part, and I think they felt, "wow, I'm really smart, I figured this out".... It helped me realize how important it is that I take that type of teaching back to the classroom [Deborah]. Those successful teaching experiences are examples of what are called mastery experiences by Bandura (1986), and are known to be the most effective 
way of creating a high feeling of self-efficacy. On the other hand, a teacher in the study by Velthuis et al. (2013b) explicitly mentioned that she learned from the classroom experiences of her colleagues. Those vicarious experiences, which are examples or experiences of others similar to oneself, can also increase the sense of self-efficacy: "if they can do it, I can, too" (Bandura, 1986).

In conclusion, aspects of a TDT that can improve self-efficacy are team discussions and teaching experiences. Discussions about science teaching influence science teaching self-efficacy directly and also indirectly, by providing emotional support and social persuasion to teach science. Successful science teaching in turn results in an increase in science teaching self-efficacy directly and also indirectly, by way of teachers' discussion of those teaching experiences (vicarious experiences) with other teachers in the TDT. All of these processes take place in the school context and are shown in Figure 7.1. The TDT teacher's current level of self-efficacy might also influence the quality of the discussions in the team and/or the quality or frequency of the teaching performed, and therefore these relations in the figure are depicted with a dotted arrow.

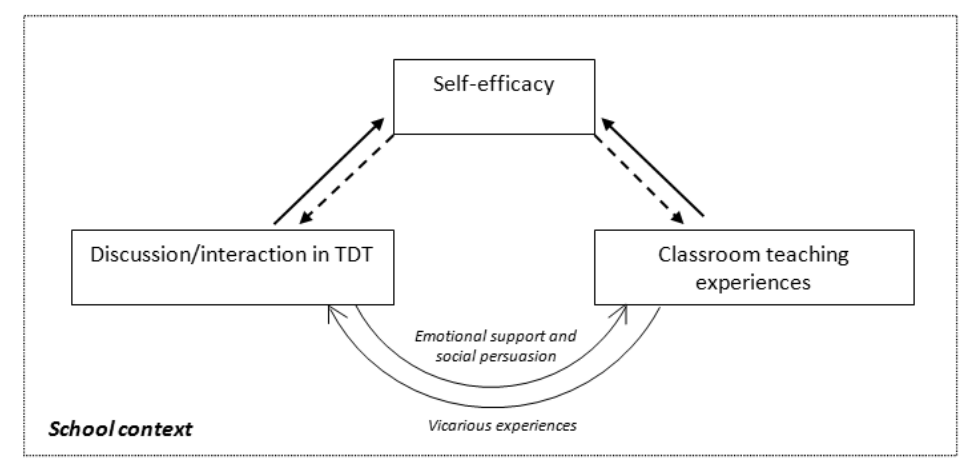

Figure 7.1 The processes in a TDT in relation to the science teaching self-efficacy of teachers in the team

\subsubsection{Improving TDTs for increasing science teaching self-efficacy}

Velthuis et al. (submitted b) observed that valuable interactions took place during the design and development stage in the TDTs, but the interactions during implementation and evaluation were less valuable for increasing science teaching self-efficacy. The interactions during the stage of implementation were less valuable for increasing self-efficacy because most of the time the discussions were 
about organizational matters and not about science teaching. It was therefore suggested that a clear focus and corresponding administrative support from the principal might result in less time spent on discussing organizational matters regarding implementation and more effective implementation of science teaching in the classrooms. The interactions during the stage of evaluation were less valuable because it was observed that the teachers were only sharing their teaching experiences, and were not analyzing them in depth.

Secondly, collaboration in a TDT did not seem to result in enough emotional support and social persuasion to convince all participating teachers to teach science in their classrooms (Handelzalts ,2009; Velthuis et al., 2013b). As a result, only some of the teachers had mastery experiences with science teaching and positive outcomes of their children, which is the major source of self-efficacy building information (Bandura, 1986). Furthermore, no increase in personal science teaching self-efficacy belief was found for the teachers who experienced difficulties with the teaching of the designed curriculum materials (Velthuis et al., submitted $b$ ). These authors suggested therefore that at least some teachers in the TDT might need support regarding science teaching. Sibbald (2009) also concluded that a team will only be successful if they form a group that is able to share, explain and resolve issues referring to details of pedagogical content knowledge. He even suggests that collaborative curriculum design itself is likely not to be a good choice if the teachers in a group lack sufficient knowledge or are unfamiliar with the content area. The target group in our current study is primary school teachers; we know that primary school teachers have a basic level of SMK but an insufficient level of PCK regarding technology education, which is in the Netherlands part of an integrative learning domain of science (Rohaan, Taconis, \& Jochems, 2012). And in addition, only $27 \%$ of Dutch teachers feel confident about teaching science in primary schools (Martin, Mullis, \& Foy, 2008). To have the TDT serve as a valuable form of professional development with the main goal of increasing science teaching self-efficacy, it seems likely that those who come in with less knowledge or lower self-efficacy in the team will benefit from being able to draw on external resources that support them with science teaching. 


\subsubsection{External support in TDTs}

The most commonly used form of external support in TDTs is coordination by an external facilitator (Coenders et al., 2010, George \& Lubben, 2002; Handelzalts, 2009; Parchman, Gräsel, Baer, Nentwig, Demuth, \& Ralle, 2006; Rock \& Wilson, 2005, Velthuis et al., 2013b) who guides the team, leads discussions, and provides study materials and other resources. Materials provided by the external facilitator can consist of literature (Coenders et al., 2010; Rock \& Wilson, 2005; Velthuis et al., $2013 b$ ) and/or exemplary and existing curriculum materials (George \& Lubben, 2002; Parchmann et al., 2006; Velthuis et al., 2013b; Voogt, Almekinders, van den Akker \& Moonen, 2005). Additional forms of external support by the external facilitator in TDTs have included personal support (George \& Lubben, 2002), bringing new ideas, alternative teaching approaches and advice (Coenders et al., 2010), observing and discussing lessons that were developed and executed (Voogt et al., 2005) and giving feedback on presentations of the lesson outlines (George \& Lubben, 2002).

Participants in the TDTs viewed the coordination by the external facilitator as an effective means of supporting collaborative curriculum design (Rock \& Wilson, 2005, Velthuis et al., 2013b), and both lesson observation (Voogt et al., 2005) and presentations of lesson outlines in combination with feedback (George \& Lubben, 2010) were mentioned as important support components of a TDT. Studying and adapting exemplary or existing materials were also valued as effective ways to support collaborative curriculum design (Parchman et al., 2006; Voogt et al., 2005); one teacher in the TDT studied by Rock and Wilson (2005) attributed her professional growth partly to the assistance she received in being provided with professional literature.

In three studies (George \& Lubben, 2002; Rock \& Wilson, 2005; Voogt et al., 2005) teachers also received external support in the form of specific training. In two of these studies (George \& Lubben, 2002; Voogt et al., 2005) the teachers received training before participating in the TDT. In the study by Voogt et al. (2005), teachers received a course in basic technology skills (3 months) and a workshop introducing learner-centered pedagogical approaches to prepare teachers for developing ICTenhanced science lessons. George and Lubben (2002) offered their teachers two four-day workshops about contextualized science lessons, before the TDTs had to construct context-based materials in science. Rock and Wilson (2005), on the other hand, arranged a two-hour workshop session in response to the request of the 
teachers in the teams. Based on the readings and discussions, both teams came to the conclusion that in addition to their readings, they would also like to have experts to provide them with additional knowledge and strategies to consider before they started to develop lessons. Teachers in the TDTs considered the training to be valuable for their professional growth (Rock \& Wilson, 2005) and for the quality of the lessons they designed (George \& Lubben, 2002; Voogt et al., 2005). In addition, one teacher in the TDT program studied by Rock and Wilson (2005) mentioned in the interview that the workshop was very meaningful and worthwhile because the information gained from the focused professional development sessions with the education experts was immediately applicable.

Several forms of external support therefore seem to have the potential to influence the science teaching self-efficacy of participating teachers in the TDT, either by improving the interactions in the TDT (coordination), or by improving the teaching experiences (feedback from the external facilitator), or via multiple pathways (workshops/training, exemplary and/or existing materials and literature), as can be seen in Figure 7.2. We defined external support in our current study as input of ideas, practices, strategies and/or stimuli to develop new teaching practices other than those constructed by the teachers themselves during the TDT meetings.

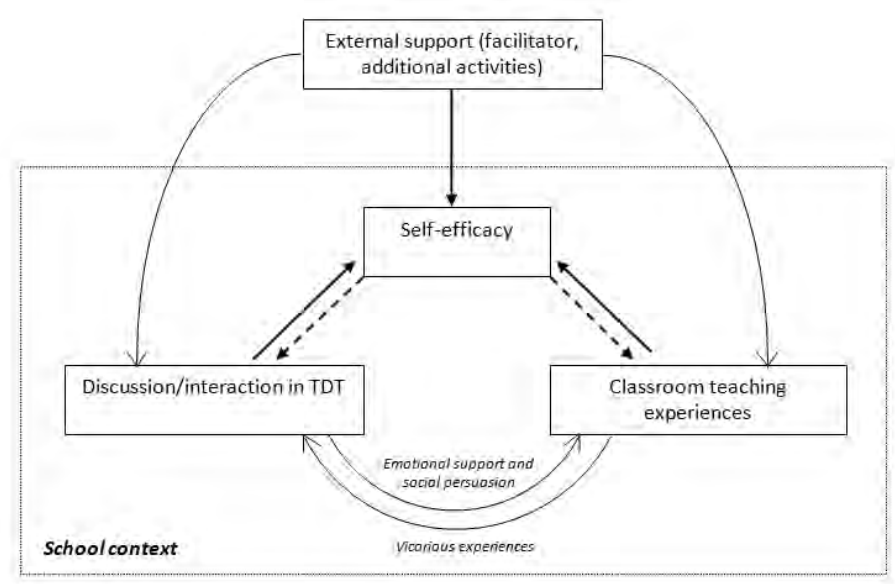

Figure 7.2 The processes in a TDT, including external support, in relation to the science teaching self-efficacy of teachers in the team 


\subsection{PROBLEM STATEMENT AND RESEARCH QUESTION}

Although we have many good indicators about what external support is valuable for the teachers in the TDT to increase their science teaching self-efficacy, we haven't yet seen this directly tested or investigated. This study will therefore focus on the following research questions:

(1) What is the effect of a TDT extended with external support on the science teaching self-efficacy of participating teachers?

(2) What is the effect of external support on the interactions in the TDT meetings?

(3) What is the effect of external support on the science teaching practices of teachers with high and low pre-intervention personal science teaching selfefficacy scores who are in the same TDT, and what kinds of external support are experienced as valuable for their science teaching?

\subsection{Methodology}

\subsubsection{Participants}

This case study was carried out in a primary school in the Netherlands, with approximately 130 children and a team of 8 teachers. All teachers and the principal participated in the TDT team. The principal participated in the team in order to provide the team with a clear focus and administrative support. Due to personal problems, one teacher, Johan, was not able to teach during the period in which the TDT took place. Because teaching experiences are a major source for increasing science teaching self-efficacy in a TDT (Mintzes et al. 2012; Velthuis et al., 2013b), in this study we analyzed only the results for the teachers who could have taught science during the TDT program. Three teachers (Jenny, Annie and Marie) voluntarily took a science methods course in the year prior to the TDT. The course lasted six meetings of approximately three hours each, and the teachers learned to develop children's talents regarding science. Other characteristics of the teachers participating in the team are given in Table 7.1. Gerry did not complete the question about her age. 
Table 7.1 Characteristics of the teachers participating in the TDT

\begin{tabular}{|llllll|} 
Teacher & F/M & Age & $\begin{array}{l}\text { Years of } \\
\text { teaching } \\
\text { experience }\end{array}$ & $\begin{array}{l}\text { Additional } \\
\text { training }\end{array}$ & Student age \\
\hline Jenny & F & 53 & 32 & Y & $6-8$ \\
\hline Janneke & F & 51 & 20 & N & $4-6$ \\
\hline Annie & F & 54 & $>20$ & Y & $10-12$ \\
\hline Marie & F & 54 & 35 & Y & $4-6$ \\
\hline Johan & M & 56 & 33 & $\mathrm{~N}$ & \\
\hline Hilde & F & 55 & 29 & $\mathrm{~N}$ & $8-10$ \\
\hline Gerry & F & & $>20$ & $\mathrm{~N}$ & $8-10$ \\
\hline Gert & $\mathrm{M}$ & 58 & 35 & $\mathrm{~N}$ & $10-12$ \\
\hline
\end{tabular}

\subsubsection{The TDT program}

The entire design process was carried out over eight meetings of approximately two and a half hours each spread over a school year. The TDT's assignment was to (re)design (a part of) their science curriculum. The team wanted to redesign their science curriculum so that teachers did not have to rely solely on textbooks and structured materials, but could follow a more inquiry-based approach that incorporates essential skills such as finding solutions to real-life problems by asking questions, designing and conducting investigations, gathering information, drawing conclusions and reporting findings (Colgoni \& Eyles, 2010; Donovan \& Bransford, 2005; Van Graft \& Kemmers, 2007). In addition, the team wanted to involve the immediate school surroundings in their science curriculum, for example, with visits to companies or excursions in the neighbourhood. The activities in the TDT were coordinated by the external facilitator. The design activities were framed by the ADDIE model, Analysis, Design, Development, Implementation and Evaluation (Dick \& Carey, 1996). After analyzing the needs and opportunities for a new curriculum, alternative solutions for the curriculum design were explored and prototype activities were developed in subgroups with teachers responsible for children of about the same age. Based on the evaluations of the lessons taught in the classroom, the team could repeat their design or even analysis activities; the process allowed for non-linear progression. Throughout the entire design process, activities were planned to support the teachers with the development of and teaching with the curriculum materials and with attention to a sustainable implementation. Apart from the coordination of the TDT, the external facilitator provided the teachers in the TDT with external support in the way of:

(1) giving feedback and facilitating the discussion during the presentation of 
designed lesson (meetings 1 and 2) and evaluation of the taught lessons (meetings 2, 3, 5 and 7) by offering new ideas, alternative teaching approaches and advice;

(2) classroom observations (halfway through the TDT program: Hilde and Annie were not teaching on the day that the observations occurred);

(3) a visit to an exemplary school that is already teaching in a more inquiry-based way (meeting 6);

(4) input in the form of additional activities to support the teachers in the team with inquiry-based teaching (meetings 5 and 8) and the organisation of excursions (meeting 7); and

(5) providing literature about inquiry-based learning and science content.

\subsubsection{Instruments}

Four different instrument were used for the purposes of this study. Table 7.2 shows how the different instruments are related to the research questions.

Table 7.2 List of instruments and related questions

\begin{tabular}{|c|c|c|c|c|}
\hline & STEBI-NL & $\begin{array}{l}\text { Teacher } \\
\text { questionnaire }\end{array}$ & $\begin{array}{l}\text { Observations } \\
\text { of meetings }\end{array}$ & $\begin{array}{l}\text { Focus group } \\
\text { interview }\end{array}$ \\
\hline $\begin{array}{l}\text { the effect of a TDT with external } \\
\text { support on science teaching self- } \\
\text { efficacy }\end{array}$ & $x$ & & & \\
\hline $\begin{array}{l}\text { the effect of a TDT with external } \\
\text { support on team interactions }\end{array}$ & & $x$ & $x$ & \\
\hline $\begin{array}{l}\text { the effect of a TDT with external } \\
\text { support on the science teaching of } \\
\text { teachers with high and low pre- } \\
\text { TDT PSTE }\end{array}$ & & $x$ & $x$ & \\
\hline $\begin{array}{l}\text { external support experienced by } \\
\text { the teachers as valuable }\end{array}$ & & $x$ & & $x$ \\
\hline
\end{tabular}

\section{STEBI-NL}

The STEBI-NL (Velthuis, Fisser, Ormel, \& Pieters, submitted a) was used to measure the science teaching self-efficacy of the teachers pre-intervention, halfway through and post-intervention. The STEBI-NL was translated from an existing, commonly used English instrument: the STEBI-A (Science Teaching Efficacy Belief Instrument), an instrument based on Bandura's self-efficacy theory 
that specifically addresses the beliefs of (pre-service) teachers about science in teaching and learning (Bleicher, 2004; Bursal, 2010; Riggs \& Enochs, 1990). The STEBI-NL is a 24-item instrument comprising two scales, Personal Science Teaching Efficacy (PSTE, self-assessment of one's teaching competence) and Science Teaching Outcome Expectancy (STOE, teachers' expectations that teaching can influence student learning). The reliability was very good for the PSTE scale, with a Cronbach's a of .84, and respectable for the STOE scale, with a Cronbach's a of .74 (Velthuis, Fisser, \& Pieters, submitted c). The teachers used a 5-point Likert scale, ranging from strongly agree to strongly disagree to indicate their opinion on the statement. The mean scores of each individual teacher are calculated for each scale (minimum is 1 and the maximum is 5). A higher score indicates higher self-efficacy.

\section{Teacher questionnaire}

After the intervention, teachers were asked additional questions following the administration of the STEBI-NL, in order to obtain information about their individual experiences regarding the external support provided during the TDT program. The TDT teachers were asked two additional questions:

(1) To what extent were the following activities (the classroom observation, the school visit and the additional activities to support inquiry-based teaching) valuable to you (not valuable, valuable and very valuable)? And can you explain?

(2) Did you use the literature and/or websites provided by the external facilitator? (not at all/once or twice/ regularly/often).

\section{Observation instrument}

All meetings except the visit to the exemplary school were video-taped for observation. By working in subgroups, the interactions of one subgroup were videotaped for observation. The value of the interactions for increasing the science teaching self-efficacy was determined by using an observation instrument that determines LISS-levels (Likelihood to Increase Science teaching Self-Efficacy) that was developed and tested in an earlier study (Velthuis et al, submitted b). The instrument distinguishes two levels of collaboration (exchange and discussion) with an increasing degree of interdependence, based on Little's (1990) classification, and four levels of instructional relevance or the extent that teams are exploring the relations between the key aspects of learning, content, teacher and student (Cohen \& Ball, 1999; Henry, 2010; Little, 1990). The level of collaboration or instructional 
relevance could change during a TDT activity, because the team could switch between sub-activities or because of a question or remark from a team member, the principal or the external facilitator. Those changes and the reason for the changes are also noted on the observation instrument.

By determining both the level of collaboration and the instructional relevance of the discussion during a design activity in combination with the time spent at the different LISS- levels, we were able to evaluate whether the design activity yielded interactions that were likely to increase the science teaching self-efficacy of participating teachers, as can be seen in Figure 7.3. The higher the LISS level of the activity and the more time spent at the higher LISS-levels, the better the activity is for improving science teaching self-efficacy. The intersubjective reliability (Cohen's kappa) of the observation instrument is .71 for both the level of collaboration and the instructional relevance, which is good enough to use the data (De Vellis, 2003).

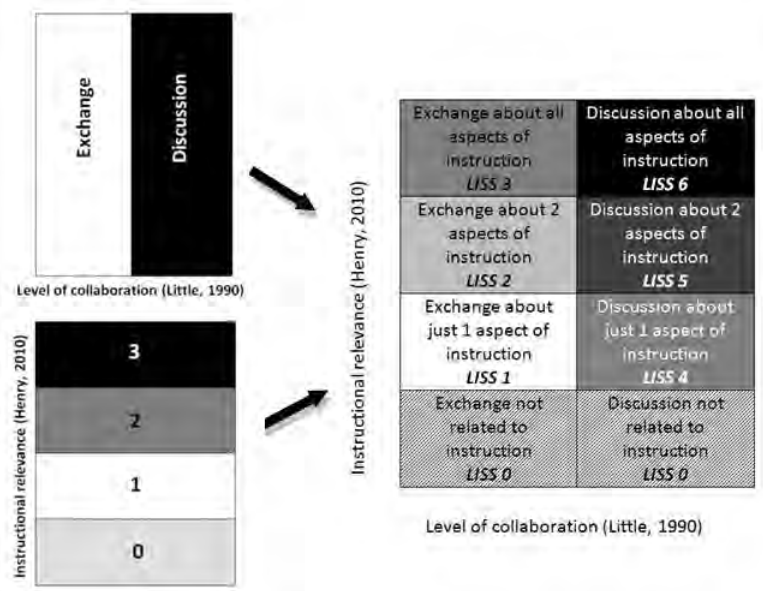

Note. White $=$ low, Gray $=$ intermediate and Black $=$ high likelihood that team interaction will increase self-efficacy.

Figure 7.3 'Level of collaboration' and 'Instructional relevance' are combined to determine the interactions' Likelihood of Increasing Science teaching Self-efficacy, or LISS level (Velthuis et al., 2013b)

In addition to determining the LISS-levels of the different ADDIE related activities carried out during the team meetings, we focused in this study on interactions about science teaching, which involved mainly the presentation of developed lessons and the evaluation of lessons taught in the classroom. Interactions in which 
teachers referred to the use of a specific kind of external support or in which a teacher explained why he or she did or did not try inquiry-based teaching were selected and transcribed. Both discussions and statements were used to illustrate what kinds of external support were used by which teachers in the TDT.

\section{Focus interview}

After the TDT program was finished, a teacher focus group interview was conducted to get more in-depth information about the external support that was provided in the TDT. Topics of the interview were: the perceived quantity and quality of the external support and the way that the external support was integrated within the TDT program. Two teachers with a high pre-TDT PSTE score (Gerry and Gert), two teachers with a low pre-TDT PSTE score (Annie and Janneke), Johan and the principal participated in the focus group.

\subsection{Results}

\subsubsection{Science teaching self-efficacy}

Pre- and post-TDT scores on the STEBI-NL are presented in Table 7.3. The teachers were divided into two groups based on their pre-TDT scores regarding personal science teaching self-efficacy (PSTE): (1) the teachers with a low pre-TDT PSTE score, that is, a PSTE lower than 3.5 (Jenny, Janneke, Annie and Marie) and (2) the teachers with an high pre-TDT PSTE score, that is, a PSTE higher than 3.5 (Hilde, Gerry and Gert). We decided to use pre-TDT scores PSTE to divide the teachers in two groups, because this factor better discriminates between teachers.

Table 7.3 PSTE and STOE results for team members before and after participating in the TDT program

\begin{tabular}{|lllllll|} 
& $\begin{array}{l}\text { PSTE } \\
\text { pre }\end{array}$ & $\begin{array}{l}\text { PSTE } \\
\text { post }\end{array}$ & $\begin{array}{l}\text { PSTE } \\
\text { post- pre }\end{array}$ & $\begin{array}{l}\text { STOE } \\
\text { pre }\end{array}$ & $\begin{array}{l}\text { STOE } \\
\text { post }\end{array}$ & $\begin{array}{l}\text { STOE } \\
\text { post-pre }\end{array}$ \\
\hline Jenny $^{*}$ & 2.08 & 2.67 & .58 & 3.58 & 3.83 & .25 \\
\hline Janneke & 3.25 & 4.00 & .75 & 3.21 & 3.08 & -.13 \\
\hline Annie* & 3.25 & 3.75 & .50 & 3.42 & 3.50 & .08 \\
\hline Marie* & 3.33 & 4.25 & .92 & 3.42 & 3.92 & .50 \\
\hline Hilde & 3.67 & 3.25 & -.42 & 3.08 & 3.42 & .33 \\
\hline Gerry & 3.83 & 3.25 & -.58 & 3.58 & 3.67 & .08 \\
\hline Gert & 4.00 & 3.92 & -.08 & 3.92 & 3.83 & -.08 \\
\hline
\end{tabular}

Note: *. Teachers who took a science methods course before participating in the TDT. 
Participating in a TDT with external support resulted in an increase of PSTE for all four teachers with a low pre-TDT PSTE score (Jenny, .58; Janneke, .75; Annie, .50; Marie, .92). For two of the three teachers with a high PSTE (> 3.5) at the start of the TDT program, their post-TDT scores went down (Hilde, -.42; Gerry, -.58). The PSTE score of the teacher with the highest pre-TDT PSTE score, Gert, remained almost the same (-.08). When the teachers' STOE pre and post-TDT scores were compared, the differences seemed to be quite randomly distributed, with a few larger gains (Marie, .50; Hilde, .33; Jenny, .25), but the rest showing mostly no change or small differences.

\subsubsection{External support and interactions}

As can be seen in Table 7.4, the interactions that were scored with a LISS-level of 6 , meaning that they were the most valuable interactions for increasing science teaching self-efficacy, took place in the TDT during the Design, Development and Evaluation stages. The less valuable discussions took place during Implementation and Analysis.

Table 7.4 Time spent on different LISS levels during design activities by the TDT

\begin{tabular}{|c|c|c|c|c|c|c|c|c|c|c|c|c|c|c|}
\hline \multirow[b]{2}{*}{ LISS levels } & \multicolumn{7}{|c|}{$\begin{array}{l}\text { TDT } \\
\text { time spent at LISS level in minutes }\end{array}$} & \multicolumn{7}{|c|}{$\begin{array}{l}\text { TDT subgroup } \\
\text { time spent on a LISS level in minutes }\end{array}$} \\
\hline & 0 & 1 & 2 & 3 & 4 & 5 & 6 & 0 & 1 & 2 & 3 & 4 & 5 & 6 \\
\hline Analysis & & 13 & 2 & 22 & & & & & & & 30 & & & \\
\hline Design & 2 & 15 & & 3 & 35 & 33 & 54 & & & & & & 30 & \\
\hline Development & 2 & & 15 & 32 & 11 & & 35 & & & & & & 30 & 49 \\
\hline Implementation & 43 & & & 8 & 5 & & & & & & & & & \\
\hline Evaluation & & 2 & & 69 & 2 & 38 & 59 & & & & & & & \\
\hline
\end{tabular}

The TDT was interacting on LISS levels 1 through 3 during Analysis, because they were only exchanging their opinions and experiences with science teaching. During the Design and Development stages, conversations were most effective when they collaborated in subgroups; for example, when they were looking for lessons that incorporated the method that they used for their own children and that matched the design criteria (Design) or when they were developing lessons that could be taught in their own classroom (Development). One consequence of working in subgroups was that time was also spent on the exchange of the results of this work in the TDT itself, which are less valuable moments for increasing science teaching self-efficacy.

The discussions during Implementation were mainly about organizational matters, which is reflected by 43 minutes of discussion at LISS level 0. 


\section{External support and evaluation}

It was argued in the theoretical framework that the external facilitator can stimulate the discussion during Evaluation activities by bringing new ideas, alternative teaching approaches and advice.

The external facilitator's feedback on the presentation of the prepared lessons in meetings 1 and 2 resulted in a discussion at LISS-level 6. Hilde and Gerry prepared a lesson about bridges during meeting 1, and the external facilitator asked them during their presentation what materials they planned to offer their children to build their bridges and noted that they needed to consider what kind of fastenings they wanted their children use. This led to an analysis of the consequences of offering different materials and ways of fastening by the teachers in the team (LISS 6). In meeting 2, the external facilitator's idea of using an assembly kit about energy in an alternative way, by beginning with studying the assembly kit instead of using it to deepen the lesson about energy again resulted in a more valuable interaction for increasing the teachers' science teaching selfefficacy (LISS 6).

Following Gert's presentation of his teaching experience with a particular lesson (LISS 3) in meeting 2, the external facilitator asked him if his lesson met all of the design criteria. He explained subsequently that he did not consciously translate the criteria to his lesson. The external facilitator encouraged the teachers to do this collaboratively, which resulted in interactions at LISS level 6 (33 minutes). Subsequently, Hilde and Gerry shared their experiences with the same lesson taught in their classrooms (LISS 3) and the different outcomes were analysed based on some additional information about inquiry-based learning provided by the external facilitator (LISS 6, 16 minutes). In meetings 3, 5 and 7, the team was just sharing their experiences with science teaching, resulting in interactions at LISS level 3. Teachers only asked elaborating questions of their colleagues and the external facilitator, primarily to get ideas for activities to use in their own classroom. For example: Janneke asked Jenny about her lesson about sound, how it works with the jumping rice. Janneke said subsequently: 'Yes, that is indeed nice to do with my group!'. And Annie asked the external facilitator about alternatives for the organization used in Jenny's lesson. 


\subsubsection{External support and frequency of science teaching}

According to what was reported during the team meetings, Hilde taught one redesigned science lesson, Jenny taught three different activities, Gerry two, Gert three, Janneke four and Marie at least seven activities. Annie said from the beginning that she was just trying 'parts' of research activities. For example, she had hyacinths in her classroom to observe what her children were going to do with them. Finally, in meeting 7, Annie shared her experiences with a complete inquiry-based lesson about the functioning of traffic lights.

\subsubsection{External support and new ideas in science teaching}

Teachers with a low pre-TDT PSTE score

From the observations of the presentation of the lesson outlines and the evaluation of the activities taught, it appeared that the teachers with low initial self-efficacy beliefs made use of information from at least one form of external support in their classroom practice.

When evaluating the first collaborative activity by Janneke and Marie, about a moldy chestnut, the external facilitator advised Marie and Janneke, both teachers with low pre-TDT PSTE, to make drawings or pictures in order to make the changes over time more visible for their children. In their next activity, on the growth of mushrooms, Janneke and Marie took that advice (meeting 3):

Janneke: 'After 3 days we started to make drawings of the mushrooms with the children. And we (Marie and I) repeated this activity 6 times.

Marie: and now, those activities hang on the timeline

Janneke: and we also have several pictures of the mushrooms ordered over time'.

During the classroom observation Marie also taught using an activity based on what she learned in the science methods class she took before participating the TDT program: a creativity stimulating activity (SCAMPER, http://www.creatiefdenken.com/scamper.php): the children have to think about what you can design with a banana. During the discussion after the classroom observation, the external facilitator brought up the idea of actually constructing one of the designs the children came up with during her lesson. Marie's experiences with this activity and the result were shared with the team in meeting 5 : 
'The children drew several designs, ideas that we had already conceived during our brainstorm, but also new ideas: a race car, headphones or a bridge. Yes, these are copies, because I asked for them back from the children because of a remark by External facilitator: very nice designs, but is it also an idea to construct one of the ideas?'

At that point, Marie had already prepared the follow-up activity. In addition, Marie wanted to teach using two lessons that she observed in the exemplary school, one about air and blowing and one about building with candle wax and foam. She said in meeting 7 that she liked the activities and that she had written down the activity so that she could do it with only some small adjustments with her own children, who are about the same age as the children she observed.

Jenny, the teacher with the lowest pre-TDT PSTE scores, read the literature about inquiry-based learning that was provided by the external facilitator, and used the literature in her science lesson: 'I tried to teach science and I realized that step 1 was in my lesson, step two a little and 4 was also going well, but step 3 was missing' (meeting 4). These steps were mentioned in an article provided by the external facilitator.

At the beginning of the TDT program, Annie was only trying parts of the research-based lessons. Annie said in meeting 3 that it was difficult for her to formulate a goal for her inquiry-based lesson, because she had no clear picture in mind of how her children would react to these science lessons. At the end, Annie taught an inquiry-based lesson and she therefore used the additional TDT activity to support inquiry-based teaching. Annie answered the external facilitator's question as to whether the support activity had helped her to teach her inquirybased lesson with:

'Yes, it helped me, especially with keeping my mouth closed; that is really the key for me. Listening to them and just coaching, despite knowing the answer yourself. That was really nice to do. Children do know a lot more than I thought beforehand.'

\section{Teachers with a high pre-TDT PSTE score}

Based on observation of the meetings, the teachers with high initial self-efficacy beliefs were more conservative regarding science teaching. This can be illustrated by a discussion in a subgroup between Hilde, Gerry and the principal, when they have to prepare an activity that meets design criteria that had just been formulated in the TDT. 
Hilde: we just said [in the TDT] that if the children notice that one window is covered with condensation and another not and the children ask: 'How is this possible?', that you should be able to teach a nice lesson about condensation. But THAT is difficult! You are not prepared at such a moment.

Gerry: and you need a lot of background information yourself. I need to know where I can find the information needed for that lesson, so that I know at least more than the children.

Hilde: What I could do is when I want to teach the lesson about condensation from their existing curriculum, that I can provide the conditions that raise questions with the children, so I can teach the lesson about air and condensation. Do you understand what I mean? Because it is almost impossible to teach like this.'

The result was that both Gerry and Hilde taught a lesson from their existing curriculum about bridges. This was also the only science lesson that Hilde taught during the TDT program; she reported in the questionnaire that she only taught science with the help of the textbook.

Gerry did teach another lesson from their existing curriculum in the context of the classroom observation. Furthermore, it became clear that she found it very difficult to teach without the help of the existing structured curriculum materials and using a more inquiry-based approach. For example, in meeting 5 after the activity to support the teachers with inquiry-based teaching, the external facilitator asked the teachers whether the activity could be helpful for them. Gerry responded: 'Yes, but this is not easy to get familiar with'.

For Gert, on the other hand, it seemed to be easy to teach science by inquiry. This can be illustrated by his remarks during the evaluation of his activities. In the second meeting during the evaluation of his experiences in using the first designed activity in his teaching in the classroom Gert said: I did not find it difficult to teach by inquiry. From the moment you tell the children what they need to do, it goes very naturally. And in meeting 4, Gert shared another experience about Christmas balls. He challenged the children to find alternatives for the missing hooks to hang the balls in the Christmas trees: 
Gert: it was just a small activity, but the children did like it

Annie: it is a nice activity

Gert: the children developed their own solutions

Gerry: we need to write this idea down, so that we can use it in next year's program

Gert: That is not necessary, I will have another idea next year.

\subsubsection{Valuable types of external support}

The teachers in the TDT rated the different forms of external support that the external facilitator provided in the TDT. The results can be found in Table 7.5.

Table 7.5 TDT teachers' ratings of the value of classroom observation, school visit and additional activities to support inquiry-based teaching $(-=$ not valuable,$+=$ valuable, $++=$ very valuable and $?=$ I'm not sure)

\begin{tabular}{llll} 
& $\begin{array}{l}\text { Classroom } \\
\text { observation }\end{array}$ & $\begin{array}{l}\text { School visit } \\
\text { (example) }\end{array}$ & Additional activities \\
\hline Jenny $^{*}$ & ++ & + & ++ \\
\hline Janneke* $^{*}$ & ++ & ++ & ++ \\
\hline Annie* $^{*}$ & ++ & + & ++ \\
\hline Marie $^{*}$ & & + & ++ \\
\hline Hilde $^{* *}$ & + & + & + \\
\hline Gerry** & + & & + \\
\hline Gert** & ++ & + \\
\hline
\end{tabular}

Note: *. teachers with low pre-TDT PSTE scores, ${ }^{* *}$. teachers with high pre-TDT PSTE scores.

Teachers with low pre-TDT PSTE scores rated both the classroom observations and the additional activities to support the teachers with inquiry-based teaching as more valuable (very valuable) compared to the teachers with a high pre-TDT PSTE score (valuable). Gerry was not sure whether the additional activities to support inquiry-based teaching were valuable for her. The visit to the exemplary school was rated as valuable by teachers with both low (3 teachers) and high (1 teacher) pre-TDT PSTE scores, and as very valuable also by both one teacher with a low and one teacher with a high pre-TDT PSTE score. Three out of four teachers with low pre-TDT PSTE scores reported that they used the literature regularly. One teacher with a low pre-TDT PSTE score and two teachers with a high pre-TDT PSTE score said that they used the literature only once or twice.

The overall conclusion during the focus group interview was that the team believed that they ultimately got the information they needed during the TDT program to be able to develop their own inquiry-based science curriculum. 
However, the team had the feeling that if they had had more external support at the start of the program, they could have started the design process faster and could have been further with the development of their curriculum. This can be illustrated by part of the focus group conversation:

Annie: If information exists, then I want to be taught: tell it to me and then we can go on.

Janneke: otherwise it costs so much time

The principal: and in particular the information that is independent from the school where you are going to teach science, because that is the way it is with science teaching.

Annie: I mean, the information that is fixed, give it to me.

The principal: but what we have to discuss is the implementation

And additionally, the team explained during the interview that examples of science lessons at the start of the TDT program could have helped this TDT to get more quickly to a clear view of what they wanted to achieve with science education in their school. This can be illustrated by another part of the interview:

Annie: we don't need an infinite number of examples, but you need an idea to make a start. So, that you have some options of what you can do in your classroom.

Gert: Indeed, you need 'a short lead'.

Furthermore, Gerry mentioned that she needed more knowledge about the science domain to be able to teach science subjects other than those provided by their science method. Both Gerry and Jenny had already indicated during the TDT meetings that they lacked the content knowledge to be able to teach these subjects by inquiry. Gerry said in meeting 3: 'the difficulty is, that the older children sometimes ask questions and then I think oops, I cannot give you the right answer' and Jenny said in meeting 4 during the evaluation of her lesson about rain and drops: 'The children said that the drops were sticking together, but that determined the level of the activity, because the children seemed to understand it better than myself. That felt really clumsy'. Jenny did not participate in the focus group interview. 


\subsection{Discussion AND CONCLUSIONS}

The effect of a TDT extended with external support on both the interactions in the team and on the quality of the science teaching in classroom practice was studied to gain insight in the value of different types of external support for the science teaching self-efficacy of the teachers participating in the TDT. Based on the results of our study, first our conclusions about the design of a TDT including external support with the main goal of improving science teaching self-efficacy will be described. Then some general remarks will be made about the study design, and about the STOE-scale of the STEBI-NL.

\subsubsection{The teachers}

The TDT program extended with external support proved to be especially valuable for teachers with low personal science teaching self-efficacy, that is, a PSTE score lower than 3.5 at the start of the TDT program. The PSTE scores of these four teachers increased between .5 and .9 on a 5-point Likert scale. Furthermore, in their science teaching these teachers made use of the information provided by different types of external support. The teachers with low pre-TDT PSTE scores used (1) the provided literature, (2) ideas from the methods course taken prior to the TDT, (3) the external facilitator's input during the additional activities about inquiry-based teaching, (4) the external facilitator's feedback during the presentation of lesson outlines and evaluation of the activity they had activity, or (5) the discussion after the classroom observation.

No change or even a decrease in PSTE scores was found for the teachers with high pre-TDT PSTE scores, that is, a PSTE higher than 3.5 at the start of the TDT program. In this study, it was observed that both teachers (Hilde and Gerry) whose PSTE decreased during the program were convinced at the first meeting that it was impossible to take children's questions as the starting point of a science lesson and that they needed existing structured curriculum materials to teach science well. It is known that teaching experience contributes to an increase in the extent of a teacher's practical knowledge, but at the same time also results in a decrease in variety within this knowledge, which is known as knowledge concentration (Bereiter \& Scardamalia, 1993). As a consequence, for teachers who have found what is for them a good way to teach science, it becomes very difficult to move into an area that he or she is not familiar with, such as inquiry-based teaching. It can therefore be questioned whether it is indeed necessary to force 
these teachers to change from the way they wanted to teach science. If Hilde does teach her lessons as she explained it to her principal, by providing conditions to raise the children's questions that correspond to the content of the lesson from the textbook, it might result in better science achievement for her children than if she had to take the children's spontaneous questions as the starting point for her lesson. And if Gerry is indeed not always able to answer science questions of the children, as she said in TDT meeting 3, it might be better for the science achievement of her children if she teaches science with the help of a textbook, including the background information. In any case, that is the mode of science teaching she preferred and what she felt pretty comfortable with, as represented by a PSTE score of 3.83 at the start of the TDT program. Gert's PSTE score remained just as high after participating in the TDT, probably because he experienced no challenge in science teaching and he felt no need to develop new curriculum material. Furthermore, neither Hilde, Gerry nor Gert had indicated that they had used any form of the external support for their science teaching. Based on these results, we conclude that a TDT extended with external support seems to be a good way to improve the science teaching self-efficacy of those teachers who want to improve their science teaching, which seems to be the case at least for teachers with PSTE scores lower than 3.5. In addition, the results of a former study (Velthuis et al., 2013b) showed that a TDT (without external support) might also be valuable for teachers who already have high self-efficacy, but are really willing to improve their science teaching.

\subsubsection{The design task}

Furthermore, TDTs proved to be more valuable for improving science teaching self-efficacy of primary teachers when the science curriculum they have to design and develop is not for all of the children in the school (ages 4 to 12), but only for certain age groups (ages 4-6; 6-8; 8-10 and 10-12), including the children, they themselves teach.

The first reason for our changed view about the design task and the corresponding team composition is that the collaborative development of lessons in subgroups by teachers responsible for children of about the same age $(4-6,6-8$, $8-10,10-12)$ was found to improve the team discussions during Development and Evaluation. The teachers in the TDTs in our previous studies and in the study by Handelzalts (2009) decided that they prefer to develop the materials individually instead of in collaboration, which reduces the value of a TDT because the team 
discussions about development were determined to be really valuable for increasing science teaching self-efficacy (Velthuis et al., submitted b). The teachers in the TDT in this study were developing curriculum materials in subgroups, with teachers responsible for children of about the same age. By working in subgroups, those teachers were working collaboratively and the interactions of the observed subgroup were at LISS-level 6, so very valuable for increasing science teaching self-efficacy. Furthermore, in this study it was observed that the stage of Evaluation became valuable for increasing science teaching self-efficacy when two teachers who had taught the same lesson in their classroom practice compared their experiences with their teaching of the science lessons in relation to the students' outcomes (LISS level 6).

A second reason for focusing the design task is that it was observed in this study that vicarious experiences, which are examples or experiences of others similar to oneself (Bandura, 1986), are especially valuable when they are shared by a teacher responsible for children in the same age group. For example, Marie wanted to teach the same science activities with only some small adjustments that she had observed during the classroom observations at the exemplary school. In addition, Janneke asked Jenny during the evaluation of the classroom observation to elaborate on what she did with her children during the lesson about sound, with the idea of doing the same activities with her children, who are just one year younger. And Annie mentioned in meeting 3 that she felt the need to have a clear picture in mind of how her children will react to the science lessons, which could be provided by the vicarious experiences of teachers responsible for children about the same age as her own students. Thus, vicarious experiences, especially those in which the teachers also get a better idea of how their own students should react or behave in the science lessons seems to be an important motivation for the teachers to teach this activity themselves. Teachers seem to feel more comfortable in an inquiry-based lesson when they can better estimate what they need to know to be able to answer the questions of their children.

One consequence of designing just a portion of the school science curriculum, with a smaller focus, might be that the team members are going to discuss the practical consequences of the science activities and the curriculum materials in their classrooms instead of how the activities fit the broader goals of the entire school curriculum. Considering how the curriculum materials fit the science curriculum is important for increasing teachers' understanding of both content 
and pedagogical knowledge (Loucks-Horsley, 2003). Ensuring that the TDT discusses how the designed activities or curriculum materials will fit the broader goals should therefore be an additional task for the external facilitator.

\subsubsection{Additional external support}

Additional external support for the TDT program does prove to be important if you want to increase primary teachers' science teaching self-efficacy for those teachers who need it to be increased. Valuable external support is: (1) feedback from the external facilitator on prepared and taught lessons; (2) classroom observations; (3) a visit to an exemplary school; (4) input in the form of additional activities to support teachers with the development of their curriculum; (5) providing literature. Teachers in this study reported that they appraised the classroom observations, the visit to the exemplary school and the additional activities performed by the external facilitator as valuable or even as very valuable. And four teachers used the literature regularly and three teachers used it once or twice to improve their science teaching. External support as offered to the TDT in this study resulted in more valuable interactions during Evaluation activities and/or in trying new ideas or teaching approaches in their lessons, which are both important for increasing science teaching self-efficacy. Furthermore, the TDT in this study felt the need for more external support, especially at the start of the TDT program. The team believed that if they had more standardized information about science teaching (6) and some exemplary lessons to try in their classroom so that they got a clear view of what they wanted to achieve with science in their school more quickly (7) that they could have been further with the development of their curriculum by the time the TDT ended.

An overview of the domain with corresponding core goals and the newest insights regarding science teaching might be valuable for the teachers in this team, because they finished their teacher training at least 20 years ago. An update could have made the stages of Analysis and Design more efficient. On the other hand, it can be questioned whether a summary with standardized information would also be valuable in teams with teachers who have just finished their teacher training.

In addition, the team mentioned that external support in the form of exemplary materials at the start might be valuable for the design process. George and Lubben (2002) used exemplary materials as a starting point in their study in 
which teachers had to collaboratively develop context-based curriculum materials for science. The external facilitator introduced context-based materials including hands-on experiences of some of the students' activities, and the team was subsequently invited to compare these with current materials used in the classroom. The consequence was that the ideas for science activities initially originated from the exemplary materials, but at a later point the teams were confident enough to use resources that were not provided by the external facilitator. This result indicates that providing exemplary materials at the start can indeed support teachers in getting familiar with a new way of teaching and also that teachers can subsequently develop their own lessons suited to their own school context. Thus, providing exemplary materials might very well support teachers to arrive more quickly at a clear focus regarding science teaching, which Gert called a 'short lead'. In addition, comparing exemplary materials with current materials used at the school might also result in more valuable discussions during the Analysis stage. It was observed in this study as well as in our previous studies that during Analysis the teachers were only sharing their experiences, resulting in a maximum LISS-level of 3. By comparing these experiences with the exemplary materials, the collaboration level could probably increase from exchange to discussion and thereby make the discussion during Analysis more valuable for increasing science teaching self-efficacy.

Furthermore, two out of seven teachers felt that they need more knowledge about science content to be able to answer children's questions and to teach them about a specific topic. First of all, it would be good to provide exemplary materials with the background information needed to be able to answer most of the children's questions. The teachers who need the background information can use it, and the others do not have to. Secondly, these teachers need support regarding the science content while they are developing their lessons. The external facilitator might provide the needed background information in the form of an additional activity, videos or specialists. However, it is important for the external facilitator to take into account that the support regarding science content may only be valuable for some of the teachers participating in the TDT.

\subsubsection{Limitations}

First of all, in this study we observed only minor differences between the teachers' pre-TDT scores regarding outcome expectancy; minimal changes in STOE were also seen (the maximum was an increase growth of .50 on a 5 point Likert scale). 
Therefore, the reliability of the STOE-scale of the STEBI-NL was checked. In this study, the STOE scale was found to hardly discriminate with a Cronbach's a of .68, which according to De Vellis (2003) is a tentative benchmark for the interpretation of Cronbach's a as unacceptable. In a previous study with 46 year 3 and 4 pre-service primary teachers, the reliability of the STOE-scale was found to be .74, which is respectable (Velthuis et al., submitted c). However, difficulties with the STOE-scale had already been experienced in the first version of STEBINL, which was also administered to pre-service primary teachers (Velthuis et al., submitted a). It was noticed in the first version of STEBI-NL (Velthuis et al., submitted a) that the pre-service primary teachers who are in their first year of college used the middle (neutral) response option from the 5-point Likert scale very often. It was therefore argued that first year students experienced difficulties with the STOE-scale, because they have limited teaching experience. In this study we found a major difference between the reliability of the STOE-scale from the pre-test (.18) compared to the reliability of the test administered half-way through the program (.44) and the post-test (.60), which indicated that the experienced teachers in this study also had difficulty with answering the items about outcome expectancy, mainly at the start of the TDT program but also half-way through and after the TDT program. This means that we could not draw any conclusions regarding outcome expectancy, because the teachers seemed not to be able to answer those items correctly.

Secondly, the external facilitator was also the researcher in this study. It could be that the researcher unconsciously influenced the answers of the participants. This bias is minimized by using four different instruments, with which triangulation is feasible.

And thirdly, the results are based on only one TDT. However, even though the results are based on one TDT, we have demonstrated that several kinds of external support are an added value to the TDT program, in which the teachers have to design a science curriculum, for increasing the science teaching selfefficacy for at least some of the participating teachers. In addition, we presented, based on the results of this study and our previous studies, our view about the design of a TDT program having the main goal of increasing teachers' science teaching self-efficacy.

However, additional research with more teachers in more TDTs in different schools is needed to gain more insight into which forms of external support and 
delivered when and to what kind of teachers are valuable in a TDT program having the main goal of increasing the science teaching self-efficacy of the participating teachers. 


\section{CHAPTER 8 \\ General conclusion and discussion}

This chapter discusses the findings from this investigation about effective science teacher training programms for increasing primary teachers' science teaching self-efficacy. First, the research is recapulated by describing the research aim of the investigation, the research questions and the research approach. The next section gives a brief summary of the research outcomes. Thereafter, conclusions are formulated, followed by a reflection on the research outcomes and on the research approach. This chapter ends with recommendations for research practice.

\subsection{ReCAPITUlAtion}

\subsubsection{Aims and research questions}

In the Netherlands, there is an increasing and urgent need to teach young children science, because the Netherlands is confronting a growing shortage of welleducated and highly-skilled workers in science-related fields, such as installers, electricians, and engineers (Techniekpact, 2013). In addition, children nowadays live in an age of constant scientific discoveries such as global warming, cloning, and engineered food. Children need to understand the nature of science in order to be able to participate in this world, to form opinions about these and other sciencerelated issues and to have the skills to find answers themselves. In order to ensure that more children will choose science-related studies and careers and that everyone is prepared to participate adaptively in a rapidly-changing world, something must change in the instructional program of primary schools. Primary teachers should teach science more frequently to give children a more realistic view of science (Walma van der Molen, 2008) and primary teachers should teach science more by inquiry to permit children to acquire the necessary skills and attitudes (Van Graft \& Kemmers, 2007). Teachers who are more confident about 
teaching science do more inquiry-based activities and allocate more time to the subject in their classrooms (Appleton \& Kindt, 1999; Harlen \& Holroyd, 1997; Jarvis \& Pell, 2004). The purpose of this investigation was therefore to raise teachers' confidence in their ability to teach science, i.e. science teaching selfefficacy, which was framed from the perspective of Bandura's (1977) notion of selfefficacy. Self-efficacy is defined by Bandura (1977) as one's perceived ability to perform an action that will lead towards a specific goal, and reflects both a selfassessment of one's ability to perform a specific task (in this study: personal science teaching self-efficacy) and his or her expectation that performing the task will result in the desired outcome (outcome expectancy). Based on this purpose, the main research question for this study was formulated as:

What are the characteristics of an effective science teacher training program for increasing primary teachers' science teaching self-efficacy?

Four sub-questions were derived from the main research question. The subquestions are:

(1) What factors in teacher training programs promote (or hinder) growth in teachers' science teaching self-efficacy?

(2) What is the effect of collaborative curriculum design on teachers' science teaching self-efficacy?

(3) Which design stages and which corresponding activities in a professional development program with a teacher design team promote (or hinder) growth in the teachers' science teaching self-efficacy?

(4) What kind of support do primary teachers need to improve their science teaching self-efficacy when they must collaboratively design and implement their own science curriculum?

\subsubsection{RESEARCH APPROACH}

The research approach in this investigation was inspired by both design-based research and action research. A plan for immediately improving what already occurs in the researcher's own teaching practice was based on the outcomes from an analysis of the educational problem in the context of two different teacher training universities and from the theoretical framework developed. 
Subsequently, just as in both types of research design, the main object in this investigation comprised the different stages of improvement of the intervention. The process of finding a solution was integral to the normal teacher practice of the researcher. The analyses of the different stages of the educational design were used in combination with assumptions based on a theoretical framework to improve not only the intervention but to create knowledge about the characteristics of an effective teacher training program for increasing teachers' science teaching self-efficacy as well.

First, to be able to identity design characteristics of an effective teacher training program that can increase science teaching self-efficacy and to prevent personal biases in data gathering and analysis by the researcher, an instrument was developed to assess the science teaching self-efficacy of (pre-service) primary teachers. Chapter 2 described the development of this instrument and presented the results of determining its validity and reliability for this purpose. Subsequently, six studies were carried out to answer the research questions. In the first two studies is the educational problem validated and analysed. The other four studies are analyses of three stages of the evolving teacher training program. An overview of the studies that includes the relation between teacher training programs and research questions is depicted in Figure 8.1 and was also presented in Chapter 1.

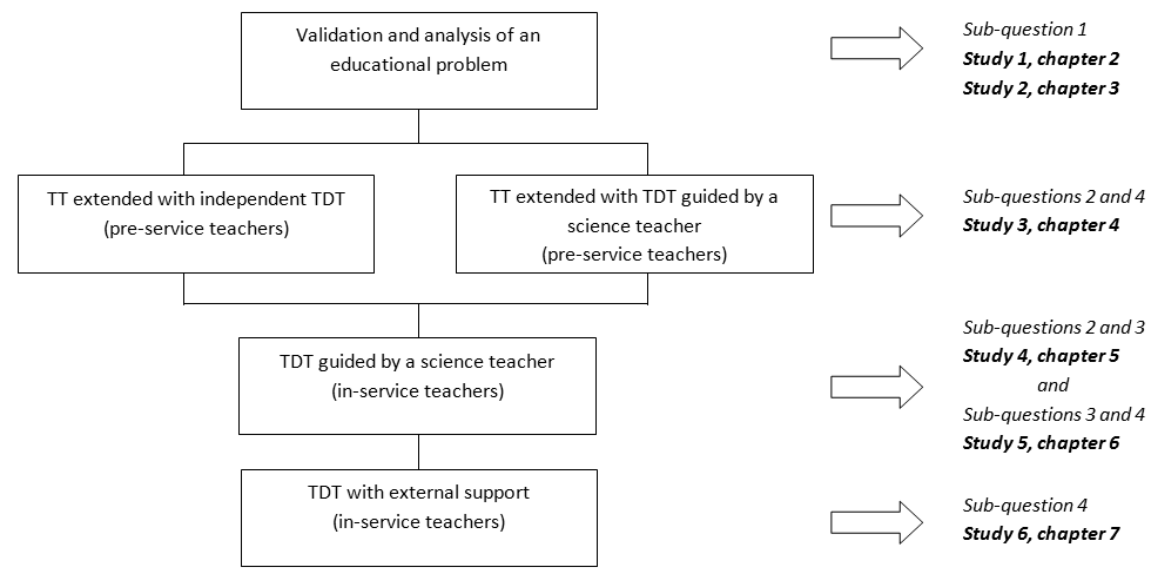

Figure 8.1 Research overview and the relation between teacher training programs (TT), research questions and the studies 
The studies are entitled as follows:

(1) Measuring science teaching self-efficacy belief, the development of the STEBINL;

(2) Teacher training and pre-service teachers' self-efficacy for science teaching;

(3) Collaborative curriculum design and the science teaching self-efficacy of preservice primary teachers;

(4) Collaborative curriculum design to increase science teaching self-efficacy;

(5) The process of collaborative curriculum design and science teaching selfefficacy;

(6) External support in collaborative curriculum design to increase the science teaching self-efficacy of pre-service teachers.

The main results from the different studies are summarized in the following subsection.

\subsection{MAIN RESUlts}

\subsubsection{Measuring science teaching self-efficacy belief, the development of the STEBI-NL}

This validation study focused on assessing the science teaching self-efficacy of pre-service primary teachers in the Netherlands. The STEBI-A (Science Teaching Efficacy Belief Instrument), an existing, commonly used instrument, based on Bandura's self-efficacy theory (Bleicher, 2004; Bursal, 2010; Riggs \& Enochs, 1990) was translated into a Dutch version, the STEBI-NL. The instrument intended to measure the self-efficacy of pre- and in-service elementary teachers with two scales: Personal Science Teaching Self-Efficacy (PSTE, self-assessment of one's ability to teach science) and Science Teaching Outcome Expectancy (STOE, teachers' expectations that their teaching can influence student learning). From the results, after a revision of the instrument, it was concluded that the STEBI-NL was a reliable instrument for measuring the PSTE of Dutch pre-service primary teachers. Therefore, the STEBI-NL was used in the follow-up studies to measure (pre-service) teachers' science teaching self-efficacy. 


\subsubsection{Teacher training and pre-service teachers' self-efficacy for science teaching}

The purpose of this second study was to answer sub-question 1: What factors in teacher training programs promote (or hinder) growth in teachers' science teaching selfefficacy? The programs at two different teacher training universities were compared on science teaching self-efficacy scores of a cross-sectional sample across four different years of study. The STEBI-NL was complemented with additional questions about self-rated subject matter knowledge (SMK) and the frequency of science teaching to determine the relation between science teaching self-efficacy and each of these factors, self-rated knowledge and frequency of science teaching experiences.

The results show that improving the level of self-rated SMK seems to be linked with increasing science teaching self-efficacy, especially when teachers believe that they have insufficient SMK to teach science. The second factor observed to influence science teaching self-efficacy in this study was the frequency of practicing science teaching in the primary school. Moreover, the results suggested that initial teaching experiences were more valuable for increasing science teaching self-efficacy than later, regular science teaching experiences. Furthermore, at the end of year one, pre-service teachers at teacher training university B, who took a science content course assessed with a theoretical test in the first year of their teacher training, had significant higher levels of science teaching self-efficacy compared to pre-service teachers at teacher training university A who took a science method course assessed by a practical assignment. However, at the end of the second year, in which pre-service teachers at both universities took method courses, there was no longer any difference between the scores of the pre-service teachers from the two different universities for PSTE and for self-rated knowledge. This result indicates that pre-service teachers might perceive themselves to be learning SMK not only in science content courses, but also in the methods courses.

Another relevant finding was that from the third year of study on, science teaching self-efficacy was no longer observed to increase, despite the fact that the pre-service teachers become more experienced with science teaching. The courses in the minor program seemed not to have an impact on science teaching selfefficacy. It was argued that the courses in the minor stage might prevent an 'implementation dip' in self-efficacy as teachers begin to implement their training 
in relation to a change initiative. Implementation of an educational change in the primary school practice seems to be a hindering factor for increasing pre-service teachers' science teaching self-efficacy.

\subsubsection{Collaborative curriculum design and the science teaching self-efficacy of pre-service primary teachers}

The major aim of study 3 was to study the effect of collaborative curriculum design on the science teaching self-efficacy of pre-service teachers (sub-question 2). The findings of the second study and a theoretical framework that was developed for this study suggested that a plain linear implementation of an educational change might be a hindering factor for increasing science teaching self-efficacy, and therefore the minor program of one of the teacher training universities was extended with teacher design teams (TDTs). In this study, the experiences of two different cohorts of pre-service teachers in the minor program (the third and fourth years of their program of study) with two different versions of a TDT were analyzed. The collaborative curriculum design by the TDTs in the first cohort was guided only by a paper process guide, which means that the goals and activities belonging to the different ADDIE design stages of Analysis, Design, Development, Implementation and Evaluation (Dick \& Carey, 1996) were planned per meeting. The TDTs in the second cohort were supported by a science teacher expert who guided the design process, asked critical questions, provided ideas and was able to answer questions regarding content and process. By comparing the two different versions of TDTs, this study contributes to answering sub-question 4: What kind of support do primary teachers need to improve their science teaching self-efficacy when they must collaboratively design and implement their own science curriculum?

The results of this study indicate that both PSTE and STOE can be significantly improved during the third and fourth years of teacher training by a minor program extended with TDTs. In addition, the minor program extended with the TDT approach resulted in a significant increase in levels of self-rated knowledge in the technology domain.

\subsubsection{Collaborative curriculum design to increase science teaching self-efficacy}

The fourth study aimed to answer sub-question 2: What is the effect of collaborative curriculum design on teachers' science teaching self-efficacy? It also provided additional information for answering sub-question 1: What factors in teacher training programs promote (or hinder) growth in teachers' science teaching self-efficacy? The purpose of this 
case-study was to gain in-depth information about the value of a TDT for increasing the science teaching self-efficacy of primary teachers who differed in years of teaching experience and interest in science. The school's principal and an external facilitator who led discussions and provided resources also participated. The teachers' task was to redesign their own curriculum. The results indicate that professional development through a TDT is a way to improve science teaching selfefficacy for experienced teachers and pre-service teachers and for teachers with both high and low interest in science, and it proved to be important to attend to some preconditions associated with the specific target group (sub-question 2). Administrative support seems to be a promoting factor for improving the STOE of teachers with high self-efficacy (sub-question 1). The provision of coaching and assistance with the implementation of the educational change in the real classroom situation seems to be a promoting factor for increasing pre-service teachers' science teaching self-efficacy. In addition, the different teachers in the team considered other elements of the TDT program as important for increasing their science teaching self-efficacy (sub-question 1). For less interested and/or less experienced teachers, the TDT program resulted in successes in the classroom that the teachers perceived to be most valuable for increasing their science teaching self-efficacy. For the more experienced teacher, the challenge in the program was to convince team members of the importance of science education. The elements that teachers considered to be important for their science teaching self-efficacy, as well as the type of knowledge to which they believed that the TDT contributed, seem to be related to what, according to themselves, they had learned in order to improve their science curriculum. The results indicated that the teachers in the TDT were able to set their own learning path regarding SMK, pedagogical content knowledge (PCK) and knowledge about curriculum design.

\subsubsection{The process of collaborative curriculum design and the science teaching self-efficacy}

The fifth study focused on answering sub-question 3: Which design stages and which corresponding activities in a professional development program with a teacher design team promote (or hinder) growth in the teachers' science teaching self-efficacy?

Team discussions during the design process of two TDTs were observed in detail to determine the design stages and activities that promote or hinder an increase in science teaching self-efficacy, and to further extend our knowledge about collaborative curriculum design as a way to improve teachers' science teaching 
self-efficacy. Observations of the level of collaboration and the instructional relevance, when combined, provide important information about the effectiveness of the team discussion during the process of curriculum design for improving science teaching self-efficacy. The observation instrument determined the LISSlevel (Likelihood for Increasing Science teaching Self-efficacy) of the team discussions (Figure 8.2).
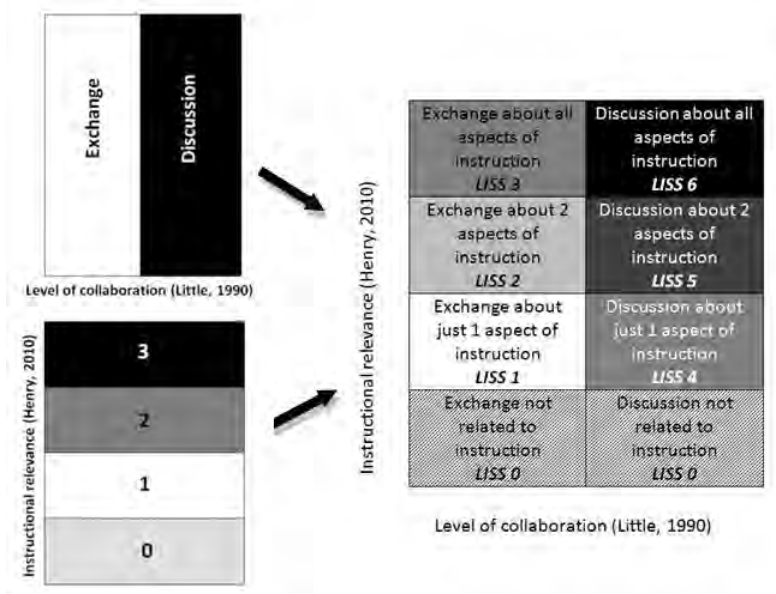

Figure 8.2 'Level of collaboration' and 'Instructional relevance' are combined to determine the interaction's Likelihood to Increase Science teaching Self-efficacy (LISS level)

Outcomes revealed that the most valuable interactions for increasing science teaching self-efficacy took place during the design and the development of curriculum materials. For TDT 1 the most valuable activity was the design activity, formulating design criteria for their own design, while for TDT 2 the most valuable activity was another design activity, the making of an overview of their science project. The stage of implementation was considered to be less valuable for increasing science teaching self-efficacy, because most of the time the discussions during implementation activities in both teams were about organizational matters and not about science teaching. The stages of analysis and evaluation were also less valuable for increasing self-efficacy in this study. During analysis and evaluation the teachers were just exchanging their experiences with science teaching instead of discussing those experiences more in depth, which was considered to be important for increasing science teaching self-efficacy. In addition, in the context of sub-question 4: What kind of support do primary teachers need to improve their science teaching self-efficacy when they must collaboratively design 
and implement their own science curriculum?, in this study both the influence of the principal on the design process and the influence of participating in a TDT on science teaching experiences were observed. It was demonstrated that it is very important for the principal to have a clear view about science education that he can communicate to his school team. Along with this, it proved to be important for the principal to provide administrative support in order to ensure that the TDT spent as little time as possible on organizational matters.

Furthermore, it was seen that not all teachers automatically felt the need to teach the lessons that they prepared in the TDT. Only one or two teachers in a team felt the need to pilot the constructed materials. Additionally, some teachers indicated that they experienced difficulties with teaching science. To ensure that teaching experiences will become mastery experiences, it was concluded that at least some teachers in a TDT may need additional support regarding their science teaching.

\subsubsection{External support in collaborative curriculum design to increase the science teaching self-efficacy of primary teachers}

The sixth study aimed to answer sub-question 4: What kind of support do primary teachers need to improve their science teaching self-efficacy when they must collaboratively design and implement their own science curriculum? In this study, a model was developed to describe the major processes within a TDT in relation to self-efficacy (Figure 8.3).

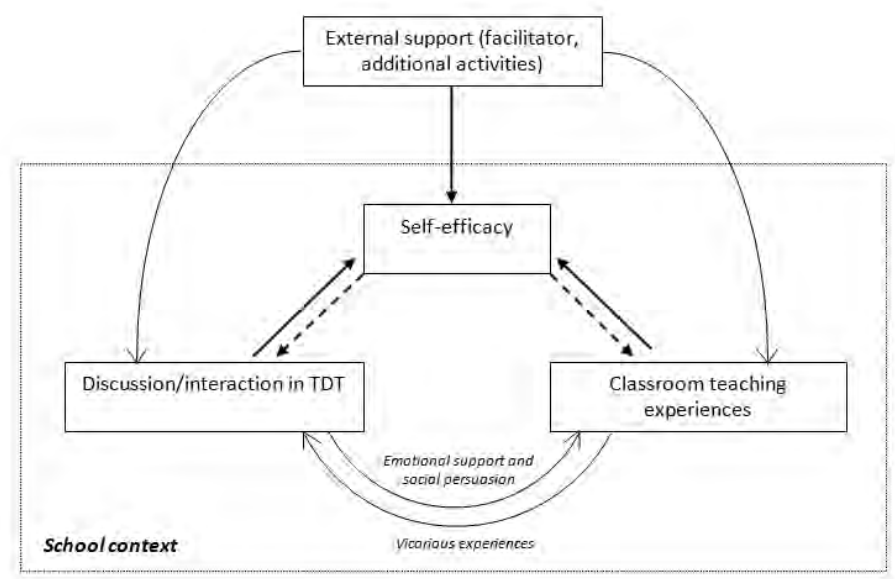

Figure 8.3 The processes in a TDT including external support, in relation to the science teaching self-efficacy of teachers in the team 
The model shows three important components of TDTs in relation to self-efficacy: interaction in the TDT, mastery experiences and external support. In this study, the TDT program and subsequently the model as well, were extended with external support. The TDT in this case-study consisted of 8 teachers, the school principal and the science teacher as an external facilitator who guided the team regarding the curriculum design process and provided additional external support. The principal participated in the team to provide the team with a clear focus and administrative support.

The results show that external support was an added value for increasing the science teaching self-efficacy of teachers with an initially low science teaching selfefficacy. The teachers with low pre-TDT PSTE scores made use of at least one of the five different forms of external support provided by the external facilitator during their science teaching. The teachers with high pre-TDT PSTE scores did not use external support for their science teaching. Based on these results, and the fact that the self-efficacy of the teachers with high pre-TDT PSTE scores did not increase, it was concluded that TDT extended with external support were especially valuable for teachers willing to improve their science teaching. On the other hand, benefits from external support for all teachers in this TDT were (1) more valuable interactions during evaluation and (2) science teaching by all participating teachers. Furthermore, the teachers in the TDT in this study felt the need for more external support, especially at the start of the TDT, in the form of (1) standardized information about science teaching and (2) exemplary lessons they could try in their lessons so that they more quickly got a clearer view of what they wanted to achieve with science teaching in their school. Thirdly, it was observed that teachers felt more comfortable in science teaching when they can better estimate how their children should react or behave in the science lesson. It was argued that it might be better to focus the design task for the TDT on the design of a science curriculum for just a subset of the children (ages 4-6; 6-8; 8-10 and 10-12). Focusing the design task is expected to result in more valuable vicarious experiences and in deeper discussions during presentations of lesson outlines and evaluation of taught lessons. And finally, some teachers need additional support regarding science content to be able to answer children's questions and to teach them about a specific topic.

Furthermore, it appeared that our target group, primary teachers, had too little experience in the field of science education to be able to properly estimate what the 
influence of science teaching is on children's' learning. The consequence was that we were not able to draw any conclusions regarding outcome expectancy in this study.

\subsection{OVERALL CONCLUSION}

The main research question that guided this investigation will be answered in this section: What are the characteristics of an effective science teacher training program for increasing primary teachers' science teaching self-efficacy?

\subsubsection{The new approach: TDTs extended with external support for increasing self-efficacy}

Based on the findings from the studies in this investigation, in this section a proposal for a teacher training program, TDTs extended with external support with as main goal increasing science teaching self-efficacy, will be described to answer the main research question in detail. To ensure that all curriculum components are taken into account in our design, a model that was previously used in this investigation to visualize the science program in the primary schools is applied: the curriculum spider web (Van den Akker, 2003). The spider web model, as shown in Figure 8.4, is a way to visualize the relationship between the various components of the curriculum and it expresses the vulnerability of the internal consistency of the curriculum.

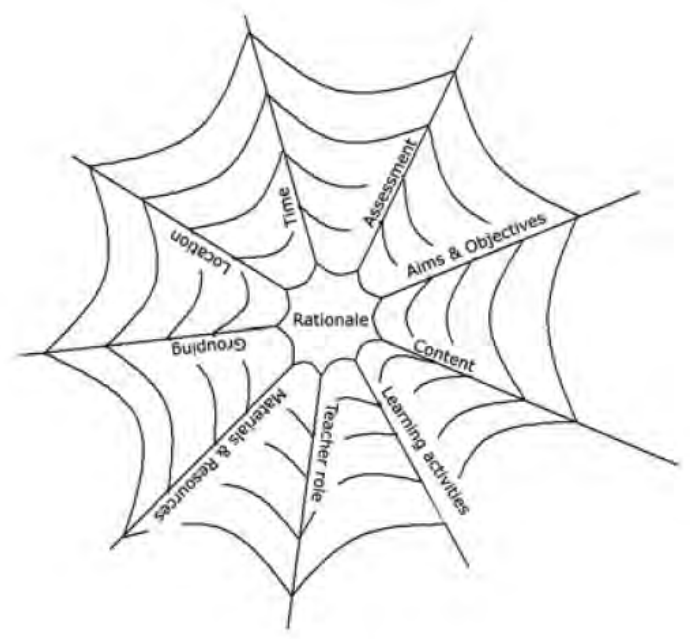

Figure 8.4 Curriculum spider web (Van den Akker, 2003) 
At the hub of the model is the rationale, which connects all of the other components: (1) aims and objectives, (2) content, (3) learning activities, (4) teacher role, (5) materials and resources, (6) grouping, (7) location, (8) time and (9) assessment. The spider web metaphor emphasizes the need for internal consistency across components. Efforts in curriculum design must therefore devote attention to balance and to linkages between the components. In Figure 8.5 an overview is given of the curriculum spider web as completed with the curriculum components related to the teacher training program designed in this research: a TDT program extended with external support for increasing selfefficacy. Because a spider web is able to stretch and still maintain its structure, some curriculum components can have more emphasis than others in new curriculum design as long as the curriculum itself is in balance. Differences in the degree of emphasis on the different curriculum components in the teacher training program is depicted in the Figure by the width of the lines connecting the rationale and the relevant curriculum components. The various curriculum components are described in more detail in the next sections.

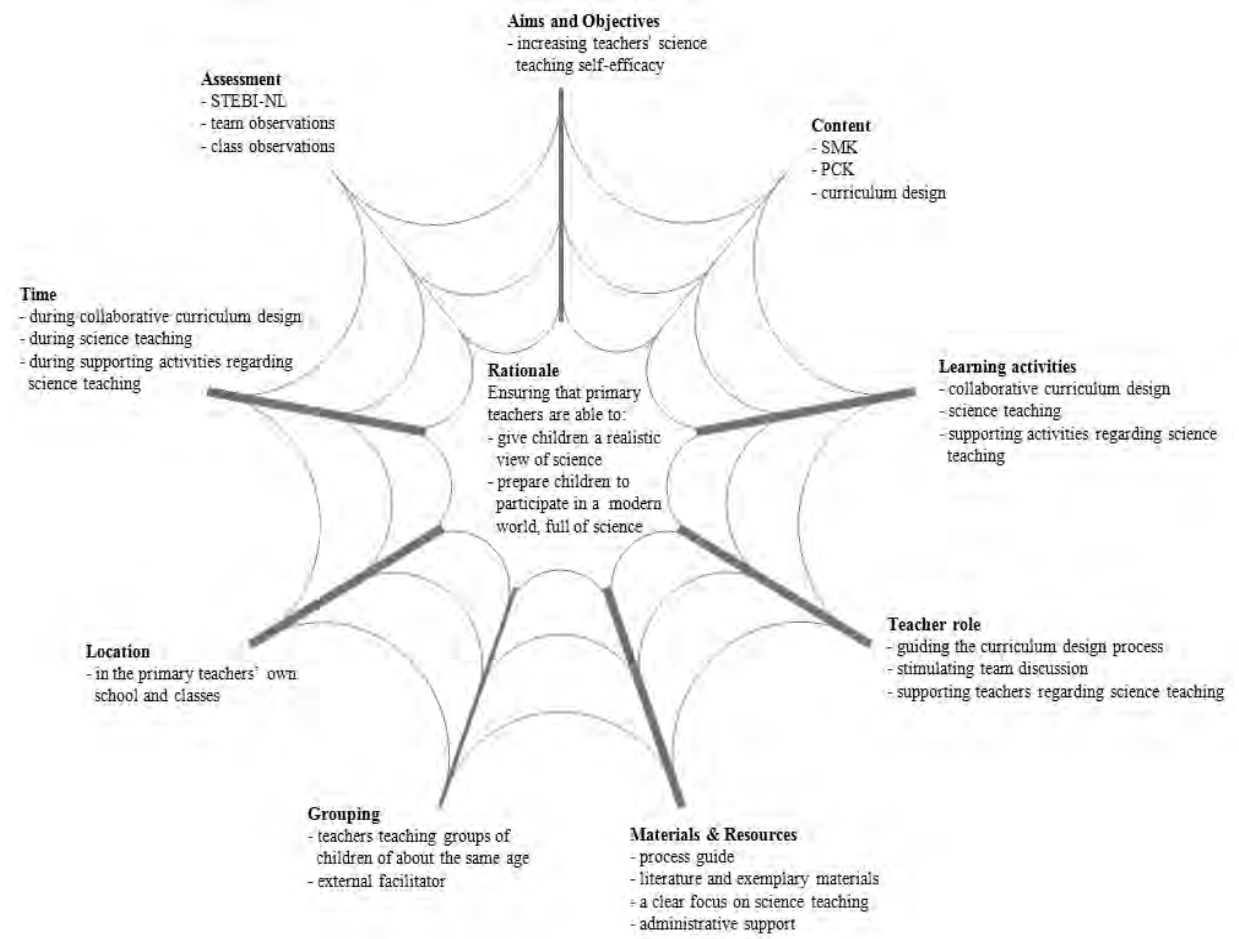

Figure 8.5 The proposed new approach to a science teacher training program for increasing science teaching self-efficacy as represented in Van den Akker's curriculum spider web (2003) 
The rationale of the teacher training program designed in this investigation is: Ensuring that primary teachers are able to give children a realistic view of science and to prepare children to participate in a fast-changing world full of science.

\section{Aims and objectives}

To achieve the goals making up the rationale for this training program, additional time should be found by the teachers in the overloaded curriculum in the primary school and primary teachers should teach more by inquiry and rely less on textbooks and other structured materials. Studies investigating the effect of science teaching self-efficacy on the way teachers teach science show that improving science teaching self-efficacy results in more science teaching and more teaching of science by inquiry (Appleton \& Kindt, 1999; Harlen \& Holroyd, 1997; Jarvis \& Pell, 2004). In addition, teachers with a high sense of self-efficacy will set higher goals for themselves, are less afraid of failure, and will find new strategies when old ones fail (Bandura, 1977; Tschannen-Moran \& Hoy, 2007). Self-efficacy is commonly understood as domain- and context-specific; because the rationale of the teacher training relates to the field of science teaching, the main aim of the training program proposed as a result of this investigation is increasing primary inservice teachers' science teaching self-efficacy.

\section{Content}

The acquisition of subject matter knowledge (knowledge about living nature, nonliving nature and technology), pedagogical content knowledge and knowledge about curriculum design was observed in this investigation (studies 2 and 4) to improve science teaching self-efficacy (main aim). It was observed that teachers were able to set their own learning path regarding SMK, PCK and knowledge about curriculum design by designing their own curriculum collaboratively in a TDT (study 4). Therefore, the curriculum component content is less emphasized in the proposed teacher training program in comparison to the curriculum component learning activities.

\section{Learning activities}

Collaborative curriculum design in their own school, teaching of science in their own classrooms and additional activities supporting science teaching are important learning activities in a teacher training program having the main goal of increasing the science teaching self-efficacy of teachers. 
In the second study, it was observed that collaborative curriculum design resulted in significant increases in PSTE and STOE scores of pre-service teachers during the third and fourth years of teacher training. The TDTs were performing activities belonging to the different ADDIE design stages (Dick \& Carey, 1996) during the team meetings. In the fourth and fifth studies, the stage of analysis was found not to be valuable for increasing science teaching self-efficacy, because the teachers were just sharing their experiences instead of analyzing those experiences more deeply. In the final study, it was argued that the stage of analysis could be improved by including an introduction by the external facilitator, with an update with standardized information about science teaching (teacher role) and exemplary lessons which the teachers can try in their classrooms (materials and resources) so that they get a clear view of what they want to achieve with science in their school more efficiently.

The team discussions during design and development activities were observed to be especially important for increasing science teaching self-efficacy. Thus, it seems to be important for increasing teachers' science teacher self-efficacy to spend most of the time in the TDT meeting on the design and the development of a science curriculum within their own primary teaching practice (location).

The stage of implementation is important to ensure that the science curriculum is implemented successfully in the primary teachers' teaching practice, but as little time as possible should be spent on implementation, because these discussions were most often about organizational matters instead of science teaching. A clear focus regarding science teaching, communicated by the principal and with corresponding administrative support was found to be very important in both studies four and five for the efficiency of the stage of implementation in the TDT program (materials and resources).

Feedback from the external facilitator (teacher role) was observed to be necessary for the stage of evaluation to be valuable for increasing science teaching selfefficacy (study 6).

Besides collaborative curriculum design, both the second and the fourth studies revealed the importance of teaching experiences for increasing science teaching selfefficacy. In the proposed teacher training program, therefore, the teachers should be prompted to teach science in their own classroom as frequently as possible (teacher role, time and location). 
And third, the outcomes of the final study showed that additional activities supporting science teaching had added value in particular for increasing the science teaching selfefficacy of teachers with a low pre-PSTE score. The additional activities provided by the external facilitator included input about aspects of science teaching that are in line with the needs of the TDT, classroom observation and a visit to an exemplary school that also matched the focus of their own school regarding science teaching (teacher role, materials and resources). Without additional support, some teachers did not teach science or experienced difficulties instead of successes with science teaching (study 5). To ensure that every teacher teaches science successfully, these additional activities must be a component of the proposed teacher training program.

The insights discussed in the previous section were used to support the design of a TDT program extended with external support for increasing science teaching self-efficacy ; a summary of the features of this proposed program is presented in Table 8.1.

Table 8.1 A summary of the TDT program

\begin{tabular}{|c|c|c|}
\hline & \multicolumn{2}{|c|}{ Teaching of exemplary lessons in their own classroom } \\
\hline \multirow[t]{4}{*}{1} & Input & $\begin{array}{l}\text { Receiving an update with standardized information about science } \\
\text { teaching (external facilitator) and a clear focus by the principal } \\
\text { regarding science education in their own school. }\end{array}$ \\
\hline & Analysis & $\begin{array}{l}\text { Brainstorming about the subject and the subject in the school } \\
\text { curriculum }\end{array}$ \\
\hline & Design/development & $\begin{array}{l}\text { Developing a science activity that suits their view on science } \\
\text { education as much as possible }\end{array}$ \\
\hline & Evaluation & Presenting lesson outlines in the TDT \\
\hline Objectives: & \multicolumn{2}{|c|}{$\begin{array}{l}\text { Broadly speaking, it is clear what the 'new' science curriculum should look like } \\
\text { A science activity that can be taught in their classroom is prepared by all teachers }\end{array}$} \\
\hline \multirow[t]{4}{*}{2} & Evaluation & Evaluation of activities taught in practice \\
\hline & Design & Formulating criteria for their own design \\
\hline & Development & $\begin{array}{l}\text { Developing a second science activity that suits the criteria as much } \\
\text { as possible }\end{array}$ \\
\hline & Evaluation & Presenting lesson outlines in the TDT \\
\hline \multirow[t]{2}{*}{ Objectives } & \multicolumn{2}{|c|}{ A start is made by formulating criteria } \\
\hline & \multicolumn{2}{|c|}{ A science activity that can be taught in their classroom is prepared by all teachers } \\
\hline \multirow[t]{4}{*}{3} & Evaluation & Evaluation of activities taught in the classroom \\
\hline & Input & $\begin{array}{l}\text { Receiving input about science teaching in line with the needs of the } \\
\text { TDT }\end{array}$ \\
\hline & \multirow[t]{2}{*}{ Design } & $\begin{array}{l}\text { Answering Tyler's questions (Tyler, 1949): (1) What are the } \\
\text { purposes of the school? (2) What educational experiences are } \\
\text { related to those purposes? (3) What are the organizational methods } \\
\text { which will be used in relation to those purposes? (4) How will those } \\
\text { purposes be evaluated? }\end{array}$ \\
\hline & & $\begin{array}{l}\text { Formulating criteria for their own design, as a continuation of } \\
\text { meeting } 2\end{array}$ \\
\hline Objectives & \multicolumn{2}{|c|}{$\begin{array}{l}\text { Criteria are formulated } \\
\text { A clear focus is formulated by the team }\end{array}$} \\
\hline
\end{tabular}


Table 8.1 A summary of the TDT program (Continued)

\begin{tabular}{|c|c|c|}
\hline \multirow[t]{5}{*}{4} & Development & $\begin{array}{l}\text { Research on existing materials, which can be used and which need } \\
\text { to be adjusted }\end{array}$ \\
\hline & Design & $\begin{array}{l}\text { Making an overview of activities in the curriculum/project: what } \\
\text { activities already fulfil the criteria and what activities need to be } \\
\text { developed/adjusted for a full science curriculum or science project }\end{array}$ \\
\hline & Implementation & Setting priorities and making a plan (now, this year, later) \\
\hline & Development & Making of a prototype \\
\hline & Implementation & The organization of activities \\
\hline \multirow[t]{2}{*}{ Objectives } & \multicolumn{2}{|c|}{$\begin{array}{l}\text { An overview is created of activities that have to be developed/adjusted with a corresponding plan } \\
\text { A 'prototype' is made and can be taught in their classroom }\end{array}$} \\
\hline & \multicolumn{2}{|c|}{ Classroom observations } \\
\hline \multirow[t]{5}{*}{5} & Evaluation & $\begin{array}{l}\text { Evaluation of classroom observations and the prototypes taught in } \\
\text { practice: answering the question: what do we want to learn at the } \\
\text { exemplary school? }\end{array}$ \\
\hline & Input & $\begin{array}{l}\text { Receiving input about science teaching in line with the needs of the } \\
\text { TDT }\end{array}$ \\
\hline & Design & If necessary: making adjustments in the design \\
\hline & $\begin{array}{l}\text { Development/ } \\
\text { implementation }\end{array}$ & Developing and organizing activities \\
\hline & Evaluation & Presenting lesson outlines in the TDT \\
\hline Objectives & \multicolumn{2}{|c|}{ Science activities are developed in collaboration } \\
\hline 6 & \multicolumn{2}{|c|}{ Visiting an exemplary school } \\
\hline \multirow[t]{6}{*}{7 en 8} & Evaluation & $\begin{array}{l}\text { Evaluation of the lessons observed at the exemplary school and of } \\
\text { activities taught in practice. }\end{array}$ \\
\hline & Input/Design & $\begin{array}{l}\text { If necessary, receiving input about science teaching and making } \\
\text { adjustments in the design }\end{array}$ \\
\hline & Development & Developing activities \\
\hline & Implementation & Organizing activities \\
\hline & Evaluation & $\begin{array}{l}\text { Presenting lesson outlines / evaluations of activities taught in } \\
\text { practice }\end{array}$ \\
\hline & Implementation & $\begin{array}{l}\text { Making an implementation plan: what must be done next year to } \\
\text { ensure that all teachers are aware of the decisions made regarding } \\
\text { science teaching? }\end{array}$ \\
\hline Objectives & \multicolumn{2}{|c|}{$\begin{array}{l}\text { The science curriculum is completed with activities that achieves the formulated criteria } \\
\text { An implementation plan is made }\end{array}$} \\
\hline
\end{tabular}

In conclusion, collaborative curriculum design, science teaching and supporting activities regarding science teaching are important means to increase the science teaching self-efficacy of teachers and thereby to goals making up the rationale for the proposed teacher training program. The curriculum component learning activities is therefore connected with a thicker line with the rationale in Figure 8.5. On the other hand, because of its strength, care must be taken that it stays in balance with the other curriculum components, especially time and materials and resources. Teachers need time and materials and resources to execute the learning activities. If there is no time or if there are no materials, teachers cannot perform learning activities and their self-efficacy will not be increased. 


\section{Teacher role}

The teacher in this study, who was called the external facilitator, was observed to have some important tasks related to increasing science teaching self-efficacy with the help of a TDT. First of all, the outcomes of the third study revealed that the external facilitator, who was guiding TDTs with curriculum design and stimulating team discussion, was an added value for increasing science teaching self-efficacy. In addition, the final study showed that feedback from the external facilitator, especially during evaluation activities, resulted in deeper discussions about science teaching. Feedback on lesson outlines and taught lessons needs to be provided by the external facilitator. Furthermore, in the sixth study it appeared that the support provided regarding science teaching by the external facilitator was an added value for increasing teachers' science teaching self-efficacy. External support must be provided by (1) presenting literature and exemplary materials, including a visit to an exemplary school, and (2) input regarding science teaching as an introduction and in line with the needs of the TDT. The external facilitator should therefore be an expert regarding science teaching and curriculum design.

The curriculum component teacher role is considered to be important for achieving the goals making up the rationale for the proposed teacher training program, because the external facilitator can make the learning activities more efficient for increasing self-efficacy by providing materials and resources, among other things.

\section{Materials and resources}

First of all, teachers' science teaching self-efficacy was increased by collaborative curriculum design that was supported only by a process guide, a document that provides goals and activities. Collaborative curriculum design becomes even more valuable when the team is additionally guided by an external facilitator (study 3). Secondly, in the sixth study all teachers reported that they used the literature provided by the external facilitator for science teaching and rated exemplary materials (from the exemplary school) as valuable or very valuable for their science teaching self-efficacy. Based on this finding, it can be concluded that supporting literature and exemplary materials need to be provided in a TDT. Finally, it was observed that it is necessary for the principal to communicate $a$ clear focus regarding science teaching and provides administrative support for the teachers in TDTs. Without administrative support, teachers become discouraged and blame external factors, such as lack of materials (Ramey-Gassert, Shroyer, Staver, 1996). The curriculum component materials and resources is therefore considered to be an important curriculum component in the proposed TDT program for teacher training. 


\section{Grouping}

From the sixth study, it was concluded that teachers felt more comfortable in science teaching when they could better estimate how children should react or behave in the science lesson, and therefore it is argued that a TDT is especially valuable for two to three teachers within one school teaching children of about the same age (4-6, 6-8, 8-10, 10-12). Vicarious experiences, which are examples or experiences of others, similar to oneself: 'if they can do it, I can do, too', will also be more valuable for increasing science teaching self-efficacy in those groups of more comparable teachers. Vicarious experiences are already known to be a major source of self-efficacy (Bandura, 1997). Moreover, the TDTs extended with external support for increasing self-efficacy seemed to be especially valuable for teachers who wanted to improve their science teaching (study 4 and 6). Secondly, it was observed that it is an added value when the principal can provide the team with a clear focus regarding science teaching and administrative support (study 5). On the other hand, the teachers in the team believed that the principal had no added value in the team. Thirdly, the external facilitator has an added value as an active team member, which is explained in more depth in the section on teacher role.

In conclusion, the curriculum component grouping was considered to be less important in the presented curriculum design. A group made up of more comparable teachers can make the TDT program extended with external support more efficient in increasing science teaching self-efficacy, but it is more important that teachers are designing their own curriculum collaboratively, that they are supported regarding science teaching (learning activities) and that they experience a clear focus regarding science teaching in combination with administrative support (materials and resources).

\section{Location}

The power of a TDT seems to lie in its developing directly in the context of the primary school and in the teachers' classroom, because this mode of teacher training directly takes contextual issues into account when the team is implementing an educational change. And because implementation of an educational change seemed to be a hindering factor for increasing science teaching self-efficacy (studies 2 and 3), the location of the TDTs extended with external support for increasing self-efficacy has to be teachers' own primary school and classrooms. The location is therefore emphasized in Figure 8.5. 
Time

The science teaching self-efficacy of the teachers in the team increased primarily during the team discussion in the TDT meetings (study 5) and during science teaching itself (studies 2 and 4). In addition, the teachers with low pre-PSTE scores in particular used the additional supporting activities to improve their science teaching (study 6). It is important that teachers have time to spend on these activities, because teachers become too discouraged to go on when they do not have enough time to improve their science teaching (Ramey-Gassert et al., 1996). In this investigation the entire design process was planned to take eight meetings of approximately two hours each, spread over an academic year.

\section{Assessment}

First of all, the influence of TDTs extended with external support on self-efficacy can be measured with the STEBI-NL, which was developed as the first step in this investigation (study 1). The STEBI-NL is intended to measure both PSTE and STOE. Furthermore, observations of team interactions and classroom observations can both be used to determine whether the teachers are changing their science teaching. The main advantage of classroom observations is that they allow direct determination of whether the TDT program contributes to more frequent teaching of science and teaching science more by inquiry, i.e., the goals making up our rationale: 'primary teachers are able to give children a realistic view on science and prepare children to participate in a world full of science'. If this is the case, it can also be concluded that all curriculum components in the proposed TDT program extended with external support for increasing self-efficacy are in balance. However, in this investigation, the classroom observations were performed in order to support the teachers with science teaching and not to assess them (study 6). To effectively reach the goals making up the rationale and its related objectives, teachers need to teach science frequently and also to teach science more by inquiry. It is therefore more important to support the teachers in the first place than to assess them.

In conclusion, the principal outcome of this research is a proposed teacher training program, TDTs extended with external support. The program is designed as a solution for increasing in-service teachers' science teaching self-efficacy. Collaborative curriculum design in their own school, science teaching in their own classes and supporting activities regarding science teaching should be the main learning activities in such a teacher training program. Furthermore, the external facilitator is essential for increasing science teaching self-efficacy and has to be able 
to guide the curriculum design process, to stimulate team discussions and to support teachers regarding science teaching. And thirdly, it is necessary that the teachers have administrative support. Without administrative support, teachers become discouraged and blame external factors, such as lack of materials or time (Ramey-Gassert et al.,1996).

\subsection{REFLECTION ON THE RESEARCH OUTCOMES}

The research approach in this research was inspired by both design-based research and action research. Its aim was twofold: developing solutions to improve teachers' educational practice as well as producing knowledge about factors that affect the intervention and the design process. In the previous section, the optimal solution for increasing teachers' science teaching self-efficacy that emerged from this investigation was described and presented as TDTs extended with external support for increasing self-efficacy. In this section the aim of our contribution to gain deeper insight into how teacher training programs influence teachers' science teaching self-efficacy beliefs will be described and reflected upon, based on the five major outcomes of this investigation. These outcomes are: (1) the development of the STEBI-NL, an instrument that can measure the science teaching self-efficacy of (pre-service) teachers, and new insights into the STOE scale; (2) the development of an observation instrument to determine the value of team discussions for increasing science teaching self-efficacy; (3) insights into factors in teacher training programs in general that promote or hinder growth in science teaching self-efficacy, (4) the value of the TDT program for teachers in relation to their science teaching self-efficacy, and (5) insights into the processes of TDT in relation to science teaching self-efficacy.

\subsubsection{The STEBI-NL}

An instrument was developed (study 1) to measure the science teaching selfefficacy of teachers to be able to determine the effect of different teacher training programs quantitatively. As a secondary result, new insights were gathered in this investigation regarding the STOE-scale of the STEBI-NL.

In the sixth study, the difference in the reliability of the STOE-scale between the pre- and the post-test indicated that the teachers in this study experienced 
difficulties with answering the items about outcome expectancy, mainly at the start of the TDT program, but also half-way and after the TDT program. Our target group, primary teachers, seemed to have too little experience in the field of science education to be able to properly estimate the influence of science teaching on children's learning, or the outcome expectancy. This result is in line with a study by Hechter (2011), in which he explained the difference in growth for PSTE and STOE for pre-service teachers by referring to pre-service teachers' lack of context for judgement of STOE because of limited classroom experience. This new insight into the STOE-scale suggests that teachers need to have a certain amount of science teaching experience before their expectations about the influence of science teaching on student learning can be effectively measured. This means that the STOE-scale of the STEBI cannot be used as an adequate measure of outcome expectancy for teachers who do not regularly teach science and thus lack classroom experiences for judging the outcomes of science teaching.

\subsubsection{The observation instrument}

An observation instrument was developed in this research to be able to conduct an in-depth investigation of the design stages and the activities within these stages that improved the science teaching self-efficacy beliefs of teachers in the TDTs. In TDTs, professional interactions or team discussions are considered to be an important means for increasing science teaching self-efficacy. The observation instrument determines the Likelihood for Increasing Science teaching Self-efficacy (LISS-level) of team discussions by observing both the level of collaboration and the instructional relevance of the discussions (see Chapters 6 and 7). With the help of this observation instrument, it was possible to determine stages of curriculum design that promoted or hindered growth in science teaching self-efficacy (Chapter 6). And additionally, by using this instrument, it was possible to observe changes in the value of teacher interactions or LISS-levels during the different curriculum design stages because of a more active role by the external facilitator (Chapter 7). More research on the observation instrument is needed, because it is yet not clear whether LISS level 4, discussion about one aspect of learning, is better than LISS level 3, sharing of experiences about science teaching (three aspects of learning), for increasing science teaching self-efficacy. In this investigation, a switch in the levels of LISS 3 and 4 will not influence our main result, but it could be that the contribution of some curriculum design activities in the TDTs are a little underestimated and others a little overestimated. 


\subsubsection{Factors in teacher training programs}

Subject matter knowledge (SMK)

The first assumption in this investigation was that self-rated SMK levels are related to science teaching self-efficacy. Study 2 showed a significant difference in PSTE between pre-service teachers with self-rated insufficient knowledge and those with sufficient knowledge, and this difference was greater than that between teachers with self-rated sufficient knowledge and those with good knowledge. This result suggests that improving SMK could be especially valuable when teachers believe that they have insufficient knowledge to teach science. This suggestion is confirmed by study 6 (Chapter 7), in which only two out of seven teachers indicated that they need additional support regarding SMK. When teachers believe that they already have sufficient knowledge to teach science, a content course might be less efficient for raising self-efficacy. This variation in PSTE differences related to self-rated SMK levels of pre-service teachers corresponds with several findings from the literature. Schoon and Boone (1998) and Watters and Ginns (2000), for instance, showed that increasing SMK resulted in a small effect on self-efficacy. On the other hand, both Rohaan et al. (2012) and Yilmaz-Tuzun (2008) showed the importance of SMK for increasing science teaching self-efficacy. Furthermore, the results in study 2 (Chapter 3) also indicate that pre-service teachers might perceive themselves to be learning SMK in method courses. Altogether, the results of this dissertation suggest that it is very important to provide background knowledge for teachers, which they can use when they are learning about science teaching and when they have to teach science. This might increase their sense of being capable of answering children's questions regarding the specific subject.

\section{Teaching experiences}

The second assumption was that teaching experiences were important for increasing science teaching self-efficacy. This assumption was confirmed in each sub-study. Teaching experiences are related to higher PSTE scores (study 2). Moreover, the results suggested that science teaching self-efficacy was increased mostly by the pre-service teachers' initial teaching experiences. Science teaching self-efficacy might continue to increase by teaching more science lessons; however, the effect seems to be less impressive. It seems that the experiences become more 'normal' and become less effective for increasing science teaching self-efficacy. Challenging pre-service teachers to try new teaching strategies or to teach subjects they feel less comfortable with was suggested to be important for 
continued growth in self-efficacy, as long as this results in successful experiences. This was confirmed in our final study, in which science teaching self-efficacy increased most for the teachers who made use of external support and changed their way of science teaching. Challenging teachers and telling them that they can meet the challenge along with encouraging them to try those activities is in line with Bandura's (1997) third source of self-efficacy, social persuasion. In our study this is argued to be an added value for teaching experiences regarding growth in science teaching self-efficacy.

\section{Implementation}

Another finding was that from the third year of study on, increase in science teaching self-efficacy was no longer observed, despite the fact that the pre-service teachers became more experienced with science teaching. The courses in the minor program seem to have no impact on increasing pre-service teachers' science teaching self-efficacy, although the courses might prevent an 'implementation dip' in self-efficacy. Several researchers have found an 'implementation dip' in selfefficacy as teachers begin to implement their training in relation to a change initiative (Mosely et al., 2002; Ross, McKeiver \& Hogaboam-Gray, 1997). Implementation of an educational change in primary school practice proved to be a hindering factor for increasing the science teaching self-efficacy of pre-service teachers in studies 2 (Chapter 3 ) and 3 (Chapter 4). The science program in years 3 and 4 (minor program) was therefore extended with TDTs. Extending participation in the minor program with TDTs, in which pre-service teachers collaboratively designed a science project directly in the context of a primary school as means to support implementation of a renewed science program, resulted in a significant increase in science teaching self-efficacy during years 3 and 4 .

In addition, in the fifth study it was argued that implementation of an educational change could also be hindering for in-service teachers. TDTs were found to spend a lot of time on implementation and mainly discussed organizational matters in the teams. They felt there was no support from the principal for implementation, no clear focus on science teaching, and no administrative support such as time to share results or to ask school team members outside of the TDT to test a prototype. Discussing organizational matters meant that these discussions were not about science teaching itself and were thus considered to be hindering as far as increasing science teaching self-efficacy directly. On the other hand, it is also known that successful implementation of a science program itself is very important to ensure success in the classrooms, which in turn is important for increasing self-efficacy 
(Bandura, 1997; Tschannen-Moran \& Woolfolk Hoy, 2007). It was therefore argued that a principal who supports the implementation of science education in the primary school is promoting teachers' science teaching self-efficacy.

\subsubsection{The value of TDTs for increasing in-service teachers' science teaching self-efficacy}

Before starting this investigation, only indirect indications were available that collaborative curriculum design in TDTs could be valuable for increasing science teaching self-efficacy. Professional development was known to increase teachers' self-efficacy in general (Cantrell et al., 2003; Settlage, 2000) and the importance of coaching and assistance during implementation of an educational change for teachers' self-efficacy was demonstrated by Tschannen-Moran \& McMaster (2009). Because both professional development and supporting the implementation by designing curriculum materials directly in the teachers' classroom practice were expected effects of a TDT (Handelzalts, 2009; Voogt, Westbroek, Handelzalts, Walraven, McKenney, Pieters, \& de Vries, 2011), TDTs could also be valuable for increasing science teaching self-efficacy.

Based on the results of the final study (Chapter 7), it was concluded that a TDT extended with external support seems to be a good way to improve science teaching self-efficacy for teachers who want to improve their science teaching. In addition, the results of the fifth study (Chapter 6) indicated that TDTs without external support were also valuable for teachers with high self-efficacy, but the TDTs without external support were considered to be less valuable for some teachers, because not all teachers felt the need to automatically teach the science lessons that they prepared in collaboration. Furthermore, some teachers experienced difficulties with their science teaching due to not having successful experiences. In the third study mastery experiences were determined to be important for increasing selfefficacy, which was in line with Bandura (1997), and thus external support was seen to be necessary for at least some of the teachers in the TDT to achieve mastery experiences as result of collaborative curriculum design.

\subsubsection{Insights into the processes of a TDT in relation to science teaching self- efficacy}

A model was developed in this investigation (see Figure 8.3) to describe processes within a TDT in relation to the self-efficacy of the teachers in the TDT. Given the complex nature of the professional development program designed in this study, 
which considered several components related to science teaching self-efficacy, it was important to understand the contribution of each component of the professional development program to the teachers' science teaching self-efficacy. This model was useful for conducting an in-depth investigation of the influence of external support on the different components of the TDT process that were valuable for increasing science teaching self-efficacy. In addition, because the model considered design characteristics of effective TDTs, the model can be helpful for designing TDT programs in other contexts. Overall, team discussions, mastery experiences, vicarious experiences, emotional support in combination with social persuasion and external support all contributed to the science teaching self-efficacy of teachers participating in the TDT program extended with external support.

\subsection{REFLECTION ON THE RESEARCH APPROACH}

It was demonstrated that effective characteristics of both approaches, designbased research and action research, could be optimally applied in an integrated manner to achieve intended outcomes. Both have similar goals of developing effective learning environments from the perspective of both teacher and learner (McNiff \& Whitehead, 2010; Van den Akker, Gravemeijer, McKenney, \& Nieveen, 2006). However, design-based research and action research differ on terms of immediate improvement of teacher's own educational practice and in their emphasis on producing scientific design knowledge of factors that affect the intervention and its design process. In this study, a combination of the strengths of both approaches is applied in order to tackle the research and design problem effectively and to answer the research questions adequately.

As expected, being both a teacher and a researcher resulted in deeper understanding of the context and the research problem which provided additional insights that helped to adequately analyse the research problem. The implication was that the developed TDT program with external support for increasing inservice teachers' science teaching self-efficacy had practical relevance from the start. In addition, being a teacher and researcher made it possible to effectively adjust the ongoing teacher training program and to seamlessly integrate data collection activities within the teacher training programs. This process of overlapping roles, activities and responsibilities made the teacher training programs that were designed ecologically valid, relevant and usable. 
On the other hand, it is known that because of the researcher double role, action research is often perceived as being inappropriate for producing models with high external validity or as lacking statistical generalizability (Van der Zee, 2010). However, the combination with design based research as used in this investigation contributed to external validity and generalizability. External validity with regard to gaining insight into underlying causes of low science teaching self-efficacy was addressed in the first study, by studying the most important factors more broadly in a more experimental design with a total of 292 pre-service teachers from two different universities, and by the other studies as well, in which analysis was a necessary condition in the design cycle, before the actual development of the intervention took place. In addition, participation in a TDT was shown to have reliable (statistically significant) value for increasing science teaching self-efficacy in the other studies, with pre-service and in-service teachers as well. By using findings from those studies and from available theory, it was possible to design a teacher training program for increasing science teaching self-efficacy for teachers and propose generalized practices that, once empirically verified, lead to theories to explain the underlying causes of what is observed.

Furthermore, it is known that a researcher's overlapping roles may hinder valid and reliable research by introducing personal biases into the data gathering and analysis. In this investigation, care was taken not to compromise internal validity and reliability by using a range of data gathering techniques and data sources, each of which illuminate a different aspect of the same issue, which is also called triangulation. Along with the range of qualitative methods, measuring perceptions and experiences, quantitative data were collected, in order to minimize personal bias. These quantitative data were derived from the questionnaire measuring science teaching self-efficacy, the STEBI-NL, and the observation instrument and were used to analyse the effects of the different teacher training programs on science teaching self-efficacy.

\subsection{RECOMMENDATIONS FOR TEACHER TRAINERS}

TDTs extended with external support proved to be a good way to improve the science teaching self-efficacy of pre-service primary teachers. In addition, TDTs extended with external support also seemed to be a good way to improve the science teaching self-efficacy of in-service primary teachers with low personal 
science teaching self-efficacy or those with high personal science teaching selfefficacy who are really willing to improve science education. A proposed TDT program extended with external support for increasing science teaching selfefficacy was designed and presented in Table 8.1. One initial recommendation for teacher trainers is to use this teacher training program to increase in-service teachers' science teachings self-efficacy. In addition, some more general recommendations will be provided in this section.

First, primary teachers need additional support regarding PCK and curricular knowledge, and for some teachers it might be necessary to increase their SMK for them to be able to implement the science lessons in their own curriculum. Therefore, it is very important that the knowledge that is provided by the external facilitator or science teacher matches the needs of the teachers in the team and that it is provided just in time, so that teachers are able to translate theory directly into their teaching practice.

Second, coaching and assisting with the implementation of an educational change in science education is an important means of increasing science teaching selfefficacy. When teachers experience implementation difficulties, it could be expected that teachers will give up, especially teachers with low self-efficacy beliefs, and will avoid science teaching, as shown by several studies (Bandura, 1977; Tschannen-Moran \& Woolfolk Hoy, 2007).

Furthermore, for teachers' science teaching self-efficacy it is very important that teachers do believe that they have sufficient SMK to be able to answer children's questions regarding the subject of their science lessons. Vicarious experiences, which are examples or experiences of others, similar to oneself (Bandura, 1997), are therefore especially valuable when such experiences take into account the three aspects of teaching, teachers, content and children, and when they come from teachers teaching children of about the same age. Thus, the exchange of vicarious experiences has to be an important aspect in teacher training programs. Along with the vicarious experiences, it is even more important for increasing science teaching self-efficacy that teachers teach science themselves, in order to have what Bandura (1997) calls mastery experiences. Moreover, for an additional increase in science teaching self-efficacy it is valuable to challenge teachers to try new teaching strategies or to teach subjects they feel less comfortable with, as long as these teaching activities result in successful experiences. It is important that 
teachers are supported, not only by an external facilitator but also by their principal, who may provide a clear focus on science teaching, allocating enough time in the curriculum, and providing available curricular and teaching materials, in line with the teacher training program.

\subsection{RECOMMENDATIONS REGARDING FOLLOW-UP STUDY}

This investigation explored the elementary design characteristics of an effective teacher training program and the impact of TDTs in order to increase science teaching self-efficacy. Overall, the findings show that the professional development program developed in this investigation has promising results regarding science teaching self-efficacy. However, more remains to be done in the following areas.

First of all, in our final study it was argued that an overview of the science domain with corresponding core goals and the newest insights regarding science teaching might be valuable for increasing science teaching self-efficacy by participating in a TDT. Providing exemplary materials might support teachers in getting a clear focus regarding science teaching more quickly, and comparing exemplary materials with current materials used in the school might also result in more valuable discussions during the stage of analysis. Therefore, it is suggested that an additional study be conducted to assess the value of providing exemplary materials at the start of the TDT program for increasing science teaching self-efficacy.

Secondly, the focus in this study was on increasing teachers' science teaching selfefficacy as a means to improve science education and thereby to ensure that children have a realistic view of science and become scientifically literate. Besides self-efficacy, observing the team meetings led to the conclusion that participating in a TDT does indeed influence how science is taught and the frequency of science teaching. However, no attention was paid to the long-term effects of teacher participation in TDTs directly in the classroom situation, and thus to the long-term quality and frequency of science teaching. It is suggested that the effects in the classroom situation be studied not only immediately after teachers participate in the TDT, but also in the longer term. It would be interesting for future longitudinal research to investigate whether teachers with high science teaching self-efficacy continue to sustainably improve their science teaching without the help of a TDT. 
Thirdly, the aim of this investigation was to study the design characteristics of effective teacher training programs, and especially TDTs, in depth. The value of action research was that the researcher gained an in-depth understanding of the context and the research problem by acting through different roles, as teacher and researcher, and this aided in solving the research problem. This deepened understanding provided additional insights that helped to adequately analyse the research problem. However, it is suggested that the value of TDTs for increasing primary in-service teachers' science teaching self-efficacy in general be studied on a broader scale. Therefore, more TDTs in different primary schools using the same TDT program supported by different external facilitators should be analysed with the same instruments to generate results with high external validity.

The STEBI-NL and the observation instrument developed in the research presented in this investigation could be used for this scaled-up study, but first more research is needed on both instruments. The STEBI-NL measures the selfefficacy of teachers with two scales: Personal Science Teaching Self-efficacy (PSTE, self-assessment of one's ability to teach science) and Science Teaching Outcome Expectancy (STOE, teachers' expectations that teaching can influence student learning). Measuring the PSTE of Dutch pre-service teachers and in-service teachers presented no problems in this study; thus, a valuable instrument for measuring the PSTE of Dutch teachers is available. Measuring STOE was more problematic. The results of the final study indicate that the in-service teachers experienced difficulties in answering the items about outcome expectancy, which could explain the low reliability of the instrument. Before scaling up the research on TDTs as a means for increasing science teaching self-efficacy, the problems with the STOE scale of the STEBI-NL should be solved or another instrument should be used to measure outcome expectancy.

The observation instrument developed in this study is intended to determine the value of the design stages and corresponding activities for increasing teachers' science teaching self-efficacy. By observing the instructional relevance and the level of collaboration during team discussion, the LISS levels (Likelihood for Increasing Science teaching Self-efficacy) can be determined, which provides information about the value of these interactions for increasing the science teaching self-efficacy of the teachers. More research on the observation instrument is needed. It is known that both a high level of collaboration and exploring relations among all three aspects of learning (teachers, content and students) in 
teams contribute to teachers' self-efficacy. This means that discussion about all three aspects should contribute most to self-efficacy and that exchange about only one aspect of learning should contribute least to self-efficacy. However, it is not yet clear whether LISS level 4, discussion about one aspect of learning, is better or worse than LISS level 3, sharing of experiences about science teaching (three aspects of learning) for increasing the teachers' science teaching self-efficacy. The consequence is that the value of some activities may be slightly underestimated or overestimated; however, before the instrument is used in a scaled-up study with more TDTs, it should be clear whether discussions on LISS level 4 are better than those on LISS 3 or the other way around. Therefore, it could be helpful first to observe the effects of the discussions on LISS 3 and 4 on the science teaching of the teachers more closely. 


\section{REFERENCES}

Agyei, D., \& Voogt, J. (2012). Developing technological pedagogical content knowledge in pre-service mathematics teachers, through Teacher Design Teams, Australiasian Journal of Educational Technology, 28, 547-564.

Alayyar, G., Fisser, P., \& Voogt, J. (2011). ICT integration through design teams in science teacher preparation. International Journal of Learning Technology, 6, 125-145.

Alayyar, G.M. (2011). Developing pre-service teacher competencies for ICT integration through design teams. Doctoral dissertation. Enschede: Universiteit Twente.

Andersen, A.M., Dragsted, S., Evans, R.H. \& Sørensen, H. (2003). Transforming the standard instrument for assessing science teacher's self-efficacy beliefs (STEBI) for use in Denmark. In Psillos, D. et al. (Eds.), Science education research in the knowledge-based society (pp. 395403). Dordrecht/Boston/London: Kluwer Academic Publishers.

Appleton, K., \& Kindt, I. (1999). Why teach primary science? Influences on beginning teachers' practices. International Journal of Science Education, 21(2), 155-169.

Appleton, K. (2008). Developing science pedagogical content knowledge through mentoring primary teachers. Journal of Science Teacher Education 19(6), 523-545.

Ashton, P. T., \& Webb, R. B. (1986). Making a difference: Teachers' sense of efficacy and student achievement. New York: Longman.

Bandura, A. (1977). Self-efficacy: Toward a unifying theory of behavioral change. Psychological Review, 84(2), 191-215.

Bandura, A. (1986). Social foundations of thought and action: A social cognitive theory. Upper Saddle River, NJ: Prentice Hall.

Bandura, A. (1994). Self-efficacy. In V.S. Ramachaudran (Ed.), Encyclopedia of human behavior (Vol. 4, pp. 71-81). New York: Academic Press. (Reprinted in H. Friedman [Ed.], Encyclopedia of mental health. San Diego: Academic Press, 1998).

Bandura, A. (1997). Self-efficacy: The exercise of control. New York: Freeman.

Baram-Tsabaria, A., \& Yardena, A. (2008). Girls' biology, boys' physics: evidence from freechoice science learning settings. Research in Science \& Technological Education, 26(1), 75 - 92.

Behling, O., \& Law, K. S. (2000). Translating questionnaires and other research instruments: Problems and solutions. Thousand Oaks, CA: Sage Publications.

Bereiter, C., \& Scardamalia, M. (1993). Surpassing ourselves: An inquiry into the nature and implications of expertise. Chicago: Open Court.

Bleicher, R. (2004). Revisiting the STEBI-B: Measuring self-efficacy in preservice primary teachers. School Science and Mathematics, 104(8), 383-391. 
Bleicher, R. E., \& Lindgren, J. (2005). Success in science learning and preservice science teaching self-efficacy. Journal of Science Teacher Education, 16(3), 205-225.

Bleicher, R. (2007). Nurturing confidence in preservice primary science. Journal of Science Teacher Education , 18(6), 841-860.

Bowling, A. (1997). Measuring Health; a Review of Quality of Life Measurement Scales (2nd ed.). Medicine, Health Care and Philosophy 1(2), 181-182.

Brickman, P., Gormally, C., Armstrong, N., \& Hallar, B. (2009). Effects of inquiry-based learning on students' science literacy skills and confidence. International Journal for the Scholarship of Teaching and Learning, 3(2). Retrieved from http://academics.georgiasouthern.edu/ijsotl/v3n2.html

Buccheria, G., Abt Grbera, N., \& Brhwilera, C. (2011). The impact of gender on interest in science topics and the choice of scientific and technical vocations. International Journal of Science Education, 33(1), 159-178.

Bursal, M. (2010). Turkish preservice elementary teachers' self-efficacy beliefs regarding mathematics and science teaching. International Journal of Science and Mathematics Education, 8(4), 649-66

Cantrell, P., Young, S., \& Moore, A. (2003). Factors affecting science teaching efficacy of preservice elementary teachers. Journal of Science Teaching Education, 14(3), 177-192.

Christol, P., \& Adams, E. (2006). Using the STEBI-B to Determine the Impacts of a StandardsDriven Course on Pre-service Students' Sense of Personal and Teaching Efficacy in Science Education. Proceedings of the 1996 International Meeting of the Association for the Education of Teachers in Science. Columbus, OH: ERIC Clearinghouse for Science Mathematics and Environmental Education.

Coenders, F., Terlouw, C., Dijkstra, S., \& Pieters, J. (2010). The effects of the design and development of a chemistry curriculum reform on teachers' professional growth: a case study. Journal of Science Teacher Education, 21(5), 535-557.

Cohen, D., \& Ball, D. (1999). Instruction, capacity, and improvement. CPRE Research Report Series, RR-43. University of Pennsylvania: Consortium for Policy Research in Education.

Cohen, J. (1960). A coefficient of agreement for nominal scales. Educational and Psychological Measurement, 20, 37-46.

Colgoni, A., \& Eyles, C. (2010). A new approach to science education for the 21st century. EDUCAUSE Review. 45(1), 10-11.

Czemiak, C. M., \& Schriver, M. L. (1994). An examination of preservice science teachers' beliefs and behaviors as related to self-efficacy. Journal of Science Teacher Education, 5(3), 77-86.

Davis, E. A., Petish, D., \& Smithey, J. (2006). Challenges new science teachers face. Review of Educational Research, 76, 607-651.

De Vellis, R. F. (2003). Scale development: theory and applications. London: Sage.

Dick, W., \& Carey, L. (1996). The systematic design of instruction, (4th ed.). New York: HarperCollins College Publishers.

Donovan, M. S., \& Bransford, J. (2005). How students learn: History, mathematics, and science in the classroom. Washington, DC: National Academies Press. 
Driel, J.H. van, Beijaard, D., \& Verloop, N. (2001). Professional development and reform in science education: The role of teachers' practical knowledge. Journal of Research in Science Teaching, 38(2), 137-158.

Duschl, R. A., Schweingruber, H. A., \& Shouse, A. W. (Eds.). (2007). Taking science to school: Learning and teaching science in grades K-8. Washington, DC: National Academies Press.

Enochs, L., \& Riggs, I. (1990). Further development of an elementary science teaching efficacy instrument: A preservice elementary scale. School Science and Mathematics, 90(8), 694-706.

Enochs, L., Smith, P.L., \& Humker, D. (2000). Establishing factorial validity of the mathematics teaching efficacy beliefs instrument. School Science and Mathematics, 100(4), 194-202.

Ergul, R., Simsekli, Y., Calis, S., Ozdilek, Z., Gocmencelebi, S., \& Sanli, M. (2011).The effects of inquiry-based science teaching on elementary school students' science process skills and science attitudes. Bulgarian Journal of Science and Education Policy, 5(1), 48-68.

Fisser, F. ( 2009). Natuurlijk nieuwsgierig, kinderen als onderzoekende ontwerpers [Naturally curious, children as investigative designers]. Hengelo: Hogeschool Edith Stein.

Fisser, P., Ormel, B., \& Velthuis, C. (2010, June). Natuur en techniek in het basisonderwijs: hoe bekwaam voelen de leerkrachten zich? [Science in the primary school: what is the science teaching self-efficacy of teachers?] . Paper presented during the Onderwijs Research Dagen, 23-25 juni 2010. Enschede.

Fullan. M. (1991). The New Meaning of Educational Change. New York; Teachers' College Press.

George, J. M., \& Lubben, F.(2002). Facilitating teachers' professional growth through their involvement in creating context-based materials in science. International Journal of Educational Development, 22, 659-672.

Green, S. B., \& Salkind, N. J. (2008). Using SPSS for Window and Macintosh: Analyzing and understanding data (5th ed.). Upper Saddle River, NJ: Pearson Prentice Hall.

Greven, J. \& Letschert, J. (Eds.) (2006). Kerndoelenboekje [Booklet of standards]. Den Haag: Ministry of Education, Culture, and Science (OCW).

Hackman, J. R. (1987). The design of work teams. In J. W. Lorsch (Ed.), Handbook of organizational behavior (pp. 315-342). Englewood Cliffs, NJ: Prentice-Hall.

Handelzalts, A. (2009). Collaborative curriculum development in teacher design teams. Doctoral dissertation. Enschede: Universiteit Twente.

Harlen, W. \& Holroyd, C. (1997). Primary teachers' understanding of concepts of science: impact on confidence and teaching. International Journal of Science Education, 19(1), 93-105.

Harris, A. (2003). Behind the classroom door: The challenge of organisational and pedagogical change. Journal of Educational Change, 4, 369-382.

Hechter, R.P. (2011). Changes in preservice elementary teachers' personal science teaching efficacy and science teaching outcome expectancies: the influence of context. Journal of Science Teacher Education, 22, 187-202.

Henry, S. (2010, April/May). Talk that talk, a qualitative exploration of relevance and depth in elementary teachers' team conversations. Paper presented at the American Educational Research Association Annual Conference, Denver.

Jack, B., Clarke, A.M. (1998) The value of quantitative research in nursing. Professional Nurse 13(1), 753-756. 
Jarvis, T., \& Pell, T. (2004). Primary teachers' changing attitudes and cognition during a two year science in-service programme and their effect on pupils. International Journal of Science Education, 26(14), 1787-1811.

Kerger, S., Martin, R. and Brunner, M. (2011). How can we enhance girls' interest in scientific topics?. British Journal of Educational Psychology, doi: 10.1111/j.2044-8279.2011.02019.x

Kotter, J. (2007). Leading change: Why transformation efforts fail. Harvard Business Review, 85, 96-103.

Loucks-Horsley, S. (2003). Curriculum development and adaptation. In S. Loucks-Horsley, Designing professional development for teachers of science and mathematics (pp. 79-85). Thousand Oaks, CA: Corwin Press.

Little, J. (1990). The persistence of privacy: Autonomy and initiative in teachers' professional relations. Teachers College Record, 91, 509-536.

Martin, M. O., Mullis, I. V. S., \& Foy, P. (2008). TIMSS 2007 International Science Report. Findings from IEA's Trends in International Mathematics and Science Study at the Fourth and Eighth Grade. Boston: Boston College, TIMSS \& PIRLS International Study Center.

Martin, M. O., Mullis, I. V. S., Foy, P., \& Stanco, G. M. (2012). TIMSS 2011 International Results in Science. Chestnut Hill, MA: Boston College, TIMSS \& PIRLS International Study Center.

Mavrikaki, E. \& Athanassiou, K. (2011). Development and application of an instrument to measure Greek in-service primary education teachers' Biology Teaching Self-efficacy Beliefs (BioTSEB). EURASIA journal of mathematics, science \& technology education, 7(3), 149160.

Meelissen, M., \& Drent, M. (2008). TIMSS-2007 Nederland: Leerprestaties in exacte vakken in het basisonderwijs [TIMSS-2007 the Netherlands: Science learning in primary schools]. Enschede: University of Twente.

Meirink, J. A., Imants, J., Meijer, P. C., \& Verloop, N. (2010). Teacher learning and collaboration in innovative teams. Cambridge Journal of Education, 40, 161-181.

McNiff, J., \& Whitehead, J. (2010). You and your action research project (3rd ed.). Abingdon: Routledge.

McKenney, S., Nieveen, N., \& Van den Akker, J. (2006). Design research from the curriculum perspective. In J. van de Akker, K. Gravemeijer, S. McKenney, \& N. Nieveen (Eds.), Educational design research, (pp. 67-90). London: Routledge.

McKenney, S. \& Reeves, T. (2012). Conducting educational design research: what, why \& how. London: Routledge.

Miles, M. B., \& Huberman, A. M. (1984). Qualitative data analysis: A sourcebook of new methods. Beverly Hills, CA: SAGE Publications Inc.

Mintzes, J. J., Marcum, B., Messerschmidt-Yates, C., \& Mark, A. (2012). Enhancing self-efficacy in elementary science teaching with professional learning communities. Journal of Science Teacher Education, 6, 1-18.

Moore, J. J., \& Watson, S. B. (1999). Contributors to the decision of elementary education majors to choose science as an academic concentration. Journal of Elementary Science Education, 11(1), 37-46. 
Moseley, C., Reinke, K., \& Bookout, V. (2002). The effect of teaching outdoor environmental education on preservice teachers' attitudes toward self-efficacy and outcome expectancy. The Journal of Environmental Education, 34(1), 9-15.

National Science Resources Center (1997). Science for all children: A guide to improving elementary science education in your school district. Washington, DC: The National Academy Press.

Nussbaum, J. \&Novick, S. (1982). Alternative framworks, conceptual conflict and accommodation: Toward a principled teaching strategy. Instructional Science, 11, 183-200

OECD.(2007). PISA 2006: Science Competencies for Tomorrow's World. Paris, France: OECD.

Osborne, J., \& Dillon, J. (2008). Science education in Europe: Critical reflections (a report to the Nuffield Foundation). London: the Nuffield Foundation.

Pajares, F. (1997). Current Directions in Self-efficacy Research. In: M. Maehr \& P. R. Pintrich (Eds.). Advances in motivation and achievement. (Vol. 10, pp. 1-49). Greenwich, CT: JAI Press.

Palmer, D. H. (2006). Sources of self-efficacy in a science methods course for primary teacher education students. Research in Science Education, 36(4), 337-353.

Parchman, I., Gräsel, C., Baer, A., Nentwig, P., Demuth, R., \& Ralle, B. (2006). 'Chemie im Kontext': A symbiotic implementation of a context-based teaching and learning approach. International Journal of Science Education, 28(9), 1041-1062.

Platform Bèta Techniek (2008). Facts \& Figures 2008. The Hague: Platform Bèta Techniek.

Platform Bèta Techniek (2009). Science and Technology Agenda 2011-2016, Continue to invest in the future of the Netherlands [Bètatechniek Agenda 2011-2016, Blijven investeren in de toekomst van Nederland]. The Hague: Platform Bèta Techniek.

Platform Bèta Techniek. (2010). Technomonitor 2010. The Hague: Platform Bèta Techniek.

Poole, M. G. \& Okeafor, K. R. (1989). The effects of teacher efficacy and interactions among educators on curriculum implementation. Journal of Curriculum and Supervision, 4, 146-161.

Ramey-Gassert, L., \& Shroyer, M. G. (1992). Enhancing science teaching self-efficacy in preservice elementary teachers. Journal of Elementary Science Education. 1(4), 26-34.

Ramey-Gassert, L., Shroyer, M., \& Straver, J. (1996). A qualitative study of factors influencing science teaching self-efficacy of primary level teachers. Science Education, 80(3), 283-315.

Reason, P., \& Bradbury, H. (Eds.) (2001). Handbook of action research. Participative inquiry and practice (1st ed.). London: Sage.

Riggs, I. M., \& Enochs, L. G. (1990). Toward the development of a primary teacher's science teaching efficacy belief instrument. Science Education, 74(6), 625-637.

Rimm-Kaufman, S. E. \& Sawyer, B. E. (2004). Primary-grade teachers' self-efficacy beliefs, attitudes toward teaching, and dicipline and teaching practice priorities in relation to the responsive classroom approach. The Elementary School Journal, 104, 321-341.

Ritter, J.M., Boone, W.J., \& Rubba, P.A. (2002). Extension of the self-efficacy beliefs about equitable science teaching and learning instruments to include learning support and gifted and talented students. Paper presented at the annual meeting of the Association for the Education of Teachers in Science, Charlotte, NC.

Rock, T. C., \& Wilson, C. (2005). Improving teaching through lesson study. Teacher Education Quarterly, 32(1), 77-92. 
Rohaan, E., Taconis, R., \& Jochems, W. (2012). Analysing teacher knowledge for technology education in primary schools. International Journal of Technology and Design Education, 22(3), 271-280.

Rommes, E., Van Gorp, B., Delwel, M., \& Emons, P. (2010). Nut, Noodzaak of Nerds?, Veranderende beelden over bètatechniek in de Nederlandse media en samenleving tussen 1989 2009. [Benefits, essential or just geeky - changing images of science and technology in the Dutch media and society 1989 - 2009]. Den Haag: Stichting Platform Beta Techniek.

Ross, J. A. \& Bruce, C. D. (2007). Professional development effects on teacher efficacy: Results of a randomized field trial. Journal of Educational Research, 101, 50-60.

Ross, J. A., McKeiver, S., \& Hogaboam-Gray, A. (1997). Fluctuations in teacher efficacy during implementation of destreaming. Canadian Journal of Education, 22, 283-296.

Rubeck, M.E., \& Enochs, E.G. (1991). A path analytical model of variables that influence science and chemistry teaching self-efficacy and outcome expectancy in middle school science teachers. Paper presented at the annual meeting of the National Association for Research in Science Teaching, Fontana, WI.

Savran Gencer, A., \& Cakiroglu, J. (2007). Turkish preservice science teachers' efficacy beliefs regarding science teaching and their beliefs about classroom management. Teaching and Teacher Education, 23(5), p 664-675.

Scharmann, L. C., \& Orth Hampton, C. M. (1995). Cooperative learning and preservice primary teacher science self-efficacy. Journal of Science Teacher Education, 6, 125-133.

Schoon, K. J., \& Boone, W. J. (1998). Self-efficacy and alternative conceptions of science of preservice elementary teachers. Science Education, 82(5), 553-568.

Settlage, J. (2000). Understanding the learning cycle: Influences on abilities to embrace the approach by preservice elementary school teachers. Science Teacher Education, 84(1), 43-50.

Shulman, L. (1986). Those who understand: Knowledge growth in teaching. Educational Researcher, 15 (2), 4-14.

Shulman, L. S. (1987). Knowledge and teaching: Foundations of the new reform. Harvard Educational Review, 57, 1-22.

Sibbald, T. (2009). The relationship between lesson study and self-efficacy. School Science and Mathematics, 109(8), 450-460.

Slavin, R. (1990). Cooperative learning: theory, research and practice. Hillsdale, NJ: Prentice Hall.

Taasoobshirazi, G., \& Carr, M. (2008). Gender Differences in Science: An Expertise Perspective. Educational Psychology Review, 20(2), 149-169.

Tabachnick, B. R., \& Zeichner, K. M. (1999). Idea and action: action research and the development of conceptual change teaching of science. Science Education, 83, 309-322.

Techniekpact (2013). Dutch Technology Pact 2020. [Techniekpact 2020]. Accessed online on 2611-2013 from http:/ / www.techniekpact.nl.

Tschannen-Moran, M., Woolfolk Hoy, A. \& Hoy, W. K. (1998). Teacher efficacy: Its meaning and measure. Review of Educational Research, 68, 202-248.

Tosun, A. (2000). The impact of prior science course experience and achievement on the science teaching self-efficacy of preservice primary teachers. Journal of Primary Science Education, 12(2), 12-31. 
Tschannen-Moran, M., \& Hoy, A. (2001). Teacher efficacy: capturin an elusive construct. Teaching and Teacher Education, 17(2001), 783-805.

Tschannen-Moran, M., \& Woolfolk Hoy, A. (2007). The differential antecedents of self-efficacy beliefs of novice and experienced teachers. Teaching and Teacher Education, 23(6), 944-956.

Tschannen-Moran, M., \& McMaster, P. (2009). Sources of self-efficacy: Four professional development formats and their relationship to self-efficacy and implementation of a new teaching strategy. The Elementary School Journal, 110, 228-245.

Tschannen-Moran, M., \& Woolfolk Hoy, A. (2007). The differential antecedents of self-efficacy beliefs of novice and experienced teachers. Teaching and Teacher Education, 17, 944-956.

Turner, S. \& Ireson, G. (2010). Fifteen pupils' positive approach to primary school science: when does it decline? Educational Studies, 36(2), 119-141.

Tyler, R. W. (1949). Basic principles of curriculum and instruction. Chicago: University of Chicago

Van den Akker, J. (2003). Curriculum perspectives: An introduction. In J. van den Akker, W. Kuiper \& U. Hameyer (Eds.), Curriculum landscapes and trends (pp. 1-10). Dordrecht: Kluwer Academic Publishers.

Van den Akker, J., Gravemeijer, K., McKenney, S., \& Nieveen, N. (2006). Introducing educational design research. In J. van de Akker, K. Gravemeijer, S. McKenney, \& N. Nieveen (Eds.), Educational design research (pp. 3-7). Londen: Routledge.

Van der Zee, F. (2010). Methodologie voor onderzoek in de Sociale Wetenschappen. Groningen: BMOOO.

Van Graft, M. \& Kemmers, P. (2007). Onderzoekend en ontwerpend leren bij natuur en techniek. [Inquiry and design-based learning in science education]. Den Haag: Stichting Platform Bèta Techniek.

Van Keulen, H. (2009). Drijven en zinken, Wetenschap en techniek in het primair onderwijs, lectorale rede, 26 juni 2009, Fontys Hogescholen

Van Uum, M., \& Gravenmeijer, K. (2012). Wetenschap- en techniekonderwijs voor en door toekomstig leraren. [ Science learned and taught by future teachers]. Tijdschrift voor Lerarenopleiders (VELON), 33(3), 54-60.

Velthuis, C., Fisser, P., \& Pieters, J. (2013a). Teacher training and pre-service primary teachers' self-efficacy for science teaching. Journal of Science Teacher Education, DOI 10.1007/s10972013-9363-y

Velthuis, C., Fisser, P., \& Pieters, J. (2013b). Collaborative curriculum design to increase science teaching self-efficacy: A case study. Paper geaccepteerd voor presentatie tijdens de International Conference New Perspectives in Science Education, 14-15 Maart 2013.

Velthuis, C, Fisser, P., Ormel, B. \& Pieters, J. (submitted a). Measuring science teaching selfefficacy belief, the development of the STEBI-NL.

Velthuis, C., Fisser, P., \& Pieters, J. (submitted b). Collaborative curriculum design to increase science teaching self-efficacy.

Velthuis, C., Fisser, P., \& Pieters, J. (submitted c). Docentontwerpteams en de self-efficacy op het gebied van wetenschap en techniek onderwijs van toekomstige leerkrachten. [Teacher Design Teams (TDT and the science teaching self-efficacy of pre-service teachers] 
Vervoort, M. (2012). Kijk op de praktijk, Rich media-cases in de lerarenopleiding [A professional view on practice, rich media cases in pre-service teacher education], Doctoral dissertation. Enschede: Universiteit Twente.

Verschuren, D. (2010). At the wheel, Leading innovations in education [Aan het roer, Leidinggeven aan innovaties in het onderwijs] 's-Hertogenbosch: KPC-groep

Visscher-Voerman, I. \& Gustafson, K. (2004). Paradigms in the theory and practice of education and training design. Educational Technology Research and Development, 52, 69-89.

Voogt, J. M., Almekinders, M., van den Akker, J., \& Moonen, B. (2005). A blended in-service arrangement for classroom technology integration: impacts on teachers and students. Computers in Human Behavior, 21, 523-539.

Voogt, J. M. (2010). A blended in-service arrangement for supporting science teachers in technology integration. Journal of Technology in Teacher Education, 18(1), 83-109.

Voogt, J., Westbroek, H., Handelzalts, A., Walraven, A., McKenney, S., Pieters, J., \& de Vries, B. (2011). Teacher learning in collaborative curriculum design. Teaching and Teacher Education, 27, 1235-1244.

Walma van der Molen, J. (2008). De belangstelling voor wetenschap en techniek in het basisonderwijs. in: Platform Bèta Techniek (Eds.). Technotopics III, Essays over onderwijs en arbeidsmarkt voor Bètatechnici (pp. 13-22). Maastricht: Platform Bèta Techniek.

Watters, J. J., \& Ginns, I. S. (2000). Developing motivation to teach elementary science: Effect of collaborative and authentic learning practices in preservice education. Journal of Science Teacher Education, 11(4), 301-321.

Woolfolk, A.E. (1993). Educational Psychology (Needham Heights, MA: Allyn and Bacon)

Yilmaz-Tuzun, O. (2008). Preservice elementary teachers' beliefs about science teaching. Journal of Science Teacher Education, 192(2), 183-204.

Young, B. J., \& Kellogg, T. (1993). Science attitudes and preparation of preservice primary teachers. Science Education, 77(3), 279 - 291. 


\section{ENGLISH SUMMARY \\ Collaborative curriculum design to increase science teaching self-efficacy}

In order to ensure that everyone has the skills to participate well in our fastchanging world full of science (scientific literacy) and that more children choose science-related study and careers, change must occur in the Dutch primarily school curriculum. Professionalizing primary school teachers with regard to (teaching) science is not enough to make teachers teach science more often and make them teach science more by inquiry. It is even more important to motivate teachers to search for alternative solutions for fitting the teaching of science into their overloaded curriculum so that they do not give up on finding additional time so easily. This is related to what is called teaching (self) efficacy.

The focus in this investigation is on developing a teacher training program for improving science teaching self-efficacy, which is framed from the perspective of Bandura's notion of self-efficacy. Self-efficacy reflects one's perceived ability to perform an action that will lead towards a specific goal. Teachers with a high sense of self-efficacy will set higher goals for themselves, are less afraid of failure and will find new strategies when old ones fail. If their sense of self-efficacy is low, teachers will avoid the task or give up easily.

Collaborative curriculum design and more specifically Teacher Design Teams (TDTs) are used in this study as a method to improve science teaching selfefficacy. A TDT is a group of at least two teachers, from the same or related subjects, working together on a regular basis, with the goal of (re)designing and enacting (a part of) their common curriculum. The implementation of an educational change in the teachers' own classroom is known to be a critical point for teachers' self-efficacy belief. Collaborative curriculum design takes place within the context of their own schools and is therefore assumed to prevent a decrease in teachers' science teaching self-efficacy, because this form of 
professional development addresses problems with the implementation directly during the TDT program.

The goal of this investigation is to develop a teacher training program aimed at increasing science teaching self-efficacy. The main research question is:

What are the characteristics of an effective science teacher training program for increasing primary teachers' science teaching self-efficacy?

In addressing this question, four sub-questions are framed:

(1) What factors in teacher training programs promote (or hinder) growth in teachers' science teaching self-efficacy?

(2) What is the effect of collaborative curriculum design on teachers' science teaching self-efficacy?

(3) Which design stages and which corresponding activities in a professional development program with a teacher design team promote (or hinder) growth in the teachers' science teaching self-efficacy?

(4) What kind of support do primary teachers need to improve their science teaching self-efficacy when they must collaboratively design and implement their own science curriculum?

The research approach in this investigation was inspired by both design-based research and action research. A plan for immediately improving what already occurs in the researcher's own teaching practice was based on the outcomes from an analysis of the educational problem in the context of two different teacher training universities and from the theoretical framework developed. Subsequently, just as in both types of research design, the main object in this investigation comprised the different stages of improvement of the intervention. The process of finding a solution was integral to the normal teacher practice of the researcher. The analyses of the different stages of the educational design were used in combination with assumptions based on a theoretical framework not only to improve the intervention but also to create knowledge about the characteristics of an effective teacher training program for increasing teachers' science teaching self-efficacy. Qualitative research methods were used to be able to determine the effects of the teacher training programs, and in addition a quantitative instrument (STEBI-NL) was developed to assess the influence of the training programs on the 
science teaching self-efficacy of (pre-service) teachers. Subsequently, six different studies were carried out to answer the research questions. In the first two studies the educational problem was validated and analysed. The other four studies were analyses of three stages of the evolving teacher training program. Studies one to three were conducted with pre-service teachers and studies four to six with inservice teachers. An overview of the studies and the relation between teacher training programs, research questions and the different studies is depicted in Figure 1.

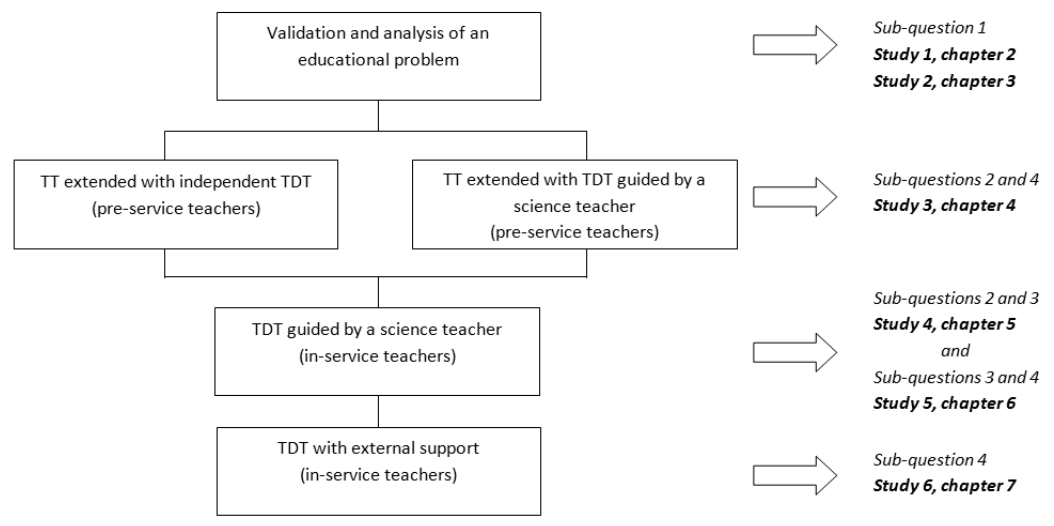

Figure 1 Research overview and the relation between teacher training programs (TT), research questions and the studies that is also presented in the introduction and the discussion of this dissertation

In the first study and in greater depth in the second study, the science programs of different teacher training universities were compared on science teaching selfefficacy scores of a cross-sectional sample across four different years of study to determine factors in teacher training programs that promote or hinder the improvement of pre-service teachers' science teaching self-efficacy (sub-question 1). The results show that improving the level of subject matter knowledge (SMK) seems to be linked with increasing science teaching self-efficacy, especially when pre-service teachers believe that they have insufficient SMK to teach science. It was noticed that pre-service teachers acquire SMK during both science method courses and science content courses. Secondly, challenging pre-service teachers to try new teaching strategies or to teach subjects they feel less comfortable with was also found to be valuable for increasing science teaching self-efficacy in teacher training. However, this was conditional upon having the teaching experiences be 
successful. Another relevant finding was that from the third year of study on, science teaching self-efficacy was no longer observed to increase, despite the relevant courses in the minor program and the fact that the pre-service teachers become more experienced with science teaching.

In the third study, based on the findings of the first two studies and a theoretical framework that was developed for this study, it was argued that a plain linear implementation of an educational change might be a hindering factor for increasing science teaching self-efficacy. The minor program of one of the teacher training universities was extended with TDTs. In this study, the experiences of two different cohorts of students in the minor program (third and fourth year of study) with two different version of TDTs were analyzed. In the first version the TDTs functioned individually, guided only by a paper process guide, and in the second version the TDTs were guided by a science teacher. The results indicate that pre-service teachers' science teaching self-efficacy can be significantly improved during the third and fourth year of teacher training by a program extended with TDTs (sub-question 2). In addition, the assistance and support of the science teacher in a TDT seemed to have added value (sub-question 4).

The fourth study was a case study conducted to determine the value of TDTs for different types of teachers: experienced and less experienced and interested and less interested in science. The TDTs made up of in-service teachers used the same process guide as the pre-service teachers used in the second study. The TDT's task was adjusted to better match in-service teacher practice. The TDT in this study had to (re)design their own science curriculum. The science teacher educator played the role of an external facilitator, guiding the team, leading discussions and providing study materials and other resources. The results indicate that professional development through a TDT is a way to improve science teaching self-efficacy for experienced teachers and pre-service teachers and for teachers with both high and low interest in science, and it proved to be important to attend to some preconditions associated with the specific target group (sub-question 2). Administrative support seems to be a promoting factor for improving the science teaching outcome expectancy of teachers with high self-efficacy. The provision of coaching and assistance with the implementation of the educational change in the real classroom situation seems to be a promoting factor for increasing pre-service teachers' science teaching self-efficacy(sub-question 3). 
In the fifth study, an observation instrument was developed and used to study the design process in the TDT in more detail to determine the design stages and activities that promote or hinder an increase in science teaching self-efficacy (subquestion 3). Team discussions during the design process of two TDTs were observed, and the design and development stages were revealed to be most important for increasing science teaching self-efficacy. The stage of implementation was considered to be less valuable for increasing science teaching self-efficacy, because the discussions during implementation activities in both teams were mostly about organizational matters and not about science teaching. It proved to be very important for the principal to have a clear view about science and to provide administrative support in order to ensure that the TDT spent as little time as possible on organizational matters. The stages of analyses and evaluation could be more valuable for increasing science teaching self-efficacy when the team should be more critical and discussing science education more in depth. Furthermore, successful science teaching experiences were considered to be important for increasing science teaching self-efficacy. However, it was concluded that at least some teachers in a TDT may need additional support to ensure that they will teach science and to ensure that the teaching experience will be successful (sub-question 4).

In the sixth study, the assumption was tested that some teachers need additional support to develop and/or implement curriculum materials for science in their classroom. Additional literature regarding external support in TDTs was studied, a model reflecting the process in a TDT in relation to science teaching self-efficacy was developed and the TDT program was extended with external support. Apart from coordination, the external facilitator also provided the teachers in a TDT with support in the way of (1) feedback on lesson outlines and evaluation of taught lessons, (2) classroom observations, (3) visiting an exemplary school, (4) additional activities that support teachers with science teaching and (5) literature. The TDT in this case study consisted of eight teachers, the school principal and the external facilitator. The results show that external support had added value for increasing the science teaching self-efficacy of teachers with an initially low science teaching self-efficacy. The teachers with low pre-TDT science teaching selfefficacy made use of at least one of the five different forms of external support provided by the external facilitator to improve their science teaching. The teachers with high pre-TDT science teaching self-efficacy did not use external support for 
their science teaching. It is concluded that the TDT program extended with external support is especially valuable for teachers willing to improve their science teaching. Furthermore, the teachers in the TDT in this study felt the need for more external support, especially at the start of the TDT, in the form of standardized information about science teaching and exemplary lessons they could try in their lessons so that they more quickly got a clearer view of what they wanted to achieve with science teaching in their school (sub-question 4).

In conclusion, the principal outcome of this research is a proposed teacher training program, TDTs extended with external support. The program is designed as a solution for increasing in-service teachers' science teaching self-efficacy. Collaborative curriculum design in their own school, science teaching in their own classes and supporting activities regarding science teaching should be the main learning activities in such a teacher training program. Furthermore, the external facilitator is essential for increasing science teaching self-efficacy and must be able to guide the curriculum design process, to stimulate team discussions and to support teachers regarding science teaching. And to ensure that the proposed teacher training program will be successful in increasing teachers' science teaching self-efficacy, it is necessary that the teachers have administrative support. Without administrative support, teachers become discouraged and blame external factors, such as lack of materials or time to teach science for not increasing the frequency of science teaching or not teaching science by inquiry. 


\section{NEDERLANDSE SAMENVATTING Gezamenlijke curriculumontwikkeling om de self- efficacy op het gebied van wetenschap en techniek onderwijs van leerkrachten te vergroten}

Om ervoor te zorgen dat iedereen de vaardigheden heeft om goed te kunnen participeren in een snel veranderende samenleving vol met wetenschap en techniek (scientific literacy) en om ervoor te zorgen dat er meer kinderen kiezen voor een studie of carrière in een bètarichting, moet het W\&T onderwijs op de basisschool veranderen. Het scholen van leerkrachten alleen is onvoldoende om ervoor te zorgen dat leerkrachten meer lesgeven in W\&T onderwijs en dat zij W\&T onderwijs op een meer onderzoekende manier gaan geven. Minstens zo belangrijk is dat zij gemotiveerd zijn om te blijven zoeken naar alternatieve oplossingen om W\&T te geven, zodat zij niet zo snel opgeven wanneer het moeilijk blijkt om tijd te vinden binnen het overvolle onderwijsprogramma op de basisschool. Dit is gerelateerd aan wat ook wel self-efficacy genoemd wordt.

De focus in deze studie is op het ontwikkelen van een onderwijsprogramma om de self-efficacy, oftewel, het gevoel van bekwaamheid van leerkrachten op het gebied van W\&T te vergroten. Self-efficacy is gedefinieerd door Bandura als het vertrouwen dat een individu in zichzelf heeft om bepaalde taken tot een goed einde te brengen. Iemand met een groot gevoel van bekwaamheid gaat grotere uitdagingen aan, is minder bang om te falen en vindt nieuwe mogelijkheden als oude strategieën niet blijken te werken. Wanneer het gevoel van bekwaamheid laag is, zullen leerkrachten een taak eerder opgeven of zelfs gaan vermijden.

Gezamenlijke curriculum ontwikkeling en meer specifiek het werken in een docentontwerpteam (DOT) is in deze studie gebruikt als methode om de selfefficacy op het gebied van W\&T onderwijs van (toekomstige) leerkrachten te vergroten. Een DOT is een groep van minimaal twee leerkrachten, die hetzelfde vak of een gerelateerd vak onderwijzen en die regelmatig bijeenkomt om in 
samenwerking een gezamenlijk curriculum (of een deel van) te ontwerpen of te herontwerpen. De implementatie van een onderwijsverandering is bekend als kritiek moment in de self-efficacy ontwikkeling van de leerkracht. Gezamenlijke curriculum ontwikkeling vindt plaats binnen de context van hun eigen school en de verwachting is daarom dat voorkomen wordt dat de self-efficacy van leerkrachten op het gebied van W\&T daalt omdat bij deze manier van professionaliseren de problemen met de implementatie direct aangepakt worden tijdens het werken in een DOT.

Het doel van deze studie is het ontwikkelen van een onderwijsprogramma om de self-efficacy van leerkrachten op het gebied van W\&T onderwijs te vergroten. De hoofdvraag van deze studie is:

Wat zijn kenmerken van een effectief onderwijsprogramma op het gebied van WET onderwijs om de self-efficacy van leerkrachten op dit gebied te vergroten?

Om deze onderzoeksvraag te beantwoorden zijn vier deelvragen geformuleerd:

(1) Welke factoren in een onderwijsprogramma zijn bevorderend (of remmend) voor het verhogen van de self-efficacy van leerkrachten op het gebied van W\&T onderwijs?

(2) Wat is het effect van gezamenlijke curriculum ontwikkeling op de selfefficacy van leerkrachten op het gebied van W\&T onderwijs?

(3) Welke ontwerpfases en welke bijbehorende activiteiten in het onderwijsprogramma van een docentontwerpteam bevorderen (of remmen) de self-efficacy groei van leerkrachten op het gebied van W\&T onderwijs?

(4) Welke vorm van ondersteuning hebben basisschool leerkrachten nodig voor het verhogen van de self-efficacy op het gebied van W\&T onderwijs wanneer zij gezamenlijk hun eigen W\&T curriculum ontwerpen?

Een systematische methode, geïnspireerd op zowel ontwerponderzoek als actieonderzoek, is gebruikt in deze studie. Gebaseerd op een analyse van het onderwijsprobleem in de context van twee verschillende pabo's en een theoretisch raamwerk, is er een plan gemaakt om datgene wat er gebeurt in de onderwijspraktijk van de onderzoeker onmiddellijk te verbeteren. Vervolgens, zoals in beide type onderzoeksopzetten het geval is, is de steeds optimaler wordende interventie het onderwerp van onderzoek. Het proces van het vinden 
van een oplossing was geïntegreerd in de onderwijspraktijk van de onderzoeker. De analyses van de verschillende stadia van het ontwerp in combinatie met voorspellingen gebaseerd op een theoretisch raamwerk zijn gebruikt om niet alleen de onderwijspraktijk te verbeteren, maar ook om bij te dragen aan de kennis over kenmerken van een effectief onderwijsprogramma voor het vergroten van de self-efficacy van leerkrachten op het gebied van W\&T onderwijs. Om het effect te kunnen bepalen van de onderwijsprogramma's zijn kwalitatieve onderzoeksmethoden gebruikt en daarnaast is een kwantitatief instrument (STEBI-NL) ontwikkeld om de invloed van de programma's op de self-efficacy van leerkrachten op het gebied van W\&T te meten. Vervolgens zijn zes verschillende studies uitgevoerd om de onderzoeksvragen te beantwoorden. In de eerste twee studies is het onderzoeksprobleem gevalideerd en geanalyseerd. De andere vier studies zijn analyses van de drie stadia van het steeds optimaler wordende onderwijsprogramma. Studie één tot en met drie zijn uitgevoerd met pabo studenten, en studie vier tot en met zes zijn uitgevoerd met zittende leerkrachten. Een overzicht van de relatie tussen de onderwijsprogramma's, de onderzoeksvragen en de verschillende studies is weergegeven in Figuur 1.

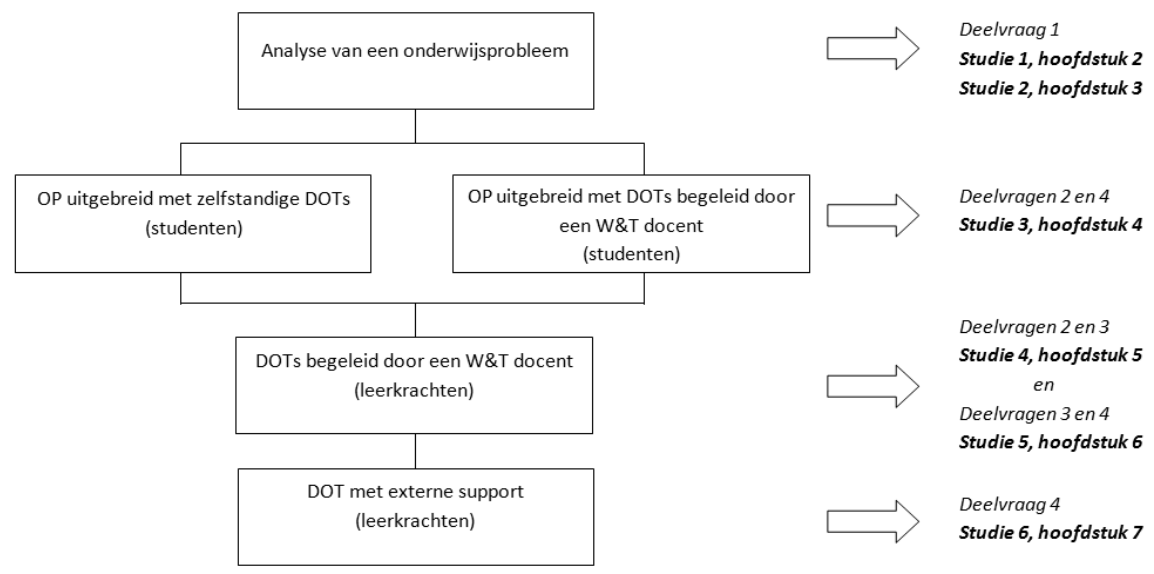

Figuur 1 Onderzoeksoverzicht, de relatie tussen de onderwijsprogramma's (OP), de onderzoeksvragen en de verschillende studies. Het overzicht is ook gepresenteerd in de introductie en de discussie van dit proefschrift

In de eerste studie, en diepgaander in de tweede studie, zijn de W\&T onderwijsprogramma's van verschillende pabo's vergeleken met betrekking tot de self-efficacy scores van de studenten op het gebied van W\&T onderwijs van een dwarsdoorsnede van jaar 1 tot en met 4 om de bevorderende en belemmerende elementen in onderwijsprogramma's te vinden voor het vergroten 
van de self-efficacy (deelvraag 1). De resultaten wijzen erop dat het verbeteren van de vakinhoudelijke kennis bevorderend is voor de self-efficacy op het gebied van W\&T, vooral wanneer de studenten zelf geloven dat zij onvoldoende kennis hebben. Het is aangetoond dat studenten de vakkennis opdoen tijdens zowel vakinhoudelijke cursussen als vakdidactische cursussen. Ten tweede, het uitdagen van studenten om nieuwe onderwijsstrategieën toe te passen of om les te geven over onderwerpen waar ze zich minder comfortabel over voelen worden ook gezien als bevorderend voor het vergroten voor de self-efficacy van studenten op het gebied van W\&T. Een voorwaarde is wel dat de onderwijservaringen een succes zijn. Een andere relevante bevinding is dat vanaf het derde jaar van het pabo progamma de self-efficacy op het gebied van W\&T onderwijs stagneert, ondanks de aangeboden cursussen en het feit dat de studenten meer ervaring opdoen in het basisonderwijs tijdens hun stages.

In de derde studie is, op basis van de resultaten van de eerste twee studies en een theoretisch raamwerk dat is ontwikkeld in deze studie, beargumenteerd dat de implementatie van een onderwijsverandering een remmende factor kan zijn op de self-efficacy groei op het gebied van W\&T. Het bestaande minorprogramma uit het $3^{\mathrm{e}}$ en $4^{\mathrm{e}}$ jaar is uitgebreid met DOTs. In deze studie, zijn de ervaringen van twee cohorten studenten met twee verschillende versies van DOTs als onderdeel van het minorprogramma geanalyseerd. In de eerste versie functioneren de DOTs zelfstandig, alleen begeleid door een handleiding en in de tweede versie zijn de teams begeleid door een W\&T docent. De resultaten laten zien dat de self-efficacy van studenten op het gebied van W\&T significant kan worden vergroot door DOTs als uitbreiding op het programma in het derde en vierde jaar van de pabo (deelvraag 2). Daarnaast lijkt de ondersteuning van de W\&T docent in de teams van meerwaarde (deelvraag 4).

De vierde studie was een casestudy uitgevoerd met als doel de waarde te onderzoeken van DOTs voor verschillende leerkrachten; ervaren en minder ervaren en geïnteresseerd en minder geïnteresseerd in W\&T. De DOT in deze studie bestond uit leerkrachten en zij maakten gebruik van dezelfde handleiding als de studenten in de derde studie. De opdracht van de DOT is aangepast, zodat deze beter aansloot bij de praktijk van de leerkrachten. De DOT in deze studie moet een eigen W\&T curriculum (her)ontwerpen. De W\&T docent heeft de rol van een externe begeleider die het team begeleidt, discussies leidt en zorgt voor studiematerialen en andere bronnen. De resultaten laten zien dat professionalisering door middel van een DOT 
een manier is om de self-efficacy op het gebied van W\&T te vergroten van leerkrachten en studenten met veel of minder interesse in W\&T (deelvraag 2). Administratieve ondersteuning vanuit het management blijkt de uitkomstverwachting met betrekking tot W\&T onderwijs te verhogen van leerkrachten met een hoge self-efficacy. Daarbij lijkt extra coaching bij de implementatie van vernieuwend $W \& T$ onderwijs in hun eigen klas bevorderend te zijn voor de self-efficacy van minder ervaren leerkrachten (deelvraag 3).

In de vijfde studie was een observatie-instrument ontwikkeld en gebruikt om het ontwerpproces in de DOTs meer gedetailleerd te kunnen onderzoeken om ontwerpfases en bijbehorende activiteiten te kunnen bepalen die de self-efficacy op het gebied van W\&T bevorderen danwel belemmeren (deelvraag 3). Teamdiscussies gedurende het ontwerpproces van twee DOTs waren geobserveerd en de ontwerpen ontwikkelfase zijn aangewezen als de meest belangrijke ontwerpfasen voor het vergroten van de self-efficacy op het gebied van W\&T. De implementatiefase was het minst waardevol voor het vergroten van de self-efficacy op het gebied van W\&T onderwijs, omdat de discussies in beide teams het grootste deel van de tijd over organisatorische zaken gingen en niet over W\&T onderwijs. Een duidelijke focus van de directeur op W\&T onderwijs en het geven van bijbehorende administratieve ondersteuning zijn belangrijk om ervoor te zorgen dat zo weinig mogelijk van de tijd wordt verspild aan organisatorische zaken. De fasen van analyse en evaluatie zouden waardevoller geweest zijn als de leerkrachten kritischer naar elkaar zouden zijn en zij W\&T onderwijs diepgaander zouden bediscussiëren. Verder is geobserveerd dat succesvolle onderwijservaringen op het gebied van W\&T belangrijk zijn voor het vergroten van de self-efficacy op het gebied van W\&T. Alleen is ook gebleken dat in ieder geval een aantal leerkrachten ondersteuning nodig heeft om er zeker van te zijn dat zij W\&T gaan onderwijzen en dat de onderwijservaring een succes wordt (deelvraag 4 ).

In de zesde studie was de aanname getoetst dat sommige leerkrachten extra ondersteuning nodig hebben om curriculum materialen op het gebied van W\&T onderwijs te kunnen ontwikkelen en/of te implementeren in hun eigen klas. Aanvullende literatuur op het gebied van externe ondersteuning binnen een DOT was bestudeerd, een model was ontwikkeld dat het proces weergeeft in een DOT in relatie tot de self-efficacy en een verbeterde versie van het DOT programma met externe ondersteuning was ontwikkeld. Naast de coördinatie bestaat de begeleiding van de leerkrachten in het team uit: (1) feedback op 
lesvoorbereidingen en evaluaties van gegeven lessen, (2) observaties in de klas, (3) het bezoeken van een voorbeeldschool, (4) aanvullende activiteiten die de leerkrachten ondersteunen bij W\&T lessen en (5) literatuur aanreiken. De DOT in deze casestudy bestaat uit 8 leerkrachten, de directeur en de externe begeleider. De resultaten laten zien dat externe ondersteuning een meerwaarde is voor het vergroten van de self-efficacy van leerkrachten die de training starten met een lage self-efficacy op het gebied van W\&T onderwijs. De leerkrachten met een lage pre-DOT self-efficacy score op het gebied van W\&T onderwijs hebben minimaal gebruik gemaakt van één van de vijf aangeboden vormen van ondersteuning om hun W\&T onderwijs te verbeteren. De leerkrachten met een hoge pre-DOT selfefficacy score op het gebied van W\&T onderwijs hebben geen gebruik gemaakt van externe ondersteuning bij hun W\&T onderwijs. Er is geconcludeerd dat dit DOT programma met externe ondersteuning vooral waardevol is voor leerkrachten die zelf hun W\&T onderwijs willen verbeteren. Verder geven de leerkrachten in het team van deze studie aan dat zij bij de start van het DOT programma behoefte hadden aan extra ondersteuning in de vorm van algemene, vaststaande informatie over W\&T onderwijs en voorbeeld lessen die zij kunnen uitproberen in hun eigen klas, zodat zij sneller een beter beeld hebben van wat zij willen bereiken met W\&T onderwijs op hun eigen school (deelvraag 4).

De belangrijkste uitkomst van dit onderzoek is een voorgesteld onderwijsprogramma voor leerkrachten, DOTs met externe ondersteuning. Het programma is ontworpen als oplossing om de self-efficacy van leerkrachten op het gebied van W\&T onderwijs te vergroten. Gezamenlijk een W\&T curriculum ontwerpen voor hun eigen school, het lesgeven van W\&T in hun eigen klas en het actief deelnemen aan ondersteunende activiteiten voor hun W\&T lessen zouden de belangrijkste onderdelen moeten zijn in zo'n onderwijsprogramma. Verder is de externe begeleider essentieel voor het vergroten van de self-efficacy van de leerkrachten op het gebied van W\&T onderwijs. De externe begeleider moet het curriculum ontwerp proces begeleiden, de teamdiscussies stimuleren en de leerkrachten ondersteunen bij het lesgeven van W\&T. En om ervoor te zorgen dat het voorgestelde onderwijsprogramma daadwerkelijk succesvol is voor het vergroten van de self-efficacy van de leerkrachten, is het noodzakelijk dat de leerkrachten ondersteuning krijgen vanuit de directie. Zonder ondersteuning, zullen leerkrachten ontmoedigd raken en zullen zij externe factoren, zoals gebrek aan tijd, geld of materialen als excuus gebruiken om niet vaker W\&T geven of om W\&T niet volgens een onderzoekende manier te geven. 


\section{DANKWOORD}

\section{'Een topprestatie lever je nooit alleen'}

Promoveren? Na mijn studie medische biologie was ik ervan overtuigd dat een promotietraject niets voor mij zou zijn. Ik wilde met mensen werken en me niet bezig houden met één onderwerp. Vijf jaar later kreeg ik binnen mijn werk als docent op de Hogeschool Edith Stein wederom de mogelijkheid om te promoveren. Toen heb ik de kans wel gegrepen en met dank aan alle fijne, ondersteunende en stimulerende mensen om mij heen, is nu mijn onderzoekstraject en het bijbehorende proefschrift af! Ik wil iedereen die op zijn of haar manier een bijdrage heeft geleverd graag hartelijk bedanken! Zonder jullie had ik deze prestatie niet kunnen leveren.

Allereerst wil ik Gabi Brühne, als manager van team 'Enschede' bedanken. Zonder haar vertrouwen en stimulerende woorden om te gaan promoveren was ik het hele promotietraject nooit begonnen. Het bleek gedurende het traject dat het soms erg ingewikkeld is om onderwijs en onderzoek te combineren, maar Gabi en later Manon Ketz (destijds directeur Hogeschool Edith Stein) hebben altijd samen met mij gezocht naar mogelijkheden om het hele traject zo voorspoedig mogelijk te laten verlopen. Dank daarvoor.

Daarnaast is een goede en stimulerende begeleiding tijdens zo'n traject natuurlijk onmisbaar. Hiervoor wil ik graag mijn begeleider Petra Fisser en mijn promotor Jules Pieters bedanken. Petra, jij hebt me geleerd hoe belangrijk het is om als onderzoeker de juiste mensen om je heen te hebben. Door goed te netwerken, te weten wie er veel weet van een bepaald onderwerp en daar op een goede manier gebruik van te maken, kom je tot mooie resultaten! Jules, na ieder gesprek ging ik altijd vol nieuwe energie weer verder. Jij wist iedere keer snel de vinger op de zere plek te leggen en dan dacht je vervolgens constructief mee, zodat ik weer verder kon. 
Heel veel dank gaat ook uit naar studenten die hebben deelgenomen aan dit onderzoek en in het bijzonder Bas, Anne, Lisa en Jur. Dank voor jullie enthousiasme tijdens het werken in de DOTs. Daarnaast wil ik ook de schoolleiders en de leerkrachten van OBS Roets in Almelo, Basisschool Bonifatius in Enschede en CBS de Kastanjehof in Hardenberg bedanken voor hun bijdrage aan mijn onderzoek. Zonder jullie was dit onderzoek niet mogelijk geweest!

Verder heb je natuurlijk ook collega's nodig waar je gewoon af en toe even je verhaal kwijt kunt. Soms om het goede nieuws de delen dat een artikel geaccepteerd was, soms omdat ik even helemaal klaar was met het observeren van al die video's. Hiervoor wil ik sowieso al mijn collega's op de UT en op de Edith Stein bedanken. Mijn bijzondere dank gaat uit naar mijn collega's Frits Hof, Janine van de Linde, Bart Ormel, Johan Oude Engberink en Nicolien Tip. Zij waren mijn inhoudelijke 'klankbord' en waren altijd bereid om een instrument te testen of een project te beoordelen. En Paul, omdat het toch altijd stimulerend is om een 'wedstrijdje' te doen... Op dit moment weet ik nog niet of ik gewonnen heb en mijn proefschrift eerder af is dan jouw boek, maar ik hoop in ieder geval dat je boek een succes wordt!

Ontspanning is heel belangrijk in een periode waarin je moet presteren. Na een weekendje 'Pieterpadden' of een bezoekje aan Zwitserland had ik weer extra energie om er weer vol tegen aan te gaan. Eva en Monique, dank voor alle goede gesprekken en het lekker actief bezig zijn. En Monique, bij deze wil ik je natuurlijk ook heel erg bedanken voor de 'voorkant' van dit proefschrift. Ik vind het echt een hele eer dat je dit voor mij hebt willen doen en ben vooral heel blij met het eindresultaat.

Maar ook vele andere vrienden waren belangrijk voor mij: Bastiaan en Anita, Collin en Kristel, Martijn en Benine, mijn oldtimervrienden, mijn FRC-vrienden, mijn Utrecht-vrienden, mijn vrienden-van-Bjorn-vrienden en mijn tennisvrienden: allemaal heel erg bedankt voor de afleiding!

En dan mijn paranimfen: Nicolien en Miranda. Nicolien, ik heb mogen ervaren hoe belangrijk het is om op een collega te kunnen vertrouwen. En daarnaast is het heerlijk om met jou te sparren over ons 'vak' en vooral ook om gewoon gezellig te kletsen over van alles en nog wat! En Miranda, grote zus, je blijft mijn voorbeeld. 
Ik was heel erg trots op jou dat jij ging promoveren. En wat vond ik het fijn om even van je te kunnen horen hoe jij het had aangepakt bij jouw promotie! Nicolien en Miranda, jullie zijn allebei heel belangrijk voor mij en ik ben dan ook heel blij dat jullie mijn paranimfen willen zijn! Heel erg bedankt allebei!

Lieve pa en ma, wat is het fijn te weten dat jullie altijd achter me staan. Papa, van jou heb ik geleerd dat als je iets wilt bereiken, dat je soms even moet doorzetten. Maar aan de andere kant heb je me ook geleerd om vooral niet te vergeten om te genieten van het leven. Mama, van jou heb ik geleerd dat het heel belangrijk is om te doen wat je zelf echt wilt. Soms bleek het lastig, maar jij was er altijd die mij het vertrouwen gaf dat mijn keuze de goede was. Dank jullie wel voor ALLES, zonder jullie was ik nooit zover gekomen!

En jawel, als laatste, maar zeker niet de minste, Bjorn. Jij was diegene die me alle ruimte gaf om deze prestatie te kunnen leveren! Maar ondertussen hield je mij wel goed in de gaten. Jij was diegene die ingreep op de momenten dat ik 'te' veel met mijn onderzoek bezig was of me hielp de chaos in mijn hoofd te structureren zodat de rust weer kon terugkeren. Op die momenten kon ik het niet altijd waarderen, maar ik wil je bij deze toch laten weten dat ze echt heel belangrijk voor mij waren. Dank je wel! En nu gaan we weer samen genieten!

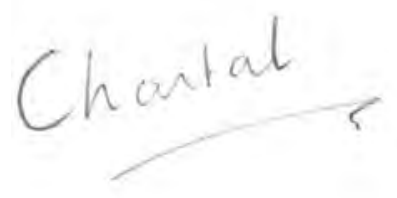




\section{CURRICULUM ViteA}

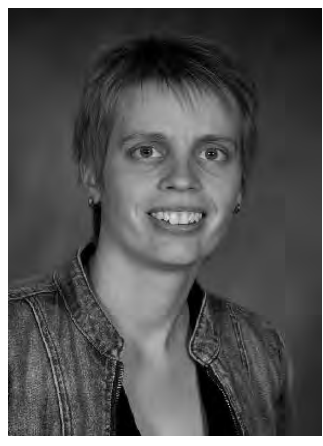

Chantal Velthuis (geboren op 17 mei 1979 te Dalfsen) is afgestudeerd in de Medische Biologie in 2002 en in de eerstegraads lerarenopleiding Biologie in 2003, beide aan de Universiteit van Utrecht.

Sinds 2003 is Chantal werkzaam als docent natuuronderwijs \& techniek (N\&T) en Gezond en Redzaam Gedrag (GRG) op de Hogeschool Edith Stein/OCT (nu Saxion Hogescholen, Academie Pedagogiek en Onderwijskunde, Hengelo). Daarnaast is ze betrokken bij verschillende projecten om wetenschap en techniek in het primair onderwijs te stimuleren (KWTO, Tech Your Future)

Chantal heeft met dit proefschrift haar promotieonderzoek afgerond, dat zij gestart is in 2009. Dit onderzoek verrichtte zij onder de begeleiding van Dr. P. H. G. Fisser en Prof. Dr. J. M. Pieters. 


\section{LIST OF PUBLICATIONS}

\section{ACCEPTED JOURNAL PAPERS}

Velthuis, C, Fisser, P., \& Pieters, J. (2013). Teacher training and pre-service primary teachers' self-efficacy for science teaching. Journal of Science Teacher Education, doi: 10.1007/s10972-013-9363-y (Chapter 3 of this dissertation)

Velthuis, C, Fisser, P., \& Pieters, J. (accepted, 2013). Collaborative curriculum design to increase science teaching self-efficacy: a case study. The Journal of Educational Research. (Chapter 5 of this dissertation)

\section{IN PREPARATION FOR PUBLICATION}

Velthuis, C, Fisser, P., B. Ormel, \& Pieters, J. (submitted). Measuring science teaching self-efficacy belief, the development of the STEBI-NL. Journal of Science Teacher Education. (Chapter 2 of this dissertation)

Velthuis, C, Fisser, P., \& Pieters, J. (submitted). Collaborative curriculum design and the science teaching self-efficacy of pre-service primary teachers. Action in Teacher Education. (Chapter 4 of this dissertation)

Velthuis, C, Fisser, P., \& Pieters, J. (submitted). The process of collaborative curriculum design and the science teaching self-efficacy. Educational Research. (Chapter 6 of this dissertation)

Velthuis, C, Fisser, P., \& Pieters, J. (submitted). External support in collaborative curriculum design to increase the science teaching self-efficacy of primary teachers. The Journal of Educational Research. (Chapter 7 of this dissertation) 


\section{CONFERENCE CONTRIBUTIONS}

Fisser, P., \& Velthuis, C. (2009). Onderzoekend leren bij natuur, wetenschap en techniek. In Proceedings Onderwijs Research Dagen, pp 252-254.

Velthuis. C. \& Fisser, P.: Betrokken leerkrachten, nieuwsgierige kinderen; Paper geaccepteerd voor de VTB-pro conferentie, mei 2010.

Velthuis, C. \& Fisser, P.: Wetenschap \& Techniek: bekwame docenten, nieuwsgierige kinderen; Posterpresentatie op de Onderwijs Research Dagen 2010.

Fisser, P., Ormel, B., \& Velthuis, C.: Hoe bekwaam voelen pabostudenten zich; Presentatie op de Onderwijs Research Dagen 2010.

Fisser, P., Ormel, B., \& Velthuis, C.: Hoe bekwaam voelen leerkrachten zich; Presentatie op de Onderwijs Research Dagen 2010.

Velthuis, C, Fisser, P., \& Pieters, J.: Werken in docentontwerpteams: een kwalitatief onderzoek naar docentinteracties; Presentatie op de Onderwijs Research Dagen 2012.

Velthuis, C., Fisser, P., Pieters, J., \& Voogt, J.: Collaborative curriculum-design to increase science teaching self-efficacy: a qualitative exploration of teacher interactions; Posterpresentatie op de jaarlijkse conferentie van de Society for Information Technology \& Teacher Education 2012.

Fisser, P. \& Velthuis, C.: Integratie van ICT in natuur- en techniekonderwijs; Presentatie op Twents Meesterschap 2013

Velthuis, C, Fisser, P., \& Pieters, J.: Collaborative curriculum design to increase science teaching self-efficacy: A case study; Paper geaccepteerd voor presentatie tijdens de International Conference New Perspectives in Science Education, 14-15 Maart 2013

Velthuis, C, Fisser, P., \& Pieters, J.: Gezamenlijk ontwerpen van een curriculum om de science teaching self-efficacy te vergroten: een casestudy; Presentatie op de Onderwijs Research Dagen 2013

Velthuis, C. \& Fisser, P.: Gezamenlijk ontwerpen van een een NET curriculum in het basisonderwijs, Presentatie op Internationale Conferentie over Docentontwerpteams 2013

Velthuis, C.: Docentontwerpteams voor het vergroten van het gevoel van bekwaamheid op het gebied van wetenschap- en techniekonderwijs (WET); presentatie op symposium praktijk en onderzoek 2014

Velthuis, C, Fisser, P., \& Pieters, J.: Ondersteuning in docentontwerpteams om het gevoel van bekwaamheid te verbeteren; presentatie op de VELON, 2014 

